HANSEI, E.J. 1897

The Choniostomatidae, a family of Copepoda, parasites on Crustacea Nalacostraca.

Copenhagen 1-205, pls, 1-13. 
, 




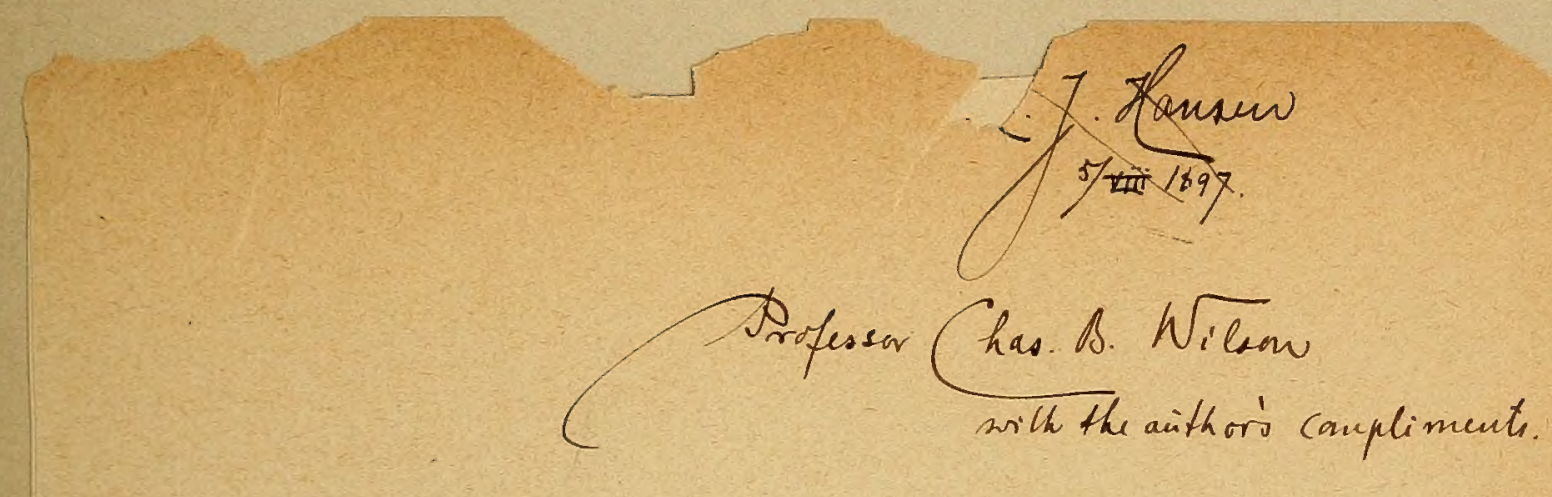



THE CHONIOSTOMATIDAE 



\title{
THE CHONIOSTOMATIDE
}

\author{
A FAMILY OF COPEPODA, \\ PARASITES ON CRUSTACEA MALACOSTRACA
}

BY

Dr. H. J. HANSEN

WITH THIRTEEN COPPER PLATES

AT THE EXPENSE OF THE CARLSBERG FUND

We want facts, not inferences, observations,

not theories, for a long time to come.

"Natural Science", 1896.

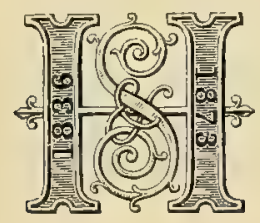

\section{GOPENHAGEN}

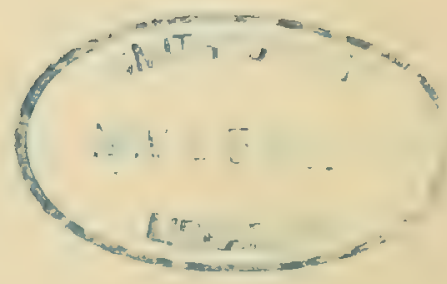

ANDR. FRED. HOST \& SON, PUBLISHERS 
COPENHAGEN - PRINTED BY H. H. THIELE 


\section{PREFACE.}

This work contains an account of forty-three species of Copepoda, all parasitic on mala1 costracous Crnstacea, and all belonging to the same family. When in $1890 \mathrm{I}$ began my study of this group, there were published descriptions of only three species, and mention had been made of a fourth. Two more have been since described and a seventh named, but not described; so that until now (July 1897) only five species have been really made known. In the present work I increase this number about nine times, and yet, most likely, my discoveries only extend to one fifth or one sixth or perhaps a much smaller part of the species extant. I have been bronght to this conclusion by the consideration that no less than thirty-three of my species have been found exclusively on Crustacea in the Zoological Museum of the Copenhagen University. What multitudes of these animals are likely to be discovered, when some day the large foreign museums acquire rich collections of non-decapod Malacostraca, and when this material is submitted to a thorough research! On the whole, my studies of late years have given me the impression that of nearly all the Crustacea living on the bottom of the sea - the Decapods excepted - - we only know from about half down to a very small percentage of existing species. Especially to the parasitic forms does this apply, and I think one of the most important results of the present work is to show the wealth of a group, which hitherto has occupied only a very diminutive place. It may be added that, in the course of the last two years, I have found on the material brought home from the sea near Iceland and Greenland by the »Ingolf " expedition several new forms which cannot be included in the present treatise, but which will be subjected to future examination.

A chance led me to this study. In dissecting a female of Idothea marina (L.) I discovered in its marsupium an unknown parasite belonging to the Epicaridea, and further researches led to the discovery of a number of specimens of this species and of a form nearly akin to it on Edotic nodulosa (Kr.). Both parasites were afterwards described from 
my material by Giard and Bonnier (the genus Clypeoniscus G. and.B.). Those authors had just previously described an Epicarid living as a parasite on Ampelisca diuctema Costa. What I had found on Idotheidse tempted me to go on looking for Epicaridea, so I examined our Ampeliscidæ and found - not these forms, - but several species of Choniostomatidæ as well as another most remarkable parasite, which I described in 1892 under the name of Rhizorhina Ampelisce H. J.H. Professor Sars has told me (1886) that he had found some species of Sphcronella on Amphipoda. Now, as my own discoveries had called forth my interest, I began in the Copenhagen Museum an examination of the material of Amphipoda and later on of the other orders of Malacostraca.

Professor G. O. Sars lent me all his material of this family for my researches, and he further provided me with newly discovered forms - seven in all, - of which four are particularly interesting; two of the most remarkable genera, the parasites on Mysidæ, are owing entirely to him - for all of which I have great pleasure in offering the eminent naturalist my best thanks. - The Rev. Canon A. M. Norinan, F. R. S., lent me the types of Aspidvecia Normani Giard and Bonnier, and the Rev. Th. R. R. Stebbing, F. R. S., determined for me some Amphipoda from the Mediterranean, the West-Indies, the Cape and Hong-Kong, for which I beg these gentlemen to accept my thanks.

Last, not least, I wish to express ny warm gratitude to the managing Committee of the Carlsberg Fund for having allowed me a considerable sum to defray the expenses of the present work.

The English translation from the Danish manuscript is the work of Miss Louise von Cossel. 


\section{CONTENTS.}

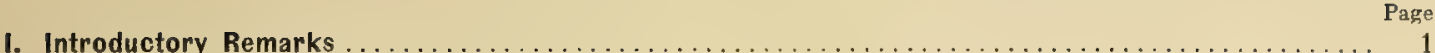

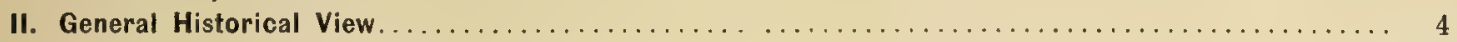

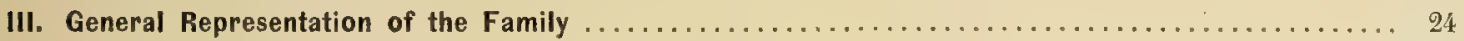

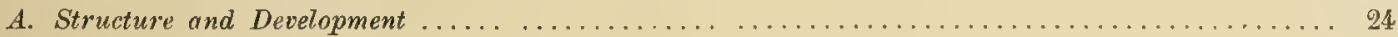

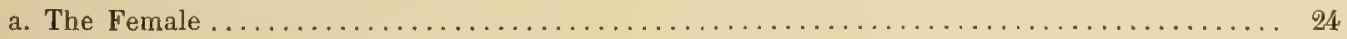

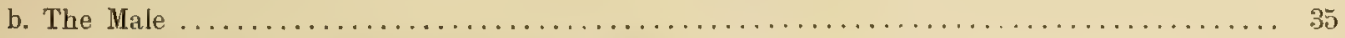

c. The Ovisacs and the Development of the Eggs........................ 43

d. The free Larva . . . . . . . . . . . . . . . . . . . . . . . . . . . . . . . . 47

e. The post-Jarval Development; the Pupæ ............................. 53

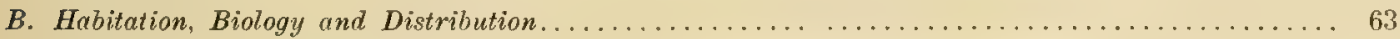

a. The Place of the Hosts in the System and the Habitation of the Parasites...........63

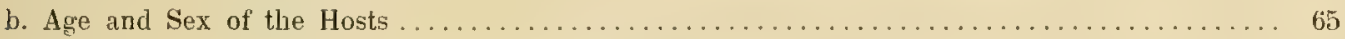

c. Number of Parasites on each particular Host.......................... 68

d. Number of Species of Parasites on the same Species of Host.................... 69

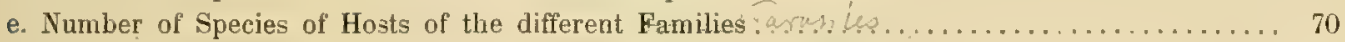

f. Occurrence together with Parasites of other Urders or Classes . . . . . . . . . . . . . 71

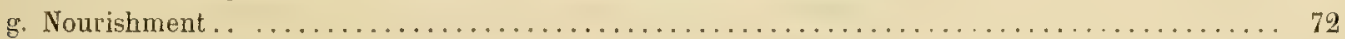

h. The Influence of the Parasites on their Hosts $\ldots \ldots \ldots \ldots \ldots \ldots \ldots \ldots \ldots \ldots \ldots \ldots \ldots \ldots$

i. Geographical and Bathymetrical Distribution of the Family . . . . . . . . . . . . . . 75

j. Geographical Distribution of the particular Species relatively to that of their Hosts $\ldots \ldots \ldots 76$

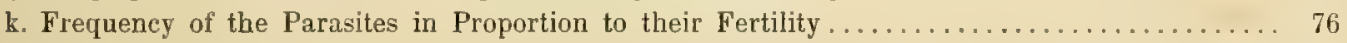

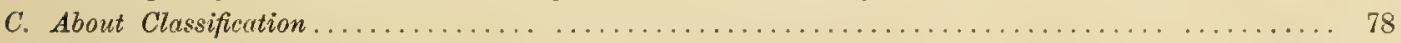

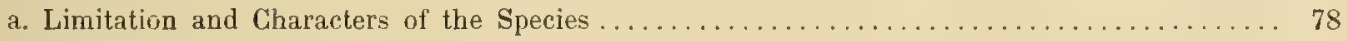

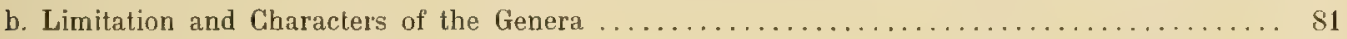

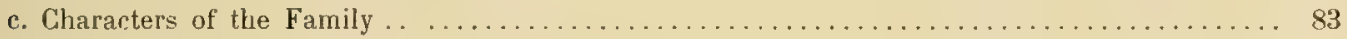

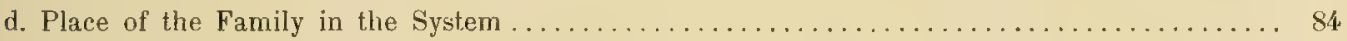

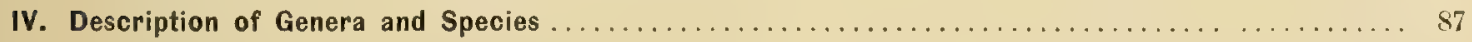

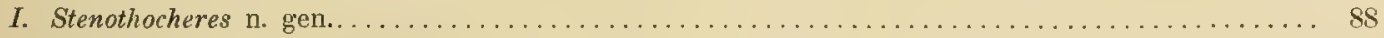

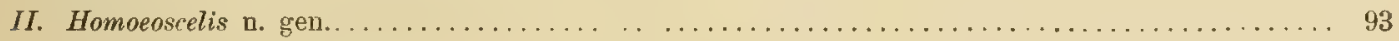

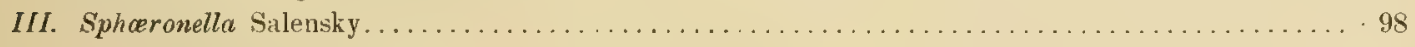

a. Parasites on Amphipoda . . . . . . . . . . . . . . . . . . . . . . . . . . . 99

b. Parasites on Cumacea .................................... 148

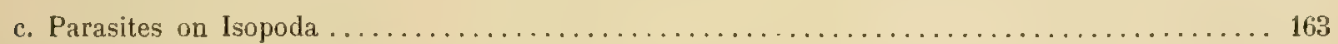

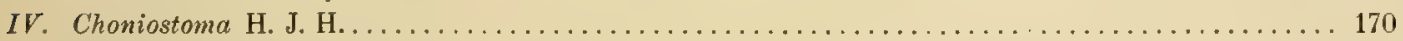

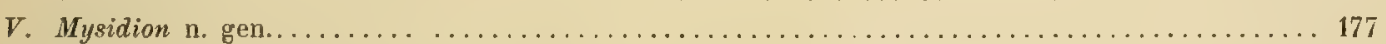

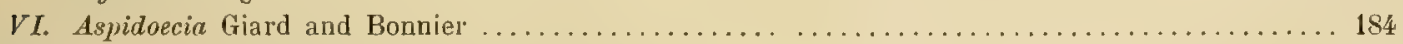

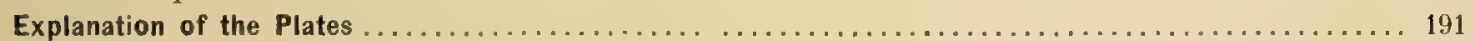

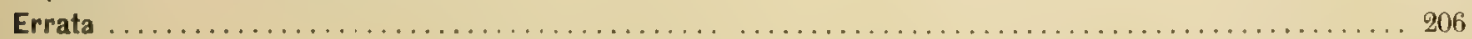





\section{INTRODUCTORY REMARKS.}

The majority of the species here described I found in examining systematically for this 1 purpose the collections of the Zoological Museum in Copenhagen. Throughout a number of years the two directors of the entomological department, the late Professor J. C. Schiødte and his successor, Inspector Dr. F. Meinert, have taken care not only to acquire as many species as possible, but - of the smaller forms - also as many individuals as could be procured, so that of a good many northern Amphipoda, and of a great number of Danish Amphipoda, Cumacea, etc., the museum possesses hundreds of specimens. This has been of the greatest use to me in my researches, for while a few of the parasites - at least of those found on our own material - are met with rather frequently, the greater number are very rare, and a considerable part so scarce, that only one or two specimens are found on each hundred of the animals examined. As a matter of course, I have examined numerous species without finding a single parasite.

Of the following forty-three species only one lives on the outside of its host (Mysidæ veræ), two occur in the branchial cavity of Cumacea, two in the branchial cavity of Hippolyte; all the remaining species are only found in the marsupium of the female of Amphipoda Gammaridea, Isopoda, Cumacea and Mysidæ veræ (or sometimes in young individuals of Amphipoda on the ventral side of the thorax between the gills). In the Isopoda, the Mysidæ, and sometimes in the Amphipoda, parasites can be seen by looking through the plates of the marsupium. In most Amphipoda and in Cumacea the marsupium has to be submitted to a closer examination; some of the plates have to be lifted up and examined through a lens; in the small forms even the adult parasites can only be discovered by help of a simple microscope. Where a closer search of an infested marsupinm is required, it is usually necessary to place the host in a hollow ground glass-plate under water, and to examine it very carefully twenty or thirty times magnified under a simple microscope, in order to be able to discover the male animals which are generally $1 / 4-^{1 / 6} \mathrm{~mm}$. in length, as well as the free larvæ and the pupæ, and to find out the way in which these minute animals are hinged. 
Parasites are not at all easy to deal with; when taken out, everything - except perhaps tolerably large females and ovisacs - must be kept in glycerine on an objectglass, for if males, pupæ, etc. are put in spirit, they are generally difficult to find and to get out of the tubes. For this use the glycerine must always be strongly diluted with water, otherwise the animals shrink very much, and the females especially are very apt to lose their shape. The water is made to evaporate by standing exposed to the air. Neither the females nor the males nor the animals in any stage of development, can bear the pressure of a glass-cover, or of part of it, without losing their natural shape. In order to make drawings of the entire animals or of parts of the females, the following method was employed: I took very small covers (frequently a middle-sized cover was cut into four parts), and placed a very thin wooden wedge under the middle of the back edge of the cover, so that by very carefully pulling the wedge a little, I made the glass truch the animal, or part of it, just sufficiently to keep it in a certain position; by means of a hair, which was introduced through the opening, its attitude could easily be changed. In this way I was able after some practice to manipulate a male of the length of $1 / 6 \mathrm{~mm}$., so that $I$ could make accurate illustrations of one specimen seen from below and sideways without damaging it at all. After use the animal and all the parts that had been examined were placed under a large glass-cover in the way described above, and the opening was closed with varnish. The female was always dissected, in order to submit the head and the genital area to a careful examination. The latter part was treated in the following way: with a sharp and very small knife I cut through the animal a little above the genital region, after which this part was placed under a simple microscope which magnified it a hundredfold; the inside of it was cleaned with a knife, so as to leave only the muscles of the genital apertures and one or both of the receptacula seminis. I specify this proceeding, which I learned by degrees through rather troublesome experiences, partly that the reader may judge of the accuracy of my illustrations, partly to enable future students, who may not possess such ample material, to conquer the difficulties with comparative ease.

As far as possible, I have everywhere given figures of an adult female, a male and an ovisac (sometimes adding one or two pupæ) magnified to the same scale, in order to show the relative size of the two sexes, the ovisacs and eggs. The size of the male compared with the female and the ova varies very much in the different species. For the convenience of the student, and in accordance with earlier statements (1890), I have always figured the males vertically from the ventral side and laterally from the left-hand side. While in symmetrically shaped Arthropoda, in dorsal or ventral view, I generally arrange the position of the legs and figure those on one side to correspond with those on the other, with the parasites described in the present work I have not ventured to do this. The animals were often a little crooked on account of a slight pressure, to which they had been exposed in the marsupium; maxillipeds and legs were found straddling in different directions, and as a rule were too small to allow of much alteration in their attitude, without great risk of 
damage ensuing. I only ventured slight attempts at construction, not being able to calculate how the details - e. g. legs of males and larvæ - would appear, if drawn in a position differing from the one in which they were found. As a rule I have figured the animals with all the irregularities they presented, and the limbs in the position they happened to occupy at the time of drawing. Where I had several specimens at my disposal, of course I chose the one which was most suitable for illustrat on.

I must briefly mention one point in my nomenclature. In 1893 I stated (in $\gg$ Zool. Anzeiger ") that the two pairs of limbs which had been formerly named the first and second pairs of maxillipeds, ought to be regarded as the second pair of maxill:x and a pair of maxillipeds. Shortly afterwards Dr. W. Giesbrecht gave very detailed proofs of the same fact (Mitth. Zool. Stat. Neapel, 11. B.). I also proposed to introduce the names "maxillulæ and "maxillæ (in analogy with the commonly used names santennulæ and »antennæ«) for the two pairs of jaws, and I shall here avail myself of these short, convenient and very intelligible names.

In conclusion a few remarks may be offered about the plan of the present work. For several reasons I have contented myself with representing the external structure of the adult animals and their post-embryonic development, and I have spent an exceedingly long time, partly in finding females and eggs, males, larvæ and pupæ, partly in studying the material I had discovered. The result is that at present scarcely any moderately large family of genuinely parasitic Copepoda is so well known as the Choniostomatidx. I have found the males of thirty-two of the forty-three species, the larvæ of twenty-three, the pupæ or other stages of the post-larval development of a pretty considerable number of species. At the same time I must call attention to the great and numerous gaps in the knowledge of the metamorphosis of these animals, which vary remarkably according to the different species. On their embryology I do not enter at all, and their anatomy is almost totally omitted; I could not have given information of any value unless I had stayed long enough at the seaside to enable me to collect a large supply of living animals of several species, but this would have considerably delayed and increased the work, which is rather voluminons as it is; so, not being able to present an exhanstive study of these topics, I have - contrary to the habit of numerous authors - only treated what was indispensable to classification (the genital region and receptacula seminis). Besides, I should advise students not to enter upon the anatomy of forms so small, diffcult and for the most part rare, before having: acquired a thorongh autoptical knowledge of representatives of various other families among parasitic Copepoda. 


\section{GENERAL HISTORICAL VIENT.}

$\mathrm{U}$ nfortunately I am obliged to go much into detail in this chapter, not only in order to give a summary of our previous knowledge and its defects, but also and particularly in order to throw light on a number of very objectionable postulates, reflections and theories put forward by Mssrs. A. Giard and J. Bonnier in their two (four) papers. Very short contributions (by G. O. Sars and J. Sparre-Schneider) are mentioned in the special part.

W. S.lLENsky: Sphcronella Leucharti, ein neuer Schmarotzerkrebs (Archiv für Natur geschichte, 34ter Jahrgang, 1868, p. 301-322. Taf. X). The author has given a very extensive account of this new genus and species, the first form which was discovered of this family. He has found females, males, eggs, larvæ and pupæ, in fact all stages, and on the whole his descriptions are good, but unfortunately the illustrations are rather rude, which is indeed a pity, as the species happens to belong to the most difficult group of the large genus. I do not think it necessary to point out some slight differences between the author's account and my own, e. $g$. his incorrect statement of the number of joints in the antennulæ of the lar'væ etc., but it must be mentioned that he has overlooked the rudimentary antennæ (2nd pair) in the male and the female, that his very detailed description of the rostrum is not correct, as he has taken the hairs outside the membranous border of the mouth for "Radiärfalten " in the membrane itself (p. 303), and that his long description of the more solid chitine lists of the rostrum is too diagrammatic. This is connected with his quite wrong idea on the maxillulæ, about which he writes: „Es sind nämlich zwei solcher Kiefern vorhanden, welche eingliedrig sind und an ihrem Ende eine Borste tragen « (comp. my description below). On the other hand it must be acknowledged that he has found and described correctly the legs and the caudal stylets of the female, but in the male he misinterprets the stylets, taking them for a third pair of legs; he has found spermatophores etc. Furthermore, his representation of the genital area is defective, and he has overlooked receptacula seminis, but he is right in stating that the female has no anus. He also gives a somewhat detailed account of the embryology of these parasites, making out their stages of development till they appear as full-grown larvæ, but this part of the development I have 
scarcely studier at all. Finally he describes three stages of the pupæ, mentioning their want of internal structure during the first stage and their considerable growth, but he has failed to understand their mouth, nor does he mention the possibility of a very different development of the two sexes. He concludes with some reflections on the place which the new form onght to occupy in the system, thinking - with good reason - that it »in keine der bis jetzt aufgestellten Familien vollkommen hineinpasst « (p. 320), but that it is nearest akin to the Lernaida on account of similarity in the structure of the mouth, an opinion which I cannot share (s. below). Salensky took his species at Naples on an Amphipod which was many years after determined by Della Valle as Microdeutopus gryllotalpa Costa. About its occurrence on males as well as on females he has a statement (p. 302) which will be mentioned later on in the part headed "Habitation, biology and distribution".

Max WEBer: Die Isopoden gesammelt während der Fahrten des Willem Barents in das nördliche Eismeer in den Jahren 1880 und 1881 (Bijdr. tot de Dierkunde, 1884). The author informs us (p. 35) that in a vesicular swelling on the carapace of a specimen of Hippolyte Gaimardii M. Edw. he found four globular bodies which contained either eggs or larvæ, and he thought they were »Bopyriden-Larven im ersten Larven-Stadium « and that the eggs "werden wohl schubweise abgesetzt vom Weibchen und von einer gemeinsamen Hülle umgeben". His suggestion of Bopyrid-larvæ is a great mistake; what he found were the ovisacs of a Choniostoma. The statement is only of interest in so far as it indicates a locality of the genus; the fact that this otherwise excellent author happens to be the first who found such ovisacs appears more than valueless to me, considering how he explains the matter, and I only mention it here, because it relates to my remarks in the criticism of Giard and Bonnier.

H. J. Hansen: Oversigt over de paa Dijmphna-Togtet indsamlede Krebsdyr (DijmphnaTogtets zool.-bot. Udbytte, 1887). In this paper (p. 271-278, Tab. XXIV, fig. 7-7h), I gave a detailed description of the female, of ova and larvæ of a species found on Hippolyte Gaimardii M. Edw. and Hipp. polaris (Sab.) in the Kara Sea, and I gave it the name of Choniostoma mirabile. Furthermore, on this torm I established a new family, Choniostomatidæ; I did not know Salensky's paper at the time, but when Prof. G. O. Sars had called my attention to it, I mentioned it in the French résumé worked out later on (p. 511); however, I maintained my new genus. In the female I found antennulæ, antennæ and a mouth with supposed mandibulæ, the anterior branch of the maxillulæ and the maxillæ. The description of the mouth is not quite correct, as I did not mention the membranous mouth-border, but I found the hairs which I thought proceeded from the margin of the mouth; I also overlooked the rudimentary maxillipeds, nor did I find the genital apertures. The description of the larva is pretty correct on the whole, but I have with some hesitation mentioned four joints instead of three in the antennulæ, nor have I understood its olfactory seta as such. In 1889 Giard and Bonnier were of the opinion that the specimen found by me on Hippolyte polaris belonged to another species which they called Choniostoma Hanseni; this opinion 
was based on the fact that it was much larger and lived on another species. The animal did in fact prove to differ from Choniostoma mirabile; however, the two reasons alleged by the authors proved to be wrong, for a female with eleven ovisacs found on Hippolyte Gaimardii and proving to be identical with the species on Hipp. polaris, was even somewhat smaller than the largest Choniostoma mirabite. Consequently Chon. Hansenii is found on two species of Hippolyte, whereas Chon. mirabile has as yet only been noticed on one.

A. Giard and J. Bonnier: Sur un Épicaride parasite d'un Amphipode et sur un Copépode parasite d'un Épicaride (Comptes-rendus de l'Acad. des Sciences, 29 avril 1889). This preliminary note is only mentioned here for the sake of completeness, as its contents are largely worked out in the following publication.

A. Grard and J.Bonnier: Note sur l'Aspidoecia Normani et sur la famille des Choniostomatida (Bull. scientifique de la France et de la Belgique, T. XX. 1889, p. 341-72, Pl. X-XI). In this paper the authors have partly described and figured the Aspidoecia Normani, the new species and genus established in their preliminary note, partly given a very detailed critique of all that has been written on the subject. Each of these parts deserves a special mention. Of their new species the authors have examined a female with five ovisacs and two males attached to it, sitting on the back of the carapace of Erythrops microphthalma G. O. Sars (belonging to Mysidæ veræ) under an obliquely placed Epicarid, Aspidophryxus Sarsi Giard and Bonnier. Accidental circumstances led them to adopt the following conclusion as the most plausible: "qu'il existe un rapport soit de parasitisme soit de mutualisme (p. 353) between Aspidoecia and Aspidophryxus (which is a mistake; o: below); they say that the female Copepod "était reliée à l'Aspidophryxus par un appareil fixateur" (p. 344), though such an object does not exist, and they declare that it »adherait certainement à la Mysis par une ventouse (p. 344), which is not the case either, as it is attached by what later on I shall call »the adhesive plate«, a congealed substance forming a plate-like cover on the forehead in front of the mouth, and which is secreted by the "glandes cémentaires « mentioned by the authors (p. 349). In their description of the female (p. 347-50) they mention »les deux points chitineux (entrances to the receptacula seminis), and they give a correct description of the genital apertures, except that the small opening which they call "pore de fécondation «, and of which they say that it serves sévidemment à l'entrée des spermatozoildes", does not serve this purpose at all. They have found "la ventouse" on the head, but they cannot make out whether the mouth is situated at the bottom of it (which it does), or whether it is found »à la partie supérieure de la ventouse, celle-ci servant uniquement à la fixation du parasite". Finally, they have overlooked the antennulæ, the maxillulæ and the maxillæ. However, it must be borne in mind that having had only one individual which they were not allowed to dissect, it would be unfair to expect them to be able to study the organs of this small and extremely difficult animal much better than they have done. With regard to the male the case is different; it is much easier to examine, besides they had two specimens. After having studied my own material of the same species, 
I came to results which differed very much from the figures and descriptions of the authors. Though feeling convinced that I had studied animals belonging to their species, I wanted to make quite sure of it and asked the Rev. Canon A. M. Norman to lend me the animals which had served as types to the French authors, and I received a male and a female. The male was kept in a preparation made by Mssrs. Giard and Bonnier, but it was considerably flattened in an oblique direction, these animals - as stated above - not being able to withstand the pressure of a glass-cover; its position was about the same as that shown on pl. XI in their paper. The spot where the animal was found was encircled by a red ring on the glass-cover, and there could be no doubt that it lay just as it had been placed by the authors. I did not open the preparation, as all I wished to see was clear enough. I found what I expected: perfect similarity between this specimen and my own males - , and the statements of the authors proved to be incorrect in the following important points:

1) »Les pattes nageoires font complétement défaut, ou sont réduites à des appendices difficilement visibles (pt.) . The first part of this sentence is right, but to judge from the specimen in hand, the two dots marked pt. are spots possessing a slight deviation in the refraction of light, and situated beneath the inner side of the skin; according to my experience with other animals, they are accidental.

2) "La partie postérieure du corps est divisée en deux renflements arrondis renfermant chacun une sphère à contour très net dont le contenu est formé de quatre sphères appliquées les unes contre les autres et déformées par pression réciproque comme les blastomères d'un oeuf au stade quatre de segmentation. Les deux sphéroïdes sont des spermathèques (p. 346-47). In the following pages I also call the two globules spermatothecæ, though I am not absoJutely certain that they are not testicles; so far we agree, but no further. In the male of their preparation there was no vestige of a fold in the middle of the body. The spermatothecæ showed inward folds which were not nearly so regularly arranged as it would appear from their description and figuring of the contents, nay they seemed to be empty. A careful and exact adjustment of the microscope showed that the granular substance usually contained in the animal was outside the spermatothecæ, though a less accurate adjustment might give the impression that it also was inside; filled spermatothecæ have a very different look. The folds are easily explained by the flattening of the animal through the pressure to which it had been exposed.

3) Abont the antennulæ they write: »elles sont formées d'une saillie basilaire sur laquelle est inséré un article unique en bâtonnet terminé par une pointe courte«. However, this "saillie basilaire in their preparation is considerably longer and somewhat different in shape from their figure of it; it is in fact the antennulæ itself (comp. my figure pl. XII, fig. $3 \mathrm{k}$.). What they call sun article" is the olfactory seta; nor is its extremity so slender and pointed as they represent it.

4) They say about the mouth (p. 346): "La membrane de la ventouse est sontenue par de fus rayons chitineux constituant les génératrices du tronc-cône. Ces rayons ont été 
vis par Salensky et par Hansen dans la rentouse de Sphroronella et de Choniostoma. Mais le premier de ces observateurs les a considerés comme de simples replis de la membrane; le second n'a pas vu la membrane et a pris les rayons pour des cils chitineux. Un examen très attentif peut seul permettre d'éviter cette double erreur". In spite of this well worded phrase, I must observe that they have not arrived at any better result than the predecessors they criticise. The membrane exists without folds and without »rayons chitineux ", for these "rayons" are free hairs, scils chitineux", which originate at the base of the membrane, leaning freely against it on the outside, and in their own preparation these hairs, as usual, stand clearly out beyond the edge of the membrane.

5) 》La première patte mâchoire (mxpi) est réduite à un long stylet droit aigu, beaucoup plus simple que l'organe correspondant du mâle de Sphcronella: (p. 346). What they describe and figure here is only the terminal joint of the maxilla (according to my definition of this pair of limbs); it is not straight, but slightly curved, in their own type specimen, as well as in my drawing (pl. XII, fig. $3 \mathrm{k}$.). They have also overlooked the very large, long and broad basal joint, which appears distinct enough in their own type; if they had seen it, they would have found the missing resemblance with Sphreronella, and it seems difficult to understand this gap in their observation.

6) However, the climax of the incomprehensible is reached in their description of the maxillipeds. In their text they mention three joints, of which ile troisième se prolonge en une dent crochue", yet this "dent" is drawn as a claw-like joint, which is well separated by an articulation and can be folded up towards the joint above it. But in examining their type specimen, I found that it agreed perfectly with my figure on pl. XII; what they describe and draw as the three first stout joints, indeed is only one single joint without a vestige of the two articulations they mention and figure. The "dent crochue is really jointed on, as they figure it, but furthermore, in their oun preparation it consists of two distinct joints, and I camnot have misunderstood their text, for their statement about the claw »à laquelle fait face un petit tubercule pointu« is fairly correct. So, seeing that their own type specimen agrees exactly with my illustrations, I leave it to the reader to compare their description, and especially their figure, with mine, and to find out how they can possibly have been so much mistaken; as for me, 1 am at a loss to understand it.

I have two reasons for yiving this detailed demonstration of the mistakes committed by the authors in their description and figure of this male specimen. In the first place I wish to verify in detail the identity of their species with my own, secondly I wanted to be able to refer to this substantiation in the following pages, where I shall have to point out that in a later paper the same authors have made considerable mistakes in their description of two other forms, of which I have not seen their type specimen.

The authors (p. 356) state their opinion that the family Choniostomatidæ is nearest akin to Chondracanthidæ, Lernæopodidæ and Ascomyzontidæ. I agree with them as to 
Lernæopodidæ; Chondracanthidæ seem to me to differ much more, and Ascomyzontidx do not show any real relationship.

The authors quote and criticise at great length all that has been written about this family, but in their eagerness to exhaust the matter, they seem to go a little tor far. They give a long quotation from H. KRöYer: "Monografish Fremstilling af Slagten Hiplolyte's nordiske Arter (Kgl. Danske Vidensk. Selsk. Skrifter, Nat. Math. Afl. IX, 1842, p. 263-64)《 in order to prove that this excellent investigator was the first to discover an animal of this family, and that his specimen belonged to the genus Choniostoma. They quote the passage in Danish (p. 368-69) and in a French translation; the latter is correct, except in three points, of which one may be called a very free translation, whereas the others are indeed important mistakes and will be mentioned presently. Kröyer states that he has found a specimen of Hippolyte gibba (from Spitzbergen), whose carapace was much swollen on both sides; however, he found no Bopyrid in it, but about a score of sub-globular; yellowish white bodies of different size (from ${ }^{2} / 5$ " to nearly $1 \frac{1}{2}{ }^{\prime \prime}$ in diameter), which were lying free and unconnected side by side. He supposes them to be eggs of an unknown parasite and adds: sthe smaller ones I found filled with a yolk-like, granulous substance [ [ de mindre af dem har jeg fundet opfyldte af en rggeblommeagtig, grynet Masse«], which Giard and Bonnier translate as follows: "Les plus petits étaient remplis d'une masse grenue ressemblant à des oenfs", but this gives a very different meaning from the word yolk-like", and may quite well be understood, as if the globules were ovisacs containing the eggs of a Choniostoma. though Kröyer's expression does not imply such an idea at all. Kröyer continues: „In the larger globules, which were probably very near maturity, I have noticed a lather long $\left(6-7^{\prime \prime \prime}\right)$, thin, vermiform body. It may be, that some leech-like animal develops itself out of these eggs" fai de storste, som rimeligviis vale nerved Modenhed, har jeg iagttagel et temmelig langt $(6-7 \cdots)$ tyndt, ormedammet Legeme. Maaske udvikler der sig altsaa af

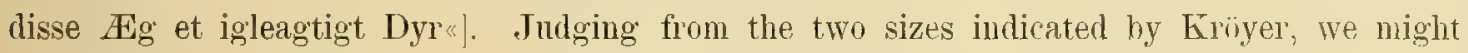
suppose that the larger globules were females, the smaller ones ovisacs of a Chonirstoma. but it seems to me very improbable, that a naturalist like Kröyer should not have seen that the small globules in reality contained eggs or larva, instead of sulnosing their contents to be a yolk-like, granulous substance, and his statement that he found a vermiform body about 13-15 millim. in length in the large globules, must in my opinion do away with any idea that it conld be the female of a Choniostoma (comp. my description of this genus later on). But then, how shall we explain that Giard and Bomnier could advance such an opinion? Well, in their translation of Kroyer's description of the rontents of the large

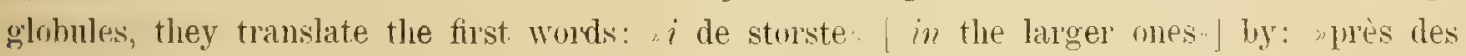
plus gros which gives quite a different meaning, allowing this remarkable, vermiform body to he taken for a free animal belonging to another class. Thus two fanlts in their translation of Kröyer lead them to find a similarity which does not really exist between a choniostoma with its ovisacs and Kroyer's description. I am unable to tell what the oljects 
examined hy Kröyer could he, hut the suggestion that the large glohnles which, arcording to his statement, contained a long, vermiform body of about half an inch or a little more in length, should be females of a Choniostoma, indeed seems overbold to me, even in our golden age of loose conjectures, and if we could really suppose Kröyer to have made such extraordinary mistakes in his statements, we should indeed consider them worse than worthless and deserving of everlasting oblivion. When in 1889 I read this passage by Giard and Bomier, I remembered, that while working at my previous investigation of Choniostoma, I had perused the short paragraph in Kröyer's excellent monograph: "Et Par' Bemærkninger om Snyltedyr par Hippolyter " "Some remarks about parasites on Himpolyte"] (p. 262-65) withont finding anything at all applying to the parasite $I$ was going to describe. On p. 371 the two authors write further: "Il est singulier que HAגses ait laissé jasser inaperçue l'observation de W Eвะr, et surtout le passage beaucoup plus important de son compatriote KRörER«. I shall presently make a few remarks about Weber, and as far as regards my overlooking Kröyer, I will only observe that it would certainly have been wiser of Msses. Giard and Bonnier, whose success in finding a pretty good proof in favour of their assertion was entirely owing to two rather unfortmate faults in translation, to consider whether they themselves had not read Kroyer wrongly, before accusing me of having done so, especially as this countryman of Kröyer's has repeatedly expressed his appreciation of him, precisely in the report on the results of the Dijmphna-expedition, and who about twenty pages earlier (p. 258) has pointed out Kröyer's description of small, but interesting, joints in the antennæ and in the mandible-palp in another Copepod.

Concerning the censure of my ignoring Max Weber, I will make a few remarks. In my dissertation: Fabrica or is Dipterornm, 1883 (Naturh. Tidsskl. 3 R. B. XIV), in orcler to avoid mnecessary length, I did not mention all authors and their opinions, but confined myself to the statement (p. s) that I had made a rule of leaving out writers whom I did not consider as having added new elements of importance to the existing knowledge of its [the month's] structure, or its use for classification, or whose incorrect riews had luored to be of no importance. I have followed the same principle in later works, but it seems that, in order to avoid the accusation of ignorance, I shall have to use the same precaution as in my dissertation, where, immediately after the quoted passage, I enmerate the anthors who are not mentioned, becanse they are unimportant with regard to the subject in hand, thongh they may be excellent in their treatment of other branches. I do not think that I had noticed the above-mentioned erroneous observation by Max Weber before publishing my essay (of which separate copies were distributed in July 188(i). and I cannot tell now if I should have quoted it, had I known it then, but, as a matter of fact, I had read and molerstood it before I wrote the French résumé (in which, as mentioned above, I corrected my omission with respect to Salensky's (to me) important work) and I puposcty forlore mentioning IVEBER, considering his observations irrelevant, though four or five lines would have been sufficient to reproduce their essence. The interest attached to his statements 
consists in his indicating new a locality for Choniostoma on the other side of Nova Zemblia opposite to mine (the Kara Sea), and that an otherwise very deserving anthor has committed. a most peculiar mistake. That is all; whether I ought to have mentioned the subject is a matter of opinion; at the time I thought it might as well be left out.

I shall pass over several other remarks which might call for censure, and take up some hypotheses set forth rather hesitatingly by the authors, p. 352--53. After having declared themselves at a loss to understand that a Choniostoma with its ovisacs can canse a swelling in the carapace of a Hippolyte entirely resembling that which is prodnced by Gyye Hippolytes, they write: "Il nous paraít heancoup plus vraisemblable d'admettre que le Copépode a infesté les Hippolytes déja parasités par les Gyge, et qu’il supplante les Epicarides ou tout au moins profite pour se loger de la déformation produite par ces derniers«. To this conclusion they add a doubt which I think rather irrelevant, and say further: "Néanmoins en rapprochant l'éthologie d'Aspidoccio de celle de Choniostoma, il nous semble bien probable qu'il existe un rapport, soit de parasitisme, soit de mutualisme, entre ces parasites et les Epicarides des genues Aspidopliryxus et Gyge". However, they go still further. They have found a genus of Epicaridea, Podascon G. and B., on a species of the genus Amprlisca, and Salensky lias found numerous examples of a Sphceronchla in all stages on an Amphipod of an altogether different family. Here we should think it wonld be rather. difficult to establish a comection between the Epicaridea (Podascon) and the Choniostomatidx (Sphcronella), which live »exactement dans les mêmes conditions «; nevertheless they continne: "on peut se demander s'il n'a pas existé autrefois entre ces denx gronves de parasites des rapports analogues à ceux que nous avous cherché à démontrer entre les autres Choniostomatidés (Aspidoecia et Choniostoma) et certains Epicarides ". With the word »antrefois « the authors resort to the past, but it will be impossible in a case like the present one to gain any perfect or imperfect knowledge concerning the former state of things. We confess that this invention would be ingenious if - as sometimes happens where an excellent thing is carried to an extreme - it had not overstepped the limit and become ridiculous.

My experience, which is based on very extensive researches, enables me to declare that, as far as the present time is concerned, these hypotheses, which the authors repeat with additional remarks in two later papers, are entirely destitute of foundation.

Of infested Isopoda this work mentions four examples of three species with three species of Sphreronelle; of Cunacea with parasites in the marsupium twenty-four examples helonging to six species (the parasites belong to five species), and of these six species I have examined several humdred specimens, in order to find those that were infested. Of two species of Cumacea seventy-three instances were found with (two species of) Homoensclis under the carapace; finally, one hundred and forty examples of Amphipoda (helonging to twenty-eight species) were found and prover to be infested with twenty-eight species of splloronella and Stenotocheres. of these twenty eight species of Amphipoda I have examined several thousand

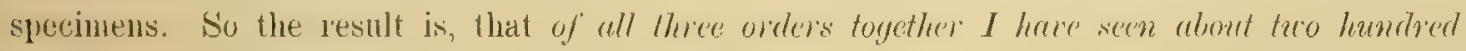


and forty sprecimens betonging to thivty-eight species infested with Choniostomatider, but neither on these, nor on any other of the thousands of individuals belonging to these thirty-eight species, have I found one single Epicarid. So we have done with thirty-eight of my species of Choniostomatidæ, and of the five remaining species two may be passed over, viz. the species of the genus Mysidion, for neither I nor any other author have found any Epicarid in the marsupium of the hosts of Mysidion, viz. the genera Erythrops and Parerythrops. Only on the outside of the body of the species belonging to the genus Erythrops, and in the branchial cavity of two species of Hippolyte, others as well as myself have found altogether three species of Choniostomatidæ, and at the same time species of Epicaridea. As a rule the animals of each order were found on separate specimens; in one case observed by myself, and in one case' mentioned by Giard and Bonnier, animals of both orders were found on the same specimen. Still it can be proved that these two quite different types of parasites, though perhaps in very rare cases they may be in each others way, stand at least in no other mutual relation. As for Choniostoma Hansenii, I can prove that the animal itself produces the swelling on the carapace (comp. my special description of this animal), and in the ouly case where Choniostoma and Gyge were found on the same side under the carapace, a male and a still smaller female of the latter genus had lodged themselves in a large swelling, which was inhabited by an artult female Choniostoma with eleven ovisacs. As for the last of my species - Appidoecia Normani - I have found it on twenty-one specimens of all five species of the genus Erythrops, but I found no Epicarid on any of these animals. Moreover, the occurrence of Aspiroecia, not only on the shield, but also on the exterior side of the tholax and on the six abdominal segments, as well as on the eyes, proves sufficiently that it stands in no commection whatever with Aspirlophyxus, which parasite lives only on the carapace.

Immediately after the paragraph criticised above the anthors write: „Toutes ces ('nnsidérations sont sans doute fort hypothétiques, mais elles penvent inspirer de nouvelles recherches et indiquer la voie anx investigaten's. Elles ont de plus l'avantage de rattacher lrar un lien éthologique commun les tyjes de Copépodes si étranges qui constituent la famille des Choniustomatirle. This "lien éthologique is quite broken now and will scarcely ever be restored. As for the first part of the quotation, I regret to say that it has indicated no path to me, and that, far from having been inspired by their cousidérations", I have been obliged to waste time and space npon proving the untenability of some unwarranted hypotheses. To suggest such hypotheses indeed is not very difficult, and most zoologists have imagination enongh to invent scores of them. If productions of this kind had any real value, it would be easy to promote the progress of science. But I confess that, though I honour everybody who is capable of suggesting a theory which proves to be well founded and fertile in results, I have always felt and, as time goes on, feel more and more distaste for superficial conjectures. 
A. Detala Vatide: "Gammarini del Golfo di Napoli" (Fanna und Flora des Golfes von Neapel, 20. Monographie, 1893, 4to). In the chapter $\gg$ Parassiti dei Gammarini $(p .289-90)$ the author informs us of some observations he has made, and suggests some hypotheses about Spheronella. The species on which Salensky found his Spceronella Lenckartii is said to be Microdeutopus gryllotalpa, and the author has found it in the locality indicated by the discoverer of the species. He further states that he has found the same Spharonella on Ampelisca diadema Costa, where it lives under the same conditions as Podascon Della Vallei. G. and B. And he proposes three hypotheses, viz. that Spheronella changes colour according to its residence, in order to look like the eggs of the two different species of hosts; that it does not live at the expence of the host itself, but by consuming its progeny, and that for some time after having left the egg, the young Spharonella is entoparasitic, not ectoparasitic, developing itself in the oviduct and consuming the eggs successively as they appear. In support of this last conjecture he states that he has found on an Ampelisca a Sphoronella with its multitude of ovisacs, which host at the same time sacchindeva in uno dei suoi ovidutti, verso l'estremo esterno, uno piccolissima Sphcronella, in cui nondimeno erano già ben visibili le nova quasi mature« (p. 290), but in spite of this rather peculiar observation, his conjecture seems mondy hasardous, as an attentive perusal of Salensky's excellent treatise with the description of the pupa stage, which follows the larval stage, would have shown its absurdity. Besides, Giard and Bonnier have refuted all these hypotheses in a later paper; they justly maintain that there is a physiological reason for this castration (scastration parasitaires) effected by the parasite on its host, and they consider the form found on $A m$ pelisca as a different species from Sph. Lenckartii, in which no doubt they are right. So I think I need not throw further light on these questions. -

About Rhizorhina Ampelisce H.J.H. the anthor in his Bibliographia, p. 897, only writes: Questo nuovo Copepodo rassomiglia molto alla Sphcronella Leuclarti, Salensky. The quality of this resemblance is treated in the following pages.

A. Grard et J. Bonnier: "Sur deux types nouveuux de Choniostomatide des côtes de France: Sphceronella microccphala, G. et B. et Salenstia tuberosa, G. et B. (Comptes-rendus de l'Acad. d. Sc., 25 sept. 1893). The contents of this preliminary note appear in a later essay, much enlarged and — in one point - altered.

A. Grard et J. Bonnirr: "Contributions à l'étude des Épicarides (Bull. Scientif. de la France et de la Belgique T. XXV, 1895 - the part headed: "Les Sphceronellidce", p. 462-85, Pl. XII-XIII). This part calls for a detailed comment.

The author's describe and figure the female and eggs of Splccronella microcephala G. et B., a species found on four specimens of Ampelisca tenuicomis Lilljeborg from Croisic. Donbtless the frame of the head is incorrect, for a list like the one represented in the illustration (PI. XII, fig. 43) as going from the outermost posterior angle towards the median line behind the base of the maxillæ, does not exist. If there is a connection between the frame and the sub-median skeleton --. which by the by they have not seen - but which is 
nevel wanting in any Sphoronolla, there must also be a list hehind the maxillipeds. However, the whole frame seems to me most problematical, now have I fround it in sperinens which, as far as I can judge, belong to the same species. I should not have dared to suppose so great a fault in this illustration, if I had not seen their type specimen of the male of Aspidoecia, which enabled me to ascertain their astonishing mistakes in the reliresentation of several organs, especially in the maxillæ and the maxillipeds (conp. above p. $7-8$ ). Moreover', they have decidedly overlooked the maxillulx, which I have never fonnd wanting in any female of this family. Abont the maxilla ("les maxillipedes internes") they say that they are sformés de quatre articles" (p. 464), but this is wrong, for these limbs in all females, males and larvæ of this family contain at most three joints, and the two last joints are even frequently so completely fused that we only find two distinct joints, as shown in my illustration (pl. VIII. fig. 2d) of the head of this species. Neither do I dombt that their representation of the maxillipeds with their strange flexion and the secund joint thick and quite as long as the first, is entirely wrong. Their description and figure of the genital region (p. 465, pl. XII, fig. 44) is not snccessful either. By the wrords of the text: »un arc de cercle chitineux (c) qui, postérieurement, se termine par deux branches... and by the illustration, it is seen that they have turned the whole part upside down, as in reality buth branches turn forward towards the hear of the anmal, seen from the rentral sicle (comul. my fig. $2 \mathrm{a}$ on pl. VIII). The chitinous arch with its branches is pretty correct. Their' representation of the genital apertures and their muscles is perfectly correct, while the apertures marked " and designed as being "les ouvertures d'me paire de grosses glandes ... les glandes collétériques" - are the orifices of the receptacula seminis (comp. my description below and my figures of several other species of the genus). In fig. $2 \mathrm{f}$ on pl. VIII, as in several other instances, I have not represented these orifices, but after a renewed examination of the same species, I can state that the orifices, leading to the receptacula seminis in my Sph. microcephala G. and B., are found precisely in this place, and from these openings each of the middle-sized receptacula - forming all oblong sac - curves gently hackmard and somewhat inward towards the centre. I am at a loss to understand anything about these glands illustrated by the authors. They alsn lepresent a pair of very large receptacula seminis as opening into the genital apertures; though unable to explain what they are, I am positive that they are not what the authors suppose them to be. Finally, what they describe as follows: "Au centre même de laire génitale il existe m espace cordiforme clair (ec), avec trois petites vésicnles gramulenses anx trois sommets, la suluérienre étant la plus grande et la plus nette; tonte cette partie est située profondément, sons le tégument is certainly no organ or organs, but accidental formations produced by coagulation or the like.

The anthor's have taken their species on Ampelisca temicnmis Lilljeborg from Croisic (sonth coast of Brittany), and their determination of the host has been confirmed by the eminent Carcinologist, Prof. G. O. Sars. The specimens described later on in this work, which I have considered as belonging to the same species, were taken on Ampclisca typica 
Sp. Bate. During the interval between the apperance of the first publication and that of the principal essay I corresponded with the authors about these questions, and as they quote some of my written statements, I must make a few remarks. It is not only the fact that Sph. microcephale had been found in Denmark on Ampelisca typica and in France on Amp. tomuicornis, which I may have thought strès curieux «, but in examining a large quantity of Danish material of Amp. tennicomis, not only had I found no specimen of Sph. microcephala whatever, but I had found several specimens of a very different species (Sph. longipes u. sp.), so it struck me as vvery curious « that Amp. temicomis from the Danish coast had a parasite which it had not near the French coast, while in the latter locality it had a parasite belonging to the same genus, and which was not found on the Danish Amp. tenuicornis, though this rery parasite lives in Denmark, but had passed on to Amp. typica. However, I will add that future researches may prove both species of parasites to live on both species of hosts in either locality. In this case we shall wonder no longer, but until further notice we have reason to find the circumstance curious.

Subsequently the authors enter upon a critique of Della Valle's observations and hypotheses. To the species found by Della Valle on Amp. diadema Costa, they give the name of Sph. diantema G. and B., which consequently is put down without description. However, as I have brietly stated the principal points of Della Valle's observations on a finmer page, I may pass them nver here; I will only add that I am not prepared to judge of the value of the reflections set forth by Giard and Bonnier abont the colour of the eggs of parasites - though I can say for certain that Della Valle's opinion is wrong. On 1. 462 - t3 the authors repeat the above criticised stagestion of a comection between Choniostomatidie and Epicaridea: „Les Choniostomatides sont-ils des parasites des Fipicarides dont ils prendraient la place en les faisant périr, ou les Épicarides facilitent ils seulement l'entrée res Choniostomatides en produisant sur les Mracostirca des déformations et une castration parasitaire plus ou moins complète? C'est cette dernière hypothèse qui nous parait actuellement la plus vraisemblable«.

That Della Valle had found a species of Spheronella on two specimens of Ampelisca diudrma, and a species of the gents Podascon (an Epicarid) on two other specimens of the same Amphipor indeed was the rnly fact of interest which had occurred since their previous work in 18s.9, but this fact only proves that a fourth species of Choniostomatidie has been arded to the three, of which it has been stated above that they live on species infested with Elicaridea, and this is of the slightest importance compared with the statistics I give un 1. 11-12, and the condusions drawn fom these statistics and from my observations.

We now arrive at the most unfortunate idea advanced by these authors, their

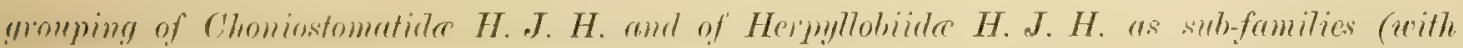
the suffix ims) of the fumily Splurmomellide $G$. and $B$. In order to refute this combination - one of the most inapuropriate I have ever met with in Carcinology - and some hypotheses connected with it, I shall also have to mention the family Herpyllobiidæ. 
In 1892 I published an essay: "Rhizorhina Ampelisca n. gen. n. sp. En ny til Herpyllobiida n. fam. hovende Copepod, snyltende paa Ampelisca lavigata Lilljeb. (Entomol. Meddelelser, 3. B. 5. Hefte p. 207-34, Tab. III), which in the first place contains a detailed description of the above-mentioned new and very curious form, in the second place makes an important contribution to the knowledge about Herpyllobius Stp. and Ltk; finally the new family Herpyllobiide is established, and the genera - seven in all — which can with more or less certainty be referred to it, are grouped together. Two of these genera, Trophoniphila M' Intosh and Oestrella M' Intosh, are described so defectively that we prefer not to consider them in this place. The female of the other five genera has a globular of oblong body without any vestige of mouth or limbs; posteriorly are two genital apertures, each with its ovisac. The front part of the female of Rhizorhina forms a short, slender stalk, which pierces the skin of the gill of its host; the inside of this stalk consists of two tubes. Just beneath the skin of its host the stalk expands very much, the tubes are considerably dilated, they separate and ramify irregularly throughout the gill, even entering somewhat into the body of the host. In the genera Herpyllobius Stp. and Ltk. and Eurysilenium M. Sars, the stalk, which consists of a single tube, is found on the rentral side of the body, pierces the skin of its host and expands inside it like a collar, but this collar is surrounded by the root of a large, oblong, foliaceous or irregularly sausage-shaped body, which is decidedly homologous with the tubes of the Rhizorhina, and, like these, has the function of drawing nourishment from the host to the external, limbless body, whose business it is to develop the eggs. In Sriccopsis Lev, and Bradophita Lev. Levinsen has indeed found the stalk, but no body at the expanded end of it in the body of the host. However, he had but slight material of both forms to work with, so I will now state as my personal opinion, that a body, or one or two tubes, may have proceeded from the stalk into the body of the host; otherwise it would be impossible to understand how the parasites could get their food. Moreover, I may mention that, when (in Nov. 1896) I spoke to the author, Inspector G. M. R. Levinsen, about the matter, he felt inclined to share my opinion. Giard and Bonnier (in their above-mentioned paper) describe a new parasite, Salenskya tuberosa, of which a single specimen was found on Ampetisca spinipes Boeck from Croisic. They contess (p. 474) that it "présente certainement une très grande ressemblance avec Rhizorhina ampelisca.... et nous avons longtemps hésité à maintenir le genre Salenskya, crée par nous [in the preliminary note] quelques mois après la publication dı travail de HANSEN《. Still they think they are justified in maintaining it, "au moins provisoirement", on the following basis:

"Au lieu d'être fixé à son hôte par des racines rappelant un pen celles de Sacculina, ou par un renflement comparable à celui des Herpyllotrins, la femelle de Salenstiya possède mu appareil chitinenx spécial, qu'on pourrait rapprocher plutôt de celui de Saccopsis terectrellidis figuré par Levinsen ...... (p. 475). I have just spoken of Saccopsis, and I will now express my opinion that if a specimen of Salenskya is found again on Amp. spimipes, and the part of the host occupied by the parasite is ent off, this part will contain internal tubes exactly 
Tike those I have describer in Rhizorhina; the two apertures mentioned and described by the anthors are the roots of these tubes. Separate copies of my essay about Rhizorhina were distributed in July 1892 (one of them was sent to the authors). Their preliminary note, in which they establish Salenslya, mentioning its "appareil fixateur en forme d'amphidisque ou de bouton de manchette", is dated Sept. 25th 1893, but it is quite evident that, at the time their manuscript was sent to the press, they had not read my essay. So, having but one specimen of the animal to work upon, they committed the same mistake which I had made with my first specimen of Rhizorhina: without having any idea of the tubular system inside the host, I detached the visible part of the parasite, thus breaking the stalk which united it to the hidden part. After what I have just said about their investigation of the male Aspidoecia, I am quite justified in not trusting their statements in a question so difficult as that concerning Salenskya, where their judgment rests on the examination of but one individual. The result is that the genus Salenskya G. and B. must be cancelled, being established only on this one single character. Whether their species differs from Rhizorhina Ampelisce will have to be proved by ascertaining if the slight differences between our representations of the males agree with facts. Though this on the whole may possibly be the case, I doubt that they are right in stating that the larva of the parasite they describe has two orifices for the ducts of the genital organs; I have only found one hole surrounded by a somewhat thickened ring.

The authors quote from their preliminary publication (p. 475-76) a long passage, in which they suggest "progénèse " and »dissogonie in the male of Salenskya. They now give up these theories, saying: "Les recherches de Hassen prouvent que chez Rhizorhina la métamorphose régressive existe bien chez les mâles de ce genre d'Herpyllobrince et qu'elle est tout aussi accentuée que chez les Choniostomatince. However, the last sentence which is meant to establish a relationship between the two groups to each other, is very misleading, as the male of Rhizorhina (and Herpyllobius) is a body entirely without limbs, mouth or any other external organ or internal muscles, with nothing in fact but genital organs, the male of any Choniostomatid whatever is a highly developed animal with antennulæ, a very complex month with mandibles, besides maxillulæ, maxillæ and maxillipeds with some joints, internal muscles etc. So in saying: "Ce charactère différentie] ["progénèse in Salenstya and other Herpyllobiidæ] entre les deux sous-groupes ne pent donc être maintenu", they are perfectly right, but snch a negative feature does not imply any kinship.

However, the principal points are contained in the following paragraph, and in order to criticise it I am obliged to quote the last half of $\mathrm{p} .476$ and a little of p. 477 in their paper; I will, however, divide the quotation into three parts. They write: "Le reste de l'organisation concorde d'une façon remarquable, non seulement chez la femelle où, en raison de la dégradation, toute comparajson peut sembler dépourvue de valeur, mais aussi chez les mâles et les embryons: même tendance à la disparition de la deuxième paire 
d'antennes, même structure de l'appareil buccal avec la ventouse si spéciale et les appendices transformés en stylets, même disposition des membres thoraciques, etc.

Les jeunes individus surtout présentent une ressemblance extraordinaire et indiquent nettement la parenté des deux groupes.

Mais il est un caractère du mâle sur lequel nous désirons particulièrement attirer l'attention, parce qu'il est très exceptionnel et qu'on ne le retrouve dans aucune autre famille de Copépodes, en dehors des Choniostomatinæe et des Herpyllobiinœ.

Les canaux excréteurs des glandes génitales mâles débouchent dans la partie céphalique de l'animal et dans le voisinage de la bouche".

Let us examine this a little more closely. Though the authors think that the larvæ in particular show »une ressemblance extraordinaile", we find that these larvæ, which indeed may be said to be in the first Cyclops-stage, resemble each other less than the larvæ of a Choniostomatid and of an Achtheres respectively, according to the illustration given by Claus (Zeitschrift wissensch. Zoologie B. XI, Taf. XXIII, fig. 5). At any rate, the likeness between the mouths of the larvæ of a Rhizorhina and of that of a Choniostomatid is not so great as the authors seem to think, and it is certainly much smaller than that between the mouth of a larvæ of the last-mentioned group and e. g. of a larva of Pennella. The maxillæ of the two groups deviate much from each other in shape and position etc. Several great differences between the males of Choniostomatidx and of Herpyllobiidæ have been pointed out above, and we shall soon mention more. The differences between the adult females also seem to be so great that we are struck by the astonishing boldness of the assertion that: sen raison de la dégradation, toute comparaison peut sembler dépourvue de valeur«. In the former type, the Choniostomatidæ, the female possesses at least the antennulæ, a well-developed mouth with mandibles, maxillulæ and maxillæ; in the latter, the Herpyllobiidæ, the body has no vestige of these organs or of any limbs, and in the three genera which are examined so thoroughly, that our knowledge about their nutrition is perfectly reliable, we know that it takes place through a large mysterious body (in Herpyllobius and Silenium) or through an equally mysterious tubular system (Rhizorhina) which is found in the body of the host, and which has a most curious, hitherto unexplained development (comp. my essay about Rhizorthina). Indeed, I can find no other likeness between the females of these families than the small size of their bodies, their subglobular or oval form, and their two genital apertures, and as this last character seems to be common to all parasitic Copepoda, we might as well pass it over.

But still more objectionable is the statement printed in italics, that in the males of both families the genital aperture is found on the head near the month. I shall begin by speaking of Herpyllobiidæ. The authors substantiate their opinion in these words: "Ce caractère, tellement extraordinaire que nous ne l'avions signalé qu'avec réserve dans notre étude sur Aspidoecia et dans nos recherches plus récentes sur Salenskya, Haxsex l'a mis 
complètement hors de doute dans son beau travail sur Rhizorhna..." This requires a comment. I have proved the following facts. The males of Rhizorhina and of Herpyllobius wre not the lavere. The larva fastens itself to the female by a gluey substance, after which all its muscles etc. are dissolved; the limbs are emptied of their contents and the whole plasma of the larva contracts and surrounds itself with a new skin, thus forming a male without limbs, mouth or other external organs, and without visible internal organs except testicles and their efferent ducts which gradually develop themselves. In the Rhizorhina this male remains inside the skin of the larva, pushing its remarkable spermatic ducts out through the hole in front of the mouth of this dead case. In the Herpyllobius the skin af the larva bursts, the male fastens itself with its front, and the spermatic ducts proceed (behind the attached end) through the split produced by the bursting of the larval skin. So in both cases the male is transformed to such a degree as to render a morphological orientation rather uncertain; at all events, we can no longer speak of "le voisinage de la bouche», as there is no mouth at all. This description of the male of Herpyllobiidæ will also give a sufficient idea of the immense difference between this animal and the males of Choniostomatidxe which, moreover, fix their spermatophores on the females in the usual way.

The authors continue: "Chez tous les Sphoronellidae, les canaux génitaux mâles servent aussi à l'excrétion d'ume substance cémentaire avec laquelle le mâle se fixe sur la femelle d'une façon plus ou moins durable. Ce rôle nouveau et ces connexions singulières des canaux génitaux constituent à coup sûr le trait le plus saillant de la morphologie de la famille des Sphceronellida, telle que nous la comprenons", namely Choniostomatidæ and Herpyllobiidæ together. The authors are bold indeed; they do not hesitate to suggest one hypothesis after another, the second more erroneous than the first. Now, to begin with Herpyllobiidæ, who has said anything that could justify the statement that the genital organs of the male secrete the viscous substance by which the animal attaches itself? The authors have seen nothing themselves, and they cannot base their statement on my essay about Rhizorhina, as I maintain that the larva of this animal attaches itself by a gluey matter proceeding from the mouth before the male is developed and before there is any indication of yenital organs. The male keeps inside the skin of the larva, which remains attached to the female, and no further fixation takes place ${ }^{1}$. How then must we qualify the sentence the author's pronounce as if it were proved? To put it mildly, we can only call it a product of imagination. - We shall now turn to the second division of their s Sphcronellide": the Choniostomatidæ, and here again we shall have an opportunity of considering their above quoted lines in italics: "Les canaux excréteurs des glandes génitales mâles débonchent dans la partie céphalique de l'animal et dans le voisinage de la bouche«.

1) In the Herpyllobius the male atlaches itself a second time by its front end, but the genital aperture is found at some distance behind this fixation (Entom. Meddel. 1. c. p. 230). 
The author's have proved (1889) that in Aspidoecia the male is hinged by a thread which proceeds from a hole on the ventral side of the front part of the head: sce filament est secrété par deux grosses glandes cémentaires probablement homologues de celles qui servent à la fixation chez les Cirripèdes«. No doubt it is this comparison on which they base their opinion that the genital aperture is found on the head, and also that the spermatic glands secrete the viscous substance which forms the thread, as these organs are believed to perform this double function in the Cirripeds ${ }^{1}$ ). A slight basis indeed for such remarkable statements! The observation about the hingement of the male is correct, but thell, has the thread to disappear in order to allow the spermatophores to come ont of the hole, or is the order of the two processes to be inverted, or does the male possess another genital aperture on its front near the base of the thread? Unfortunately we get no answer to all these legitimate questions - though indeed we can scarcely imagine any possibility besides these three. No, the doctrines about the genital aperture on the head and the double function of the sexual organs in the Choniostomatidæ are postulates without any foundation. Wíhin the family mentioned it is an ordinary phenomenon to find the male attached by a thread; this prevents it from being washed away and allows it to creep as far as the thread can reach, giving it frequent opportunities to fix its spermatophores on the entrances to the receptacula seminis. Besides, the genital aperture is not found on the head; in Sphceronella paradoxa I have been able to prove the existence of two genital apertures at a short distance from each other on the ventral side of the trunk: from each spermatotheca proceeds an efferent duct forward and obliquely towards the median line, and these canals open on the posterior side of the depression between the first pair of trunk-legs, or at least somewhat behind the basis of the maxillipeds. But then, what remains of the hypotheses advanced as facts by the two authors, that the genital aperture of the male in the Choniostomatidx is found on the head, and that the scanaux génitaux secrete the viscous substance by which the animal attaches itself? Nothing, absolutely nothing! And what remains of their best proof - based on these organs --, that Choniostomatidæ and Herpyllobiidæe ought to be grouped in one family? Equally: nothing! except a rather surprising impression of the loose method of the authors: to establish unreliable conjectures as facts in order to prove an absurdity.

Though I suppose that most readers have now formed a pretty clear idea of the great differences between the two families, I will give a summary. The likeness between the two families is limited to the following features: both are parasitic Copepoda, in which the males are several or many times smaller than the females; in both sexes the body is small, sub-globular or oblong; the last larval stage of Herpyllobiidæ is the first Cyclops stage, it resembles to a certain degree the larva just coming out of the egg in the Cho-

1) I will not here enter upon criticisms which have appeared elsewhere about Darwin's unfortunate statements upon this subject, nor on Giard's later suggestions concerning Rhizocephala. 
niostomatidæ. The differences between the families will be shown most clearly by giving a short description of each. In the Choniostomatidæ both sexes possess at least antennulæ, a month with mandibles, maxillulæ and maxilla, and the males have always maxillipeds, and they fix their spermatophores on the females in a normal way. The female deposits its eg'gs in one or two free lumps or, in most cases, in ovisacs, of which at least four or five and sometimes more than twenty are found; the larvæ attach themselves by an adhesive plate on the forehead and - whether passing through the pupa stage or not - develop themselves into animals of either sex. In Herpyllobiidæ both sexes lack antenmæ, mouth and. appendages; the females project a mysterious body or two ramified tubes into the host and draw nourishment through these organs. The males project from the anterior part of their body in advance of the mouth of the larval skin two long spermatic ducts, which are formed by a secretion in the genital organs, and through these canals nearly the whole substance of the body, having been transformed in the service of propagation, is transferred into the female. The female has two ovisacs; the larva attaches itself by a gluey substance proceeding from the mouth, and is transformed into a limbless male or female. In the latter case the animal forms a stalk which pierces the skin of the host, inside which it dilates and develops into the above-mentioned organ of nutrition. - Whereas the Choniostomatidæ, on the whole, fit in well among the other families of parasitic Copepoda, the Herpyllobiidæ remove themselves from the others by a series of very peculiar features, occupying a more isolated position than any other of the families.

This, I hope, will be sufficient to prove that the juxtaposition by the authors of the two families in question as sub-divisions of one family, is contrary to all sound classification. I think also that sufficient light is thrown on the characters and hypotheses of the authors. The present work being a kind of monograph, I found it necessary to write this rather detailed critique of their publication. However, this task has not been at all pleasant to me, because in another branch, the Epicaridea, they have published works which must be considered the principal sources of our knowledge about important groups belonging to this large and difficult family. In the interest of the authors and of carcinology, as well as for my own sake, I wish they had not published their four, at least not the two last of their contributions (the preliminary note in 1893 and their final essay 1895) about Choniostomatidx. It would indeed have been very natural to postpone the publication of their two last papers, as their material of these animals (whose manipulation presents considerable technical difficulties) was rather scanty, and as, even as early as 1891 , they know that I was preparing a work based on very abundant naterial. (I need scarcely add that the fact of their publishing a report about one species previously to myself affects me very little; indeed I might easily have secured this priority by some spreliminary note ). If, nevertheless, they were intent upon describing their few animals, their researches might and ought to have been much better, and they ought to have abstained from filling up real 
or imaginary gaps by a number of mprnved assertions and unwarranted hypotheses regarding structure, biology and classification.

Nowadays many athors have a remarkahle weakness for publishing innumerable immature notes, for building zoological card-houses, drawing up genealogical trees and inventing theories and hypotheses, especially where they know very little. Where they have acquired considerable knowledge based on thorough study of a large material, as a rule, they abstain more from hazdrdous conjectures. One result indeed has been obtained: Zoo$\log y$ has been encumbered with endless preliminary notes, with papers abounding in faulty and defective representations and unaccountable postulates and reflections, so as to render the study of it troublesome to an almost unsurmountable degree.

Jutws Bonnter: Résultats scientifiques de la Campagne du saudan dans le Golfe de Gascogne, Aout-Septembre 1895. Edriophthalmes. (Ann. de l'Université de Lyon, 1896) ${ }^{1}$ ). In an appendix to this valuable work the anthor describes and figures a new species, Spheronclla sedentariu Bonn., which he has discorered in the branchial carity of Cyclaspis longicandatu G. O. Sars of the order Cumacen, in a depth of 960 metres, lat. $44^{\circ} 5^{\prime} \mathrm{N}$., long. $4^{\circ} 45^{\circ} \mathrm{E}$. He found an adult female, four ovisacs and a small specimen, which he considers to be a young female, but which is no doubt a male. The species belongs to my new genus Homoeoscelis, and comes very close to my $H$. minuta. He begins by describing the small specimen, and his description of its body, the borders of its head, its antennulæ, maxillipeds, trumk-legs and candal stylets is essentially correct. He also corrects Salensky's erroneons conception of the caudal stylets as a third pair of legs, but he has certainly overlooked the maxillulæ (comp. my drawings of the males of my species: pl. II, fig. $1 \mathrm{i}-1 \mathrm{k}$ and pl. XIII, fig. $1 \mathrm{f}-1 \mathrm{~g})$, which are never wanting in any species of the whole family - unless the onter part of the mandibles possibly may be the larger part of the maxillulæ, which might indeed be supposed from the drawing. The hairs surrounding the membranous border of the month are overlooked, and the basal joint of the maxillæ which he mentions (his maxillipède interne") does not exist; what he takes for this joint is no doubt a part of the sub-median skeleton. As will appear from my subsequent description, the only feature by which the male and a young female of the same size of the genus Homoeoscetis can in all cases be distinguished from each other, is the distinctness of the genital apertures in the female. The author has found no such apertures, and this circumstance, as well as the occurrence of the animal together with an adult female, indicates that it must have been a male. The author's comparison of the female with the small specimen is correct; only his description of the genital area calls for a few remarks. He

1) A special copy of this paper, kindly sent me by the author, arrived on Febr. 11th 1897, so that the present remarks had to be written and inserted in my work when a large part of the fair copy of it was already written. 
is of the opinion that each of the genital apertures is provided with a separate frame, of which he presents a drawing (fig. 5e), but the anterior part of these frames is scarcely correct in drawing, as it is not likely to reach up to the "pore de fécondation " (orifice of the receptaculum seminis) which - we see - here for the first time is proved to exist in an animal of this family. Neither has he seen the median part of the firm chitine of the genital area which unites the two "frames «, but it must be pointed out, that without a special dissection - in which, moreover, a certain amount of practice is desirable these details are difficult to discover. The whole description of the two small specimens is considerably better than the above-mentioned joint work on this family by the same author and Prof. A. Giard. 


\section{GENERAL REPRESENTATION OF THE FAMILY.}

$\mathrm{I}^{\mathrm{n}}$ n order to facilitate the use of this large section it is divided into three chapters, the first of which contains a general view of the structure and development of the animals. the second of their habitation, biology and distribution, the third some general observations about the classification. Each of these chapters contains several sub-divisions.

\section{A. Structure and Development.}

\section{a. The Female.}

This sex is known in all species. The body is nearly always a little flattened seldom more than a little; if seen from below or from above it is ovate or globular. The young specimens are generally much longer than they are broad; the adults are now a little longer than they are broad, now the reverse; sometimes their broadest dimension is a little in front of, sometimes a little behind the middle. Specimens which are going to lay, or have commenced laying eggs, are always somewhat - probably as a rule much — larger than old ones which are emptied of eggs (pl. 6, fig. 3 a shows such a female which is going to lay eggs, fig. $3 \mathrm{c}$ a female (with a male) which is emptied of eggs, both enlarged to the same scale). In consequence of this evacuation the animals frequently shrink and become vaguer of ontline. We often happen to see specimens which have become crooked and irregular from pressure, otherwise all the animals are naturally symmetrical. The size of the adults varies considerably; in most species the diameter of the animal seen from below is $2 / 3-1^{1 / 2} \mathrm{~mm}$; it can even decrease to about $3 \mathrm{~mm}$. (Homoeoscelis mediterranea), and Choniostoma Hansenii G. and B. can obtain a lenght of 5.3 and a breadth of $5.5 \mathrm{~mm}$. As a rule there is a certain proportion between the size of the parasite and that of its host; however, it must be borne in mind that the parasites themselves differ in size according to their habitation in the marsupium or under the carapace; in the latter place they are comparatively smaller. As a matter of course, small Amphipoda cannot 
support large parasites, whereas large species like Calliopius leviusculus Kr., Munnopsis typica M. Sars and Hippolyte, are inhabited by large animals.

In most species the regular, rounded, ovate or globular shape of the body is interrupted in front or a little behind the anterior margin on the ventral side by a small protruding head, which as a rule is tolerably well defined at the basis. In the adults it is most frequently very small, compared with the trunk; in small, and particularly in recently hatched specimens (pl. VIT, fig. 2e, and especially pl. III, fig. 2c) it is of a very considerable size. The reason of this difference is that the hend and its organs do not grow or at most grow very little, whereas the trunk greatly increases in size, in order to give room for the mighty production of eggs. In some forms there is no separate head at all, so that its (very small) organs: antennulæ, antennæ, mouth, maxillulæ, maxillæ and maxillipeds, are situated near each other anteriorly on the ventral side of the vaulted body. In Stenothocheres (pl. I) the thorax has two rather small pairs of limbs; in the other genera these limbs are quite minute or wanting altogether. In Stenothocheres we find a distinctly marked, prominent abdomen. - In no species the body shows any vestige of segmentation.

This will give a general idea of the females. In giving a closer deseription of their structure I think the best plan is to begin with Spharonella and kindred forms, as the geums Stenothocheres, though in two important points - the size and development of the trunk-legs and the existence of an abdomen - more closely related to less transformed Copepoda, in other respects is less qualified for serving as base of the description.

I. Homoeoscelis, Sphreronella and Choniostoma. Many species have a prominent, well defined head: the back, front part and sides are evenly vaulted and pretty well chitiniser, and the chitinous border to the front and on the sides stands out a little beyond the rentral side, which is partly covered by a soft membrane, and has a somewhat concave surface. Seen from below, the sides of the head are arched posteriorly, for the abovementioned protruding lateral borders are somewhat removed from the outline of the head; they are generally ciliated, whereas the margin of the frontal border is mostly hairless. As a rule, a narrow, arched, transversal list, or two narrow, parallel lists, proceeding from the posterior ends of the lateral margins and passing behind the basis of the maxillipeds, forms or form the posterior limit of the head. Sometimes this list is interrupted at the median line (pl. III, fig. $2 \mathrm{c}$ ), sometimes it does not reach the lateral margins (pl. VIII, fig. $1 \mathrm{~d}$ ).

Choniostoma (pl. XI) at first sight seems to have no distinct head at all, however, the abnve-described borders in front, posteriorly and on each side remain, forming a frame round the sint area, in the middle of which the mouth and its appendages are situated. The front part of this frame in Chon. Hansenii (pl. XI, fig. 2d) rises a little beyond its surroundings, thus representing the only remaining part of the anterior and upper surface of the hear.

Sphrr. Accuthozonis (pl. VII, fig. 5 a and $5 \mathrm{~b}$ ) presents a fine intermediate form between Chomiostoma Hansenii and the species that have a well defined, prominent head 
(illustr. on pl. II to pl. VII etc.). In all species with well-developed head, or at least with the frame left, we see behind the frontal margin and inside the lateral parts of the frame a broad band of thin, soft skin. Somewhat behind the middle of the frontal margin is the rostrum (proboscis) with antennæ and maxillulæ, and from this part backward towards, or quite up to the list behind the basis of the maxillipeds, we see a system of plates or lists. This system, which I shall call the sub-median skeleton, is partly or all the way divided into two halves by softer skin along the median line; its structure differs in nearly every species; as a rule it expands considerably in the middle of its lateral margins. The inner margin of the basal joint of the maxilla touches the outer margin of the front part of the expansion, whereas the maxillipeds are articulated behind the expansion touching the outer margin of the narrower posterior part of the skeleton.

In several species of the genus Spharonella, namely Sphor. microcephala, S. dispar, S. insignis, S. Munnopsidis and S. marginata (pl. VIII, fig. $2 \mathrm{~d}$; pl. IX, fig. $3 \mathrm{f}$ and fig. $4 c$; pl. X, fig. $4 \mathrm{~b}$, and pl. XIII, fig. $6 \mathrm{~d}$ ), there is no separate head and no harder chitinous borders (only in $S$. marginata and in $S$. microcephala there is a low border or a transverse list in front of the mouth (pl. XIII, fig. $6 \mathrm{~d}, \mathrm{pl}$. VIII, fig. $2 \mathrm{e}$ )), whereas the sub-median skeleton exists, strongly developed as a solid plate in S. Munnopsidis (pl. X, fig. 4b), much reduced in S. dispar and S. insignis (pl. IX), and particularly so in S. marginata.

The Antennula. In all species, except the five without separate head and without frame, the antennulæ are well developed, and in these they are articulated to the solid frame, each at one of the angular points where the lateral margin merges into the frontal margin (comp. e.g. pl. II, fig. $1 \mathrm{~h}$ and fig. $3 \mathrm{a}$, pl. XI, fig. 1a). Each antennula is usually composed of three joints, of which the second is generally the shortest, the third the longest. The front angle of the first joint is mostly provided with two or three shorter or longer setæ; the terminal joint is rather well provided with bristles of different length, among which an olfactory seta (b) can be frequently pointed out. In the genus Homoeoscelis the antennulæ become 2-jointed by the fusion of the second and third joints (pl. XIII, fig. 1d). In Sphar. decorata (pl. VIII, fig. $3 \mathrm{e})$ the first and second joints are coalescent. In Spher. mar.ginata the antennulæ (pl. XIII, fig. 6d) are constructed as in Homoeoscelis. In the other four species of Sphceronella, which are devoid of separate head and of frame, the antennulæ are situated at the same points, but fastened to the thin membrane, besides being shorter and rednced so as to show only indistinctly separated joints or no division at all.

The Antenne. These organs I have been unable to discover in the species of the genus Homoeoscelis, and in Sphor.modesta, S. dispar, S. insignis, S. marginata, S. Munnopsidis and S. microcephala, whereas they exist in the other species of Sphoronella and in Choniostoma. They are always placed on the side of the rostrum itself near the margin of its expanded basal part, and they are always short, slender, generally 3-jointed (e. g. pl. V, fig. 2 d), without hairs and terminating in one shorter or longer seta. In a few species, e.g. Sphrer. decorata, the number of joints is reduced to two, in Sphar. antillensis (pl. III, fig. 2c) they are 
rudimentary, 1-jointed and have a very short seta, and so they are in the seven remaining species belonging to the group of Sphor. Leuckartii Sal. (comp. the systematic part).

The Rostrum. It is always of good size and bluntly conical, or like a cylinder with dilated base. Its structure is very complex, and we will begin by studying its distal part, for the representation of which Choniostoma Hansenii (pl. X, fig. 6 a and fig. 6 b) will serve as type. In fig. 6 a the cylinder is seen sideways and without the expanded part at its base. At the margin of the terminal face of the cylinder originates a membrane which has the shape of a kind of border or very short inverted cone. In looking at it from the distal end (fig. $6 \mathrm{~b}$ ) we see that the membrane covers the whole terminal face, having the shape of a cup or perhaps rather of a flat funnel, as it leaves an oblong aperture at the bottom in the centre; this is the entrance of the mouth, beyond the margin of which the points of the mandibles are seen to proceed. In front of the mouth the membrane is divided in the middle by a deep incision; the opening thus produced is filled by an odd median plate, on each side of which is another plate which is partly covered by the membrane. In the illustration these parts are narked $d$. The membrane is downy at its edge (fig. 6 b), and the whole imner surface of the funnel is covered with peculiar dots, which are smaller near the edge than towards the centre, and which probably represent tiny knots. Outside the membrane are seen a number of cylindrical hairs which are sometimes furcate at the apex (b). They are articulated to the distal edge of the cylinder at the base of the membranous border and, being longer than its height, proceed somewhat beyond its free margin. When - as in the present instance - the rostrum is cut off, it is easy enough to see that these hairs do not exist within the membrane, but only lean against it. In some species, e. g. in Sphceronella curtipes ( $\mathrm{pl} . \mathrm{X}$, fig. $2 \mathrm{~d}$ ), the membrane (viz. the free part of it) is considerably broader, in others narrower, than in Choniostoma Hansenii. The hairs in some species are much more numerous and much thicker than in others, and they often converge or diverge very irregularly, according to the position they happen to occupy; in a few species I was not able to discern them. My figures as a rule are too small to allow of drawing the membrane, but these hairs are drawn as well as it could be done. It must be observed that the shape of the mouth varies considerably in specimens of the same species; I have found it more or less funnel- or cup-shaped, in accordance with the angle formed by the membranous border and the surrounding hairs against the terminal face. In the systematic part of the present work the free part of the membrane together with the hairs is called the mouth-border.

The outer surface of the rostrum shows several harder chitinous lists, and when the rostrum is examined from its distal end, some harder parts are seen through the semi-diaphanous membrane as circles, which are interrupted in front at the median line. In my opinion the distal part of the rostrum must be explained as being a highly modified labium, or rather hypopharynx, which forms a kind of sheath round the mandibles and stretches so far towards the front that its edges approach very near to each other, and that the abovementioned median part marked $d$. must be considered as the labrum. However, I am not 
able to account more fully for the structure of these parts and the attachment of the mandibles: When looking at the rostrum from its distal end (fig. $6 \mathrm{~b}$ ), we see them through the intermediate substance, like narrow lists in appearance, the free distal points of which are visible in the month-aperture and are somewhat different in shape on the right and the left maudible. Departing from the points, they turn outward, at the same time running down the rostrum, their basal end lying inside its walls rather far from the aperture of the mouth.

It is only the distal part of the rostrum which can be considered as formed by the hypopharynx and the labrum, the proximal part must be chitine belonging to the ventral side of the head itself, which here has become cone-shaped or forms the foot and the proximal part of the cylinder. I draw this conclusion from the fact that the antemnæ, where they are found, proceed from the basal part of the cone or from the foot (Choniostomu, pl. XI, fig. $2 \mathrm{~d}$ ), and that the maxillulæ are situated on its lateral surfaces (see e.g. pl. X. fig. 6 a, c, and many illustrations of heads of females seen from below). But these last-mentioned mouth-organs must be treated separately.

The Maxillule are found in all species. Each maxillula consists of a somewhat oblong plate which almost throughout its whole length is coalescent with the middle and the more proximal part of the rostrum, and in the latter place this coalescence is so complete that it becomes impossible to distinguish the outline of the proximal part of the maxillula (fig. 6a), whereas its distal part (c) detaches itself from the lateral surface of the cylinder. Here it divides itself into two branches, the anterior of which forms, now a shorter or fairly long: now, and mostly, a very long process, which looks somewhat like a proximally very thick and distally more slender seta. The posterior branch has a quite similar structure. These two more or less setiform processes I consider as the principal branches of the maxillula; they are never wanting, and as a rule they are somewhat curved (in the specially examined specimen of Choniostoma their terminal half was sinuous), and on examining the head from below, the anterior branch of the maxillula is mostly seen to proceed beyond the foremost part of the lateral margin of the mouth-border, the posterior branch behind the posterior part of the same lateral margin, whereas the distal part of its plate and the base of the two brauches are covered by the lateral part of the mouth-border, through which they can be seen (e. g. pl. $V$, fig. $2 d$ and especially fig. $3 d$ ). Besides, in most species the maxilla possesses as an additional branch a process shaped like a stout and usually long seta, articulated to that part of the maxilla which is coalescent with the rostrum, and often so proximally that, in looking at the head from below, we get the impression that it is situated outside the basis of the maxilla. The basal part of this additional branch is frequently set off by an articulation. This branch is wanting only in Homoeoscelis and in the three species of Sphceronella which are parasites on Cumacea, and which have no separate head.

The whole rostrum is movable, so that its distal part with the mouth is turned more or less forward or backward, now protruding, now receding considerably, which differences are seen most distinctly by observing the head sideways, and comparing the 
position of the rostrum with the lateral margins of the head (comp. the rostrum in the numerous figures of males seen from left side).

The Maxilla are always (except in one single species mentioned below) well developed, often very powerful. They are situated far from each other, somewhat behind the base of the rostrum, on the onter margin of the sub-median skeleton, the expansion of which reaches their inner margin and frequently extends behind their posterior margin. Typically they have three joints, of which the first one is very thick, often not much longer than broad; the second and third joints together are usually shaped like a slender, distally somewhat curved cone, which can be folded up like a claw against the oblique terminal margin of the basal joint, and as a rule these two joints are coalescent, though sometimes we find them very distinctly separated (e.g. in Sphceronella insignis, pl. IX, fig. 4c). The basal joint is often provided with one or two protruding knots or taps, and its terminal margin at the articular membrane is frequently furnished with hairs, or, as in Sphrer. Munnopsidis, with some peculiar cylindrical bristles or fine processes ( $\mathrm{pl}$. X, fig. 4b); in Sphrer. decorata (pl. VIII, fig. 3e) and in S. modesta (pl. IX, fig. 2d) a part of the articular membrane between the first and the second joint is decorated with rather numerous small chitinous taps. The terminal joint usually ends in a point; in Sphor. dispar (pl. IX, fig. 3f) the apex is blunt, but has several fine, setiform points. In Spher. marginata (pl. XIII, fig. $6 \mathrm{~d})$ the maxillæ are quite rudimentary.

The Maxillipeds are well developed in Sphceronella and in Homocoscelis. They are articulated on the posterior part of the sub-median skeleton and are usually somewhat closer to each other than the two maxillæ. They consist typically of four joints, of which the basal one is thick, very long and always distinctly longer, often much so, than the other's together; these can be folded up against it in a very acute angle. The basal joint is often decorated with processes, spines, rather long hairs, shorter or very short hairs, or very fine, conical taps; the hairs and taps are arranged in spots, stripes or rings. The second and third joints are slender, distinctly or indistinctly articnlated or quite fused together without the slightest distinction. The third joint has generally on the inner side of its distal end a spine, which in those species of Spheronella which live on Cunacea, is provided with fine points, besides being sometimes broad and flat (pl. XIII, fig.6d). The list joint is more slender than the others, somewhat curved and often ending in a point with one or two spines on the inner side behind the point; in most of the Spharonellae living on Cumacea the joint expands a little towards its somewhat flattened and rounded extrenity, along the margin of which we see numerous fine and short, setiform processes. A somewhat similar structure is noticed in Sphcronella Munnopsidis (pl. X, fig. $4 \mathrm{~b}$ ). In sipher. microcephala (11. VIII, fig. 2d) the maxillipeds are weak and comparatively rather small, second and third joints coalescent and very short, the last joint very small and stunterl. In the genus Choniostoma the maxillipeds are quite rudimentary (pl. XI, fig. $1 \mathrm{a}, \mathrm{g}$ and fig. 2 d), and reduced to two very small or quite diminutive joints. 
Before leaving the head I will mention some peculiar formations, which I am at a loss to molerstand. In Sphcer. frontalis we notice at the middle of the frontal margin (pl. VIII, fig. $1 \mathrm{~d})$ a strange cup-shaped, rather large expansion in which I have been unable to find any hole which might be the outlet from some gland. In Sphar. modesta, on the ventral side of the protruding frontal border, inside its margin we see a square of considerable size (pl. IX, fig. $2 d, x)$ with rounded corners, which seems to be pierced with rather numerous holes.

The Trunk. The body - except the head - of course corresponds to thorax and abdomen, but in the three genera treated here, the latter never appears as a separate part; we must consider it as being represented by the genital area and its surroundings, which, however, are not marked by distinct outlines. I beg to give notice that, as a separate abdomen only appears in the genus Stenothocheres (s. below) and in no other genus of the whole family, I shall - for practical reasons - in mentioning and describing all the genera, except Stenothocheres, always both here and in the systematic part use the word "trunk "for the whole body, except the head.

The shape of the trunk is mentioned above, for as the head, at least in adult specimens of most species, is very small, I can refer to my description of the body (p. 24-25). The skin - except on the genital area - is very thin, often quite naked, sometimes covered with hairs behind the head, being naked everywhere else, sometimes hairy all over. In several species the trunk is more hairy during the early, not half-developed stages, than when the animals have grown to their full size, so e.g. in Spher. danica, whose young ones are covered all over with peculiar thin, flat hairs, whereas the older specimens are either quite naked or have only a hairy part behind the head. In Sphar. Calliopii (pl. III, fig. $3 \mathrm{~d}$ and fig. $3 \mathrm{~g}$ ) the trunk has a rather close coat of very peculiar three-branched hairs growing out from tiny knots, the middle hair being longer than the two others. In Sphar. irregularis (pl. XIII, fig. $5 \mathrm{c}$ and fig. 5d) somewhat similar two- and three-branched hairs are seen.

In most species the trunk has two pairs of entirely uniform legs, but in a good number of species (as in Sphcer. microcephala, and in all eight species of the Sphceronella living on Cumacea and Isopoda) legs are entirely wanting. The legs are placed on the ventral side, now at some distance within the outline, now at the lateral margin, and as a rule there is no considerable difference in the distances between the first pair and the head, between the first and second pairs and between the second pair and the leg-like caudal stylets. In Homoeoscelis the legs, though small, are comparatively conspicuous, each apparently consisting: of a diminutive, short and rather thick basal part, from which proceeds a much longer, very narrow, conical, almost setiform branch and a pair of very short bristles or a short tap as an indication of a second branch. In Sphceronella and Choniostoma the legs are nearly always exceedingly small; in recently hatched or young specimens they are as a rule easy to find, but as they do not grow, they are often very difficult to point out in adult animals. Each leg consists of a small cylindrical joint ending in two short setæ. In Sphcer. longipes (pl. VII, fig. 2 a and fig. 2 e) only, the legs are somewhat larger, particularly becanse one of the setæe 
is long. In Sphcer. Acanthozonis (pl. VII, fig. 5 a and fig. 5b) they are reduced to rounded eminences without setæ.

A genital area is found in all species of these three genera, and it is in some cases much smaller, in others somewhat larger than the head. In its most developed form it is a more or less thickly chitinised plate, which is sometimes nearly circular (Sphcronella curtipes, pl. $\mathbf{X}$, fig. $2 \mathrm{e}$ ), mostly considerably broader than it is long, and not unfrequently with a more or less concave anterior or posterior margin. In this plate we find the genital apertures more or less close to each other, so that the distance between them is nearly always shorter than the length of each; they are usually placed near the posterior margin, seldom in the middle or even nearer the anterior margin. Sometimes the central part of the plate or two rather lateral parts of it are thin-skinned (pl. II, fig. $3 \mathrm{~b}$ ), and in this last case the plate is really reduced to an oval ring with a median longitudinal band. In Sphrer. Munnopsidis (pI. X, fig. 4c) the plate is more than twice as broad as it is long, and a large inner part of the same shape as the outline is more thin-skinned; the genital apertures are placed transversely and somewhat further from each other than the length of each. In other species the plate is reduced to about two thirds of a more or less oval, transverse ring, the posterior margin of which is close to the genital apertures, whereas the sides are further removed from them. A further reduction is noticed e.g. in Sphar.frontalis (pl. VII, fig. 6i), where the more couspicuous parts consist only of a chitinous arch behind and outside each genital aperture, the two arches yet being connected in the median line. In Sphar. microcephala (pl.VIII, fig. 2f) the genital area is much longer than it is broad, and the chitinised part of it forms a semi-circle which opens towards the front, its two extremities running forward and forming two rather long, nearly parallel and partly dilated lists. The genital apertures are - as stated above - nearly always closer to each other than the length of each, besides they are curved and placed in an oblique direction, so that their convex sides turu towards each other, and their anterior ends are much closer together than the posterior ones; e. g. in Sphcer. microcephala, and especially in Sphor. Munnopsidis, these apertures are turned so as to be almost or quite transverse; and in Spher. Munnopsidis the distance between them is greater. Each genital aperture is provided with two chitinous lists, the lips, of which the hindmost one is nearest to the median line and covers the front part of the other lip, when the genital aperture is closed. From the outer lip proceeds a strong muscle outward and obliquely forward, its proximal end being attached to the inner side of the plate or to the ring mentioned above. The contraction of this muscle pulls ontward the outer lip, thus opening the genital aperture (pl.XI, fig. 4d). For this purpose the skin close outside the outer lip is always thin (in many figures kept in a grey tint) though the surrounding parts may be a pretty hard chitinous plate.

In front of each genital aperture, at a shorter or longer distance from it, though always within the genital area, is a very diminutive orifice which forms the entrance to an oval or somewhat elongate vesicle, the receptaculum seminis (pl. I, fig. $3 a, r$ ). These two 
orifices are shown only in some of the illustrations of the genital region, and they are often very difficult to find, if one or each of them has not a spermatophore attached to it; this, however, is rather frequently the case; sometimes we find even two spermatophores, or at least their stalks, on each orifice ( $p l$. XIIT, fig. 1 e). Such a spermatophore is a globular or ovate vesicle with a stalk twice or three times as long as itself; this stalk - a thin tube - is attached to the skin closing on the above-mentioned orifice, or sometimes - by mistake - outside it (pl. IV, fig. 2c, where we find one spermatophore on each orifice and the stalk of a third one outside it). The two receptacula, when filled, have a strong refraction of light, which as a rule makes them easy to find. Their ontlines are traced with dotted lines in some of the illustrations. - In Spher. Munnopsidis I have found in the anterior part of the plate two holes (pl. X, fig. 4c, k) corresponding to those in Mysidion abyssorum and Aspidoecia (see p. 34-35).

In the species which have trunk-legs there is always a pair of caudal stylets shaped somewhat like the legs. In Homoeoscelis (pl. II and pI. XIII) they are a little thicker and longer than the legs; in Sphceronella and Choniostoma they consist either of a cylindrical, a rounded or a triangular joint terminating in two or three setæ (which rather frequently fall off during the preparation); they are sometimes longer, sometimes shorter than the setæ of the legs (as e.g. pl. VII, fig. 2e). In Sphceronella Acanthozonis each caudal stylet has one single rather long seta (pl. VII, fig. 5d). In Spher. modesta, which has no trunk-legs, each stylet consists of a rather short, thick joint, from the inner posterior angle of which proceeds an acute »joint « twice as long but scarcely half as thick, which must be considered as a transformed seta, and ontside it are seen one or two simple setæ (pl. IX, fig. 2e). Nearly all the other species which lack trunk-legs are devoid of caudal stylets as well. The place of these stylets varies much; in most species they are situated close together, either on the plate or the ring, a little behind the genital apertures, or close behind the posterior margin of the ring or plate, but in the species belonging to the group of Sphcronella Leuckartii they are situated pretty far or very far from each other, and also more or less far behind the genital area (pl. II, fig. $2 \mathrm{e}$ and fig. 3 b).

The remarkable fixation of Sphcronella paradoxa will be described in the systematic part; here it may be sufficient to draw attention to it.

II. Stenothocheres (pl. I). This genus, comprising two species, deviates considerably from the three recently mentioned genera, and in at least two important features: - larger trunk-legs with two branches and a separate abdomen - it comes nearer to the less transformed Copepoda.

The body is sub-ovate or nearly globular; its abdomen is comparatively rather small and prominent posteriorly on the ventral side or on the hind margin itself. It has no separate head, not even the vestige of a frame (like the one in Choniostoma). The sub-median skeleton is reduced to a plate in front of each maxilliped (pl. I, fig. 1e, h and fig. $2 \mathrm{f}$ ), and this plate may extend forward like a list between the maxillæ and the outside of the rostrum. Antennulæ, antennæ, rostrum, maxillæ and maxillipeds occupy a larger space on the ventral 
side of the body than in the other genera. The antemulæ (fig. $1 \mathrm{a}$, a and fig. $2 \mathrm{~g}$ ) are of medium length, without distinct articulation, they have a few rather short setæ, among them one olfactory (fig. 1e, b). The antennæ (comp. fig. $1 \mathrm{e}$ and fig. $2 \mathrm{f}$ ) are placed somewhat obliquely outside and in front of the rostrum, but not on its basal part; they are of medium length, in St. egregius (fig. 1e, c) probably 3-jointed, with a couple of short terminal setæ of unequal length; in St. Sarsii (fig. 2f, c) they are weak, with indistinct articulation. The rostrum is on the whole like that in Spharonella, though it must be observed that the mouth-border is very narrow. The maxillulæ (fig. 1e, e) are on the whole like those of Sphoronella, the principal branches rather short or of medium length, the additional branch wanting. The maxillæ (fig. 1a, f; fig. $1 \mathrm{e}$ and fig. $2 \mathrm{f}$ ) are powerfinl and do not show any important differences from those species of Sphoronella which are parasitic on Amphipoda. The same remark can be applied to the maxillipeds with regard to their structure, but these limbs, compared with the maxillæ, are shorter and slenderer than in most species of Sphoronella, and we may add that the second and third joints are always fused into one single comparatively short joint, which at most is a little longer than the pointed terminal joint and lacks the spine at the distal inner angle, as the terminal joint lacks a spine inside its apex.

The trunk is naked all over (so is the whole body with all its appendages). The trunk-legs are placed differently from those of the preceding genera; both pairs being situated on the ventral side at a good distance within the lateral margin, the first pair (fig. $1 \mathrm{a}, \mathrm{m}$ ) somewhat behind the middle of the body, and the second pair (fig. 1a, n) close in front of the basis of the abdomen. Both pairs, though rather small, are very large compared with those of the preceding genera. Each leg consists of a peduncle with two branches not distinctly set off by articulation, and as a rule the outer branch is the longest. In the first pair the outer branch terminates in two strong setæ of mequal length, in the second one (fig. $1 \mathrm{~g}, \mathrm{u}$ and fig. $2 \mathrm{i}$ ) each branch apparently consists of two joints, of which the terminal one is somewhat spine-like, but it must be preferred to consider each branch as being composed of one joint with a long and very thick terminal spine.

A comparison between the figures $2 \mathrm{a}$ and $2 \mathrm{~d}$ shows that in the same species the abdomen may be found more or less distant from the posterior margin on the ventral side of the trunk, according as the animal is more or less swelled with eggs. The abdomen is not set off from the trunk by an articulation; it consists of a broad, rather stout basal part with arched lateral margin (fig. $1 \mathrm{~g}$ and fig. 2i), and a narrower terminal part with a more or less deeply incised extremity, which forms two very short and clumsy, badly defined candal stylets (fig. $1 \mathrm{~g}, \mathrm{t}$ ), each with four thick setæ. The abdomen seen from below (fig. $1 \mathrm{~g}$ and fig. $2 \mathrm{i}$ ), presents near the outer margins of the basal part two very long genital apertures (g) in their whole or a considerable part of their length; in the abdomen seen sideways (fig. $1 \mathrm{~h}$ ), the genital aperture $(\mathrm{g})$ shows its longest extent, and the muscle which opens it $(\mathrm{m})$ is directed towards the dorsal side of the abdomen. Fig. $1 \mathrm{~h}$ also shows a receptacnlum seminis ( $r$ ) as a large oblong vesicle, placed a little above the abdomen. I have repeatedly 
seen two such receptacula, but I cannot indicate their external orifices, as, strangely enough, I have never found spermatophores on any of the rather numerous specimens I have examined. III. Mysidion (pl. XI-XII). The head is pretty well defined from the trunk, but so feebly chitinised in front and at the sides that the frontal and lateral borders are wanting. The antennulæ are much reducęd and either 2 -jointed or 1-jointed (pl. XIL, fig. $2 \mathrm{a}$, and fig. 1a, a). Antennæ seem to be wanting. Mouth and maxillulæ as in Sphceronella. The basal joint of the maxillæ has at the inner edge one or two processes, and the appendage is a powerful prehensile organ. The basal joint of the maxillipeds has irregular outlines. Trunk-legs and caudal stylets are wanting. There is no genital area: the genital apertures are situated very far from each other (pl. XI, fig. $3 \mathrm{~b}$ and fig. $3 \mathrm{e}$ ); each of them has - besides the lips - its own skeleton, consisting of a list which is semi-circular or forms the larger part of a defective oval, the longest diameter of which runs parallel with the median line of the animal, and the opening of which is turned towards this line. The genital aperture is situated close to the posterior part of the list, and the muscles radiate towards its foremost part. The receptaculum seminis - odd, as far as I can see - is situated in the median line, far in front of the genital apertures (pl. XI, fig. 3e). The skin covering it is closely set with many - as many as twenty-six — spermatophores (s), and between them are seen stalks of other vanished spermatophores, some of these sticking together in bulks which cover the skin so completely that, in spite of several attempts, I have been unable to find the entrance or entrances to the receptaculum seminis. In fig. 3 e the letter $r$ marks receptaculum seminis, which on each side opens into an obliquely backward running duct, which I have been able to follow towards the genital aperture (comp. the following genus). In Mysidion abyssorum I have found in the semi-circle surrounding the genital aperture a hole (or perhaps rather a spot, covered with a thin membrane pierced with small holes (pl. XII, fig. $2 \mathrm{~b}, \mathrm{k}$ ) forming the outlet from a gland which I have found, though I have not been able to examine it more closely, and whose function is incomprehensible to me. - Several parts of the head of this animal are frequently covered with a viscous substance, by which it fastens itself to the marsupium of the host. This substance, in the females as well as in the males and the larvæ, is probably secreted by glands placed in front of the month (comp. the female of the following genus).

IV. Aspidoecia (pl. XII). This genus (one species) approaches very near to Mysidion. In this place only its most important characters will be mentioned, an exhaustite description being given in the special part of this work. The body is considerably broader than it is long, the head is distinctly defined from the trunk and pretty well chitinised, with rounded forehead and sides. The front is covered by a large adhesive plate (fig. $3 \mathrm{~d}$, s) by which the animal is attached, this plate at the same time covering the 1 -jointed antennulæ (fig. $3 \mathrm{~h}, \mathrm{a}$ ). Antennæ are wanting; the maxillulæ are very small, without additional branch; the mouth is normal, but I have found no hairs along the mouth-border; the maxillæ are like those in Sphcronella; maxillipeds are wanting. Trunk-legs and caudal stylets are wanting. Each 
of the genital apertures - as in Mysidion - has its own list, which in this animal forms a ring (fig. $3 \mathbf{i}$ ); in the front part of this ring we see a rather large hole $(\mathbf{k})$ which serves as opening to a gland (comp. Mysid. abyssorum). The genital aperture (g) lies up to the part of the ring which is turned towards the median plane of the animal. Contrary to Mysidion, the distance between the rings varies between being a little greater and very much smaller than the diameter of each. A long way in front of the genital apertures we see two knots a little apart from each other (fig. $3 \mathrm{~g}, \mathrm{r}^{\prime}$, fig. $3 \mathrm{e}, 0$ ) which show as it were irregular cracks in the thick chitine; no doubt they form the entrances to the receptaculum seminis (fig. 3e, r) which is odd, much broader than it is long, and at each side bends backward, thus continuing as two almost parallel ducts, which are wide, at the middle sowewhat narrowed, and run to the genital apertures. No spermatophores have been found.

\section{b. The Male.}

Out of my forty-three species I know the males of thirty-two, viz. of all species of the genera Stenothocheres, Homocoscelis, Mysidion and Aspidoecia, as well as of twenty-five ont of the thirty-four species of Sphceronella. So in nine species of Spharonella and in the two species of Choniostoma the males are still unknown. With respect to the latter genus particularly the gap is keenly felt.

The male is always much smaller than the adult female - as a rule quite disproportionally so. In three species only: Spher. frontalis, S. decorato and S.curtipes, its length exceeds $1 / 2 \mathrm{~mm}$. The largest male I know belongs to $S$. curtipes and measures $92 \mathrm{~mm}$. in length and $3 / 5$ of this size in breadth. In most species the length is about $1 / 4-1 / 5 \mathrm{~mm}$., and the length somewhat exceeds the breadth. The smallest normal males I have found in Aspidoecia Normani, two specimens of which were respectively 147 and $138 \mathrm{~mm}$. long. In Mysidion abyssorm the normal male seems to be about $164 \mathrm{~mm}$. long, though I have found two perfectly dwarfish specimens, of which one was $099 \mathrm{~mm}$. long - and this is one of the smallest of adult Copepods hitherto discovered, however, it may be that these two specimens were recently hatched and had not grown to their full size (s. below under "postlarval development $)$. The genus Homoeoscelis shows least difference between the male and the female, especially $H$. meriterranea, of which the largest female was $31 \mathrm{~mm}$. long, $32 \mathrm{~mm}$. broad and rather flat, whereas the male was $174 \mathrm{~mm}$. long, $096 \mathrm{~mm}$. broad and equally thick. The greatest difference between the sexes I have found in Sphrer. microcephala, in which the largest female was $1.44 \mathrm{~mm}$. long, of the same breadth and almost perfectly globular, whereas the male without counting the rostrum was $18 \mathrm{~mm}$. long, $15 \mathrm{~mm}$. broad and ah. $11 \mathrm{~mm}$. thick, which gives a volume of between 800-1000 times smaller than the female.

The body, as a rule, is somewhat longer than broad, and seen from below, varying from sub-globular to an elongate oval, seen sideways, the back is strongly vaulted, the 
ventral side almost flat, and the animal is nearly always somewhat broader than it is thick. In the genus Homoeoscelis (pl. II and pl. XIII) as in Sphcer. curtipes (pl. X, fig. $2 \mathrm{f}$ and fig. $2 \mathrm{~g}$ ) the body is much longer than it is broad, the length varying from $1^{2 / 3}$ to a little more than twice the breadth: besides, in S. curtipes it is curved, so that, seen from the side, it presents a moderately concave ventral outline. The length of the head varies between a little more and a little less than half of the total length, in Sphcer. frontalis (pl. VII, fig. 6a-6b) it does not take up a third part. The body is usually broadest somewhat behind or almost on a line with the base of the maxillipeds. In Sphar. modesta (pl. IX, fig. 2f) the greatest breadth lies before the middle of the maxillæ; in several species it is rather far behind the head, and in this case the trunk is somewhat or much larger than the head, viz. in Spher. Bonnieri (pl. VII, fig. 1 a), in S. frontalis (pl. VII, fig. 6a) and in Mysidion abyssorum (pl. XII, fig. 2 e). A distinct abdomen is found only in the genus Stenothocheres. Antennulæ, antennæ, rostrum, maxillulæ, maxillæ and maxillipeds are much like those of the female, still we find a number of minor differences which must be mentioned. Trunk-legs and caudal stylets are well developed in all the species whose females possess these organs, though as a rule they differ very much in the two sexes, and they are also found in a few species, as Sphrer.microcephala and S. modesta, whose females lack both trunk-legs and caudal stylets, or only trunk-legs. In Spher. dispar, S.insignis, S. marginata, as well as in the genera Mysidion and Aspidoecia, the males have not the slightest rudiment either of trunk-legs or of caudal stylets.

In the genus Stenothocheres the antennulæ, the antennæ, the rostrum and the mouthappendages are situated on the foremost rather flatly vaulted part of the ventral side of the body. In all the other genera the surrounding of the rostrum and the mouth-appendages in front and at the sides lie more or less deep and are limited anteriorly by an outstanding border, which is frequently rather high or forms a slanting plate, at the sides by very conspicuous lateral borders, which usually run nearly parallel from the front towards the base of the maxillæ, whence they curve more or less outward towards the lateral margins of the animal and vanish somewhat behind the base of the maxillipeds. The shape of these lateral borders is rather variable and difficult to describe, but the numerous illustrations will show two outstanding rounded plates bending like a cape towards the base of the maxillæ, and outside these protruding borders we can always see something of the slanting lateral surfaces of the head, when looking at the animal from the ventral side. The frontal border is sometimes distinctly separated from the lateral ones, but it usually forms a direct or nearly direct continuation of them; in most forms it is evenly curved; in Sphcer. elegantula (pl. II, fig. 2f) and in kindred species it has a deep incision on each side, by which the frontal plate is divided into a large, median, almost square part and two much smaller rounded lateral lobes. In Sphar. Calliopii (pl. III, fig. $3 \mathrm{~h}$ ) the frontal margin is divided into six lobes, in $S$. decorata (pl. VIII, fig. $3 \mathrm{f}$ ) the frontal plate is much elongated, with the anterior end cut off transversely and with several incisions, one in the middle and two on each side, by which it is divided into four square and two low triangular lobes, all of which 
bear small spiniform processes on their onter margin. In Spher. dispar (pl. IX, fig. $3 \mathrm{~h}$ ) and in Sphar. insignis (pl. $\mathbf{X}$, fig. $1 \mathrm{~b}$ and fig. $1 \mathrm{c}$ ) the frontal plate expands in a most peculiar way. Seen from below, the head tapers very much towards the front, whereupon it dilates to an almost circular plate or a transverse oval with acute lateral angles; the sides and the front margin of the circular plate and the front margin of the oval project into a series of closely situated spiniform little processes; on the ventral side of the plate we see a chitinous ring; from the inner edge of which four processes run towards the centre; in S. dispar these processes do not meet, but form the surroundings of a cross-shaped space, whereas in S. insignis they meet in the centre, thus forming a cross, and dividing the space into four parts, (which perhaps are pierced with small holes). The purpose of this peculiar ring is unknown to me.

The part surrounded by the protruding frontal and lateral borders frequently lies very deep, and where the lateral borders are high, sometimes, as in Spher. curtipes (pl.X, fig. $2 \mathrm{f}$ and fig. $2 \mathrm{~g}$ ), they hide the rostrum and the maxillæ, if the animal is seen from the side; as a rule a lateral view shows these organs in almost their whole, or in half of their length. Several males of the same species may show great individual difference in this point, whereas on the other hand, there are species, as e. g. Spher. curtipes, in which the rostrum and the maxillæ are always partly invisible because of the height of the lateral borders, in other species again, as in Sphar. microcephala (pl. VIII, fig. $2 \mathrm{~g}$ and fig. $2 \mathrm{~h}$ ), the borders are so low, that the above-mentioned organs are always visible in nearly their whole length.

The sub-median skeleton, which is found in all females and has been described as far as this sex is concerned, is also seen in all males, and in most respects shows a similar structure, but in most species of the genus Sphceronella it is produced into free processes. Three pairs of such processes may be found. Those of the first pair are usually rather short and broad, sometimes rounded, in S. microcephala (pl. VIII, fig. $2 \mathrm{~g}$ and fig. $2 \mathrm{~h}, \mathrm{i}$ ) pretty long, slender and pointed, being situated behind or below the basis of the maxillæ; sometimes, as in S. elegantula (pl. II. fig. $2 \mathrm{f}$ and fig. $2 \mathrm{~g}$ ), they extend backward over the basal part of the maxillipeds. The second pair of processes are found most frequently, and may become much longer than any of the other two pairs; they proceed at a shorter or longer distance from each other between the maxillipeds, and are sometimes parallel, sometimes or mostly diverging. The third pair appears in very few species only, as in $S$. paradoxa (pl. III, fig. $4 \mathrm{~h}$ and fig. $4 \mathrm{i}$ ), in S. Metope and in S. Hollølli (both on pl. V.); they proceed between and a little behind the second pair and are much shorter than these ones. In the systematic description of the species I use the terms: first, second and third pair, in speaking of these processes.

The Antennulce are found in all species; in Stenothocheres they are situated in front of and outside the antennæ, in all other forms they are found on the lateral margins of the head, where these merge into the frontal margin. They are constructed much like those of 
the females, e. g. where the antennulæ of the females are well developed and 3-jointed, those of the males are equally so, and where they are reduced in size or ill number of joints, we generally - though not always (Sphar. microcephala, Mysidion commune) - find a similar reduction in the male. In Spher. microcephala (pl. VIII) the antennulæ of the female are very short and 1-jointed, those of the male long and likewise without distinct articulation. In Mysidion commune (pl. XI and pl. XII) those of the female are very short and 1-jointed, those of the male short and 2 -jointed. Their bristles are much the same as in the female, and they have frequently a rather conspicuous olfactory seta. The greatest reduction is noticed in Aspidoecia (pl. XII, fig, $3 \mathrm{k}$ and fig. $3 \mathrm{l}$ ), the antennulæ of which consists of a very short, naked joint terminating in an olfactory seta which is several times longer than the antennula.

The Antenne are altogether so like those of the female that a special description of them is superfluous; where they are wanting or reduced in the female, they are equally so in the male.

The Rostrum is very like that of the female, but seems now and then to be longer and more slender; in Sphcer. microcephala it is much longer than that of the female (pl. VIII). In several species, e. g. in Sphcer. modesta (pl. IX), the mouth-border is much broader, its hairs at least are considerably longer in the male than in the female.

The Maxillule are always found and are constructed like those of the female. In dissecting the head of a male of Sphcer, frontalis I found that, in addition to the two long though unequally long - principal branches and the long additional branch, the maxillula of this animal possesses a fourth shorter one ( $\mathrm{pl}$. VII, fig. $6 \mathrm{~d}$ ), which proceeds within the base of the anterior principal branch. As this supplementary branch is not likely to be discovered without undertaking a dissection expressly for this purpose, I cannot tell whether it is found in the female as well; withont dissecting the rostrum $I$ have looked for it in vain in the female as well as in both sexes of other species of spharonella. Fig. 41 in pl. III. will give a good idea of the rostrum with antennæ and maxillulæ in a male which possesses all these organs in their typical form.

The Maxille are well developed in nearly all species and are in the main constructed like those of the females; sometimes they are somewhat smaller, sometimes rather larger, in Aspidoecia (pl. XII) much larger. Occasionally we find differences of detail in the two sexes; in Sphcer. capensis the basal joint of the male has at its distal end, where the inner and the posterior side meet, a rather high, prominent plate, the margin of which runs out into spiniform processes (pl. VI, fig. $1 \mathrm{c}$ and fig. $1 \mathrm{~d}$ ); this excrescence is wanting in the female. In the male of Spher. insignis the posterior side of the basal joint is provided with a considerable number of peculiar processes (pl. X, fig. 1 c) which the female lacks. In Sphcer. marginata (pl. XIII) whose female has rudimentary maxillæ, these organs in the male have about the same general shape and size as in kindred species, but all three joints are fused together.

The Maxillipeds are well developed in all species and essentially like those of the females, though in the male the basal joint is frequently provided with hairs, and also some- 
times with processes, whereas in the female there are no processes and fewer or no hairs etc. In Mysidion commune the male possesses on the outer side of the basal joint a knotlike excrescence and a process of very considerable size (pl. XI, fig. $3 \mathrm{~g}$ and fig. $3 \mathrm{~h}$ ), and its second joint has a conspicuous process, all of which are wanting in the female. In Aspidoecia (pl. XII) the female lacks maxillipeds; in the male, though somewhat smaller than usual, they are well developed: the basal joint is much as in Stenothocheres, but the second joint, which as in several other forms consists of two completely fused joints, is exceedingly short, somewhat shorter than the terminal joint.

Trunk-legs and caudal stylets. The occurrence of these organs is mentioned above on p. 36. In Homoeoscelis (pl. II and pl. XIII) there is but a slight difference between the two similarly shaped pairs of trunk-legs and the caudal stylets, and as both are like those of the female, they do not require further mention; we shall only add that they are sometimes rather larger than, sometimes of the same size as those in the other sex. In Stenothocheres (pl. I) the trunk-legs are very similar to those of the female and of almost equal size, however, as the trunk of the female is large, that of the male small, of course the legs of the latter are much more conspicuous and appear larger. In the male the basal part of the legs stands more ont from the body, and the longer robust terminal spine on the onter branch is longer than in the female; the other differences are insignificant. Thus, in Stenothocheres Sarsii the spine on the inner branch of the second pair of legs is curved like a hook, in Sten. egregius it is less curved, and in the illustrated specimen the right and the left spine curve differently. Behind and above the basis of the second pair of legs both species show two considerable spines which are situated close together on a small projection; I should think they might possibly be considered as rudiments of a third pair of legs, but I do not presume to have any definite opinion about the matter. The abdomen is small, with short, distinct, rather broad stylets, not set off by an articulation, and each provided with four spines, of which the two innermost are the longest and thickest.

In Sphceronella, as a rule, there is a great difference between the two pairs of trunklegs and between each of these and the caudal stylets. The shape and size of the trunklegs vary much according to the species, and the appearance of the legs as well as of the stylets presents very great variation on account of the very different length of their terminal setæ. In this genus the first pair of legs usually originates outside and behind the basis of the maxillipeds, nearly in the middle between the lateral margins and the median line of the trunk, at the bottom of a pretty broad transverse depression. Each leg consists of a basal part, a peduncle, differing much in length and breadth (sometimes, as in Sphcer. intermedia (pl. V, fig. $3 \mathrm{f}$ and fig. $3 \mathrm{~g}$ ), this part in exceedingly large), and of two branches, one of which is generally longer than the other, sometimes the one is wanting altogether. As a rule, noue of the branches are articulated on the peduncle, and frequently one or both of them terminate in setæ, one of which is longer than the others, the one on the outer branch often exceedingly long, occasionally half as long as the whole animal. The second pair of 
legs is situater at or behind the middle of the trunk, and if seen from below, near or on the lateral margin; as a rule it is shorter than the first pair, the peduncle is not much thicker than the rather short inner branch, whereas the outer branch - if there is one is triangular and often ends in a short seta. The terminal setæ of the inner branch vary as much in length as those of the onter branches of the first pair of legs, and one of them can attain to half the length of the animal. The caudal stylets are usually situated rather close to each other, most frequently near the posterior end of the body, sometimes very much to the front about at the middle of the trunk, especially where it is very large, as in Spher. Bonnieri and in S. frontalis (pl. VII); in the latter species they even appear in front of the second pair of legs. Both stylets as a rule are rather short, sometimes very short, nearly cylindrical; one terminal seta on each stylet is often rather or very long, occasionally exceeding in length the above-mentioned long setæ on the trunk-legs. - Several species of Spharonella deviate now in one, now in more respects, from this description which is based on the main bulk of the species. In Sphcr. modesta (pl. IX, fig. $2 \mathrm{f}$ and fig. $2 \mathrm{~h}$ ) the first, and especially the second pair of legs are considerably reduced in size etc., whereas the caudal stylets are comparatively large and constructed like those of the fernale (see above). In S. decorata (pl. VIII, fig. $3 \mathrm{f}$ and fig. $3 \mathrm{~g}$ ) the two pairs of trunk-legs are very much alike, each leg consisting of a short basal part with two short branches, and each branch ending in a thick, but rather short seta; caudal stylets are wanting. Concerning S. microcephala (pl. VIII, fig. $2 \mathrm{~g}$ and $2 \mathrm{~h}$ ) which deviates considerably and is difficult to understand, I refer to my description in the systematic part of this work. In S. curtipes (pl. X, fig. $2 \mathrm{f}$ and fig. $2 \mathrm{~g}$ ) both pairs of legs are very small, slender and 2-jointed, the caudal stylets are quite minute and situated far from each other on the posterior margin of a long and broad, but not much projecting eminence, the posterior angles of which are decorated with peculiar rounded processes and knots (might the whole formation possibly be a reduced abdomen?). It has been mentioned already that trunk-legs and caudal stylets have disappeared altogether in several species of Sphceronella as well as in Mysidion and Aspidoecia.

In the species belonging to Stenothocheres and Aspidoecia the body of the male is quite naked, whereas all the other species are more or less clothed with hairs. In not a few species the frontal margin is furnished with very short hairs or with fine spiniform processes (the species of Spheronella which live as parasites on Cumacea). In nearly all species the margin of the lateral borders of the head are trimmed with a series or a stripe of hairs usually of medium length, which as a rule extends towards the front in a curve round the base of the antennulæ, ending just in front of it; posteriorly it follows the lateral margin up to its curved extremity, whence (or a little in front of it) the stripe continues across the sides and the back, now straight on, now curving or in a broken line, now advancing, now receding obliquely. This line I consider as forming the boundary between the head and the trunk, its hairs being now very long (pl. III, fig. $3 \mathrm{i}$; pl. VI, fig. $1 \mathrm{~d}$ ), now of the same length as those which cover the sides of the trunk. Sometimes (e.g. pl. IV, fig. $3 \mathrm{~h}$ ) 
we see instead of a single line a wider or narrower band of hair going from the posterior extremity of the lateral margin up across the back, and behind this line or band is a larger or smaller transverse naked area, whereas the other parts of the trunk: the back, the sides, the posterior extremity and the ventral surface, are closely covered with shorter or longer hairs, with the exception of a transverse band in front between the first pair of legs - and frequently their surroundings - which is naked. These hairs are usually simple; in Sphar. frontalis (pl. VII, fig. $6 \mathrm{a}$, fig. $6 \mathrm{~b}$ and fig. $6 \mathrm{~h}$ ) and in Mysidion commune (pl. XI, fig. $3 \mathrm{~g}$ and fig. $3 \mathrm{~h}$ ) the trunk is closely covered all over with transverse minute knots, each of which bears several (in $S$. frontalis at least many of them ten) fine hairs. In Sphar. Giardii the trunk is covered with 2- or 3-branched hairs similar to those mentioned above in the female of $S$. Calliopii and in S. irregularis. In the male of $S$. Calliopii (pl. III, fig. $3 \mathrm{~h}$ and fig. 3 i) the hairs of the boundary line between the head and the trunk are particularly long, whereas the dorsal surface and the posterior extremity are covered with fine dots resembling the roots of hairs, though $I$ have been unable to find any hairs, and across the back to the exterior angles of the first pair of legs we find a narrow, naked band; the ventral surface behind the caudal stylets is provided with ordinary hairs. In Spher. microcephala (pl. VIII, fig. $2 \mathrm{~g}$ and fig. $2 \mathrm{~h}$ ) the hair-covering is less developed than in any of the other species, as only the hindmost part of the lateral borders of the head and the ventral surface of the trunk are covered with hairs, the other parts of the body being naked. In a few species we find hairs in front of the base of the maxillipeds, and in Sphor. chinensis (pl. III., fig. 1 a) and kindred species there is a bunch or a short band of hairs outside the base of the maxillulæ.

As to the internal structure of the male I confine myself to the following observations. In a well-preserved specimen we usually perceive through the transparent skin two larger or sinaller globular bodies in the middle of the trunk or somewhat more to the front; in Stenothocheres they are situated close to the front of the abdomen behind the base of the second pair of legs. I will call these bodies spermatothece, though I cannot make out whether they have really the function of such organs, or whether they are the testicles themselves. I have illustrated them in several forms, as Sphar. paradoxa (pl. III, fig. $4 \mathrm{~h}, q$ ), S. capensis (pl. VI, fig. 1 c), S. Bonnieri (pl. VII, fig. $1 \mathrm{a}, \mathrm{q}$ ), S. frontalis (pl. VII, fig. 6 a, q) and Mysidion commune (pl. XI, fig. $3 \mathrm{~g}, \mathrm{q}$ ); in this last species the spermatothecæ are particularly large and obliquely situated (probably a case of anomaly or of accidental pressure in the figured specimen, for in the next species: Mysidion abyssorum (pl. XII, fig. $2 \mathrm{c}, q$ ) they are normal). In Aspidoecia Normani the specimen illustrated (pl. XI, fig. $3 \mathrm{k}$ ) showed a single, but very large spermatotheca $(q)$, but in a couple of other specimens I saw two considerably smaller and normally situated spermatothecæ. In Sphcer.paradoxa I succeeded in finding the genital apertures very close to each other on the posterior wall of the depression which runs across the front part of the trunk on its ventral surface. From each spermatotheca a rather short duct goes forward and obliquely towards the median line to its aperture. 
In Homoeoscelis minuta (pI. II, fig. $1 \mathrm{i}$ and fig. $1 \mathrm{k}$ ) I have found the rather small spermatothecæ (though they are not illustrated) close together in the. line between the hindmost pair of trunk-legs, and I think I have found the two genital apertures in close proximity in the posteriol wall of the ventral depression - which is particularly conspicuous in fig. $1 \mathrm{k}$ in a line between the first pair of legs.

In a number of species belonging to Sphreronella I have found a most peculiar structure beneath the larger part of the skin of the head at its back and sides. It appeared most distiuctly in $S$. paradoxa, where I saw very plainly beneath the skin a single layer of rather large hollow spaces; fig. $4 \mathrm{k}$ in $\mathrm{pl}$. III is drawn to the same scale of enlargement as fig. $4 \mathrm{i}$ and shows the skin and two rows of the afore-mentioned hollow spaces beside each other. In S. Metopre (pl. IV, fig. 3i) the spaces were filled and appeared in outline as shown in the illustration.

The males are sometimes hinged on the females, but much more frequently on the gills or on the marsupial plates of the host by a thread which proceeds from the median line of the front close in advance of the rostrum. This thread is secreted by a gland or glands and can presumably be produced by the males of all species. The shortest thread I found in Homocoscelis minuta, in two specimens, in one of which its length was similar to that of the first joint of the maxilliped, in the other somewhat shorter. In e. g. Sphar. paradoxa (pl. III, fig. $4 \mathrm{~h}, \mathrm{~s}$ ) the thread is about $3 / 8$ of the length of the animal, in Stenothocheres Sarsii (pl. I, fig. $2 \mathrm{k}, \mathrm{s}$ ) a little shorter and in $S$. abyssi (pl. IV, fig. $2 \mathrm{~d}$ ) even a little longer than the whole animal. I found the longest thread in a specimen of Aspidoecia Normani, where it was between twice and three times as long as the animal, whereas in the specimen illustrated in pl. XII, fig. $3 \mathrm{k}$ it was scarcely half as long as the male. This last instance shows that the length of the thread can vary very much in the same species, but this is not usnally the case, as in some species a shorter, in others a long thread is always found. In all the above-mentioned and in several other species the thread is always simple and cylindrical, generally a little dilated towards the distal end by which it attaches itself, and not unfrequently the end is expanded into a disk. Deviating forms of this thread are met with in the species of the genus Mysidion, and especially in the species which I have placed together below under the heading of the Sphcronella Leuckartii-group. In Mysidion the proximal part of the thread is simple, the distal part appears in two varieties; either, as in Mysidion abyssorum (pl. XII, fig. $2 \mathrm{~g}$ ), it shows two considerable fusiform expansions, the middle parts of which are each surrounded by a peculiar collar-shaped ring, or, as in Mysidion commune (pl. XI, fig. $3 \mathrm{~h}, \mathrm{~s})$, the apical part is very thick and above it the thread dilates still more and becomes fusiform; its widest part has a collar-like ring, and a similar ring surrounds it somewhat higher up, where the thread is only half as wide. In the species belonging to the Sphcer. Leuckartii-group we often find the male hinged by a thread which varies in extent between nearly half and almost the full length of the animal, and is constructed in the following way: it is divided into two parts, either of equal length, or 
the proximal part longer than the distal one, the former ending in a thick, bell-shaped and thick-skinned, hairy expansion (pl. II, fig. 4 b); the distal part comes out of the bell in which its extremity forms a little ball; its other extremity expands into a disk which is glted on to the Amphipod. I have found several of such threads and examined them as carefully as possible, but it is quite incomprehensible to me how the animal has been capable of producing them.

\section{c. The Ovisacs and the Development of the Eggs.}

1. The Ovisacs. Of forty-one species the ovisacs have been found, and only in two species of Spharonella they are unknown to me. In the two species of the genus Stenothocheres they differ so much from those met with in the other genera, that I prefer to leave out this genus for the present, setting it aside for separate treatment.

In Homocoscelis, Sphreronella, Choniostoma, Mysidion and Aspidoecia each female deposes several - no doubt at least four or five - or many ovisacs, which, if not deformed by pressure, are sub-globular, oval or, in Mysidion, of a short pyriform shape. In Homoeoscelis mimuta, of which I have examined a large material, I can assert that the female deposes at most eight ovisacs, thongh usnally but five to seven are found; in Choniostoma the maximum seems to be twelve, in Aspidoecia thirteen to fourteen, in Mysicion seventeen or still more. In the numerous species of Sphreronella which live in the marsupium of Amphipoda, I cannot indicate the maximum of the ovisacs, partly because my material of each particular species is too small, or because not unfrequently a couple or more of females are lodged in the same marsupium, partly because, in many cases, one cannot be certain that some of the sacs have not been washed away. Better information can be given about some species living in the marsupium of Isopoda and Cumacea: in Sphor. Munnopsidis I found one female with twenty ovisacs, in $S$. decorata the same number, in one specimen of $S$. modesta twenty-two, in another twenty-eight ovisacs, all laid by one single female. This latter number may be supposed to be about the maximum, not only in the abovementioned species, but in the whole family. It is very difficult to indicate the smallest number of ovisacs made by normal females of the different species, as, for one thing, it has to be ascertained, whether the specimen in hand has altogether finished laying eggs, and a considerable material has to be examined for this purpose alone; still, though I have not done this, I think I can say that the number is never less than four or five, perhaps seldom less than five or six. In all five genera each ovisac is smoothly rounded, its eggs being as usual enclosed in a common membrane. In Homoeoscelis, Sphreronella and Choniostoma all ovisacs are deposed freely without being attached to the female or having any real connection with each other. Indeed, we see rather frequently some, or many, of the ovisac's sticking together, or one, or several of them, adhering somewhere to the body of the female; however, this kind of adhesion is of a secondary, quite unimportant nature, 
and is certainly owing to the fact that the membrane surrounding the ovisac was not sufficiently stiffened, when - or shortly after - the ovisac was laid. In Mysidion and Aspidoecia all ovisacs, from the moment they are laid till the larvæ have swum out, are hinged to the lips of the genital apertures by stalks, which are rather short (in Mysidion), or very short (in Aspidoecia), so that we see pretty frequently six to seven, or sometimes more ovisacs hinged at one genital aperture (pl. XI, fig. $3 \mathrm{~b}$ ); fig. $2 \mathrm{~b}$ in pl. XII shows how the lips of the genital aperture and the part bebind them are covered by a plate formed of a coagulated viscous substance, from which the stalks of the ovisacs proceed; the plate must be considered as the coalescent basal parts of the stalks.

The genus Stenothocheres deviates considerably from the other genera, but unfortunately I am not prepared to represent its conditions as precisely as I should like to do. Of one of its two species I have seen but one single female with eggs, of the other (St. egregius) my material is indeed very abundant, but not particularly good, some of it being very old, and most of it, though of later date, having shrunk somewhat, because its hosts - while still alive - had been put into too strong spirit. In many cases I only found a single lump of eggs, which was rather larger, or considerably larger than the female, had no regular form, and was not surrounded by a common membrane. Sometimes, but not always, this lump seems to consist of two — seldom three - smaller coalescent lumps; four instances were of a more instructive nature. A female of St. Sarsii showed two lumps of about equal size, one of which was free, the other (no doubt accidentally) adhering to the female. One of them is illustrated in pl. I, fig. $2 \mathrm{c}$, which shows the irregular shape and want of a common membrane, as well as the size in proportion to the largest female which is illustrated in fig. $2 \mathrm{a}$ and magnified to the same scale. The three other cases have been observed in St. egregius; in all of them the female had donbtless finished laying eggs. In one case two smaller, short oval lumps were glued together at their extremities, one containing seven, the other nine eggs; in the second there were two lumps, one of them a little larger, the other a little smaller than the female; in the third case there was an oblong lump containing ten eggs, the young animals of which were a little more than halfdeveloped, six to seven larvæ which were about to break out of the shells, and thirteen free larvæ; all this indicated that the eggs had been laid at intervals. It seems probable, on the whole, that the eggs are not laid all at the same time, but successively, though the intervals must be rather short, whereas the ovisacs, at least in most and probably in all the other genera, are deposed at rather considerable intervals; this is easily seen from the fact that among ovisacs deposed by the same female, we often find one or two which have evidently been laid recently, whereas some others contain more or less developed larvæ. We sum up our observations in the following statement, that in Stenothocheres the eggs are deposed in one single large and free lump, or in a couple of smaller and free lumps of irregular form and without the common membrane which belongs to a proper ovisac; and finally, it seems rather probable that the eggs are not laid all at the same time. 
We have now to deal with several other questions, some of which are difficult to answer definitely, namely: the size of the ovisacs compared with that of the females in the different species, their relative size in females of the same species and of different species, the number and size of the eggs in the ovisacs of the different species, and the fertility of each species. Here, however, we at once meet two difficulties: the one mentioned above on p. 24, that shortly before her laying eggs the female is always somewhat (and no doubt usually much) larger than after it, and in most cases it is quite impossible to procure specimens which are going to lay eggs, such as have half done and such as have quite done laying eggs; most frequently one only finds from two to five specimens altogether, all of which have half done or quite done, or else one or two of them are not full-grown; besides, an ovisac is somewhat smaller when it has just been laid, than later on, when the larvæ break out of it, for during the development the ovisac increases somewhat in size, getting at the same time less firm, as each egg, which is always globular or polyhedrous at the beginning, becomes elongated. Making allowance for this fact, it is seen that in most species there is not usually much difference between the sizes of the ovisacs deposed by the same female, whereas in some species the ovisacs often, though not always, differ very much in dimension (pl. $\mathrm{X}$, fig. $4 \mathrm{a} ; \mathrm{pl}$. XI, fig. $3 \mathrm{c}$ ). There is a great difference, on the other hand, between the average size of the ovisacs compared with the adult females of each species; comp. e. g. the proportion between fig. 3 a and fig. $3 \mathrm{c}$ in pl. III with that between fig. $4 \mathrm{a}$ and fig. $4 \mathrm{~d}$ in the same pl. Of course, we may say that as a rule the ovisacs are comparatively smaller in the species which depose a very large number of them than in those which lay rather few, yet even in these the ovisacs sometimes do not exceed middle size. In the species whose females are large, as a matter of course, the ovisacs are much larger than in the small species.

The number of eggs contained in the ovisacs naturally depends on the size both of the eggs and of the sacs. It is true, I have not measured the eggs of various forms, but as I know the larvæ that come out of the eggs in more than half of my species, as the length of these larvæ varies between about $15 \mathrm{~mm}$. and $30 \mathrm{~mm}$. only, and as they show no relatively great differences either of breadth or thickness, I possess a pretty accurate standard for judging the relative size of the eggs, for, evidently, the largest eggs (judging from the larvæ: those of Spher. decorata and of the genus Choniostoma) cannot be much more than donble the diameter of the smallest (in the genus Homoeoscelis). The further result is, that in the species whose females are very small, as Stenothocheres egregius (pl. I), Homoeoscelis minuta (pl. II), and especially in Hom. mediterranea (pl. XIII), the eggs must by very large compared with the females, whereas the eggs must be proportionally small where the females are very large, as in Sphar. Calliopii (pl. III) and in the two species of Choniostoma (pl. $\mathrm{X}$ and $\mathrm{p}$. $\mathrm{XI}$ ). That these statements agree with facts appears very clearly from the illustrations of the eggs and females of the above-mentioned species; - it must be borne 
in mind that the female and eggs of the same species are always illustrated enlarged on the same scale.

As the difference of size between the very small species (or rather those whose adult females are very small), as Homoeoscelis minuta and $H$. mediterranea, and the very large ones, as Choniostoma mirabile and Ch. Hansenii, is exceedingly great (s. above p. 24), and the difference between the eggs not being greater as just stated, it follows that, with equal proportion between fertility and volume, the large species lays manifold more eggs than the small one. To abide by our example: the number of ovisacs in Homoeoscelas amounting to about eight; in Choniostoma to about twelve, it is evident that in the small species we find few, in the large ones numerous eggs in each ovisac, and this fact is indeed proved by the following figures: in an ovisac of Homoeoscelis minuta are found only about 14 to $18 \mathrm{eggs}$, in $H$. mediterranea no more than about 6 to 10 , whereas in a middle-sized ovisac of Choniostoma mirabile I have counted $10.7 \mathrm{eggs}$. If, in a smaller species, as e. $\mathrm{g}$. Sphrer. dispar and S. mortesta, the number of ovisacs increases to about twenty, or, as in the latter species, to about twenty-eight, the quantity of eggs containeả in an ovisac is naturally rather small (pl. IX, fig. 3e, fig. 3c and fig. 2c), whereas in the gigantic Sphcer. Munnopsidis, of which species one specimen - consisting only of a half-emptied skin - was about $5 \mathrm{~mm}$. in diameter, the number of ovisacs may indeed amount to twenty, still the average number of eggs in each ovisac (in this species I have found great variety in the size of ovisacs of the same specimen) is nevertheless very great, as is shown quite distinctly in fig. 4 a on pl. $X$.

The entire bulk of eggs deposed by a female - as stated above - is always larger than the animal itself after it has laid them, and it is often so marvellously large, compared with the female, that we hardly understand the possibility of it (s. pl. XI, fig. $3 \mathrm{a}$ ). This state of things, however, may be partly explained by the fact that the ovisacs are deposed at certain intervals (about a possible deviation in Stenothocheres, see above), and that consequently the eggs can be gradually developed in the female. If we find seven or eight ovisacs in a female, the development of at least one or two of these is nearly always so far advanced, that the larva are in the Nauplius stage; where ten or eleven, or still more, ovisacs are found, one or two of these usually contain almost or quite full-grown larvæ. The length of time which elapses between the laying of the first and of the last ovisac in specimens containing a large number of these sacs, as Sphcer. decorata and the other species living in the marsupium of Cumacea, seems to be about equal to that which the first laid ovisac requires for its development: the division of the germ, the Nauptius stage, and the development of the larva with numerous limbs, though I cannot tell how many days are required for this process. The two species which lay the smallest number of eggs are the diminutive forms Homoeoscelis mediterranea and Stenothocheres egregius, the former has as many as eight orisacs containing in all 60 to $70 \mathrm{cggs}$, whereas St. egregius, as a rule, only lays about $30 \mathrm{eggs}$ (I have foumd between 16 and 42 eggs, the latter number in an exceptionally large specimen). The largest species, 
viz. Spher. Mumopsidis and the two species of Choniostoma, lay the largest number of eggs. In a specimen of Ch.mirabite with eleven ovisacs I counted the eggs in one of these presumably of middle size, and I found $1057 \mathrm{eggs}$, so the number of eggs laid by this specimen may be said to amount to 11,620 , and if we take this figure as the normal quantity in $C h$. mirabile of the Kara Sea, at any rate we do not exaggerate. In Spher. Munnopsidis the number of eggs seems to be even much higher, however, it would scarcely be possible to calculate the exact amount. Between these last-mentioned species and Stenothocheres egregins the other species present a variety of transitions, as far as fertility is concerned. In a following chapter about distribution etc. I shall have an opportunity of making some further observations on these rather remarkable differences.

II. The development of the eggs. As for the division of the germ and the earlier part of the embryological development, which I have not studied myself, I shall refer to the representation of Salensky. As in all Copepoda a Nauplins stage is developed (pl. XI, fig. $1 \mathrm{c}$ and fig. $1 \mathrm{~d}$ ); but this stage never becomes free, it evolves itself into the stage of a highly organised larva, of which a detailed description is given below. When this larva, which corresponds with the first Cyclops stage in other parasitic Copepoda, is full-grown, it breaks out of the egg-membrane and of the ovisac. As for the details concerning the development of the Nauplius stage and of the larva, I must again refer to Salensky.

It may be added that in material preserved in spirit (and I have seen no other) the ovisacs, when younger, are of a light yellowish colour, but they gradually get whiter, as the larvæ are developed.

\section{d. The free Larva.}

I. The Material. Of several species $\mathbf{I}$ have found free larvæ, which were either swimning out of, or had recently swum into the marsupium, and these specimens, of course, were excellent, showing the normal shape of the larvæ. Of a number of species I have procurer a rich material of larva by pulling them out of an ovisac; they were good enough when taken while about to break out of the egg-membrane, though the body might be somewhat soft and not extended in its full length, thus showing a vagner outline which did not quite correspond with that of the swimming specimens. Sometimes I had to content myself with younger animals, which had to be pulled out of their egg-membranes, and which had indeed a well-developed mouth, maxillæ, maxillipeds etc., but whose cephalothorax was deciderly shorter and stouter than those of the full-grown larvæ, and which also showed other signs of unfinished development, so that no reliable observations could be made of difficult parts, is e.g. the branches of the maxillulæ. Finally, of a few species I had only larvæ which had, swum into the marsupium of a new host, where they had attached themselves ( $h$ : below), and in these the cephalothorax, as a rule, was shorter and broader than in the free specimens. Of some species I had larvit of this kind as well as of others, 
that had been taken in a free state, or had been pulled out of an ovisac. All this put together gives the result, that I have been able to examine the larvæ of twenty-three species, lacking only the larva of Stenothocheres Sarsii and nineteen species of Sphreronella; thus I possess the larva of Sten. egregius, of fifteen species of Spheronella and of all seven species of the four remaining genera. Fortunately the fifteen species of Sphceronella represent nearly all the more important types of this large genus.

As for the illustrations, I beg to notice that I have frequently omitted the two pairs of natatory legs, or at least their branches, as their representation, as a rule, would have been exceedingly difficult, and the omission is of little consequence, as the number and the arrangement of the natatory hairs are very much alike in the different species. In some cases the abdomen is also left out. My representations of the maxillulæ include all that a careful study enabled me to observe; however, I am inclined to think that a better material would sometimes have allowed me to discover one - occasionally two - more branches.

II. Structure of the Larve. The length of the body usually varies between 20 and $.25 \mathrm{~mm}$; the longest larva I found belonged to Sphcer. decorata, and it is $.30 \mathrm{~mm}$. long; the shortest, $15 \mathrm{~mm}$. in length, belongs to Homoeoscelis minuta. The body is divided into two parts: the cephalothorax and the abdomen. The cephalothorax is somewhat depressed, usually oval and about $\mathbf{1}^{1 / 2}$ time as long as it is broad, sometimes (Mysidion, pl. XII, fig. 2h) more elongated, almost double as long as it is broad; it consists of two rlivisions, namely, the cephalothorax properly speaking, and a single trunk-segment (pl. III, fig. $3 \mathrm{k}$ ), which are joined by a rather sinuate articulation, whereas the trunk-segment is between five and eight times (in a single case about eleven or twelve times) shorter than the anterior division. I have found behind the segment mentioned a very short portion which looked like the rudiment of a second free segment (pl. III, fig. $3 \mathrm{k}$ ) and belonged to the cephalothorax, not to the abdomen; I cannot, however, say anything definite about this part and will content myself with stating what $I$ have observed. The abdomen is narrow, and its length varies between a little more than one sixth and rather more than one third of that of the cephalothorax; it always consists of three distinctly separated segments and has two caudal stylets, which as a rule are plainly articulated on the third segment, but sometimes are coalescent with it (e. g. pl. I, fig. 11).

The foremost half of the large anterior division of the cephalothorax is always provided with antennulæ, antennæ, rostrum with mandibles, maxillulæ, maxillæ and maxillipeds; the hindmost half has a longer or shorter odd pouch, which turns backward, decreasing in width towards its distal end (pl. I. fig. 1l, l); its posterior part forms a free, either pointed or rounded bag along the ventral surface, often covering the transversal band which unites the first pair of natatory legs (pl. III, fig. 3l), sometimes even the band between the second pair of natatory legs (pl. II, fig. 11). The first pair of natatory legs is situated at the posterior extremity of the first division of the cephalothorax, whereas the second pair proceeds from the free trunk-segment. It may be mentioned finally, that Salensky has 
shown the existence of an eye (op. cit. p. 314, Taf. X, fig. 21 and 23, oe), which in the illustration is drawn as situated on the ventral side of the forehead in Form von zweien am oberen Theile etwas verdickten sichelförmigen Pigmentflecken, welche in der Mitte sich berithren und eine x-fömige Figur darstellen«. As a matter of course, the eye must be found on the dorsal surface, but $I$ have been unable to find it on my larvæ, probably because the spirit had dissolved the pigment.

The Antennulce are always rather short; they consist typically of three joints, the second of which is usually short and not unfrequently coalescent with the first, in which case we only perceive two joints. The first, and particularly the third joint, are provided with pretty long setæ; the terminal seta of the third joint is very long, and from the lower side of this joint proceeds always a single, particularly long olfactory seta (pl. T, fig. 11, b), which is at least double, usually several times, the length of the whole antennula; sometimes this seta is exceedingly long, as e.g. in Spher. dispar (pl. IX, fig. $3 \mathrm{k}$ ) and in Sphor. insignis (pl. X, fig. 1e), where it reaches further than the middle of the abdomen, nay in the lastmentioned species the olfactory seta in itself is longer than the whole cephalothorax. The antennulæ are always attached pretty far from each other at the edge of the cephalothorax, the area between them forming what I call the front. Close to the inner margin of the base of the antennula we often see an oblique list; moreover, in nearly all species of Sphcronella which are parasitic on Cumacea, the front is decorated with one or several rows of delicate and peculiar processes, which decoration reaches its highest development in Sphrer. recorata (pl. VIII, fig. $3 \mathrm{i}$ and fig. 31). In Spher. modesta these processes are replaced by transverse lists (pl. IX, fig. 2 i).

The Antennce proceed behind, and usually at the same time somewhat obliquely inside the antennulæ, but never from the base of the rostrum. Sometimes they are considerably shorter than the antennulæ, sometimes about the same length, and in the genus Homoeoscelis (pl. II, fig. 11 and pl. XIII, fig. 1h) more than double the length. In Sphrer. marginata (pl. XIII, fig. $6 \mathrm{~g}$ ) only two joints are found, in all other species they consist of three or four joints, three of which are always distinct, but it is often difficult to make out for certain, whether the eminence from which the supposed second joint proceeds, is a real joint, or in other words, if the apparent basal joint consists of two joints; as, however, Sphror. rentillensis has four very distinct joints (pl. III, fig. 2e), this is probably the typical number. The terminal joint is nearly always short and usually ends in a long, thick seta, beside which we frequently find a shorter one. The next joint is now rather short, now long, or very long, and where the antenna is long, it is on account of the length of this joint, as the basal joint, or where there are four joints, the two first of these are never elongate, but sometimes (pl. IX, fig. $2 \mathrm{i}$ and fig. $3 \mathrm{k}$ ) comparatively broad. In Mysidion (pl. XII, fig. $2 \mathrm{~h}$ ) the antennæ are very small, and in Sphar. microcephala (pl. VIII, fig. 2i) almost rudimentary, in both cases 3-jointed, with an exceedingly short terminal seta.

The Rostrum seems to correspond only with the more distal part of this organ in 
the female and the male, for not only are the antennæ situated a little outside its hase, but the maxillulæ are found quite, or nearly quite, outside it. The general structure of the mouth is like that of the adult animal; the mandibles are frequently seen in the opening, but the hairs of the month-border are always short, frequently so short. that they can only be discovered with the greatest difficulty.

The Maxillulce are difficult to understand, and it is very difficult to discover all their setæ. As mentioned above, in the various illustrations of the larvæ I have drawn what I have found, but I am pretty sure that I have not everywhere found all the elements. The highest development I met in Sphor. Calliopii (pl. III, fig. 3l) as well as in the species which are parasitic in the marsupium of Cumacea, as Sphar. decorata (pl. VIII, fig. 3i), S. modesta (pl. IX, fig. 2i) and S. dispar (pl. IX, fig. 3k). In these figures we see obliquely behind and outside the rostrum on each side four setæ, the two hindmost of which are coalescent or adjacent at their base, one or both of them being plumose. Obliquely from these and somewhat nearer to the rostrum proceeds a third seta, which turns straight towards the front, and obliquely before this one again, there is a fourth, shorter seta. I suppose that all these four setæ belong to one maxillula, the basal part of which is not separated from the ventral side of the head. In Sphar. marginata (pl. XIII, fig. $6 \mathrm{~g}$ ) the innermost seta is reduced to a short process. In most of the other forms I have only been able to find three setæ, e. g. in Sphrer. microcephala (pl. VIII, fig. 2 i) and in Choniostoma mirabile (pl. XI, fig. 1e), or two, or only one. In Stenothocheres egregius (pl. I, fig. 11) I have found a maxillula (e) which reminds me much of those in the adult animals, as it consists of a short, basal part, from which proceed two thick setæ, of which the hindmost is shorter, the foremost very long. In the genus Homoeoscelis (pl. II, fig. 11 and pl. XIII, fig. $1 \mathrm{~h}$ ) I have been unable to find vestiges of maxillulæ.

The Maxille nearly always consist of three distinct joints, and are very much like those of the adult animals, though the stout basal joint, as a rule, is narrower and the two next joints are longer than in the adult; these two joints are slender, and the last one somewhat curved and claw-like. In Homoeoscelis only the two last joints are entirely coalescent, forming one curved joint, which moreover along the larger part of both margins is provided with exceedingly fine and short setiform processes (pl. XIII, fig. $1 \mathrm{~h}$ ). As a rule all three joints are simple and smooth, but in those species of Sphceronella which live in the marsupium of Cumacea, the iuner margin of the third joint is coarsely or finely serrated, and the first joint has on its inner margin, against which the second joint can be folded up, a double row of fine cylindrical processes (pl. VIII, fig. $3 \mathrm{n}$ and fig. 3o), and a similar decoration is seen in Sphar. Munnopsidis (pl. X, fig. 4d). - The two maxillæ are always situated at some - usually at a considerable - distance from each other.

The Maxillipeds, as a rule, are placed close behind the maxillæ, and also generally somewhat closer to the median line than these; in Homoeoscelis only (pl. II, fig. 11 and pl. XIII, fig. $1 \mathrm{~h}$ ) there is a great distance between these two pairs of appendages. The 
maxillipeds are always of considerable size, they are very like those of the males, and always consist of four distinct joints. Their rather stout basal joint is nearly as long as. or somewhat longer than, the three following joints together; the second and the third are very slender, and their joint length is a little longer, or somewhat shorter, than the last joint, which is extremely slender, almost setaceous, slightly curved and pointed. All the joints are nearly always smooth and naked; in Sphor. Munnopsidis the fourth joint has towards its apex three spiniform processes (pl. X, fig. $4 \mathrm{~d}$ ), and in Mysidion abyssorum there are five or six somewhat similar processes along the more central part of the inuer margin (pl. XII, fig. $2 \mathrm{~h}$ ); the third joint at its extremity is always furnished with a spine inside the articulation of the fourth joint.

In most figures I have carefully illustrated the sub-median skeleton, which consists of lists running backward from the base of the rostrum and the maxillulæ, surrounding the base and forming the articulation of the maxillæ and the maxillipeds.

The two pairs of natatory legs of each specimen are very much alike, and they differ very little, comparatively, in the various species. Each leg consists of a good-sized peduncle, which is particularly broad in Stenothocheres egregius (pl. I, fig. 11, m and n), somewhat narrower, or rather narrow, in the other species (see particularly pl. VIII, fig. $2 \mathrm{i}$ ); from the posterior margiu proceed at some distance from each other two one-jointed, about equally long branches, and the outer branch, which proceeds from the end of the peduncle, is broader than the inner one and rather dissimilar in outline. The outer branch of the first pair of legs, as a rule, has four rather short, naked setæ on its outer margin, two very long plumose setæ on its terminal margin; on the inner margin it has either two very long plumose setæe (pl. IX, fig. $3 \mathrm{k}$ ) or one of this kind and one much shorter, naked seta (pl. I, fig. 11). The outer branch of the second pair of legs is very like that of the first pair, but its onter margin has only three shorter, simple setæ, its terminal margin two, and its inner margin two exceedingly long plumose setæ, all four of which are longer than in the first pair of legs. The inner branch of the first pair of legs has four, of the second pair three very long, plumose setæ on its inner margin, and in both pair of legs two similar setæe on its terminal margin (all these setre are longest in the second pair), whereas the outer margin has only one single seta, which is either short and naked, or very long and plumose. These are the results of my researches in the few species whose natatory legs have been examined with special care, but it must be observed that these species belong to three genera: Stenothocheres, Sphcronella and Choniostoma. Even if an examination of more species should show greater variety in the number of setæ, such differences are not at all likely to be considerable, and furthermore, it is in most cases exceedingly difficult to count the setre accurately, as the legs are very frequently folded up or standing on edge; therefore it would be all but impossible to make any practical use of the presence or absence of such a seta as characteristic mark of species or genera. - The two legs belonging to each pair are, as usual, united by a prominent, movable transverse band (pl. I, fig. $1 \mathrm{l}, \mathrm{m}^{\prime}$ and $\mathrm{n}$ '). 
The first abdominal segment always dilates considerably from its base towards its end, and the free posterior angle has a powerful, often spiniform, seta, the length of which varies between being a little longer than the following segment (Stenothocheres, pl. I, fig. 11) and being longer than the whole abdomen, and plumose in its distal half (Choniostoma, pl. XI, fig. 1e). Inside or outside this seta and close to it there is always another seta, which, as a rule, is much shorter, and only in Sphor. microcephala (pl. VIII, fig. 2i) is remarkably long, though somewhat shorter than the first one. The second segment is sometimes shorter, and in this case not unfrequently somewhat narrower, than the first one, e.g. in Choniostoma, sometimes quite as long, and always without setx. In Stenothocheres (pl. I, fig. 1l) the third segment, together with the not separated caudal stylets, forms a large and broad, elongate segment, much larger than any of the preceding ones, and incised posteriorly in the median line. In all other species the third segment, together with the caudal stylets, is nearly always somewhat, and generally much, smaller than the second segment, and the stylets are sometimes not set off from the segment, but most frequently distinctly articulated on it as two short, almost cylindrical joints. Each stylet has always a very long and thick, sometimes plumose, seta, which in Stenothocheres egregius is only a little longer than the abdomen, in Mysidion and Aspidoecia somewhat longer, though not nearly half as long as the cephalothorax, in Homoeoscelis, Sphoronella and Choniostoma longer than half the length of the cephalothorax, and sometimes attaining to three quarter's the length of this part, e.g. in Sphar. dispar (pl. IX, fig. 3k). Outside this long seta each stylet has in Stenothocheres four, in the other species two or three, comparatively short setæ.

Whereas there were great differences between the females among themselves and between the males among themselves in the different genera and species, we see from the detailed description given above, that all larva I know are surprisingly uniform, so much so, that I have been able to find rather insignificant generic characters only in Stenothocheres and Homoeoscelis, as distinct from the four other genera; at the same time the larvæ of Mysidion and Aspidoecia - whose females deviate much from those of the other genera with regard to receptaculum seminis, the position of the genital apertures and the hingement of the ovisacs - deviate less from various larvæ of Sphceronella, than these differ from each other.

III. Further Development of the Larve. The larvæ, after making their way out of the ovisac, - at least as a rule, swim out and seek a new host. I cannot deny the possibility that one or a few of the larvæ may remain in the branchial cavity or in the marsupium of the mother's host, though I doubt it very much. In a marsupium which was infested beforehand I have repeatedly found one or several larvæ, which were decidedly invaders. I met with the greatest invasion in a specimen of Hippolyte Gaimaidii, where in one of the branchial cavities I discovered a very young female of Choniostoma mirabile and certainly more than fifty larvæ and pupæ hinged on the gill-fibres (s. the special description below). 
When the larva has found its new host, it attaches itself either beneath the carapace to the branchiæ or in the marsupium to one of its plates, to one of the gills, or simply to the ventral surface of the body, or to the basal part of a leg, and in case it attaches itself to a not full-grown female of Amphipoda, of course it must content itself with one of the three last-mentioned places. The larvæ of Aspidoecia fasten themselves either outside on the dorsal surface of the host (an Erythrops), if they are growing into females, or on a female of their own species (pl. XII, fig. $3 \mathrm{~b}$ ), if they are going to be males. The fixation, which is very solid, is effected by a viscous substance, which expands itself so as to form a larger or smaller plate on the front (pl. IV, fig. $1 \mathbf{e}, \mathrm{s}$; pl. VIII, fig. $2 \mathrm{i}$; pl. XI, fig. 1 e, s). This viscous substance must be secreted of a gland in the front part of the head, the orifice of which, however, I have tried in vain to find; the gland itself must be studied from fresh material. (It was pointed out long ago by several authors, that the larvæ of various Caligidæ, of Achtheres etc., in their first stage fasten themselves in a somewhat similar manner by a "Stirnband (Claus).) The larva, after hinging itself in this way, relaxes the grip of its limbs and hangs quite free; thereupon it begins to change form, bending forward the last joint of the maxillæ, and its cephalothorax getting gradually shorter and broader (pl. XI, fig. $1 \mathrm{e}$; pl. IV, fig. $1 \mathrm{e}$ ); how short and broad it may occasionally become, may be seen on pl. IV, by comparing fig. $1 \mathrm{c}$, which represents a free larva, and fig. $1 \mathrm{~d}$, which represents a larva that has reached its full breadth, and which no doubt is going to develop into a male; fig. $1 \mathrm{e}$ is an intermediate form shortly after the fixation. Then the muscles etc. in all the limbs and in the abdomen dissolve themselves, and the contents of these organs are transferred into the cephalothorax, the muscles of which have also been dissolved, and finally this united substance is surrounded by a new skin under the old one. The subsequent development will be treated in the next division.

\section{e. The post-larval Development; the Pupæ.}

The post-larval development, which takes place between the larval stage just described and the appearance of adult males and of females (which, though very small, in all important features resemble the egg-laying specimens), offer the greatest deviations between the different forms, but, unfortunately, the representation I am capable of giving is very fragmentary. The larva in many cases develops into a pupa, out of which evolves the female, and, in some cases, the male; in other cases the male is developed immediately from the larva etc., and in Mysidion the metamorphosis is more complicated. I know the complete development only of two species of Sphceronella and of Homoeoscelis mimuta, but the two first-mentioned, in particular, are fortunately very different from one another; I know, moreover, the development of the male in Aspidoecir, and of the females belonging to the species of the Sphar: Leuchartii-group. Finally I have found a pupa of each of four other species of Sphreronella 
(S. Argissa, S. longipes, S. microcephala and S. insignis), numerous pupæ of Choniostoma mirabite, and three different stages of development of Mysidion commune.

Let us begin with the simplest form of development. On a completely adult female of Aspidoecia Normani, sitting on the dorsal surface of the abdomen of Erythrops serratus G. O. Sars, I found four larvæ attached (pl. XII, fig. $3 \mathrm{~b}$, where one of the larvæ is left out and two of the others designated by a v.) One of these came off easily, when touched, and it appeared that its skin had begun to burst along the lateral margin; on a closer examination it burst somewhat more, and it proved to contain a full-grown male. In this state the preparation is illustrated in pl. XII, fig. $3 \mathrm{~m}$. The spermatothecæ of the male were filled, and it had a very short and very thick frontal thread (s). This instance sufficiently proves, that the male develops itself directly in the larva, without the intermediate pupa stage and without a second moult. I also found a single larva, which had placed itself directly on the carapace of the host, but its examination gave no result, its development not being far enough advanced. However, I have found exceedingly small females sitting on different parts of the host, and I have not the slightest doubt that the larvæ which are going to become females, attach themselves directly to the host, though I do not know, whether they pass throngh the pupa stage or change directly into females, yet I feel inclined to accept the latter alternative, seeing that the parasite sits on the outside of its host, thereby running the risk of falling off very easily.

We now come to a species in which both sexes pass through a pupa stage, namely. Sphcer. Giardii (pl. VI, fig. $3 \mathrm{i}$, fig. $3 \mathrm{k}$ and fig. $3 \mathrm{l}$ ). I have found three male pupæ and not a few female ones. The body is of a short ovate shape; the males are more oblong and smaller, $\cdot 125 \mathrm{~mm}$. in length (fig. $3 \mathrm{k}$ ), the female pupæ stouter and varying in length between $\cdot 125 \mathrm{~mm}$. and $142 \mathrm{~mm}$. (fig. $3 \mathrm{l}$, which is drawn on the same scale of enlargement as fig. $3 \mathrm{k}$ ). In the female the foremost two thirds of the ventral surface form a broad, naked, odd area, whereas the whole remainder of the body is closely covered with rather short hairs. The male pupa is covered with hairs like the female, except that part of the back which corresponds to the head and the upper parts of its lateral surfaces, which are naked (fig. $3 \mathrm{k}$ ). Fig. $3 \mathrm{i}$ shows a male pupa from below, fig. $3 \mathrm{k}$ from the side; the antennulæ (a), the antennæ (c), the maxillulæ, the maxillæ, the maxillipeds, the trunk-legs and the caudal stylets are seen as naked, smooth, pouch-shaped processes, whereas the mouth is developed as in the adult animal; in front of the mouth we notice a semicircular, rather vaulted and prominent area, and between the maxillæ and the maxillipeds two pairs of oblong, somewhat prominent knots, corresponding with the sub-median skeleton. The female pupa has also a free mouth and all the same processes and projecting parts as the male, from which, however, it is easily distinguished, not only by the above-mentioned difference in the extent of the haircoat, but also by the size of the processes which stand in the place of the trunk-legs, and which are very small, whereas in the male pupæ these organs - especially the first pair -- are much larger and furcate at the end This difference between the trunk legs, which 
entirely agrees with that in the adult animals, proves in a satisfactory way that my suggestion with regard to the sexes is correct. One of the illustrated male pupæ (fig. $3 \mathrm{k}$ ) is fastened by a frontal thread, which is about one third the length of the body and considerably dilated towards the end, but its extreme expanded part is of a different quality and forms a disk-like plate. In the other male pupa (fig. $3 \mathrm{i}$ ) the thread is shorter and somewhat thicker, but its distal end is broken off. The fixation of the female pupa is effected by a thread, which is so short that the front part of the animal is pressed against the gill, or the plate of the marsupium, to which it is attached. - It is stated above that the pupæ have a well-developed mouth, and it would seem probable that at least the female pupæ take food and grow a little. Undoubtedly the males and females come ont directly of their respective pupæ, like the females of the species belonging to the group of Spher. Leuchartii, in which I have observed the fact myself. Only one point seems to present some difficulty, namely, that my male pupæ are only $125 \mathrm{~mm}$. in length, whereas the male animals are between 17 and $21 \mathrm{~mm}$. long and of a similar shape. With regard to this point I refer to my ubservation of the growth of the male of Spher. paradoxa mentioned below on 1). $57-58$.

Homoeoscelis minuta. A single pupa (pl. I, fig. $3 \mathrm{~b}$ ) was found hinged by a frontal thread to the gill-bearing epipod. The pupa is $18 \mathrm{~mm}$. long, of an elongate oval shape and naked all over. We see the pouch-shaped processes in which the antennulæ (a), the antennæ (c), the maxillæ (f), the maxillipeds (g), the first pair of trunk-legs (m), the second pair (n) and the caudal stylets (p) are developed; but besides all these, we notice between the second pair of trunk-legs and the caudal stylets a pair of very small, most peculiar processes $(\mathrm{x})$, which are possibly. a rudimentary third pair of legs that do not develop any further, and which disappear again. The month with the mandibles is like the pupa of Sphar. Argissce (s. below); the frontal thread is scarcely a fourth of the length of the animal, it is simple, with a discoid expansion at the end. This pupa was hinged in the branchial cavity between two adult males attached in the same way, but there was no female, and these two circumstances make it more than probable that the pupa was a female, especially, as in a large material of this species I have seldom found more than one male, and never more than two males and one female in the same branchial cavity. Later on I found in two specimens respectively two and three pupæ, one among the latter of which - being no doubt youngel' than the others - was somewhat smaller and had less developed rudiments of limbs, thongh otherwise it was similar to the other four, all of which agreed with the above-described specimen. (The frontal thread in one of the specimens was half as long as the body). Considering that (as stated above) I have never found more than one female and two males in the same branchial cavity, the four large pupæ must either all be males, or — which is probable - be male and female pupæ. So, judging from the sex of the minutely described pupa. there is no differmce between the development of the two sexes, and this agrees very well with the fact that recently hatched females can sometimes be distinguished from the males only by possessing genital apertures, as in several males the spermatothecæ are not distinctly seen. 
At least with regard to the structure of the pupæ we know, Sphcronella Argissa, Spher. insignis and Choniostoma mirabile come rather close to the two preceding species; each of them will now be treated separately.

Sphceronella Argissc. Of this species I have found a single female pupa (pl. IV fig. 31 and fig. $3 \mathrm{~m}$ ), which in the most important features agrees with the female pupa of S. Giardii. The body is ovate, naked all over, $15 \mathrm{~mm}$. in length, and, like the last-mentioned species, provided with the pouch-like processes, in which antennulæ (a), antennæ (c), maxillulæ (e) maxillæ (f) maxillipeds (g), trunk-legs and caudal stylets (p) are developed, and all these processes show about the same relative size as the corresponding organs in the females compared with each other; moreover, the mouth is distinct, and the mandibles are also seen in fig. 31. The animal is attached by a very peculiar crooked funnel of considerable size (s), which is of course made of a viscous substance, and its narrower, though comparatively thick, base proceeds from the front.

Sphceronella insignis. Of Diastylis cornuta Boeck a single pupa was found (pl. X, fig. $1 \mathrm{~h}$ ), $14 \mathrm{~mm}$. in length and sub-globular in shape. The mouth is well developed, as in an adult female; antennulæ, maxillulæ, maxillæ and maxillipeds are seen as protruding naked pouches of somewhat irregular shape; in front of the mouth are found two rather large, odd. connected areas, and close behind them a smaller spot on each side of the median lime; in front of, and in an oblique direction from, the maxillulæ, there are several small areas, and finally a large transverse area, expanded in the middle, which joins the bases of the maxillipeds. All these areas are naked, and more or less prominent compared with the surronnding skin. Except these organs and areas and the surface between them, the whole ventral surface of the pupa and its sides are covered with hairs of medium length; the back is covered in the same way on its most anterior part and on its posterior half, whereas a broad, transverse area extends over the larger part of its anterior half; this area is naked, and closely covered all over with irregular projections of a comparatively rather considerable size, the real shape of which can only be recognised when seen obliquely, whereas a perpendicular view gives the impression that this surface is covered with numerous irregular lines, forming ovals, oblong spots or simply flourishes. I have been unable to find out with certainty the sex of this interesting pupa, as the adult male of this species is devoid of trunk-legs; however, I consider it to be a female.

Choniostoma mirabile. On the gills of a Hippolyte Gaimardii M.-Edw. I have found a number af larvæ, which showed all the stages transitional to that of the pupa, besides numerous fully developed pupæ (pl. XI, fig. $1 \mathrm{~g}-1 \mathrm{k}$ ). A comparison between the figures $1 \mathrm{~h}, 1 \mathrm{i}$ og $1 \mathrm{k}$, which are drawn to the same scale of enlargement, will show that the pupæ differ much in size and somewhat in shape; the largest specimen $\mathrm{I}$ have measured is $38 \mathrm{~mm}$. broad and $27 \mathrm{~mm}$. long, the smallest only $27 \mathrm{~mm}$. broad and $19 \mathrm{~mm}$. long, and one specimen, which was still enclosed in the skin of the larva, is only $19 \mathrm{~mm}$. broad and $18 \mathrm{~mm}$. long. So the pupe grow very considerably after breaking out of the larval 
skin, and there can be no doubt that they take nourishment through their well-developed mouth (s. later on under Sphcer. danica.) They are always considerably depressed, the anterior margin is long, now quite straight, now a little concave, in the younger specimens occasionally a little convex; the lateral margins converge rather considerably backward and merge more or less evenly into the posterior margin. The mouth is pretty well developed, with distinct mandibles (fig. $1 \mathrm{~g}$ ), and is situated much to the front on the ventral surface; it is surrounded by rather small pouch-like processes: antennulæ (a), antennæ and maxillæ, and behind it is found a rather large, peculiar area. Near the anterior margin on the ventral surface is seen a body with an irregularly curved posterior margin, and this is the adhesive plate (s), by which the animal is hinged. The parts just described on the ventral surface are surrounded by a naked area, whereas the greater part of the remainder of its surface is provided with hairs, which are sometimes arranged in rows of two or three or more, sometimes are more scattered, and the hairs which grow close to the edge are rather long, the more central ones are short; the larger part of the dorsal surface is naked. Fig. $1 \mathrm{i}$ and fig. $1 \mathrm{k}$ reveal that the contents of the pupa - perhaps on account of alcoholic influence - do not reach the outer skin, whereas fig. $1 \mathrm{~h}$ shows a very large and entirely filled pupa; fig. $1 i$, the specimen represented on a larger scale, so far shows the same as the two illustrations just mentioned, but it reveals at the same time that the inner body has its own skin with distinct setæ at its margin. The male of Choniostoma being unknown, I cannot decide how far all the specimens found are only female, or both female and male pupæ.

We now come to a species - Spharonella paradoxa - whose development differs very much from that of Sphor. Giardii, or that of Homoeoscelis minuta, and the forms which, according to my just stated (though rather defective) knowledge, are related to these species. In Sphor. paradoxa both sexes develop themselves without passing through the stage of an independent pupa properly speaking, nevertheless there is a considerable difference of aspect between the development of the sexes. Let us first examine the development of the male. I had a very considerable material of larvæ, which were hinged by their front, and in which the cephalothorax was nearly as broad as long, besides being very thick (pl. IV, fig. $1 \mathrm{~d}$ ); however, as it was impossible to me, in spite of careful searching, to find a single male pupa, I conceived the idea of submitting my big larvæ to a thorough examination, and in a single specimen I fancied that I saw two spermatothece through the skin. I succeeded in taking away the skin of this larva, and I found a young male with hairs on its abdomen, rather short caudal stylets, and two spermatothecæ, whereas the limbs were still for the most part rather indistinct. Hereby, then, we have got the proof that the males come out directly of these big larve (comp. Aspidoecia, p. 54), still there remains a single point which is not fully explained. My rather numerous males are - with very rare exceptions - about .245 and $.27 \mathrm{~mm}$. in length, though one of the big larvæ is only $19 \mathrm{~mm}$. long, the empty abdomen included, and the cephalothorax of one of the largest of these larva is only $16 \mathrm{~mm}$. in length (in pl. III, fig. $4 \mathrm{c}$ I have represented a male, in fig. 4 e such a larva eularged on 
the same scale, and a comparison between these two figures offers a pretty good illustration of the different sizes seen from below). Fortunately I have found a single male which without any doubt, judging from its inward and outward condition, is quite recently hatched, and which is only $18 \mathrm{~mm}$. in length, consequently $.02 \mathrm{~mm}$. longer than the above-mentioned cephalothorax; now, if we consider the prominent frontal border in the male and its rather more elongate shape, this slight difference is accounted for. The result is, that immediately after hatching, the male must grow to some extent, for, as males of small size in this (as in other) species are pretty rare, we have good reason to suppose that this growth is comparatively rapid.

The female apparently passes through a pupa stage. I have found three such "pupæ《 altogether, which were all about the same size; the specimen illustrated in pl. IV, fig. $1 \mathrm{f}$ is $174 \mathrm{~mm}$. long. The body is ovate, somewhat flattened and attached at the front by a broad adhesive plate (s). In the illustration several limbs are seen, but, on closer examination, it appears that all these organs are those of the larva: antennulæ (a), antennæ (c), maxillæ, maxillipeds $(\mathrm{g})$, first pair of natatory legs $(\mathrm{m})$, second pair of natatory legs $(\mathrm{n})$ and abdomen (0), in other words, the animal is enclosed in the skin of the larva, whose appendages and abdomen are not only emptied of their contents, but have shrunk, so as to be almost unrecognisable. There is no mouth. Under the skin we see the scarcely developed mouth, the maxille and the folded maxillipeds of the young female. So the skin of the larva has acquired the appearance of a pupa; a real pupa does not exist. The animal cannot possibly take any nourishment. Fig. $1 \mathrm{~g}$ in $\mathrm{pl}$. IV represents a young female that has just burst the ventral side of the »skin of the pupa", whereas its ragged dorsal part still hangs on to it; this specimen was only $207 \mathrm{~mm}$. in length, consequently only $034 \mathrm{~mm}$. longer than the pupa represented. This young female was still attached by the adhesive plate (s) of the skin of the larva.

A pupa deviating from those of the above-mentioned types is found in Sphcronella danica, Sphar. chinensis and closely allied species, which, together with Sphar. Leuckartii, form a small group, which I have named after this species. Salensky (in his op. cit.) has described and illustrated several stages of development of Sphcer. Leuckartii, and his observations agree very well with mine, only I have been able to make some additional statements. The pupa is ovate, sometimes naked on its anterior part (pl. III, fig. $2 \mathrm{f}$ ), though, as a rule, it has only a smaller naked spot in the midst of the ventral surface (pl. II, several figures); otherwise it is all over pretty closely covered with rather short hairs; from the anterior end, which is always narrower or more pointed, proceeds a tuft of longer hairs, and in the midst of these is a rather short thread, which ends in a disk (pl. II, fig. 6 e), by which the pupa is hinged, either to one of the plates of the marsupium, to the inner side of the basal joint of a leg, or to a gill. (Usually this frontal thread proceeds from a small depression with flat bottom, however, in one case, I have noticed that it proceeded from a stouter, short, cylindrical eminence (pl. II, fig. $4 d$ and fig. $4 \mathrm{e}$ ). On the posterior half of the above- 
mentioned naked spot we find a somewhat prominent mouth (pl. II, fig. 6 e and fig. 6 f; pl. III, fig. $2 \mathrm{c}$ ), which is supported by some chitinous lists, the two longest of which point straight forward, are as long as, or somewhat longer than, the diameter of the mouth and enclose the anterior half of the naked spot. Of mouth-appendages we only see the welldeveloped mandibles, the points of which project in the orifice of the mouth; the hairs round the mouth-border are apparently wanting (but perhaps the magnifying power of my microscope does not suffice to discover them). Outside the anterior half of the mouth, and beneath the naked area in front of it, several muscles are seen, which evidently serve the action of the mouth. 'The pupæ of the same species show great difference of size. In Spher. chinensis a small pupa is $146 \mathrm{~mm}$., a large one $\cdot 24 \mathrm{~mm}$. in length, and both are illustrated in pl. II, fig. $6 \mathrm{c}$ and fig. $6 \mathrm{~d}$ magnified on the same scale. But I have found a much greater difference in Sphcer. danica, of which species I have seen nine pupæ: the smallest (pl. II, fig. $4 \mathrm{~d}$ ) is only $\cdot 115 \mathrm{~mm}$. long and $085 \mathrm{~mm}$. broad, an other (fig. $4 \mathrm{c}$ ) is $185 \mathrm{~mm}$. long, and the largest is . $25 \mathrm{~mm}$. long and $194 \mathrm{~mm}$. broad, thus somewhat more than double the length and double the breadth of the smallest specimen. In the small pupce I have not been able to find the vestige of any organ, and theiv contents - except the muscles of the mouth -- consisted of a granular sulstance. Salensky writes (op. cit. p. 317): "Weder imere Organe, noch selbst irgend welche Formelemente liessen sich im Innern wahrnehmen; doch könnte möglicher Weise der Darmkanal vorhanden sein und nur durch die zahlreichen Körnchen verdunkelt werden - ; later, on p. 318, he describes the mouth, but he has seen neither the mandihles nor the muscles, nor has be been aware that he had a mouth before him, and he concludes his statement about his youngest specimen, which is $12 \mathrm{~mm}$. long, in the following words: "Das Wachsthum geht in dieser Periode sehr rasch vor sich ". This last observation I consider to be correct, and as it appears from the above-stated measurements, that the pupa during its development grows to a manifold larger volume, it is clear that it must talie nourishment through its mouth, of which we have given a description, but it must be left to new examinations of fresh material to explain how this is eftected, if there really exists an intestinal tube - which we must naturally suppose - but the contents of young and halfgrown pupæ preserved in alcohol have made the impression on me of being evenly granulous, withont organs. In the above-mentioned largest $(\cdot 24 \mathrm{~mm}$. long) pupa of spher. chinensis (pl. II, fig. $6 \mathrm{~b}$ ) and in the largest $(.25 \mathrm{~mm}$. long) pupa of Spher. danica I found young females, and Salensky writes (p. 319): „Das letzte von mir gesehene Stadium zeigte das unter der Puppenhaut schon vollkommen ausgebildete Thier mit allen Anhängen. Die Puppe hat eine Länge von $0,27 \mathrm{Mm}$. erreicht....; an ihrer Oberfläche sind keine Veränderungen sichtbar"; whereupon he describes the animal, though without mentioning that it is a female, however, this is easily seen from his illustration. My specimen of Sphar. chinensis (pl. II, fig. (if) shows antennulæ, mouth, maxillæ, maxillipeds, the two pairs of trunk-legs, the not yet fully developed genital apertures and the caudal stylets, which are seen through the hairy skin. It is seen that the mouth of the young female is situated far more to the front 
than that of the pupa, and is much larger. The largest pupa of Sphor. danica agreed entirely whith fig. $6 \mathrm{f}$, except in one remarkable point: the mouth of the female projected freely through the skin of the pupa (though I was unable to discover any rent or larger opening in the skin), thus presenting the extraordinary sight of two mouths protruding beyoud the ventral surface of the pupa; the mouth of the female is situated a little behind the front extremity, that of the pupa nearly in the middle of the surface; the diameter of the latter in proportion to that of the former being as seven to ten. - Fig. $2 \mathrm{c}$ in pl. III illustrates such a young female belonging to Sphar. antillensis, which has rent and thrown off about the front third of the skin of the pupa, whereas the hindmost part of the body is still enclosed in the larger posterior part of the skin, including the mouth of the pupa, and as the same animal is illustrated in fig. 2 a magnified on the same scale as the ovisac exhibited in fig. $2 \mathrm{~b}$, a comparison of these two figures will show clearly, how much the animal grows from its stage as an egg up to the moment when it comes out of the pupa. But what about the male? The animal which Salensky found in its earliest stage as pupa, and of which he has had several specimens, according to his description and illustration is only the female, and of the pupæ I have seen, the smaller ones contained no animals, and the very large ones contained females. As mentioned above, a pupa containing a female of Sphar. danica is $25 \mathrm{~mm}$. long, but a male which, judging from its appearance, seemed to be recently hatched, was only $15 \mathrm{~mm}$. long, whereas a full-grown male of the same species was $24 \mathrm{~mm}$. in length. So we notice here the same growth of the young male as mentioned above in Spher. paradoxa, but at the same time we find that the fullgrown male is somewhat smaller, and the recently hatched male only a little more than half as long as the large pupa ( $25 \mathrm{~mm}$.). As the small pupæ examined by Salensky and by myself never contained any animal, it is very probable that the male of this species, as well as that of Sphcer. paradoxa, is developed directly from the larva, and the size of the recently hatched male agrees perfectly with this supposition. Unfortunately, of all my eight species of this group I have only seen very few larvæ, however, the contents of a single specimen of these seemed to indicate that a male, not a pupa, was developing in it, still its growth was not sufficiently advanced to decide the question with absolute certainty.

Of Sphcer. longipes I have found a single specimen of a pupa (pl. VII, fig. $2 \mathrm{~g}$ ), which essentially coincides with those belonging to the group Sphcer. Leuckartii. This pupa is ab. $17 \mathrm{~mm}$. long and $11 \mathrm{~mm}$. broad, rather elongate, as we see; the lateral margins run almost parallel in part of their length, the front extremity is somewhat pointed and has a small orifice, out of which a short broken thread is protruding. The pupa is quite naked and possesses in the centre of its ventral surface a small, but well developed, projecting mouth, at the front and at the sides of which some chitinous lists and muscles are noticed. Its contents consist of a granular substance, in which no organs are indicated; only towards the front extremity we see - as shown in the illustration - some vague indications of an organic structure. 
In this place I will briefly mention an organism, which I found on the glass after having prepared Spher. microceplacla, and which, I suppose, is the pupa of this rather deviating species. It is somewhat depressed (pl. VIII, fig. $2 \mathrm{k}$ ); its outline is ovate with a straight posterior margin, whereas its rounded front margin bears a somewhat protruding adhesive plate (the stripes of which are too strongly marked in the illustration); its dorsal surface is provided with some short hairs, the ventral surface is naked. It is $.20 \mathrm{~mm}$. long, has neither mouth nor other outer organs, nor do we find distinct indications of internal organs.

In Mysidion commune the metamorphosis is more complicated than in the preceding forms, but, unfortunately, my material is not large enongh to allow me to elucidate it in all details, besides, the forms in hand present several features which I do not understand. I lave found altogether three stages of development, two instances of the earliest, one of the medium, and two of the last and largest stage. I will begin with this last stage, which indeed presents a kind of semi-pupa, or a young female in possession of features which it afterwards loses. The two specimens found are of about equal size, the one illustrated in pl. XII, fig. $1 \mathrm{~d}$ is $31 \mathrm{~mm}$. long. The body is elongate ovate, rather pointed at the front extremity, which has a mouth provided with a border and its surrounding hairs; on its sides are the maxillulæ, and on the ventral surface, a little behind the inouth, are the maxillæ and the maxillipeds, which, though well developed, in some small, unimportant points deviate from those of the adult female; on the dorsal side, at a rather good distance from the mouth, we find the one-jointed organs, which for a long time I considered to be the antennulæ (a), but which no doubt are better explained as being the antennæ. On the ventral surface, at a considerable distance from the posterior extremity, we see an odd, strongly protruding, elongate and somewhat pointed process $(\mathrm{x})$, and nearer the posterior margin, somewhat up on the back, the scarcely fully developed crescent $(r)$ which surrounds the future genital aperture. In the middle of the back appears an odd, rather low, blunt excrescence, from which proceeds a most peculiar fixation-thread, consisting of two divisions. The first part ( $\mathrm{n}$ ) is somewhat shorter and thinner than the basal joint of the maxilliped, and its distal part is tubular; from the inside of this tube the second division comes out as a thread, which is thin in a considerable part of its length, then dilates rapidly and widely (v), forming a low collar at its widest expansion; it continues beyond the collar rather thick, in the middle somewhat thinner; this part is hollow, very light and is no doubt furnished with very thin walls, and its end is fastened to a plate of the marsupium of the host. Can this singular fixation-thread be considered as homologous with the frontal thread of other pupa? This would seem probable, though it is placed rather far backward; how it is produced is incomprehensible to me, but its distal end is very like the thread I have described in the male of Mysidion abyssorum, and its proximal part exhibits great likeness to the frontal thread in the male of Spher. Aanica. Somewhat in front of this thread, on each side, at a short distance from the ontline of the back, we see a conical process (t), which for a long time was inexplicable to me, but which I suppose must be explained as the 
antennulæ; according to this interpretation they ought to have been marked "a " in the illustration, and the antennæ not "a", but "c". Somewhat behind the fixation-thread I found a pair of bodies (z) which were situated at a short distance from each other aud looked as if they were pasted on; whether they belong to the animal I do not know, though I suppose they do, as one of the specimens was provided with both these small bodies, the other with one of them. The hindmost part of the body and a sinaller part of the surface surrounding the large ventral process, are provided with a number of rather short hairs.

Fig. $1 \mathrm{c}$ in $\mathrm{pl}$. XII shows the stage of development which immediately precedes the afore-described stage. The only specimen found is $24 \mathrm{~mm}$. long; the scale of enlargement is like that of the last stage. The body has about the same shape, and the mouth, the maxillulæ, maxillæ (f), maxillipeds (g) and antennæ (a) have a similar structure and position; but the antennule (t) are placed further backward than in the more advanced stage, almost behind the middle of the animal; their form is somewhat vague. The dorsal fixation-thread ( $\mathrm{u}$ and $\mathrm{v}$ ) proceeds at some distance behind the middle of the median line of the back; it is almost constructed as in the older stage, but is considerably longer, and its distal part is much less stout. The crescent of the genital aperture $(r)$ is not found on the dorsal, but on the ventral surface, near the posterior extremity of the body. The odd ventral process $(\mathrm{x})$ is situated almost in the middle between the base of the maxillipeds and the posterior end of the body; it is rather short and very stout and broad; it is indeed a projection, which has on its top a well-developed mouth (y) with mandibles, and whose sides and front part are provided with chitinous lists, like those which surround the mouth of the pupa in the group Sphrer. Lenckartii; on the side this skeleton forms a figmre (y'), which, seen as in the drawing obliquely sideways, looks very much like a maxillula; however, on closer examination it turns out not to be any appendage. Now we should feel much inclined to think, that the pupa just described does indeed represent an animal provided with an apical month in the act of breaking out of the skin of the pupa, the mouth of which is marked "y», however, repeated and careful examinations of the admirably preserved pupa, which I have been able to roll under a glass-cover, and to study from all sides, give the result, that it is really an animal with a larger apical and a smaller, but very well developed. ventral mouth, the latter of which disappears in the following stage, only leaving the odd ventral process $\mathrm{x}$ in fig. $1 \mathrm{~d}$. That the existence of two months in the same animal is perfectly incomprehensible to me, goes without saying. - The whole animal is naked.

Finally I have found two badly preserved, infinitety small pnpæ of about equal size, one of which is illustrated in $y^{l}$. XI, fig. $3 \mathrm{i}$. The body is $136 \mathrm{~mm}$. long, shortly ovate, with a well-developed month at the rather pointed front extremity, and a little more backward on the ventral side maxilla and maxillipeds, the former of which being of pretty good size, but with thin walls and of a somewhat vague form, whereas the maxillipeds are almost smaller than the maxillæ, 2-jointed, and very weak. Beneath the skin, between the maxillæ, is seen a pretty large, anteriorly inflexed ring $(x)$, which seems to be the beginning of a 
month. The pupa appears to have been attached by a dorsal thread, as in the preceding stage, however, it is too badly preserved to allow of a more precise definition. I am unable to give any more details about this stage; I do not see at all how it can be an earlier stage in the development of the female, and consequently be followed by the two above-described stages; so it may possibly be a male pupa; however, it must be left to the fiture to solve these and other problems in the remarkable development of Mysidion commune.

I have now communicated in detail all I know about the post-larval development of the forms of this family. Being unable, on account of the great gaps, to generalize very much, I have preferred to collect all I know in this place, instead of contenting myself with making a shorter extract and distributing the greater part among the forms in question in the later systematic representation. Though I think I have found a series of rather interesting facts, this is only the begiming of a complete elucidation of the very peculiar metamorphosis of these animals with their extraordinary variations in the different species. It would indeed repay the trouble to carry out such an investigation in numerons representatives of this family, but it would at the same time present enormous difficulties, on account of the nature, as well as of the rarity, of the material.

\section{B. Habitation, Biology and Distribution.}

\section{a. The Place of the Hosts in the System and the Habitation of the Parasites.}

Of the forty-three species examined by me, two (the genus Choniostoma) live in the branchial cavity of two species of the genus Hippolyte Leach, which belongs to the tribe Caridea of the order Decapoda; two species (the genus Homocoscelis), live in the branchial cavity of two species belonging respectively to the genera Diastylis Say and Iphinö̈ Sp. Bate, which two genera belong to widely differing families of the order Cumacea; one species (the genus Aspictoecia) lives on the outside of the body (on the carapace, on the back and the sides of the last free thoracic segment and of the six first abdominal segments, as well as on the eye-stalks) of the species of the genns Erythrops G. O. Sars, which belongs to Mysidæ veræ. All the remainder - thirty-eight species - live in the marsupium of species belonging to the following orlers: Mysidacea, Cumacea, Isopoda and Amphipoda; however, their distribution within these orders is rather interesting. In Mysidacea I have only found two species (the genus Mysiltion) on the genera Erythrops G. O. Sars and Parerythrops G. O. Sars, belonging to Mysidæ veræ, and the three species on which they are found live - according to G. O. Sars - in a depth varying from 30 to 300 fathoms. An examina- 
tion of a very large material of Danish species of the genus Mysis Latr. (sens. Sars in 1879), and of Macropsis Slabberi (v. Ben.), as well as of a number of specimens of Gastrosaccus Norm. -- all shallow water species, - gave a negative result, neither did I find any parasite on numerous specimens of a species of Mysidæ taken in shallow water in the WestIndies, nor on a great number of specimens belonging to two pelagic species of the genus Siriella Dana. In Cumacea I have found altogether five species of the genus Sphcronella on six species belonging to the genera Diastylis Say, Eudorella Norm. and Iphinoë Sp. Bate, which three genera belong each to one of the eight families established by G. O. Sars, whereas an investigation of numerous other species, among which a very large material of several species which were taken in Denmark in very considerable quantity, as Cuma scorpioüdes (Mont.), Lamprops fasciata G. O. Sars, Leucon nasicus $\mathrm{Kr}$. Leucon nasicoüdes Lilljbg., Leucon acutirostris G. O. Sars, Eudorellopsis deformis (Kr.) Diastylis resima ( $\mathrm{Kr}$.) and Leptostylis ampullacea (Lilljbg.), gave a negative result. Within the order Isopoda, these parasites - altogether three species of the genus Sphceronella - are only found in two species of the genus Janira Leach and in Munnopsis typica M. Sars, all three forms belonging to the large tribe Asellota, whereas an investigation of numerous forms belonging to other families, among which some species of Idothea F., Astacilla Cordiner, and Gnathia Leach, were represented by a great number of specimens, gave no result. (Of the small order Tanaidacea I have examined a good number of specimens from Denmark and numerous specimens of several species from Sicily, without finding a single parasite). The chief quantity of the parasites, namely twenty-eight species (the genus Stenothocheres and about three quarters of the genus Sphoronella), were found on Amphipoda, and within this order exclusively on Gammaridea (on twenty-eight species). An inspection of a great number of specimens of different species of Caprellidæ and of some specimens of Cyamidæ gave no result. (Among the material from the "Ingolf « expedition I found in 1895 on an F Egina Kr. a species, which will be described in the report on the results of this expedition). Of Hyperiidea I have only examined a few species. In giving a short general view of the occurrence of the parasites within the Gammaridea-group, I will avail myself of the twentyfive families adopted by G. O. Sars in his new important work: "An Account of the Crustacea of Norway, Vol. I, Amphipoda"; they are found in one or more representatives of the following fourteen families: Pontoporeiidæ (the genera Bathyporeia Lindstr. and Argissa Boeck), Ampeliscidæ (the genus Ampelisca Kr.), Amphilochidæ (the genera Astyra Boeck, Amphitochoides G. O. Sars and Gitanopsis G. O. Sars), Stenothoidæ (the genera Stenothoë Dana and Metopa Boeck), Oediceridæ (the genus Perioculodes G. O. Sars), Paramphithoidæ (the genus Paramphithoë Bruz.), Epimeridæ (the genus Acanthozone Boeck), Syrrhoidæ (the genus Bruzelia Boeck), Calliopiidæ (the genus Calliopius Lilljbg.), Atylidæ (the genus Paratylus G. O. Sars), Gammaridæ (the genus Cheirocratus Norm.), Photidæ (the genera Lemboides Stebb., Protomedeia Kr., Leptocheirus Zadd., Gammaropsis Lilljbg. and Microprotopus Norm.), Corophiidx (the genus Corophium Latr.) and Dulichiidæ (the genus Dulichia $\mathrm{Kr}$.). Of the remaining eleven families the 
majority are small, with one or very few genera and rather few species, but the family Phoxocephalidæ is pretty considerable, the family Podoceridx is large, and the family Lysianassidx is exceedingly large (in Sars' work thirty-three genera), wherefore it seems interesting to me that no parasite of our Choniostomatidx has been found on any species belonging to these families. One species was found in the Mediterranean in the genus Microdeutopus Costa, belonging to the Photidæ, another species has been quite recently discovered in Cyclaspis G. O. S., belonging to the family Cumidx, and these genera are the only two mentioned in the literature of the subject, in which I have not personally observed the parasites of this family. To give an account of the forms the examination of which led to no result, would be too tedious, neither would it prove much; I will only say that $I$ have examined a good number of exotic species, most of which were only represented by a few specimens, besides nearly all of the large material our museun possesses of Gammaridea from Denmark, Greenland and the Kara Sea, and many of these species were represented by from fifty to hundreds of specimens. In F. Meinert's three papers, of 1877, 1880 and 1890 respectively, about Danish Malacostraca, and in my own similar papers about the fauna of Western Greenland and of the Kara Sea, will he found the names of most of the northern and arctic species examined, of which I have had a large material.

In a later paragraph I shall mention a little more in detail the following phenomenon which stands in a certain connection with the matter above, namely, that of several species a considerable material from a large sea can be examined without showing a single parasite, whereas sometimes a smaller material of the same species from another sea reveals several parasites. This proves that we cannot conclude that a species is not infested, from the fact that an investigation of hundreds of specimens from different localities of a certain country has not led to the discovery of any parasite. In most cases such examinations must be undertaken on a much larger scale than I have been able to do, before any valne can be attached to the negative results.

\section{b. Age and Sex of the Hosts.}

It serves our purpose best to divide the hosts into two sections according to their parasites, viz. whether the typical residence of these animals is in the marsupium or in other places. I will begin by the latter section, repeating my above statement that I only have examined five species of parasites which do not live in the marsupium.

Aspidoecia Normani, which, as has just been said, lives on the outside of the body of species belonging to the genus Erythrops, I have found on young specimens as well as on adult males and females, but in the latter the narsupium was either empty, or occupied by a species of the genus Mysidion. The two species of the genus Choniostoma live in the branchial cavity of two species of the genus Hippolyte. From the Kara Sea I have seen 
altogether seven infested specinens, four of which were adult females without eggs, and each of these females was infested with one adult parasite, three of which having laid numerous ovisacs; two of the hosts were males: one was an adult infested with a parasite with numerous ovisacs, the other was a little smaller with eight smaller parasites; and finally, the seventh host was a female with eggs containing half-developed young ones, on its right side was an empty swelling on the carapace about two thirds of the normal size, on the left side a very small and quite young female, and besides numerous larvæ and pupæ hinged on the gills. - The two species belonging to the genus Homoeoscelis live in the branchial cavity of two species of Cumacea; of one of these: Iphinö̈ trispinosa (Goods.), I have seen seven infested specimens: one female, whose marsupium contained a Sphreronella, three not quite full-grown females, one of which - whose marsupium was in an early stage of development - was infested on one side with a female, a male, and eight ovisacs, in one of which were full-grown larvæ. The three last specimens were a male before the last moulting and two adult males, one of which with an adult female and two ovisacs, a young female and a male in one branchial cavity, the other containing only a half-grown female. Of the other species, Diastylis lucifera (Kr.), I have seen sixty-six infested specimens - most of them females, in at least three cases young males, but not a single adult male, though this last circumstance is of less weight than might be expected, as our naturalists have neglected to throw out the surface-net at night and in the evening in order to catch the full-grown roving males. About three fourths of the females had a well-developed marsupium; in more than two thirds of these it was empty, but in at least thirteen cases is was filled with half or fully developed young ones, never with eggs. Females which had not yet begun laying eggs appeared in females of Diastylis with young ones in the marsupium, as well as in specimens without marsupium; there were found likewise female parasites with the full number of ovisacs in females of Diastyls with young ones in the marsupium, and in younger specimens without marsupium. - In a subsequent paragraph I shall have an opportunity of entering into further consideration of these statements; more special statistics are found in the systematic part.

We now come to the thirty-eight species which live typically in the marsupium of forms belonging to four different orders. I may say at once that the ten species which appear in Mysidacea, Cumacea and Isopoda, I have only found in perfectly developed marsupia, but it must be added that I have also constantly found at least one older female with ovisacs in such a marsupium, so I know nothing about the stage of development of the host at the time when the first (and often only) female attached itself to it as a larva; I have examined numerous specimens of Cumacea, in which the marsupium was beginning to develop itself (it appeared as small plates), but withont finding any parasite. Amphipoda presented somewhat different facts. Salensky writes about Sphar. Lenckartii (op. cit. p. 302): "Das Thier fand sich in der Bruthöhle der Weibchen und an der unteren Fläche der entsprechenden Brustsegmente der Männchen und war an den äusseren Bedeckungen des Wirthes mittelst eines besonderen Saugapparates befestigt. « By this »sucking apparatus 
the author means the rostrum, but this observation is not just, for the attachment certainly takes place by a frontal thread; moreover, I suppose that the animals Salensky took for males were in fact somewhat younger females without marsupium, founding this suggestion partly on his (otherwise bad) description of the host "Amphitoë sp.", - according to Della Valle: Microdentopus gryllotalpa Costa, — in which he does not say a word about the very great difference in the "hand « of the first pair of trunk-legs between the two sexes, partly on the fact that I have never found a Sphceronella on any adult male; whether some of the not full-grown specimens on which I found typical marsupium-parasites, were young males, I cannot tell, but I doubt it. The twenty-four of the species parasitic on Amphipoda I have found exclusively in marsupia, and though, in not full-grown animals, I may not unfrequently have overlooked larvæ, pupæ or very diminntive females, in any case I cannot have overlooked many females with ovisacs. Only in the following four species of Amphipoda: Metopa Bruzelii (Goës), Argissa typica Boeck, Protomedeia fasciata $\mathrm{Kr}$. and Ampetisca tenuicornis Lilljbg:, have I found parasites in specimens without or with half-developed marsupium. In a specimen with scarcely half-developed marsupium of Metopa Bruzelii, two larvæ were found, and in a still younger one without marsupium, a single larva. In two young females without marsupium of Argissa typica appeared respectively one pupa and a tiny female of Sphar. Argissa. In a young specimen of Protomedeia fasciata Kr., from Greenland, were found a not half-grown female and a male of Sphar. Bonnieri. Sphcer. longipes I found in nine specimens of Ampetisca tenuicornis; two of these only were females with fully developed marsupium. the third was a young female with half-developed marsupium, which contained a not half-grown female of the parasite; the six remaining specimens were young, without marsupium, and on each of the five of these I found a single female between not half-grown and very small, - in one case even recently hatched; in the sixth specimen there were only two Joose larvæ. The result hereof is, that in Amphipoda I have not found a single adult female in a specimen without entirely developed marsupium, and never ovisacs except in marsupia. It is probable that larve not unfrequently fix themselves to immature females, beginning their development there, and thus entailing the necessity that larvæ as well as young females, and rarely males, remain on the host, while it passes through its last moultings; however, as said above, not a single observation has been made of ovisacs being found in females not fully developed, which by the by, seems natural enough, as they would certainly be washed away, if they were laid. However, I cannot prove that most specimens are infested before the marsupium is fully developed. No doubt, the larvæ seek either perfectly mature females - and at least rather often those whose marsupium is already infested by at least one (half-grown or quite adult) female and a male -, or such younger specimens as are so far advanced, that they will have got their marsupium before, or at the time when the females that have developed themselves out of some of them, are ready to begin laying eggs. Whether the larvæ of species that live in 
the marsupitum of Isopoda, Cumacea and Mysidacea sometimes, or often, fix themselves to not full-grown females, I repeat, I cannot tell.

I will add that in three cases (in Ampelisca tenuicornis, Protomedeia fasciata from Denmark, and in the same from Greenland) I found in the marsupium, together with one female Spheronella without ovisacs (in two cases a male attached to it), four to six of the Amphipod's own eggs, in one case with half-developed young ones. In the marsupium of an Ampetisca typica I found a large female and two ovisacs of Spher. microcephala and two of the Amphipod's own eggs. In Eudorella truncatula I found one of its own eggs together with an adult female, three ovisacs and a male; in another specimen were found no less than twenty-four of its own eggs together with an almost adult female and two larvæ which were invaders.

\section{c. Number of Parasites on each particular Host.}

In the systematic part of this work I give a kind of statistics of each species, accounting for my findings, and giving numerous data concerning the number of each sex, of the ovisacs and the stages of development found on each particular host. Of this considerable material I put down some extracts here, which will give a condensed view of this matter. Of Aspidoecia Normani which lives fixed on the outside of Erythrops, I have often found one or several females of very different sizes on the same host, in one case as many as six females with ovisacs, three younger females and one larva on one single specimen. In a large material of Diastylis lucifera with Homoeoscelis minuta in the branchial cavity, I have never found more than one female, as a rule only one male, very seldom two males on one specimen, whereas of Iphinoë trispinosa, infested with Hom. mediterranea, only four specimens have been thoroughly examined by me; one of these had two females, six ovisacs and two males in the same branchial cavity, one had an adult and a young female, two ovisacs and a male in the same branchial cavity, one carried a male in one branchial cavity, a female with eight ovisacs and a male in the other. Of the species of Choniostoma which live in the branchial cavity of Hippolyte, I have found only one specimen of an adult female on a host, whereas of younger female parasites one specimen contained three in one branchial cavity, five in the other; in another specimen I saw an empty swelling covering one of the branchial cavities, whereas the other contained one female which was far from half-grown, besides certainly more than fifty larvæ and pupæ hinged on the gill-fibres; however, I doubt very much whether most of these would have been able to develop themselves into adult females (and perhaps males) on this shrimp; it seems to me rather doubtful that the animal should be able to afford the nourishment required, and still more so whether the parasites would find sufficient room to grow.

In the parasites living in the marsupium we find the greatest differences as to the numbers of them on one host, but at the same time it must be observed that while 
some species as a rule only contain a single female and a male, sometimes two males and seldom two females in the same marsupium, in other species we pretty frequently find two, three, or more females and several or many males on the same host. Of twenty-six out of twenty-eight adult specimens of Metopa Bruzelii (Goës) infested with Stenothocheres egregius which were examined and noted, there were found only one female and frequently also one, seldom two males on each specimen; in one specimen were found only eggs and young ones, in one two females and no male. In Cumacea and Isopoda the marsupium never contained more than one female, often also a male, sometimes two, and in a single case three males, besides, in one case I found one pupa, in another, where no male existed, some invading larvæ. In Mysidacea some deviations are observed; of adult females we very rarely find more than one specimen, but rather frequently also one or two young females or tiny young ones which have not gone through the whole metamorphosis, besides frequently one or more, in one single case even ten males; (as for further details, s. statistics in the systematic part). In one specimen of Erythrops serratus there had lived at least three females with ovisacs and one male. Several Amphipoda infested with species of Sphoronella as a rule only show one single female (with one or two males), others not unfrequently two or three females, mostly of somewhat different age, but here I will mention some cases of peculiarly abundant invasion. In one specimen of Calliopius laviusculus (Kr.) were found one female with eight ovisacs and five males, in another specimen six females with twentyfive ovisacs and two males, but the richest finds were supplied to me by Sphrer. paradoxa in species of Bathyporeia. In one specimen I found one large female, two small females, no ovisacs, eight males, four broad larvæ, sixteen »male pupæ« and one semale pupa ; in another specimen four females of widely differing size, four ovisacs, eight males, two larvæ and one "male pupa«; in a third animal three large femules, two very small females, three ovisacs, two larve and seventeen males, the largest number of the male sex I have ever found. - The result of a large infestation is that the marsupium of the host swells to the same extent as if it were filled with its own half or almost fully developed young ones.

\section{d. Number of Species of Parasites on the same Species of Host.}

On most species of hosts I have only found a single species of Choniostomatidx, yet in several cases I found two species of parasites, now of the same genus, now of different genera, on the same species of hosts, sometimes even on the same specimen; nay I have happened to discover three species of parasites, not only on the same species, but on one single specimen. As the particular cases are interesting in several respects, I will enmmerate them here. On Metopa Bruzelii from Godthaab (through a renewed examination with the assistance of Sars's new important work, I have made sure that all infested specimens really belonged to this species, and not partly to Metopa sinuata G. O. Sars) were found in the marsupium of specimens from the same locality, now Stenothocheres egregius, 
now Spheronella Metopre, but never both forms in the same specimen. In a large material of the same host from another Greenlandish locality appeared a number of specimens of the former, not one of the last-mentioned prasites. On specimens of Hiynolyte Gaimardii M.-Edw. from the Kara Sed appeared now Choniostoma mirabile, now CH. Hansenii, and the latter species was also found in Hipy. polaris (Sab.) from the same sta. In Danish specimens of Ampetisca tennicomis Lilljhg. I have found Sytharomella longizus; whereas Giard and Bonnier have found in specimens of the same species from le Croisic (Brittany) the very deviating Splari. mirioctphala. Danish specimens of Protomedeia fasciata Kr. were infested with Sphar: Giardii, and Greenlandish specimens with the closely related species Spher. Bonmievi. On a specimen of Iphinö̈ trixpinosa (Goods.) from Messina Homoeoscelis mediterranea was found in the branchial cavity and Sphcronelle marginate in the marsupium. In Norwegian specimens of Erythrops serratus G. O. Sars and Erythrops abysorum G. O Sars we not unfrequently find a species of Mysidion in the marsupium, and one or several specimens of Aspidoecia Normani on the ontside of the body of the same species. In one specimen I found two specimens of the latter species on the outside of the body, an adult and a young female of Mysidion abyssorum, and a young female of Mys. commune in the marsupium, which makes three species of parasites on one animal.

\section{e. Number of Species of Hosts of the different Parasites.}

The answer to this question presupposes the answer to another, namely that of the limitation of the parasitic species, and as this latter question is not treated in detail till later on in a separate chapter, I will content myself with mentioning the results of this examination, using them in answering the question indicated by the heading.

Twenty-nine of my species, as a matter of fact, are only found each on one particular species. Of the remaining fourteen species eight (belonging to the group of Sphar. Leuckartii) are also limited each to one particular species; however, it may perhaps be questioned whether these eight species can really be maintained as such, or must be regarded as chance varieties of a single species (see later on). The remaining six species must be mentioned each separately. Choniostoma Hansenii has been ascertained in two species: Hippolyte Gaimardii M.-Edw. and Hippolyte polaris (Sab.). Of Sphceronella insignis indeed I have only had a small material which was taken on Diastylis cornuta Boeck and Diastylis lavis Norm.; however, the difference between the parasites of the two species was so slight, that my experiences from other species led me to consider them as belonging to one species. The species found by Giard and Bonnier on Ampelisca tenuicornis Lilljbg. from le Croisic, which they have described under the name of Spher. microcephala, as far as I can see, is identical with the species described by me in this work under the same name, and this is taken on Ampelisca typica Sp. Bate in Danish waters. Spharonella paradoxa I have found on Bathyposeia noveyica G. O. Sars, Bathyporeia pelagica Sp. Bate and B. Robertsonii Sp. Bate, and even if it were proved that the two 
last-mentioned cannot be maintained as separate species, but must be considered as one, at any rate this parasite has been taken on two good species of the same genus. But now we come to a remarkable fact, viz. that three adult females have been taken on three specimens of Perioculodes longimanus (Sp. Bate) belonging to a different family altogether, and these females I have not been able to distinguish from those taken in Bathyporeia. If some day the male of the parasite is found in Perioculodes, probably the interesting question will be settled, whether the same parasite can be found in animals belonging to such widely differing families. Mysidion commune I have found on the following three species: Parerythrops obesus G. O. Sars, Erythrops serratus G. O. Sars and Er. abyssorum G. O. Sars; moreover, it seems likely that it will be found in some other species of Erythrops living in Norway. Finally, I will state as my opinion that the parasites living on all five Norwegian species of the genus Erythrops, belong to the same species: Aspidoecia Normani.

I will sum up by stating what I consider as an established fact, namely that several species of Choniostomatidæ live each on two or more species of the same genus or of two closely related genera, probably even to a considerably greater extent than I have been able to ascertain; perhaps, in exceptional cases, they may be found on animals of different families. On the other hand, I certainly think with regard to several species, that each of them infests only its particular species of hosts, and this result exactly agrees with what is known about the biology of other parasitic families belonging to Arthropoda. Only with regard to Epicaridea, Giard and Bonnier have made the assertion that each parasite has its particular host and is found on no other species, an assertion which $I$ think is incorrect, seeing that this division also comes in under the rule which applies to Choniostomatidæ ${ }^{1}$ ).

\section{f. Occurrence together with Parasites of other Orders or Classes.}

In nearly all orders of Malacostraca have been found species of the group or family Epicaridea belonging to Isopoda. Giard and Bonnier have expressed the opinion that there exists a certain connection between Choniostomatidæ and Epicaridea; but this objectionable hypothesis I have mentioned above in detail (p. 11-12), and at the same time I have stated all I know from my own experience and most of what has appeared in literature about the occurrence of Epicaridea on the species which, according to our present knowledge, are infested by Choniostomatidæ. I have written that of Cumacea, Isopoda and Amphipoda together, I have seen about 240 specimens belonging to thirty-eight different species infested with Choniostomatidæ, but that neither in any of these 240 specimens, nor in any other of the thousands of animals belonging to these thirty-eight species, have I found one single specimen of any Epicarid. In Italy Della Valle has found two specimens of Ampelisca

2) It may be added here that in my treatment of the Malacostraca from the "Ingolf"expedition I shall give more detailed information about the arctic Epicaridea. 
diadema Costa infested with a species of Spharonella (S. diadema Giard and Bonnier, withont description) and two other specimens of the same Amphipod with Podascon Della Vallei Giard and Bonnier. Of Decapoda there have only been found as yet Choniostomatidx on Hippolyfe Gaimardii M.-Edw. and on Hipp. polaris (Sab.); both these species, we know, are not unfrequently infested, either with Hemiarthrus abdominalis (Kr.) under the abdomen, or with Gyge Hippolytes $(\mathrm{Kr}$.) in the branchial cavity. In a specimen infested with Choniostoma J. Sparre Schneider has observed a specimen of Hemiarthrus, and on a specimen of Hipp. Garmardii, under a large swelling on the right side of the animal, I have found eleven ovisacs and an adult female of Chon. Hansenii: as well as an adnit male and a tiny female (smaller than the male) of Gyge Hippolytes, and besides, under the apparently normal left side of the carapace, a male of Gyge. In the species of the genus Erythrops (order Mysidacea), G. O. Sars has found the Epicarid Aspidophryxus peltatus G. O. S., and Giard and Bonnier have reserved this name for the form found on Er. erythrophthalmus (Goës) (E. Goësii G. O. S.), and established a new species, $A$. Sarsii G. and B., for the form which lives on E. microphthatmus G. O.S. Giard and Bonnier have found their type specimens of the latter species (the value of which future examination will have to decide) on the same specimen as their type specimens of Aspidoecia Normani, and I have found a specimen of Aspidophryxus on an Er. erythrophthalmus sent to me by Prof. Sars as infested with Aspidoecia, but this parasite must have fallen off before the animals were sent to me, if it was ever there at all.

The genus Sylon Kr., belonging to Rhizocephala, lives, as we know, on the ventral side of the abdomen in some species of Hippolyte, but I have not found it on any specimen infested with Choniostoma. The remaining species belonging to Rhizocephala and Copepoda, which are parasitic on Malacostraca, have all been taken on forms on which no Choniostomatidæ have been found.

Together with Sphreronella paradoxa I have found repeatedly in the marsupium of Bathyporeia several specimens of a species belonging to the family Tyroglyphidæ (the order Acarida).

Of other parasites I have only detected some Protozoa on the branchiæ and the marsupial plates in the material of Malacostraca with Choniostomatidæ examined by me.

So I have arrived at the result that there exists no connection at all between Choniostomatidæ and any of the other parasites of different orders found on the same species of hosts.

\section{g. Nourishment.}

I cut a bit of skin of an Erythrops in the place where an Aspidoecia had been attached, cleaned it with caustic potash from muscles and viscous substance, and discovered a small hole, where the mouth of the parasite had its place. And this seems very natural indeed; in the first place, the mandibles appear quite well qualified for producing such a hole; secondly, the mouth is doubtless suctorial, and lastly, the female, which is permanently 
attached, must draw her nourishment from the host in order to be able to grow to a bulk which, adding its own volume after having finished laying eggs, to that of the eggs it has produced, is frequently hundreds of times larger than the volume of the larva at the time when it attached itself, and after having fixed itself it is impossible for the animal to procure the nourishment necessary for this enormous growth in any other way than by a hole worked through the comparatively solid skin of the host, whose blood must form the food of the parasite.

Hereby we have found a fixed starting-point in this question, and it is more than probable that the females of all the other Choniostomatidæ also grow and nourish themselves by sucking the blood of their host through a hole they have gnawed. At the same time, it seems rather probable that the females of many of these species, either voluntarily or involuntarily, e. g. by pressure of another specimen, or by the bulk of ovisacs, are pushed out of their place and have to gnaw a new hole for themselves. I have frequently found a female in such an attitude relatively to some of the ovisacs it had laid, or the ovisacs arranged in such a manner as to make me suppose that the animal had changed place.

How far the males of this family take food, I do not know, but as their mouth is as well developed as that of the females, it seems likely that they do it while young, and perhaps not when they are old (about their growth, s. above on pag. 57-58). I consider it rather doubtful whether the larvæ take food, but I am quite certain that the pupæ, which are provided with a mouth, and about whose considerable growth several facts have been stated above, nourish themselves in a way similar to that of the females.

\section{h. The Influence of the Parasites on their Hosts.}

Giard and Bonnier have proved that parasitic Crustacea of different groups (as Entoniscinæ, Rhizocephala) cause a »castration parasitaire in their hosts. In the last of their papers quoted above they mention Della Valle's untenable hypothesis that Spharonella eats the eggs of its host, and they maintain that this suggestion is wrong, and that this is also a case of "castration parasitaire", after which they continue: "Dans des cas très rares, l'hôte ayant été infesté tardivement, cette action [namely the castration] ne s'exerce pas aussi énergiquement, et quelques oeufs peuvent être pondus et fécondés, comme nous l'avons vu une fois chez Clypeoniscus a genus belonging to Epicaridea which they have treated in the same paper, and which they use as example and parallel], mais ce sont la des exceptions. En général, l'hôte est infesté avant qu'il ne soit arrivé à l'état adulte. Sous l'influence du parasite, son développement génital est arrêté sans que la croissance discontinue, de sorte qu'à l'époque où devrait se produire normalement la maturité sexuelle, la progéniture légitime est remplacée par le parasite et les embryons de celni-ci«. This explanation, on the whole, agrees well with the numerous data which I have given above on $p .65-68$ in the division about the age and sex of the hosts, from my observations about my thirty-eight species 
which live in marsupia. In the afore-mentioned place it is stated that only in six cases I found the eggs of the host together with a parasite, and it may be added here that in almost 160 cases I only found parasites (one or more specimens), but no eggs of the host, in the marsupium. But at the same time I have stated that I have found no parasite on any specimen of Cumacea or Isopoda in which the marsupium was wanting, and of Amphipoda I have only found altogether twelve specimens belonging to four species, whose marsupium was either wanting or only half developed, and on which, nevertheless, I found parasites; all these, without exception, were half-mature or tiny females, or larvæ (one male). However, this material is too small to allow me fully to adopt the opinion of the authors that the host »en général is infested before its maturity; in the fully developed marsupium of several specimens of Corophium crassicorne Bruz. I have found only a half-developed or still younger female and either a male, a larva, or a pupa, but no adult females. But it is certainly an established fact that, as a rule, we notice a "castration parasitaire in the hosts which have parasites in their marsupium.

It is much more doubtful whether the four species living in the branchial cavity of Hippolyte and Cumacea, are usually, or sometimes, capable of causing a castration parasitaire of their hosts. In page 66 , and particularly later on, in the systematic part, detailed information is given about the age and sex of these hosts, but $I$ do not think we can draw definite conclusions from these statements. I have said that I have found specimens of Diastylis lucifera containing a female of Homoeoscelis with the full number of ovisacs in the branchial cavity, and the young ones of the host in the marsupium, but knowing neither the time required for the development in the marsupium of the eggs and young ones of the host, nor the time required by the parasite for its own growth and the laying of all its ovisacs, it seems impossible to me to draw a definite conclusion with regard to a "castration parasitaire «; however, that such a castration may take place, seems to follow from the above-stated fact that the marsupium of more than two thirds - namely thirty-one of the infested adult females was empty, whereas in thirteen specimens it was filled with young ones; yet it must be observed that in the non-infested females, the marsupium was found to contain eggs or young ones in 182 specimens, whereas it was empty in 74 specimens. It is rather probable that Aspidoecia Normani causes a castration, as the marsupia of the four infested females which were not occupied by Mysidion, were empty.

The four species living in the branchial cavity of Hippolyte and Cumacea cause a swelling of the carapace of the host, which, to begin with, increases in size with the growth of the parasitic female, and thus - at least in Cumacea, and probably also in Hippolyte continues gradually increasing with the number of ovisacs. In Hippolyte the swelling may reach the same size as if it enclosed a large Gyge, and in the subsequent description of Choniostoma Hansenii, it will be proved that this parasite itself produces the swelling. In Diastylis lucifera the swelling assumes a somewhat other shape, though it may be very conspicuous. 
Finally it may be added, that in those specimens of Hippolyte in whose branchial cavity was found an adult female with ovisacs of Choniostoma, the gills belonging to the two foremost pairs of trunk-legs were either somewhat reduced, or had quite disappeared, and in one case the three other gills situated more behind appeared a little curled, as a sign of degeneration. In one specimen, which was infested with several smaller females, the gills were slightly curled.

\section{i. Geographical and Bathymetrical Distribution of the Family.}

Of the forty-three species described here, sixteen come from Denmark, and one of these was also found at le Croisic; eight are from Norway, eight from West-Greenland, and two of these also in the Kara Sea, three only from the Kara Sea, besides the two which are also found in Greenland, four from Sicily, two from the Pacific near the East-coast of Asia, one from the Cape, and one from the West-Indies. It may be added that in the most northern part of Norway and in the Barents Sea there has been found an undetermined species of Choniostoma, though no doubt one of those which occur in the Kara Sea, that one species (Sphreronella Leuckartii Sal.) was taken at Naples, another species (Homoeoscelis sedentaria (Bonn.)) in the Atlantic off Gascogne, and besides, a non-described Spher. diadema G. and B. in the Mediterranean. Without counting Norway, whose species - with one exception - have been discovered and sent me by Prof. G. O. Sars, the number of species from the different countries and seas is nearly proportional to the material which our museum possesses of Amphipoda and Cumacea - the two orders in which most parasites have been found - from the same localities. From this fact we can pretty safely draw the conclusion that the examination of a manifold larger material than was at my disposal, e. g. from the Mediterranean and from eastern Asia, will bring numerous unknown forms to light. The above statements also suggest the probability that the family is distributed over all seas, though of course I cannot form any precise notion how far its geographical distribution will extend, when some day the chief bulk of the existing species has been discovered, for, as stated in the preface, I think there can be no doubt that their number amounts to hundreds.

Unfortunately I am not prepared to give many data concerning the bathymetrical extent of my species, for in most cases I lack precise indication of the depth in which the special hosts have been found. Most of the sixteen Danish species and four species from the Mediterranean were taken in a depth of between a few and twenty-five fathoms, but unfortunately I cannot state precisely in how shallow water the most littoral species is generally found, or may sometimes be found; it may be stated, however, that a specimen of Bathyporeia with its parasite, Sphceronella paradoxa, was taken in a depth of between eight and eighteen feet. Stenothocheres egregius was taken in a depth of forty fathoms, a few specimens in a depth of between forty and sixty fathoms; my only specimen of Sphcer. 
curtipes came fiom a depth of a hundred fathoms. Possibly a large part of the specimens of the three forms which live on Mysidacea were taken as far down as one to two hundred, some even to three hundred fathoms, but as the hosts in question may occur in a depth of less than a hundred fathoms, I cannot say anything definite about them. So it may be stated here, that in the material from the sIngolfexpedition I found a couple of specimens parasitic in Cumacea, from a depth of respectively a thousand and thirteen hundred fathoms. which sufficiently proves that the family also occurs in a very considerable depth.

\section{j. Geographical Distribution of the particular Species relatively to that of their Hosts.}

It appears from the preceding paragraph that each of the forty of my species was taken in one particular country (as Denmark, Norway, Sicily etc.), or in a particular, comparatively smaller sea. Only three species (Sphceronella microcephala, S. decorata and Choniostoma Hansenii) show a wider distribution. As a matter of course, we shall gradually find that most species of Choniostomatidæ have a much wider range than is known at present, but from this I do not think we can draw the conclusion that they are as widely dispersed as the species on which they live. In a smaller material of Iphinoë trispinosa (Goods.) from Messina I found seven specimens with parasites, one specimen even with two parasitic species, but in a larger material of the same species from Denmark I have been unable to find a single parasite. In a pretty considerable material of Calliopius lcviusculus ( $\mathrm{Kr}$.) from the East-coast of Asia between lat. $40^{\circ}$ and $51^{\circ} \mathrm{N}$. I found seven specimens with parasites (Sphcronella Calliopii), but my examination of several specimens from West-Greenland, and numerous specimens from Denmark, gave a negative result. (Yet it must be mentioned that Sars, in his work on the Amphipoda, considers the Danish specimens to belong to another species, Call. Rathkei (Zadd.), but I doubt whether this will be maintained in the future). Several specimens of Hippolyte Gaimardii M.-Edw. from the Kara Sea were infested; at the most northern coast of Norway, Sp. Schneider, and at West-Greenland E.Vanhöffen, have found Choniostoma in the same species, but I have examined without result a very large material of the same Hippolyte collected from numerous localities near the Danish coast, and I feel inclined to think that these parasites do not occur in the waters surrounding this country. The same may be said about Diastylis Rathkei (Kr.), of which in about half of the females with marsupium from West-Greenland and from the Kara Sea, I found Spheronella decorata, whereas of the same species from different Danish localities I have examined at least several scores of adult females without finding any parasite.

\section{k. Frequency of the Parasites in proportion to their Fertility.}

In mentioning the eggs of the parasites, I pointed out (p. 46-47) the enormous difference of fertility between the species with very small and those with very big females. Of 
Hippolyte Gaimardii M.-Edw. I have had a large material from the Kara Sea, and one of similar size from West-Greenland; in the former I only found six infested specimens: four with Choniostoma miralile, two with Ch. Hansenii; in the latter I found none at all, though a few specimens of $C h$. Hansenii have been discovered there at least either on $H$. Gaimardii or on $H$. polaris. On the latter species I found one Ch. Hansenii from the Kara Sea and one Chon. sp? from the coast of West-Greenland, though H. polaris is not unfrequent in the former, and of common occurrence in the latter locality. This shows distinctly enough that the genus Choniostome with its two very large and particularly fertite species is pretty scarce in the Kara Sea and rare in West-Greenland. Most of the middle-sized and rather small species of parasites I have found in between very few and about seven specimens of their respective hosts, though my material of the latter was frequently very rich. Only of two parasites: Stenothocheres egregius and Homoeoscelis minuta have I found a great number of specimens in a large material of their respective hosts: Metopa Bruzelii (Goës) and Diastylis lucifera (Kr.). The first-mentioned parasite is the least prolific of all my species, and the second, in this respect, comes nearest to it among the species of which my material of infested hosts was sufficiently large; moreover, the hosts came from several localities. That the number of parasites cannot be determined only by the number of infested hosts, has been proved above, as of some species, e. g. the two afore-mentioned: Stenothocheres egregius and Hom. minuta, we seldom find more than one female and one male on each host, whereas on others we pretty frequently find several females and males as well as pupæ in one host, but the only parasite of which, from the last-mentioned reason, I have found as many specimens as of the above-named species, is Sphoronella paradoxa (living on Bathyporeia, a genus of very frequent occurrence in Denmark); it belongs to the smaller species and, as it seems, does not lay more than four of five ovisacs, which are comparatively large. All these data decidedly point in one direction, but considering the insufficiency of my material, I will take good care not to lay down any rule or law which might possibly not prove quite tenable, and I will content myself with suggesting the direction. We might feel inclined to suppose that the conditions of life of most of these parasites are pretty similar, and that consequently the most prolific species would occur most frequently, the more so, as there is such an enormous difference in their fertility, that a species like Choniostoma mirabile lays at least more than three hundred times as many eggs as Stenothocheres egregius; however, the above-mentioned examples prove in a striking manner that such a conclusion cannot be drawn. Consequently there must be circumstances to account for the fact that the two least prolific species: Sten. egregius - taken in two localities - and Hom. minuta taken in several, probably in many places at considerable distance from each other - occur much more frequently than the prolific and very prolific species. An explanation of this fact is required, and I will attempt to explain it, at least partly. No doubt, the critical point in the life of the parasites must be the short period during which the full-grown, thongh very small, larva leave the ovisac and their mother's host in order to seek a new 
host for their own further development. and no dnutht, a considerahle numier of the larvæ of all species are destroyed while swimming about, partly because many of them cannot find their object in due time. Then again, there must be circumstances which cause a comparattively smaller percentage of the brood of the least prolific species, and an enormous percentage of the brood of the most prolific species, to be destroyed during this period. 'This, again, must be supposed - at least partly - to have something to do with the difference of the number of specimens of the species which constitute the hosts. Now, as the larvæ of the most prolific species seek large forms, those of the least prolific small forms, and as the large forms, as we know. are found on an average in much smaller number than the small forms, it follows that the larva by which they are sought, have as a rule much less chance of finding them in due time, for, as previously stated in detail. there is no considerahle difference in the structure and size of the different larvæ, -..e.g. The larva of Choniostomu mirabile is only about one eighth longer than that of Stenothocheres egregius, but, as far as I can see, scarcely so vigorous and so well adapted for swimning, (comp. the peduncles of the natatory legs in the two species; pl. I, fig. 11 , and pl. XI, fig. 1 e). - On the base of my material of parasites and of my knowledge of the biology of the hosts, I might set forth several points, thus giving a wider scope to the discussion of these matters, but for varions reasons I abstain from doing so.

\section{About Classification.}

\section{a. Limitation and Characters of the Species.}

Of small Crustacea, such as Cladocera, Ostracoda and free-living Copepoda, there are in most cases some or many specimens of each species at the student's disposal for determination of the forms, and even where these animals are so small that the compound microscope has to be used in order to determine them, most of them can stand the pressure of a glass-cover, and as a rule it is unnecessary to submit the specimens to much particular preparation, except where a description of them has to be given; finally, most species have a very fixed shape. All these factors help to facilitate the determination of the species. In Choniostomatidæ the circumstances are different. The animals are so rare, that of most species only a single specimen or a few specimens of each sex can be procured; neither males nor females can bear the pressure of a glass-cover; the males are so small, that they cannot be examined without high magnifying power, and before the examination particular care has often to be taken in placing them in the preparation, and though the females are much larger, the parts of their body which have to be investigated are exceedingly small 
and very difficult or impossible to examine in detail on intact specimens, so that in numerous cases one is obliged to undertake a difficult dissection, and to place the head and the genital area in a preparation; lastly, the general form of the body in both sexes, and particularly in the females, is far less fixed than in the free-living forms. On account of these circumstances it is sometimes difficult to form a positive judgement about some species, e. g. in how far they present varieties of one species, or form separate species. It is sufficiently well known that a similar difficulty is not unfrequent with regard to the free forms, and trom what has been said about Choniostomatidæ, it is easy to understand that, with respect to this family, the difficulties are sometimes so great that a final settlement of some questions must be left to the future.

It has been specially mentioned that most species of Choniostomatidæ have been found each on its particular species of Malacostraca, but, at the same time, I can prove to a certainty that the same species can be found on different species of the same genus (e.g. Choniostoma Hansenii on two species of Hippolyte), or even in forms of two different genera (Mysidion commune on Parerythrops and on two species of Erythrops); and further, on the same species of host one may find two species of parasites in the branchial cavity or in the marstrpium, nay even two species in the same marsupium (Mysidion commune and Mysid. abyssorum in $E r$. abyssorum). The result hereof is that we cannot absolutely take for granted that we know a parasite, becanse we have found it on a certain host, nor that a parasite belongs to an unknown species, because it is found in a host that is not mentioned in this work. All the same, in most cases the host is of the greatest importance in determining a parasite, and where parasites are found in new hosts, most frequently they will prove themselves to be new species.

Most of the species established in this work have been easy to distinguish from each other, and in the majority of cases there has been no hesitation at all in establishing the different species. It is mentioned above that on Perioculodes longimanus (Sp. Bate) I found females which were exactly like the Spheronella paradoxa living on species of Bathyporeia Lindstr., but as the male belonging to the females found on Perioculodes is wanting, I have not been able to decide whether the same species really lives on forms of different families. On account of rather small material, I have also had a little doubt concerning the identity of the forms found on Diastylis cornuta Boeck and D. lavis Norm.; but with regard to this question, as well as to Aspidoecia Normani, I refer to the subsequent special representation. The greatest difficulty I met with in the species very closely allied to Sphceronella Lenckartii Sal. Of these species I have established eight, taken in six genera belonging to four rifferent families of Amphipoda, and four of these species of hosts (belonging to four different families) came from Denmark, two from Sicily, one from the West-Indies, one from HongKong. The difficulties were so great, that I liesitated for a long time whether to establish them each separately, or as belonging all to one species. Though this question will be treated more thoroughly in the systematic part, I thought it right to call attention to it here. 
We now come to the question concerning the characters of the species. It appears hat everywhere, except within the just mentioned group of Sphor. Leuckartii, the males offer a considerable number of excellent and, as a rule, easily observed characters. In this respect they generally surpass the females; they are not only easier to examine, but the shape and decoration of the frontal margin, the processes from the sub-median skeleton, their often very peculiar two pairs of trunk-legs and the hajr-coat of their trunk frequently afford excellent characters, which do not occur in the other sex. Other distinctive marks are not unfrequently found in the antennulæ, the maxillæ and the maxillipeds, in the presence or in the want of caudal stylets, and in the former case, often in the length of their longest terminal seta etc. But, at the same time, we must point out that minor differences in the general shape of the body, in the distance of the caudal stylets from the posterior extremity, in the length of very long setæ, are frequently seen in specimens of the same species; also, that such a feature as the rostrum protruding or receding may give a very different appearance to the animal. In the females the chief characteristics are found in the structure and the organs of the head, especially the antenuulæ, the maxillæ and the maxillipeds, and in adult specimens usually in the genital area, (in Mysidion, however, in the arch round each genital aperture). As a rule the heads of the females are much more uniform than those of the males, and must be examined with great care; the size of the genital area compared with that of the head, its form, the extent of the solid chitine, as well as its hair-covering or want of hair-covering, often afford good characters; nevertheless, it is often necessary to make a preparation, and as far as my experience goes, one must frequently pass over several smaller differences, as some variation may be found in the same species. The candal stylets, their position etc., or the want of them, is always of importance. Within the genus Sphceronella, the females of many species have trunk-legs, whereas these appendages are wanting in others, but in adult specimens they are often so hard to find, that the character drawn from their presence is not easy to make use of, and one has to examine the animals very carefully before being able to deny their existence. In the adult females of very few species we notice a peculiar haircoat, but it must be remembered that in Choniostoma Hansenii the younger specimens are more hairy than the adults, and e. g. in Sphoronella danica, the trumk of the young ones is closely covered all over with hair, that of the adults mostly or totally naked. In the females the general shape of the body is sometimes rather characteristic, but often rather variable according to chance circumstances, e. g. some kind of pressure, or the periods of beginning and ceasing to lay eggs.

But, in order to find good characters of the species, we are not confined to the males and females only. In a large material it is not difficult to procure larvæ of a number of species, partly free specimens, partly in preparing those contained in one or some of the ovisacs. Of all the five species found in the marsupium of Cumacea, the larvæ are known to me, and these not only differ from all other larvæ yet found, they also show very distinct differences among themselves, particularly in the frontal decoration and in the two distal 
joints of the maxillæ; however, I may also observe that I have found very considerable difference in the length of the olfactory seta of the antennulæ between larvæ of the same species (Spher. modesta). Most other larvæ we know also differ from each other in a number of features: length of the olfactory seta of the antennulæ, structure of the antennæ, the relative size of the abdominal segments and of the caudal stylets, and the length of their long setæ, sometimes (Mysidion) also in the presence or absence of fine processes on the terminal joint of the maxillipeds. However, in one case, namely in the genus Choniostoma, I have not been able to find any difference between the larvæ of the two closely allied, yet distinctly separate species. - The size of the ovisacs and the size of their eggs compared with the female present considerable differences between the species, yet they do not naturally form good distinguishing marks. Finally, the few pupæ known to me differ very much according to species, except those belonging to the group of Spher. Leuckartii.

\section{b. Limitation and Characters of the Genera.}

All the species may be classed under six genera, which offer an almost regular gradation in the reduction of the females. The males too become considerably degraded, but not to such a degree as the females. This gradual reduction is combined with great changes in the way of laying the eggs, whereas there are very little differences and 110 reduction at all in the structure of the larvæ, and the post-larval development is too little known to allow of making general statements about it. Consequently, the arrangement of the genera in the systematic part is easily and naturally carried out in considering the gradual reduction indicated.

The first genus, Stenothocheres, deviates from all the following by possessing a distinctly prominent abdomen, by the more conspicuous and distinctly two-branched trunk-legs of the females, and by the way they lay their eggs: in one or two (rarely three) free lumps of indefinite form - not in ovisacs, where the eggs are surrounded by a distinct common membrane. In the two first mentioned characters the genus approaches the less reduced forms of Copepoda. In the other five genera there is no abdomen, the trunk-legs of the females are small with at most one distinct branch, generally consisting of one single joint, or they are altogether wanting, and the eggs are deposed in several or in numerous ovisacs.

These five genera are naturally divided into two groups: in the three first, viz. Homorosertis, Splureronelle and Choniostoma, the genital apertures of the females are situated close together and surrounded by a more solid plate, ring or semicircular list, inside which are also fround the entrances of the two receptacula seminis; the ovisacs, when laid, are free, not attached to the female. In the other group: Mysidion and Aspidoccia, the genital apertures of the female are often placed at a greater distance or very far from each other; each has its crescent or ring, and far in front of them is situated one receptaculum seminis; the ovisacs are hinged on the lips of the genital apertures. In the first group most females 
and most of the males known have 3-jointed antennulæ, distinct antennæ, distinct and, in the males, often very considerable trunk-legs as well as caudal stylets, whereas a few species, through a reduction of these parts, form a transition to the genera of the last group, having antennulæ which are 2-jointed or quite indistinctly articulated, and no antennæ, trunklegs or caudal stylets in either of the two sexes. Another slight difference between the two groups may still be mentioned, namely, that in the males the maxillipeds, especially their distal part, is stouter and more normally developed in the first than in the second group.

Homoeoscelis does not deviate very much from Spheronella, though it differs distinctly in having trunk-legs and caudal stylets, which are similarly shaped in the same individual, as well as in the two sexes, and whose form differs very much from that in the female of Sphoronella; finally, the larvæ of this genus differ from all others in their very long antennæ and in the great distance between the maxillæ and the maxillipeds. It is also a character of this genus that its species occur in the branchial cavity of Cumacea. In Choniostoma, unfortunately, the male is unknown; the female only differs from Sphoronella in having rudimentary maxillipeds; however, this feature, as well as the fact that its species live in the branchial cavity of Hippolyte, appear to me sufficient to maintain the genus. Mysidion and Aspidoecia are distinguished most decidedly by differences in both sexes and in the mode of living, which it is hardly necessary to mention in detail, and Aspidoecia is the most reduced of all forms of the family, both sexes having 1-jointed antennulæ, no antennæ, very small maxillulæ without additional branch, and, as a matter of course, no trunk-legs or caudal stylets; moreover, the maxillipeds are entirely wanting in the female, and their distal part is greatly reduced in the male.

No less than thirty-four of the here described species are referred to the genus Spharonella, and these species differ very much from each other in several respects which, at least apparently, are of considerable importance: 1) Antennulæ mostly 3-jointed in both sexes, sometimes shorter and either 2-jointed or with indistinct articulation. 2) Antennæ closely similar in both sexes, generally pretty well developed, in some species rudimentary, in others wanting. 3) Maxillulæ almost alike in both sexes, generally with an additional branch, sometimes without it. 4) Maxillæ rudimentary in the female of S. marginata, well-developed in all other forms. 5) Trunk-legs and caudal stylets are good-sized in the males of most species, but are wanting in a few; these appendages are found in most of the females, though they are very small; they are wanting in some forms, and it may be said that where they are wanting in the male, they are also wanting in the female of the same species, though the reverse is not always the case. 6) The peculiar attachment of the female in $S$. paradoxa. - In spite of these salient differences $I$ have not ventured to divide the genus into two or more genera, as $I$ have been unable to discover any feature of sufficiently decisive importance. For it is easy enough to say, as many authors do, that if a species (as e. g. S. paradoxa) presents some striking characteristic, it must be set apart as the type of a new genus, but frequently we have no guarantee that such a feature is really of sufficient importance. We meet a similar difficulty where several 
species have the distinct negative character of wanting trunk-legs and caudal stylets in both sexes, for as there are species which, though wanting these organs in one sex, not in the other, or through the male having trunk-legs, but no caudal stylets, form a transition to the species in which both sexes possess trunk-legs and caudal stylets, one cannot very well set apart the first mentioned species as a separate genus. If I can find no leading principle to guide me in carrying out the division of a large genus, the elements of which seem to be heterogeneous, and if $I$ am not obliged to undertake a division in order to bring about an equivalence with previously established acceptable genera, I prefer putting off the division till the discovery of new forms has thrown new light on the question. If I had had to subdivide Sphceronella, the result would have been, not two or three, but six or seven genera (some of which would have consisted of only one or a couple of species), in order to establish a pretty correct equivalence, but these new genera would not have been tolerably equivalent with such types as Homoeoscelis, Mysidion etc.

\section{c. Characters of the Family.}

An examination of the genera will show very clearly that, in spite of several differences, they are all very closely related and belong to the same family. We will here attenupt to give a summary of all its more important characters, some of which separate it from one, some from another, of the rather numerous families of parasitic Copepoda, for it would be impossible to give a condensed characteristique with merely exclusive features, our knowledge of several points in the organisation and development of other families being too defective.

The adult Females are ovate or sub-globular. The head occupies only a smaller or a minute part of the greatly swollen, unsegmented body; the abdomen is comparatively rather small and unsegmented, or mostly altogether wanting. Antennulæ 1-3-jointed; antennæ small or wanting; rostrum good-sized, comparatively stout with cup- or funnel-shaped mouth provided with a border formed by a membrane which is interrupted only in front and supported outside by free hairs; maxillulæ consisting of a basal part almost entirely fused with the rostrum, and of two or three usually setiform branches; maxillæ short and powerful prehensile limbs consisting of a stout basal joint and a slender, 1- or 2-jointed, somewhat claw-shaped, distal part; maxillipeds rarely wanting, mostly appearing as good-sized grasping appendages, consisting of a long, rather stout basal joint and a shorter, slender, 2- or 3-jointed distal part. We often find two pairs of rather small or minute trunk-legs, each of which consists of one single joint or sometimes of a peduncle with one or two unjointed branches; the legs are wanting in not a few species. Caudal stylets present or wanting. Some species, at least, can hinge themselves by an adhesive plate or a frontal thread. Spermatophores (found in many species) consisting of a globular or oval vesicle on a rather long thread-shaped stalk. 
The Males are several or many times smaller than the females, oblong or sub-globular. The head forms a little more or a little less than half of the unsegmented body. Abdomen nearly as in the females. Antennulæ, antennæ, rostrum, maxillulæ and maxillipeds nearly similar to those of the females. Frequently, though far from always, we find too pairs of trunk-legs, which are often good-sized and two-branched, with long terminal setæ, but very rarely jointed. Candal stylets fiequent. They hinge themselves by a rather long, or very long frontal thread.

Development. The eggs are deposed in one or two (rarely three) free, irregular lumps, or most frequently, in several (at least four or five) or many (up to twenty-eight) ovisacs, which, as a rule, are free, though sometimes hinged on the lips of the genital apertures. The Nauplius stage is passed through in the egg; the forthcoming larva is in the first Cyclops stage, with an oval, somewhat depressed cephalothorax, which is divided far back by one articulation, and a 3-jointed abdomen with caudal stylets, each with a very long terminal seta. Cephalothorax with 2-or 3-jointed antennulæ, provided with a very long olfactory seta, 2-, 3. or 4-jointed antennæ; rostrum in the main as in the adults, maxillulæ with - as a rule - indistinct basal part and (one) two, three or four setiform branches; 2- or 3jointed maxillæ and 4-jointed maxillipeds, both pairs chiefly constructed as in the adults; finally, two pairs of natatory legs, each with two 1-jointed branches. Out of this larva, which hinges itself by a frontal adhesive plate, the males not unfrequently, the females sometimes, appear directly, without passing through any intermediate stage. In other species the larva develops into a pupa, out of which the male proceeds. In most species the same metamorphosis is gone through by the female; in one case the female passes throngh at least one additional intermediate stage. Where a pupa is found, it is always hinged; besides it is nearly always provided with a mouth and increases considerably in size. After hatching the males grow comparatively rather little, and the same is the case with the head of the females, whereas the trunk of this sex swells excessively.

A distinctive mark of this family is the above (p. 27-28) described mouth, which appears, not only in the female and in the male, but - as far as its most important features are concerned - also in the larva, and nearly always in the pupa.

\section{d. Place of the Family in the System.}

During the last thirty years and more, the parasitic Copepoda have been very little studied, and not a single really leading work has appeared about this subject. Several authors have established a series of genera, some of which might easily be ranged in the old families, while others stand rather isolated. Some smaller families have also been instituted. If, however, we try to get a general view of our present knowledge, we find that several families are badly defined, and others so imperfectly known, that we cannot form a definite opinion of their place in the system: whether they belong to one of the established families, or must be taken as types of new families. The reasons 
of this uncertainty are partly, that the males of too few forms are known, partly - and particularly - that the metamorphosis of numerous genera among the old families and of the more abnormal forms is entirely unknown, and that the structure of the mouth in the adults as well as in the larvæ is often badly studied, etc. A revision of the classification of the parasitic Copepoda would be most desirable and ought to be based upon a thorough stndy of the external structure of both sexes, and upon numerous new data which throw light on the post-embryonic development; that a representation of the internal structure of numerous types would be excellent, goes without saying, but even without undertaking this gigantic work such a revision as the above-mentioned would be exceedingly useful. However, as such a work does not exist, I do not see that it can be of much use to discuss the relationship of the Choniostomatidx and their place in the system more in detail, so I will content myself with some few remarks.

The last detailed systematic arrangement of the parasitic Copepoda was undertaken by A. Gerstaeckel in "Bronn's Klassen und Ordn. des Thier-Reichs, fünfter Band, erste Abth." p. 721-729, and this part was published about 1870. Perhaps we might also mention the more condensed grouping in „C. Claus: Grundziige der Zoologie, B. I, 1880, p. 554-58, « as it is set up by the author who has also gained great distinction in this domain of carcinology. By studying these treatments and several papers on special groups, I have found out that the family Choniostomatidæ stands far apart from all hitherto established families, except Lernæopodidæ, from which, however, it also differs considerably. If Salensky in his often mentioned paper means that Sphceronella comes nearest to Lernæidæ, because he thinks that in the structure of the mouth and in the form and position of the maxillæ and the maxillipeds, it resembles Lernea branchialis in the pairing stage, we admit indeed that the resemblance in the structure of the mouth is doubtless very striking, but in other respects the various larval stages of Lernca and Pennella differ widely from the larvæ and pupæ of Choniostomatidæ, and the subsequent development of the two genera of Lernæidæ, as we know, differs so thoroughly from that of the Choniostomatidæ, moreover, the structure and egg-laying of the female of Lernoe is so exceedingly different from these features in our family, that a closer relationship is entirely out of the question: in my opinion Lernæidæ and Choniostomatidæ stand very far from each other. But undeniably it stands even farther apart from Herpyllobiidæ, though Giard and Bomnier have attempted to unite it with this most remarkable family, which differs widely from all other parasitic Copepoda. They do so by establishing a new family: Sphæronellidæ, which they subdivide into Choniostomatinæ and Herpyllobiinæ. This peculiar classification I have criticised at length in my general histrrical view (p. 10̃-21), to which I refer. The same two authors, in their earlier work, published in 1889 , say that Choniostomatidæ comes nearest to Chondracanthidæ, Lernæopodidæ and Ascomyzontidæ. The first and the last of the families in several respects - e. g. in the structure of the mouth - deviate so mnch from Choniostomatidæ, that any closer relationship is out of the question; indeed our family stands widely apart from both, 
but as for Lernæopodidæ, there is a considerable resemblance in various points, e. $g$. in the structure of the male and the female, and especially in that of the larvæ; at the same time, there are numerous and important differences. However, as the family Lernæopodidx is comparatively well known ${ }^{1}$ ), I do not think it necessary to repeat and compare all the characteristics of the two families, but will content myself with stating my opinion that the Choniostomatidæ, though coming much closer to the Lernæopodidæ than to any other form of parasitic Copepoda, yet differ very much from them in the way they lay their eggs, in their development after the first larval stage, in several peculiarities in the internal and external structure of the male (e. g. in that of the mouth), and most conspicuously, in the structure of the mouth, the antennæ and the maxillipeds of the female. A comparison of the figures in: W. Kurz: Studien über die Familie der Lernoopodiden (Zeitschr. für wiss. Zool., B. XXIX, 1877)" with my present work, will give the best idea of the resemblances and the differences between the adults of these two families. In elucidation of the matter I will add, that Kurz concludes from the development that the pair of limbs which in the females of Lernæopodidæ are fused together into one long arm that serves as organ of fixation, are the "first pair of maxillipeds." If this be correct - which is quite possible - this appendage would correspond to what I term the maxillæ.

1) In the above-mentioned „Grundzüge ${ }^{\kappa}$ (p. 557-58), Claus enumerates most of its characteristics and refers to the most important accounts of its structure and development. 


\section{DESCRIPTION OF GENERA AND SPECIES.}

\section{Conspectus of the Genera, based on the Females.}

A. Abdomen is found, it protrudes from the trunk, is comparatively rather small. unsegmented and not set off by an articulation. Eggs are laid in one free lump or in a two (or three) lumps without distinct shape. (Live in the marsupium of Stenothoidæ, a family of Amphipoda). . . . . . . . . . . I. Stenothocheres $n$. gen.

B. Abdomen is wanting, though caudal stylets are frequently found. Eggs are laid in a smaller or greater number of ovisacs.

a. Genital area is found; genital apertures close together and surrounded by a common plate, ring or semi-circle, which is more solidly chitinised than the remainder of the skin. The entrances into the two receptacula seminis are situated within the genital area. The ovisacs are deposed freely.

$\alpha$. Trunk-legs and caudal stylets apparently consist of a very small, short basal part which tapers into a comparatively rather long and very narrow conical branch. Live in the branchial cavity of Cumacea. . II. Homoeoscelis $\mathrm{n}$. gen.

$\beta$. Trunk-legs and caudal stylets not unfrequently wanting; if found, they are very small, generally sub-cylindrical and terminating in two - the caudal stylets sometimes in one or three - setæ. Live in marsupia.

§. Maxillipeds good-sized and at least always longer than the maxillæ. Live in the marsupium of Amphipoda, Cumacea and Isopoda. III. Spharonella Sal.

$\S \S$. Maxillipeds quite rudimentary, several or many times shorter than the maxillæ. Live in the branchial cavity of Hippolyte Leach, a genus of Decapoda . . . . . . . . . . . . . IV. Choniostoma H. J. H.

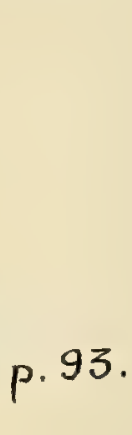


๙. Maxillipeds good-sized. Genital apertures very far from each other, placed very near the line where the hind margin and the lateral-margin meet. Live in the marsupium of the genera Erythrops G. O. S. and Parerythrops G. O. Sars, belonging to Mysidacea............ V. Mysidion n. gen. p.l

p. Maxillipeds wanting. Genital apertures closer together, somewhat up on the dorsal surface. Live attached outside on the back and on the sides of the body or on the eye-stalks of the genus Erythrops. G. O. Sars, belonging to Mysidacea.............. VI. Aspidoecia Giard and Bonn. p.

\section{Stenothocheres n. gen.}

FEMALE. The body somewhat longer than broad; naked all over. The head which is comparatively good-sized, is not marked out from the trunk; it has neither frontal nor lateral borders. Antennulæ comparatively long, without distinct articulation and with few setæ. Antennæ middle-sized. The mouth-border with very short hairs. Maxillulæ without additional branch. Maxillæ robust, without hairs. Maxillipeds of scarcely medium size, second and third joints coalescent, all joints without hairs, spines or processes. Sub-median skeleton very feebly developed, consisting only of a plate in front of each maxilliped. The trunk-legs are situated rather far from the lateral margin; they are comparatively of considerable size and consist of a basal part with two unjointed branches, each as a rule ending in a strong or spiniform seta, besides, on the outer branch of the first pair of legs, is found a smaller seta. Abdomen pretty well developed, consisting of a robust basal part and a narrower distal part, which passes without articulation into two short and broad caudal stylets, each of which bears four setæ of unequal length. Genital area wanting. Genital apertures situated partly on the lateral surface, partly on the ventral side of the basal part of the abdomen, more or less close to its lateral margin. Two large receptacula seminis, the entrances of which have not been found. - Spermatophores have not been noticed.

MALE. Agrees with the female in most features, so that only some characters need be pointed out. The head is not marked out, it occupies about half of the body. The trunk-legs are situated at a short distance inside the lateral margins of the trunk; both pairs are comparatively very considerable, with a thick basal part. A little behind and outside the second pair of trunk-legs proceed a pair of spines (pl. I, fig. 2 l, x), which are possibly the rudiments of a third pair of legs. Only the narrower, distal part of the abdomen can be distinguished from the trunk. The body is naked, but on its dorsal side, and especially on its front part, it is furnished with moderately small, irregular protuberant knots, and on 
the ventral side, particularly outside a line between the base of the antennulæ and the first pair of trunk-legs, with peculiar, irregular stripes or with keels and knots.

OVISACS. Real ovisacs are not found; thé eggs are laid in one free lump or in two (or three) lumps.

LARVA. Is only known of one species. Antennæ about the length of the antennulæ. The maxillulæ have a short but distinct basal part and two stout branches, the anterior of which is very long. The maxillipeds are situated closely behind the 3-jointed maxillæ; all joints of both pairs are smooth. The peduncle of the natatory legs is very broad. The third segment of the abdomen, together with the broad caudal stylets, which are not set off by an articulation, is almost as broad as and nearly double the length of the second segment. The longest seta of the caudal stylets is only a little longer than the abdomen and not nearly half the length of the cephalothorax.

POST-LARVAL DEVELOPMENT. Unknown.

HABITAT. The two species known live each in a species of the genera Metopa Boeck and Stenothoë Dana. Hitherto found only in Norway and at the western coast of Greenland.

REMARKS. My material of the Amphipod family of Stenothoidæ, which contains a great mnltitude of species, being somewhat limited, because I have only seen a few specimens of most Greenlandish and Danish species, it may be expected that researches made in a large material will lead to the discovery of a number of new species of this interesting genus.

\section{Conspectus of the Species.}

The basal joint of the maxillipeds in both sexes conspicuously longer than that of the maxilla. The female without median frontal process. The male elongated.

1. St. egregius n. sp.

The basal joint of the maxillipeds in both sexes almost shorter than that of the maxillæ. The female has a median frontal process. The male is short and broad.

2. St. Sarsii n. sp.

\section{Stenothocheres egregius n. sp.}

(Pl. I, fig. 1 a-1 l.)

FEMALE. A very large specimen is $63 \mathrm{~mm}$. long. The specimen represented (fig. $1 \mathrm{a}$ and $\mathrm{fig} .1 \mathrm{~b}$ ) is ab. $59 \mathrm{~mm}$. long and $46 \mathrm{~mm}$. broad. The body as a rule a little longer than broad, apart from the abdomen evenly rounded; seen laterally (fig. 1 b), the ventral side is rather flat, the back strongly convex. No median frontal process between the bases of the antennul. The antennæ distinctly jointed; the terminal joint furnished with two short setre of unequal length. The basal joint of the maxillipeds conspicnonsly longer than that of the 
maxillæ. Each maxilliped proceeds from a chitinous list (fig: $1 \mathrm{e}, \mathrm{h}$ ), projecting between the bases of the maxillæ. The proximal part of the abdomen two to two and a half times broader than the distal part. Each of the triangular candal stylets (fig. $1 \mathrm{~g}, \mathrm{t}$ ) has four setæ, the foremost of which is short, the apical one moderately long.

MALE. A well developed specimen is $196 \mathrm{~mm}$. long and $11 \mathrm{~mm}$. broad - thus good-sized in proportion to the fentale (fig. $1 \mathrm{c}$ : fig. $1 \mathrm{~d}$ ). So the body is a good deal longer than broad (fig. 1 i). On the ventral side, stretching from the base of the antenmulæ outside the maxillæ, the maxillipeds and the legs, backward towards the abdomen, and from the appendages towards the lateral ontline, are found a comparatively small number of irregular stripes or grooves. On the basal part of the first pair of legs we see some irregular projections and taps; similar thongh blunter taps or knots are spread more scantily over the dorsal side of the animal, whereas the frontal part is closely covered with larger knots. Antennula shorter than in the following species. The basal joint of the maxillipeds longer than that of the maxillæ and more robust than in the following species. In the second pair of leg's the apical spine on the inner branch is frequently somewhat curred, but not hooked. Of the setæ on the caudal stylets, the apical one is thick and longer than the others. - A frontal thread was found in a few cases; it was about as long as the animal (fig. $1 \mathrm{c}$ ), simple and somewhat dilated towards the distal end.

EGGS. They are very large (fig. $1 \mathrm{~d}$ compared with fig. $1 \mathrm{a}$ ), and are deposed in a large, loose, irregular lump, or in two (or very rarely three) lumps; the greatest number found is forty-two, the usual number is about thirty.

LARVA (fig. 1 l). Length of the body (except caudal setæ) $22 \mathrm{~mm}$., which shows that it is longer than the male, though its volume is somewhat smaller. Cephalothorax oval, somewhat longer than broad. The front has a transverse band which curves backward, ending at a short distance from the base of the antennulæ. Antennulæ 3-jointer; olfactory seta at least double their length, reaching a little behind the middle of the cephalothorax. Antennæ of medium length, 3-jointed; basal joint broad and longer than broad, about the same length as the second joint; third joint short, terminating in two or three setæ, one of which is stout and as long as the second and third joints together. Second and third joints of the maxillipeds of about equal length. The longest seta at the hindmost angle of the first abdominal segment a little longer than the second segment. Each caudal stylet furnished with five setæ, one of them a little longer than the abdomen, two of the others a little longer than the last segment plus the caudal stylets. (See besides the diagnosis of the genus).

\section{POST-LARVAL DEVELOPMENT. Unknown.}

HABITAT. On Metopa Bruzelii (Goës) from two localities near the western coast of Greenland. In a glass labelled: 》Godthaab, deep water [probably 40-60) fathoms], in Sertuluria, Holboll", were found numerous specimens of Met. Bruzelii (Goës) and of $M$. simuata G. U. Sars, as well as a number of specimens of $M$. longicornis Boeck, M. longimana Boeck 
and $M$. neglecte H.J.H., and an examination of all these only exhibited parasites on eight adult females of $\boldsymbol{M}$. Bruzelii; in five specimens this Stenothocheres was found, in three others Spheronella Metope n. sp. (s. later on). The second locality is: "lat. $66^{\circ} 30^{\prime} \mathrm{N}$., long. $54^{0} 50^{\prime} \mathrm{W}$., forty fathoms, stones with many Balani, 5. VIII. 1886, Th. Holm《; here was taken a very great number of Met. Bruzelii and of $M$. sinuata, but whereas the latter is free from parasites, Stenothocheres occurs frequently in the first mentioned species, while no specimen of Spher. Metope was found. Unfortunately the abundant material from this locality was somewhat ronghly handled, as the animals while still alive had been put into too strong spirit. I investigated and put down statistics on the contents of the marsupia of twenty-three infested females, which, added to those from the former locality, makes a total of twenty-eight. In one case neither females nor males were found, but at least twelve larvæ and a lump of six eggs without larvæ. In another case only one not half-developed female was found; in a third marsupium two females, but neither males nor eggs. In twentyfive cases a female was found, and often a male besides, in one case even two males (once I also found a normal male and the larger part of the skin of a dead male), and finally, I frequently met with eggs or recently hatched larvæ. Concerning the eggs, I refer to the description given on p. 44. The female was always seen in the foremost part of the marsupium, the male and the eggs behind. Only in a few cases a frontal thread was found in the male. Subsequently more material of Met. Bruzelii was examined (adult females as well as young specimens), in order to find - if possible - stages of development. Several finds in adult females corresponded to the above stated results, but in one young female with scarcely half-developed marsupinm I succeeded in finding two larvæ which had evidently swum in beneath the body of the animal, and in a young specimen without marsupium I found a single larva. From all these data it may be concluded that, at least as it rule, the female is infested before the marsupium is quite developed. At least one of the last-mentioned larvæ had hinged itself by the usual adhesive frontal plate, but about the subsequent development I learned nothing.

\section{Stenothocheres Sarsii n. sp.}

(Pl, I, fig. $2 \mathrm{a}-2$ l.)

FEMALE. The largest specimen (fig. 2 a) is swollen to such an extent that the borly is vaulted beyond the abdomen, so that this part does not add to its length or breadth which are respectively $.80 \mathrm{~mm}$. and $69 \mathrm{~mm}$. The specimen exhibited in fig. $2 \mathrm{~d}$ and fig. $2 \mathrm{e}$ is only $67 \mathrm{~mm}$. in length. Seen from below, the body (apart from the abdomen) is a short, at the ends rather flattened oval; seen laterally (fig. $2 \mathrm{e}$ ), the ventral surface is rather flat, the back considerably vaulted. Between the base of the antemnulæ is found an odd, blunt, horizontal process of considerable size. The antennæ weak, with indistinct articulation, the distal 
joint terminating in a short spine. The maxillipeds comparatively short and slender, their basal joint almost shorter than that of the maxillæ. The proximal section of the abdomen more than three times broader than the distal section (fig. 2 i); each of the oblong caudal stylets furnished with four setre, the foremost of which is the longest. - Fig. 2 a shows that this specimen possessed two long frontal threads (s), the proximal parts of which are united into one single thread.

MALE. The largest specimen (fig. $2 \mathrm{k}$ and $2 \mathrm{l}$ ) measures to the extremity of the caudal stylets $27 \mathrm{~mm}$. in length; breadth $24 \mathrm{~mm}$; a rather considerable size compared with the female (fig. 2 b: fig. 2 a). So, the body is proportionally only a little longer than broad and somewhat depressed. The ventral surface outside the limbs from the base of the antennulæ to the abdomen, the posterior part of the sides, the hindmost part of the back, the stout basal part of the trunk-legs and the inner branch of the first pair, are closely covered with peculiar, very irregular eminences, which are partly shaped like keels, partly like knots or short, acute taps. The median part between the maxillipeds and the trunklegs shows fewer keels and stripes. The dorsal side has very few knots, whereas the front part of the head is covered with numerous blunt knots. The maxillipeds like those of the female. The terminal spine on the inner branch of the posterior legs is strongly curved and hooked. Of the setæ of the candal stylets, the two apical ones are stout and of subequal length. - The frontal thread (fig. $2 \mathrm{k}, \mathrm{s}$ ) a little shorter than the animal, simple, slender, yet somewhat thickened towards the distal end.

EGGS. Much smaller, but also much more numerous than in the preceding species. In one female were found two somewhat oblong lumps of eggs of about equal size and of irregular shape; they did not show any trace of larvæ. One of these lumps is exhibited in fig. $2 \mathrm{c}$, enlarged to the same scale as the largest female, fig. 2 a, and a comparison of these figures with the male (fig. 2 b) will show the relative size.

\section{LARVA and POST-LARVAL DEVELOPMENT. Unknown.}

HABITAT. On Stenothoë marina (Sp. Bate) from Norway. The locality cannot be precisely indicated, but, according to Sars, the host occurs along the southern and western coast of Norway up to the Nordland coast (Tjötö). I have only seen two infested specimens lent me by Prof. G. O. Sars, after whom I have named this remarkable form discovered by him. One of the hosts was a female with marsupium, in which were found an adult female, a very small female and the two afore-mentioned lumps of eggs, one of which, probably by chance, was adhering to the abdomen of the female, whereas the other was free and situated more to the front; the female had attached one of its above-mentioned frontal threads to it, which I think shows that the animal must have moved after deposing this lump. The other host was also a female; its marsupial plates were somewhat smaller, though they appeared to be quite developed, being furnished with marginal setæ, and in this specimen were found an adult female, a male and an empty skin of a somewhat smaller male. 


\section{Homoeoscelis n. gen.}

FEMALE. The head small and distinctly defined from the circular, rather depressed trunk. Frontal and marginal borders and sub-median skeleton well developed. Antennulæ of scarcely medium length, 2-jointed. Antennæ wanting. Mouth rather small, the mouth-border being somewhat narrow, with well developed hairs. Maxillulæ without additional branch. Maxillæ about middle-sized, smooth. Maxillipeds of medium size, second and third joints coalescent. Body entirely naked in the adults, at the utmost a few hairs on the sides behind the head; in the recently hatched and younger specimens the haircovering resembles that of the male. The trunk-legs are situated on the lateral margins; they are small, each apparently consisting of a rather thick, short basal part which is jointed without articulation to an elongated, very narrow conical, sometimes partly hairy branch, at the base of which the basal part bears either a few setæ or just a vestige of another branch. Abdomen wanting. Well developed genital area with a transverse chitinous arch, opening towards the front and surrounding the genital apertures, which are situated close together, and the entrances of receptacula seminis. Rather close behind the genital area are the two caudal stylets which are a little thicker and longer than the legs. - Spermatophores frequently seen.

MALE. Body seen from below elongated ovate, from nearly twice to a little more than twice as long as broad. Length of the head somewhat exceeding a third of the total length. (The antennulæ 2- or 3-jointed, and very small antennæ are perhaps found in one species). In other respects all the other organs of the head, as well as the trunk-legs and caudal stylets, mostly agree with those of the female. The trunk, except the anterior part of the ventral surface, is covered rather closely all over with comparatively short hairs.

OVISACS. Are deposed freely, and are of moderate or rather large size, containing few, six to eighteen, eggs which are very or exceedingly large. The number of sacs laid by one female can amount to eight.

LARVA. Is known of both species. Antennæ much longer than in any other genus, more than twice the length of the antennulæ, owing particularly to the fact that the penultimate joint is very much elongated; the terminal seta is very long. Maxillulæ I have been unable to discover. Maxillæ only 2-jointed, the second and third joints being fused and forming one curved joint, which, moreover, along the larger part of both margins is funished with extremely fine and short, setiform processes. Maxillipeds far behind the maxilla; all joints smooth; second joint half or scarcely half as long as the third one. Peduncle of the natatory legs rather slender. Third segment of the abdomen together with the small caudal stylets distinctly articulated to the segment, much smaller than the second segment. The longest seta of the caudal stylets sometimes shorter, sometimes considerably longer than half of the cephalothorax.

POST-LARVAL DEVELOPMENT. Observen only in one species and described above, p. 55. 
HABITAT. The animals live in the branchial cavity of Cumacea, causing a gradual swelling of the carapace above the place which is occupied by the parasite and its ovisacs. A parasite with several ovisacs may be found on immature specimens of both sexes as well as on adult females. Two infested adult males have also been found. The larvæ infest not only immature specimens, but frequently also females with marsupium. The two species here described come respectively from Denmark and from Messina (and a deep-sea species was found on a Diastylis brought home by the (nggolf « expedition) ${ }^{1}$ ).

REMARKS. The genus is distinguished partly by the shape of the trunk-legs, partly by the similarity of both pairs in the male as well as in the two sexes mutually, and by their resemblance to the candal stylets. In giving the genus its name, I have tried to allude to this conformity in the appendages. The females are very small, more so than in any other genus, which harmonises well with the scanty room left for them in the branchial cavity of their rather small hosts. The males, on the contrary, are uncommonly large in proportion to the females: in the large species about half the length, in the small one even longer than a iniddle sized adult female. (In $H$. mediterranea the antennulæ of the male are decidedly 2-jointed; what in fig. 1 f on pl. XIII appears to be a short basal joint, is an angular excrescence proceeding from the head. On the other hand, the antennulæ of $H$. minuta sometimes appear to be 3-jointed, as the two last joints, though coalescent, are separated by a distinct line, which, however, is too strongly marked in the drawing.)

\section{Conspectus of the Species.}

In the female the basal joint of the maxillipeds is comparatively more slender, a good deal longer than half the breadth of the head at its base. Trunk-legs and caudal stylets of the male are long, longer than half the breadth of the body, and furnished with hairs about all over the distal half ................. . H. minuta n. sp.

In the female the basal joint of the maxillipeds comparatively stout, scarcely longer than half of the head at its base. Trunk-leg's and caudal stylets of the male shorter, not nearly half the breadth of the body, and with very few or no hairs . 2. H. mediterranea $\mathrm{n} . \mathrm{sp}$.

\section{Homoeoscelis minuta 11. sp.}

(Pl. I, fig. $3 \mathrm{a}-3 \mathrm{~b}$; pl. II, fig. $1 \mathrm{a}-1 \mathrm{l}$ ).

FEMALE. The largest specimen (fig. 1 b), which had not begun laying eggs, is $.52 \mathrm{~mm}$. in length and $49 \mathrm{~mm}$. in breadth. A female which has nearly finished laying eggs (fig. $1 \mathrm{c}$ ) is only $35 \mathrm{~mm}$. long and $39 \mathrm{~mm}$. broad. The frontal margin has seven small incisions

1) J. Bonnier, in his above-mentioned treatise, published probably in Febr. 1897, under the name of Sphoronella sedentaria Bonn. described a species belonging to this genus. He found it in the branchial cavity of Cyclaspis longicaudata G. O. Sars, taken in a depth of 960 metres in "Le Golfe de Gascogne". 
(fig. 1h) and very short hairs. Basal joint of the maxillipeds rather slender and a good deal longer than half of the breadth of the head at its base. The genital area (fig. 3a) more than double as broad as long; between, behind and obliquely outside the genital apertures, as well as behind the caudal stylets, are a number of very fine hairs.

MALE. A normal specimen (fig. $1 \mathrm{i}$ and fig. $1 \mathrm{k}$ ) is $20 \mathrm{~mm}$. in length and $09 \mathrm{~mm}$. in breadth, or about half the length of a middle-sized adult female (comp. fig. $1 \mathrm{~d}$ with fig. $1 \mathrm{~b}$ and fig. 1c). The body between scarcely double and a little more than double as long as broad. The frontal margin seems to be like that of the female; the incisions are extremely difficult to see (the hair-covering in fig. $1 \mathrm{i}$ is too long). Basal joint of the maxillipeds of a shape similar to that of the female. Trunk-legs and caudal stylets long, longer than half the breadth of the body, and very distinctly furnished with hairs about all over the distal half.

OVISACS. Of medium or rather large size, globular or shortly ovate (fig. $1 \mathrm{e}$ and fig. 1f). As a rule there are fourteen to eighteen very large eggs in each sac. It is a not common occurrence to find eight ovisacs with one female, and a greater number has never been observed.

LARVA. A free specimen (fig. $1 \mathrm{~g}$ ) is $15 \mathrm{~mm}$. in length. Its cephalothorax is nearly double as long as broad. Having only one such specimen in hand, I prepared some larvæ out of their egg-membranes and examined them more closely; one of them is seen in fig. 11. We notice that its cephalothorax is still somewhat shorter and broader than that of the freely swimming larva, and the animal is only $14 \mathrm{~mm}$. in length. The olfactory seta of the antennulæ turned backward reaches beyond the posterior extremity of the cephalothorax. Distance between the maxillæ and the maxillipeds about as long as the basal joint of the latter. Second abdominal segment as long as the first. The longest seta of the candal stylets considerably longer than half the length of the cephalorhorax, about half the length of the body in the free specimen.

POST-LARVAL DEVELOPMENT. Described in detail above, on p. 55.

HABITAT. In the branchial cavity of Diastylis lucifera (Kr.) from Denmark. The parasite I have found in sixty-six specimens, the special locality of fifty-seven of these are unknown to me; five specimens were taken at Hellebæk (four by Dr. Jol. Petersen, one by the author), and four in the following four stations of the expeditions of »Hanch : Stat. 25 (110 fathoms), Stat. 368 (13 fath.), Stat. 370 (15 fath.) and Stat. 383 (14 fath. $\left.)^{1}\right)$. Either the right or the left side is infested; in no specimen have I found both sides infested. Only ome female and generally also one male, rather seldom two males, are found in the same branchial cavity. Where the parasite has laid several ovisacs, the carapace of the host is very ronsiderably swollen, and frequently this swelling rises somewhat above the median dorsal line.

1) Details about the exact localities of these stations, the description of the bottom etc. is found in: "C. G. Joh. Petersen: Det videnskabelige Udbytte af Kanonbaaden „Hauch"s Togter i de danske Have indenfor Skagen i Aarene 1883-86*, p. 1-33, 1893. In my descriptions of several of the following species, other stations from these cruises will be quoted and may be looked for in the afore-mentioned work. 
An adult parasite, especially when it has laid several ovisacs, is easily seen through the carapace, but if we want to find out if a specimen without swelling is infested with larvæ, pupæ or recently hatched specimens, we must examine it carefully under a good dissecting microscope.

I will try to give special statistics of my material, but unfortunately, at the beginning of my investigation some years ago, I omitted to put down sufficient notes about a few of my specimens, so I cannot give as perfect statements as I should like. Of 433 specimens of Diast. lucifera, 66 were infested, 367 were not. Of the latter, 182 were females with eggs or young ones in the marsupium, 74 females with empty marsupium, 28 adult males, 7 young males (before the last moulting) and 76 young females (some of them may have been males without rudiments of abdominal appendages). Of the 66 infested specimens 13 were females with young ones in the marsupium, (there was not one with eggs), 31 females with well-developed though empty marsupium, no adult males, 3 young males and 15 young females; concerning 4 specimens sufficient notes are wanting, at all events none of them was an adult male. Of the 62 specimens, 33 contained an adult female with one or more ovisacs, and also, of course, a male, and of these 33 hosts, 4 were females with young ones in the marsupium, 13 were females with empty marsupium, 13 young females and 3 young males. In 29 of the 62 specimens was found either a moderately large female without eggs, or one (or two) males, or in many cases recently hatched specimens or pupæ, and in at least one case, only one recently entered larva. Of these 29 hosts, 9 were females with young ones in the marsupium, 18 were females with well-developed, empty marsupium, and 2 young females (without marsupium). No help is needed to draw various conclusions from these figures; I will only observe that the number of males collected is too small to allow us to conclude that they are never infested (s. the following species).

REMARKS. The three infested specimens first observed were discovered by the Inspector, Dr. F. Meinert, whom I had asked to look out for eventual parasites in determining the Cumacea from the cruises of the "Hauch". With respect to the figures it may be observed that in fig. $1 \mathrm{a}$ I haven given a drawing (in the same enlargement as fig. $1 \mathrm{~b}$ and $1 \mathrm{c}$ etc.) of a rather young female, whose limbs are remarkably long, as in the male (fig. 1d), and which has already four spermatophores attached to its genital area, though it is far from being old enough to begin laying eggs. Fig. 3a (pl. I) exhibits two spermatophores (s) fixed at the entrances to the receptacula seminis $(r)$, which are seen through the skin and are indicated by dotted lines.

\section{Homoeoscelis mediterranea n. sp.}

(Pl. XIII, fig. $1 \mathrm{a}-1 \mathrm{~h}$ ).

FEMALE. The specimen represented (fig. 1 a) is $28 \mathrm{~mm}$. in length, $23 \mathrm{~mm}$. in brearlth; the largest specimen taken ont measures $31 \mathrm{~mm}$. in length, $32 \mathrm{~mm}$. in breadth. 
The frontal margin uninterrupted, with scarcely any hairs. The basal joint of the maxillipeds moderately stout (fig. $1 \mathrm{~d}$ ), scarcely longer than half the breadth of the head. The genital area (fig. 1e) not nearly twice as long as broad; the whole area between the genital apertures and the caudal stylets, a narrow part behind the latter, and an area outside the soft membrane which borders the genital apertures, are covered with rather short hairs. The remainder as in the preceding species.

MALE. The well-developed specimen illustrated (fig. $1 \mathrm{f}$ and fig. $1 \mathrm{~g}$ ) is $-17 \mathrm{~mm}$. long and $09 \mathrm{~mm}$. broad, thus a little more than half the length of the largest female. The body more clumsy than in the preceding species, not twice as long as broad. Frontal margin and maxillipeds as in the female. Trunk-legs and caudal stylets shorter, not nearly half as long as the breadth of the body, and with very few or no hairs.

OVISACS. Rather large (fig. 1c), shortly ovate or sub-globular. There may be five to twelve, but generally we find six to ten comparatively extremely large eggs in each ovisac, and as many as eight ovisacs have been found with one female.

LARVA. In one ovisac were found larvæ nearly on the point of swimming out; one of these is figured (fig. $1 \mathrm{~h}$ ); its body is $15 \mathrm{~mm}$. in length, and the cephalothorax is very elongated. The olfactory seta of the antennulæ reaches the posterior extremity of the cephalothorax. Distance between the maxillæ and the maxillipeds considerably shorter than the basal joint of the latter. Second abdominal segment scarcely the length of the first. The long setx of the caudal stylets considerably shorter than in the preceding species, not half the length of the cephalothorax and frequently much shorter.

\section{POST-LARVAL DEVELOPMENT. Unknown.}

HABITAT. In the branchial cavity of Iphinoë trispinosa (Goods.), at Messina. In May and in the beginning of June 1893 I caught fifty-eight specimens in all ages of this species in the harbour of Messina, in a depth of ten to twenty fathoms, and seven out of these were infested with the parasite. It was only found in specimens which were either much more than half-grown or full-grown, so that no parasite appeared on a single one of the numerous specimens which were only half-grown or still younger. A female with the marsupium containing Spheronella marginata (s. later on), had on its right hand side a considerable swelling, in which were two adult females, two males and six ovisacs. In a female with less than half-developed marsupium, the left branchial cavity contained a male; the right hand side of the carapace, especially its posterior part, bulged very much, and under the hindmost part of it were found an adult female, in front of it a male and eight ovisacs, the foremost of which was evidently newly laid, whereas another, which was lying close up to the female, contained full-grown young ones; this arrangement showed clearly that the female had changed place. An adult male contained in its left branchial cavity one half-grown female. Another adult male contained, also in its left hand side, one adult female, one young female, one male and two ovisacs. The three remaining hosts, viz. a male before its last moult and two not quite adult females, have not been dissected, but it 
conld be observed through the carapace that in one of the specimens (a female), the parasitic (no doubt adult) female had not begun laying eggs, whereas the two other specimens lodged not a few ovisacs beneath their carapace.

REMARKS. In this small species the female is smaller and the eggs comparatively larger than in any other form of this family hitherto found. It is closely allied to Homoeoscelis minuta, though the male in particular is easily distinguished from this species by its shorter legs. It may be observed that an examination of numerous specimens of Iphinoë trispinosa from Denmark gave a negative result.

\section{Sphæronella Salensky (1868).}

FEMALE. Head small, generally, though not always, defined from the trunk, which is ovate or globular, sometimes even a little broader than long. Maxillipeds large or rather large and at least always longer than the maxillæ. Trunk-legs sometimes wanting; if found, they always consist of one minute cylindrical joint with a couple of terminal setæ, or they are reduced to small eminences. Genital area is found and always well developed, so that the genital apertures - which are rather or very close together - and the entrances to the two receptacula seminis, which are situated close in front of them, are surrounded or at least bordered posteriorly and at the sides by common rather solid chitine. Caudal stylets are sometimes wanting; if found, they are shaped somewhat like the trunk-legs and terminate in one, two or three setæ. - Spermatophores frequently observed.

MALE. This sex is known in a little more than two thirds (twenty-five) of the species. The body, seen from below, is ovate or sub-globular (seen laterally, the back is much vaulted, the ventral side rather flat, sometimes even concave in the middle). The head always furnished with frontal and lateral borders. The trunk is covered with hairs on the larger part of the ventral surface, as a rule, also on its sides and on the whole or part of the back. Trunk-legs and caudal stylets sometimes wanting, but generally found, and in this case differing much from each other. The trunk-legs always deviating very much from those of the females.

OVISACS. Always deposed freely.

LARVA. Observed in scarcely half of the species. Antennæ at most a little longer than the antennulæ, sometimes very short. Maxillipeds situated close behind the maxillæ. Peduncle of the natatory legs of medium breadth or narrow. Posterior abdominal segment together with the caudal stylets nearly always smaller than the penultimate segment. Long seta of the caudal stylets longer than half the length of the cephalothorax.

POST-LARVAL DEVELOPMENT. Known or partly known in several species (s. above). 
HABITAT. The marsupium of Amphipoda, Cumacea and Isopoda. Younger females and animals in various stages of development of some species are also found on the ventral surface of the thorax in Amphipoda. Found in Denmark, Norway, Greenland, in the Kara Sea, the Mediterranean, off Cuba, and finally on the East-coast of Asia between about lat. $22^{\circ}$ and $51^{\circ} \mathrm{N}$.

REMARKS. This genus is very large. Subsequently thirty-four species will be described, besides S. Leuckartii Sal., which I have not seen (and S. diadema G. and B. which has not been described). The above given diagnosis of the genus is rather meagre, and it is easy to see that some of the characteristics are qualified by an »either . . or The obvious reason is that many of the species in several respects vary considerably among themselves. Above, on p. 82-83 I have already given a general view of the most important of these differences, stating my reasons for not feeling justified - in spite of these differences to divide the genus into several genera.

It is impossible, for two reasons, to give complete analytical keys of the two sexes in all species, firstly, because the male is unknown in nine species, secondly, because the diferences between the females and between the males in one small division are too vague to be represented with sufficient preciseness in such a conspectus. However, in order to procure a kind of general view, I will divide all species into three groups according to the order's of their hosts, subsequently giving as good a conspectus as possible of each of the two sexes in the species of each group. In this place I will only give the analytical keys of the first division; the other keys will be found immediately preceding the divisions to which they belong.

\section{a. Parasites on Amphipoda.}

It may be observed that the males of this group always have well developed trunklegs and caudal stylets. In the larvæ the front is never furnished with processes or lists in the sub-median part (there are one or two rather small lists near the basis of each antemnula), the basal joint of the maxilla is smooth, without combs, and the terminal joint not serrated.

\section{Conspectus of the Females.}

The figures preceding the names of the species indicate their number in the subsequent representation. In this conspectus all species are included except $S$. abyssi $\mathrm{n}$. sp., of which my knowledge is too fragmentary ( $\mathrm{s}$. the description below).

1. Head with distinct frontal border and distinct prominent lateral borders. Genital area

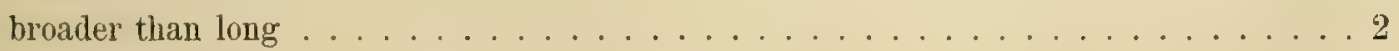


1'. Head without distinct frontal border; lateral borders wanting. Genital area longer than broad...................26. S. microcephala G. and B.

2. Antennæ quite rudimentary. A tuft of hair near the base of each maxillula.

Group: S. Leuckartii Sal. including the following species: . . . 1. S. elegantula n. sp., 2. S. Atyli n. sp., 3. S. danica n. sp., 4. S. vestita n. sp., 5. S. Leptocheiri n. sp., 6. S. messinensis n. sp, \%. S. chinensis n. sp., 8. S. antillensis n. sp.

2'. Antennæ pretty well developed. No hair-tufts near the base of the maxillulæ . . . 3

3. Frontal margin without expansion in the middle . . . . . . . . . . . . 4

3'. Frontal margin with a flatly cup-shaped expansion in the middle . . 25. S. frontatis n. sp.

4. Trunk covered with short hairs, 2- or 3-branched at their basis .........5

4'. Trunk naked or with rather few, simple hairs . . . . . . . . . . . . 6

5. Candal stylets situated between the genital apertures. The trunk thickly covered with hairs ...................... . . . . Calliopii n. sp.

5'. Caudal stylets situated behind the genital apertures. Hair-covering less thick.

10. S. irregularis $\mathrm{n}$. $\mathrm{sp}$.

6. Trunk fastened to the host by a very short ventral thread. . . 11. S. paradoxa n. sp.

6'. Trunk never attached to the host ....................... 7

7. Trunk-legs - if found - cylindrical, with two setæ ............ 8

7'. Trunk-legs distinct, rounded eminences without setæ ... 24. S. Acanthozonis n. sp.

8. Maxillipeds good-sized; their basal joint much longer than that of the maxillæ . . .9

8'. Maxillipeds rather small; their basal joint not much longer than that of the maxillæ.

23. S. Dutichice n. sp.

9. Trunk-legs, if found, with short setæ .................. 10

9'. One of the terminal setæ of the trunk-legs remarkably long, about three times as long

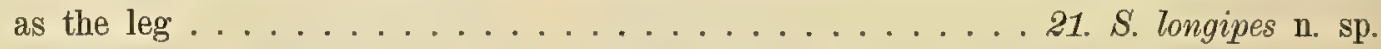

10. Genital area naked or with rather few and - as a rule - scattered hairs .... 11

10'. Genital area provided on each side with a curved line of long hairs.

15. S. Holbölli n. sp.

11. Genital area forming a solid plate . . . . . . . . . . . . . . . 12

11'. Genital area for the most part thin-skinned, the more solid chitine forming a greater

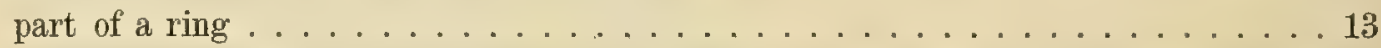

12. Numerous hairs between the base of the maxillæ and the maxillipeds. Genital area with a number of scattered hairs .............. 16. S. intermedia n. sp.

12'. No hairs between the base of the maxillæ and the maxillipeds. Genital area naked.

17. S. capensis n. sp.

13. No transverse list between head and trunk behind the base of the maxillipeds.

13. S. Argissce n. sp. 
13'. At least one transverse list between head and trunk behind the base of the maxillipeds . . 14

14. Head with naked lateral margins (margins of the lateral borders) . . . . . . 15

14'. Head with hairy lateral margins . . . . . . . . . . . . . . . 16

15. Antennulæ rather short and clumsy. Sub-median skeleton without a process at the basal inner angle of the maxillipeds ................ S4. Metope n. sp.

15'. Antennulæ moderately long and slender. Sub-median skeleton with a small process at the basal inner angle of each maxilliped .......... 18. S. Gitanopsidis n. sp.

16. Exceedingly short hairs on the lateral margins of the head. Basal joint of the maxil-

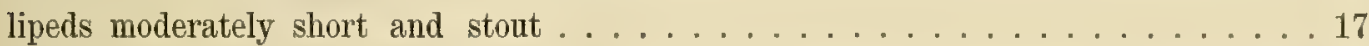

16'. Moderately long hairs on the lateral margins of the head. Basal joint of the maxillipeds long and slender........................... Amphilochi n. sp.

17. Caudal stylets behind or on the posterior margin of the ring of the genital area.

19. S. Giardii n. sp.

17'. Caudal stylets at some distance in front of the posterior margin of the ring of the

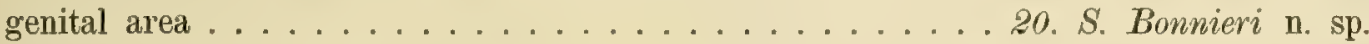

\section{Conspectus of the Males known.}

1. Dorsal surface of the trunk with (at least) a transverse line or belt of hairs, or covered

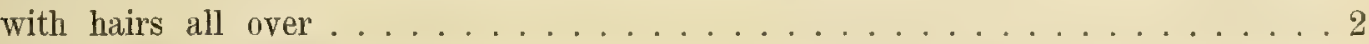

1'. Dorsal surface of the trunk quite naked ............26. S. microcephala

2. Frontal border with two very deep and broad incisions dividing it into three plates, the median one of which is large, long and broad and nearly square, the lateral ones

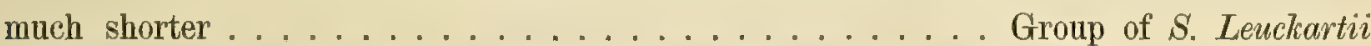

2'. Frontal border not deeply incised, the margin crenate or entire . . . . . . . 3

3. Frontal margin crenate, forming six lobes of which the most external ones are low.

9. S. Calliopii

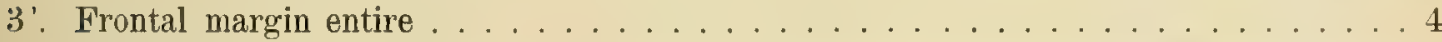

4. Trunk covered with single hairs or with (at most) 3-branched setaceous hairs (3 hairs

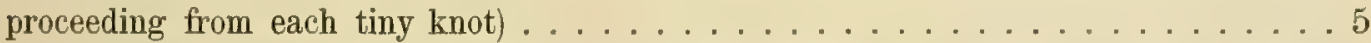

4'. Trunk covered with tiny oblong transverse knots, from each of which proceed about ten very fine hairs, radiating backward and sideways ........ 25. S. frontalis

5. Each caudal stylet with a very conspicuous seta, which is from about thrice to many times the length of the stylet . . . . . . . . . . . . . . . . . .

5'. Each candal stylet with two or three moderately short setæ, none of which is very

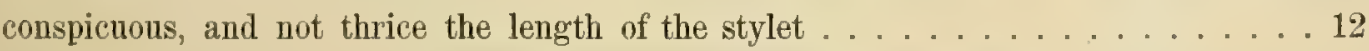

6. First pair of legs 1-branched, the branch ending in a long seta ......... 7

6. First pair of legs 2 -branched, the outer branch ending in a long and a shorter seta, the inner branch in a conspicuous, shorter or longer terminal seta . . . . . . 9 
7. Sub-median skeleton with two pairs of processes (second and third pairs) between the bases of the maxillipeds. Terminal setæ of the caudal stylets somewhat longer than the basal joint of the maxillipeds ....................... paradoxa

7'. Sub-median skeleton with only one pair of processes (second pair) between the bases of the maxillipeds. Terminal setre of the caudal stylets scarcely the length of the

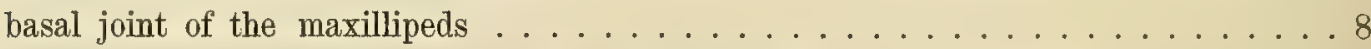

8. Basal joint of the maxillæ without any prominent plate ....... 16. S. intermedia

8'. Basal joint of the maxillæ with a prominent plate with spiniform marginal processes round the distal, inward and backward turning angle ......... 17. S. capensis

9. Terminal seta of the caudal stylets somewhat longer than the terminal seta of the outer branch of the first pair of legs ............... 12. S. abyssi

9'. Terminal seta of the caudal stylets a little or much shorter than the terminal seta of the outer branch of the first pair of legs .......................

10. Terminal seta of the caudal stylets at least four to six or eight times longer than the stylets, and much longer than the secondary seta of the outer branch of the first pair

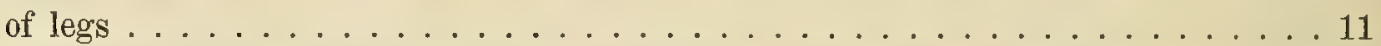

$10^{\prime}$. Terminal seta of the caudal stylets only about three times the length of the stylets and not longer than the secondary seta of the outer branch of the first pair of legs.

13. S. Argissa

11. Terminal seta of the inner branch of the first pair of legs equal in length to, or longer than the distance between the base of the same leg and the end of its outer branch.

14. S. Metope

11'. Terminal seta of the inner branch of the first pair of legs somewhat shorter than the distance between the bases of the same legs and the apex of their outer branch.

15. S. Holbölli

12. First pair of legs with a long seta at the apex of the single branch, none on the

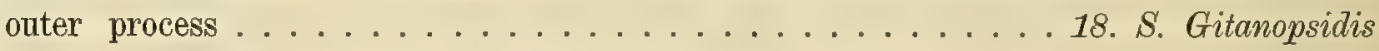

12'. First pair of legs with two branches, the terminal setæ of which are shorter than the

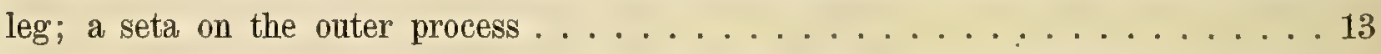

13. Trunk not much larger than the head, with setaceous hairs, proceeding two or (generally) three together from tiny knots .................. 19. S. Giardii

13'. Trunk more than double the size of the head, with moderately thin, normal hairs.

20. S. Bonnieri.

\section{About species 1-8: Group of Sphoeronella Leuckartii.}

In seven species belonging to the genera Paratylus G. O. Sars, Cheirocratus Norm., Leptocheirus Zadd., Gammaropsis Lilljbg., Microprotopus Norm. and Corophium Latr., taken in Denmark, Sicily, Cuba and Hong-Kong, I have found parasites which bear a close resem- 
blance to one another and to Sphar. Leuckartii Sal. from Naples. The Danish forms which are taken on animals of the two first and the two last-mentioned genera, deviate quite as much from each other as from the exotic forms, and quite as much as the latter deviate from each other. In studying a not very large material of specimens taken on two of the genera (Cheirocratus and Corophium) it appeared, on the one hand that the haircovering of the females sometimes, but not always, varied very much according to age (Salensky already found that the recently hatched females of $S$. Leuckartii were more hairy than the adults), on the other hand that adult, egg-laying females taken on the same species (Cheirocratus Sundevalli) also varied much with respect to the quality of their hair-covering on the anterior part of their trunk and on the genital area, and to the appearance of tufts of hairs on various parts of the ventral side of the head; however, these last-mentioned differences seem to be accounted for by the fact that one of the adult specimens had retained part of the hair-covering it had had when young. Between adult females taken in the same species there was some difference in the distance between the caudal stylets and the genital area, still the differences in this area and in the situation of the caudal stylets were much smaller in animals taken in the same species than in several of the forms taken in hosts of different species. The size of the egg-laying females was very different, varying according to the size of the infested species, so that a specimen from Cheirocratus was thrice the length of one from Gammaropsis. There was considerably less difference of structure between the males of various species than between the females, and much less difference of size. Some of the differences found between the males were decidedly of an individual or accidental nature. These data placed me in the dilemma of either considering all the animals I had found as belonging to one species, though a very variable one, infesting animals of widely differing families of Amphipoda, and being spread over an immense geographical area, or to admit the eight species established here. Future naturalists who will have a much larger material at their disposal to throw light on the varieties of individuals taken in the same species, and at the same time will have many parasites from hosts of different genera, must pronounce the final verdict on this matter. (Perhaps some day it will be possible to solve the question, whether parasites from one genus often can infest animals belonging to other genera, by cultivating in an aquarium non-infested specimens of the genera that are to be examined, together with infested and non-infested animals of another genus; then perhaps it will be seen, whether the larvæ, which no doubt swim about only a short while, exclusively seek specimens of the same species as the host of the mother, or whether they also infest and develop themselves on the other genera). Not having found any parasite on Microdeutopu. gryllotalpa Costa, I must consider Spher. Lenckartii Sal. as a ninth (to me unknown) species. Unfortunately Salensky's description and figures are far from being sufficiently exact in the details with which we are here concerned. If my species were to be united into one, no doubt it would have to be under the name of S. Leuckartii, but I will conclude with the remark that I consider it rather improbable that such an arrangement would prove to be well-founded. 
I think the best plan is to begin by giving an account of the features which are common to all species, subsequently describing each species separately. A tuft of hairs outside the base of the maxillulæ in both sexes, and the shape of the frontal border in the male, are probably the most characteristic features which distinguish them from all other species of the genus Spheronella.

FEMALE. Body ovate or sub-globular, with well-defined head. Antennulæ of about medium length, 3-jointed, the last joint provided with rather short setæ. Frontal margin naked. Antennæ rudimentary (pl. ПII, fig. $2 \mathrm{c}, \mathrm{c}$ ), but generally visible. The mouth of middle size. Setæ of the mouth-border of medium length. Maxillulæ provided with an additional branch; outside and somewhat behind their base a peculiar, pretty large tuft of hairs turning outward. Maxillæ of medium size. Maxillipeds normal, with hairy spots on their basal joint. The sub-median skeleton between the rostrum and the base of the maxillipeds forms rather broad longitudinal plates, but there is no transverse list on the ventral side at the posterior limit of the head. The lateral margin of the head provided with a row or a stripe of moderately long hairs. Trunk-legs and caudal stylets always distinct (e. g. pl. II, fig. 6 a). Genital area much narrower than the head, broader than long, platelike or only with a solid ring which has no opening in front. The curved genital apertures turu their front extremity forward, their hind extremity sideways, and their distance from each other is shorter than the length of each. Caudal stylets either on the posterior margin of the genital area (pl. II, fig. $5 \mathrm{~b}$ ) or, as a rule, behind or far behind it (pl. II, fig. 3 b).

MALE. This sex is known of six of the species. The body is from one third to one half longer than broad. The head about the size of the trunk. The frontal border produced so as to form in advance of each antennula a pretty large, rounded, distally ciliated lobe, which is separated by a deep and broad incision from the odd, long, broad and almost square median plate, the sides of which are often somewhat diverging, sometimes parallel; its slightly curved anterior margin, as well as the distal part of the lateral margin, are furnished with fine and short hairs. Antennulæ, antennæ, rostrum, maxillulæ, the hair-tuft at their basis, maxillæ and maxillipeds, chiefly as in the female. The sub-median skeleton with first and second pairs of processes well developed; first pair rather prominent, triangular, pointed, situated close in front of or overlapping the base of the maxillipeds; second pair situated at the inner angles of the maxillipeds, elongated, extending over the basal part of the trunk, and more or less diverging. Lateral margin of the head ciliated; from its posterior extremity a narrow belt of long hairs extends upward over the side and in an oblique direction across the back. The ventral surface, the sides and the hindmost part of the trunk are covered with moderately long; posteriorly towards the back with very long hairs, leaving a large naked area behind the above-mentioned transverse belt. The legs of moderate and sub-equal length; the first pair consist of a peduncle, one branch, and a short conical process on the outer side at the apex of the peduncle; the proximal part of the peduncle is stout and rather broad; the branch which must be homologous with the outer one in the following 
species, is shorter than the peduncle and terminates in two setæ, one short, the other longer or somewhat shorter than the peduncle plus the branch, and finely plumose; the outer process terminates in a short seta. The branch - at least in most cases - is not distinctly set off from the peduncle by an articulation; if nevertheless this seems to be the case sometimes, it may be owing to an optical delusion. The second pair of legs consist of a rather short and slender peduncle and two branches, the outer of which is short, conical and terminates in a short seta, the inner one agrees with the branch on the first pair of legs and terminates in similar setæ ${ }^{1}$ ) (the outer branch is never set off by an articulation). The caudal stylets are comparatively long, with a seta which is shorter than the stylet and proceeds from its inner angle. - The animals are sometimes hinged by a frontal thread (pl. II, fig. 4 b), the very complex structure of which is described above on p. 42-43.

OVISACS. They are ovate, in the large species of comparatively medium size, in the small ones very large compared with the females, and in the small species the female probably lays only four to five, in the largest species as many as ten ovisacs (possibly even more).

LARVA. Known in only two species: S. elegantula and $S$. antillensis (pl. III, fig. 2 e); the latter is the one described here. Cephalothorax seen from below, a somewhat elongate oval. On the front, inside the base of each antennula, two lists, running so as to form a somewhat acute angle, but they do not quite meet. Antennulæ 3-jointed, the olfactory seta reaching a little beyond the middle of the cephalothorax and measuring less than three times the length of the antennula. Antennæ somewhat longer than the antennulæe and specially characteristic by consisting of four joints of subequal length and a terminal seta which is longer than the two last joints together, or about as long as the three last joints. Of maxillulæ only two naked branches have been found. Maxillæ rather robust. Maxillipeds of scarcely medium length, second and third joints of about sub-equal length. Peduncle of the natatory legs moderately slender. Abdomen proportionally short and broad; the long, stout seta at the posterior angle of the first segment reaches far beyond the extremity of the caudal stylets; third segment very short, and the not defined caudal stylets also short, their terminal seta more than three quarters the length of the cephalothorax.

POST-LARVAL DEVELOPMENT. Very peculiar; we refer to the description given above on p. 58-60.

HABITAT. All my eight species were found exclusively in fully developed marsupia which contained no eggs or young ones of the host. Salensky states that his S. Leuchartii were found both in females and in males, but the latter, no doubt, were young females (comp. above, p. 66-67).

1) For a long time I considered the branch on the first pair of legs to be not the outer but the inner one, and the conical process to be the outer branch of the leg, but a comparison with some of the other species (e. g. S. Metopa and S. Giardii) will prove the interpretation adopted to be correct. Perhaps the interpretation of the branches of the second pair of legs will not prove to be correct, but for the present it is impossible to decide this question with any certainty. 


\section{Sphæronella elegantula $\mathrm{n}$. sp.}

(P1. II, fig. 2a-2 g.)

FEMALE. An adult specimen (fig. 2 a) was $1.31 \mathrm{~mm}$. long and $1.16 \mathrm{~mm}$. broad; the head is a little more than middle-sized, the trunk globular. One of the specimens dissected differed considerably in hair-covering from the two others and may be described first. Tufts or rows of hairs were found on the proximal part of the inner side of the basal joint of the maxillæ and on the skeleton in front of and outside the articulation of the maxillæ, in front of the anterior inner angle of the maxillipeds, above their posterior inner angle and behind their articulation. The greater part of the trunk was naked; a moderately broad, transverse belt behind the head was rather closely covered with most peculiar hairs, which are also found on the genital area. This area (fig. 2 e) is considerably broader than long, and the solid chitine forms a rather broad ring and a median list which is broad posteriorly; the distance between the genital apertures is of medium length; the caudal stylets are situated far from each other and at a considerable (though not equally considerable) distance from the posterior margin of the area. The region between the caudal stylets, the interval between these stylets and the genital area, the posterior part of the genital area, the part in front of it and just inside its outline are more or less densely covered with most peculiar, very broad, somewhat flattened, long hairs, which, however, are so strangely transparent and membranous, that their ontlines are difficult to follow, whereas, on the contrary, their bases form conspicuous ovals, one half of which is more distinct than the other (in fig. 2 e all these ovals are drawn, but only very few of the hairs themselves). - In another specimen the ventral side of the head had hairs only in front of the basis of the maxillæ and at the anterior and posterior inner angles of the articulation of the maxillipeds. Behind the head the trunk had a belt provided with short and fine, basally somewhat dilated hairs. The genital area had nearly the same shape as that of the preceding specimen, but its posterior margin was slightly more concave; the caudal stylets were situated a little nearer (but not equally near to) the area, and the part between and behind the genital apertures, as well as the skin stretching from the genital area to a good distance behind the caudal stylets was less densely furnished with hairs of the same shape as those on the front part of the trunk, while the membranous hairs were entirely wanting. - A third specimen agreed essentially with the last-mentioned one.

MALE. The largest specimen is $31 \mathrm{~mm}$. in length, the smallest, which is not fullgrowu, measures $23 \mathrm{~mm}$. It is of medium size compared with the female (fig. $2 \mathrm{~b}$ : fig. 2 a). The body comparatively slender (fig. $2 \mathrm{f}$ ). The lateral margins of the median frontal plate diverge distally, the anterior angles are sharp. The processes between the base of the maxillipeds are long or very long; the trunk-legs proportionally long; the terminal seta of the branch on the first pair and of the inner branch in the second pair longer than the leg. 
OVISACS. Of medium size (fig. 2 c), only slightly differing in size.

LARVA. Only one specimen was found, it was hinged. Its cephalothorax is very broad and thick; the condition of the contents seems to indicate that the larva was developing into a male (comp. above, p. 60). Except in this clumsiness of shape, it agrees entirely with the larva of $S$. antillensis (pl. III, fig. $2 \mathrm{e}$ ).

HABITAT. The marsupium of Cheirocratus Sundevalli (Rathke) from Denmark; till now found only in four specimens. In one specimen were found: one adult female, two males and six ovisacs; in the second: one adult female and four pupr; in the third: one adult female, one male and ten ovisacs; finally, in the fourth: one adult female, three males (one of them hinged to the base of the hindmost gill), six ovisacs and one larva hinged on the base of the penultimate gill.

REMARKS. The above-described difference in the hair-covering of the adult females appears remarkable to me. The female is larger, the male longer and more slender than in any of the following species.

\section{Sphæronella Atyli $\mathrm{n}$. sp.}

(Pl. II, fig. $3 \mathrm{a}-3 \mathrm{~b}$.)

FEMALE. The largest specimen was $99 \mathrm{~mm}$. in length, a specimen with seven ovisacs only $66 \mathrm{~mm}$. Shape like the preceding species. Two specimens have been dissected, and the skeleton of their heads (fig. 3 a) was found to want all the hair-tufts described in the afore-mentioned species, so as to leave only the tufi of hairs at the base of the maxillulæ, which is a distinguishing mark of the group. The trunk naked except a belt behind the head, which is covered with numerous, but exceedingly fine and short hairs. The genital area (fig. 3 b) considerably broader than long, the solid chitine forms a ring; the larger part of which is rather broad, as well as a median list; anterior and posterior margins considerably concave; moderately long distance between the genital apertures; the caudal stylets are situated far from each other and at a long or very long distance from the area; genital area and its surroundings naked, except the usual, narrow arch outside each genital aperture.

MALE. Length $.22 \mathrm{~mm}$. More like the male of S. chinensis (pl. III, fig. $1 \mathrm{a}$ ) than like that of the preceding species. The body is clumsier than in this species, the median frontal plate is shorter, with converging margins and rounded anterior angles. The trunk-legs more slender than in S. elegantula; the terminal seta on the branch of the anterior legs shorter than the leg, that on the inner branch of the posterior pair slightly longer than the leg.

OVISACS. Comparatively larger than in the preceding species, differing little from one another in size. 


\section{LARVA and POST-LARVAL DEVELOPMENT. Unknown.}

HABITAT. The marsupium of Paratylus Swammerdamii (M.Edw.) from Denmark. Found only in five specimens. Two of these contained only one adult female each, the third had an adult female and a male, the fourth one male and seven ovisacs. The fifth specimen contained no female, but thirteen ovisacs, but whether all these belong to one single female which has fallen ont, cannot be decided; some of the sacs contain almost fully developed larvæ.

\section{Sphæronella danica $\mathrm{n}$. sp.}

(Pl. II, fig. 4 a-4 e; pl. XIII, fig. 2 a.)

FEMALE. The largest specimen was $\cdot 88 \mathrm{~mm}$. in length, $\cdot 76 \mathrm{~mm}$. in breadth. Shape of the body much the same as in S. chinensis. It will be to the purpose to begin with a description of this specimen. The most proximal part of the basal joint of the maxillæ is hairy on its inner side; there is moreover an area densely covered with hairs in front of, and a similar one behind the base of the maxillipeds. A part of the trunk behind the head is furnished with a number of fine, simple hairs, the remainder of it is naked. The genital area (fig. $4 \mathrm{a}$ ) is somewhat broader than long, the greater part rather solidly chitinised; the genital apertures at moderately long distance from each other; the caudal stylets far from each other, but not very far from the posterior margin of the area; between and behind the genital apertures the area is furnished with normal, fine hairs, and so is the skin extending from the area to somewhat behind the caudal stylets. - A much smaller specimen, only $45 \mathrm{~mm}$. long, has a comparatively large head, and its trunk is a little longer than broad. Distribution of hairs on the head as in the large specimen; the trunk seems to be quite naked, and the genital area, which was not cut off, is well developed and - as far as can be judged - seems to agree with that of the large specimen (a spermatophore was also attached to it). - In a somewhat smaller specimen, $41 \mathrm{~mm}$. long, which was dissected, the hairs behind the base of the maxillipeds were wanting, the trunk was hairy anteriorly as in the largest specimen, but the genital area was not developed (pl. XIII, fig. 2 a), the more solidly chitinised part being represented only by a rather small area surrounding the entrances to the receptacula seminis (one of these is indicated by a dotted line). The genital apertures themselves are as in the adult animal, but the caudal stylets are situated close behind them, and the surface between and behind these apertures extending beyond the stylets, is furnished with normal hairs. - Another specimen which is even a little smaller, measuring $.407 \mathrm{~mm}$. in length, deviates in many respects from the preceding animals. The body is a nearly elongate oval; the head which takes up a good deal more than one third of the whole length, and which is very large, has, in addition to the hairs found in the large specimen in front of and behind the base of the maxillipeds, conspicuous tufts or stripes of hairs on the inner side of the base of the maxillæ and on the skeleton in front of and 
outside the articulation of these appendages. The trunk is closely covered all over with the peculiar membranous hairs which are mentioned above as having been found on the anterior part of the trunk and on the genital area of the one specimen of $S$. elegantula. - Two still smaller specimens - the smaller one only $\cdot 34 \mathrm{~mm}$. long and $19 \mathrm{~mm}$. broad, - are very like the last-mentioned specimen, which shows that these three very young animals differ very much from the older ones in the hair-covering of the head and - particularly - in that of the trunk. As a matter of course, the genital area is not developed in these small specimens, but the animal mentioned as measuring $41 \mathrm{~mm}$. shows that, at least sometimes, this area does not develop its final shape till some time after the animal has lost the hair-covering that was characteristic of it when young. For want of ampler material I cannot decide whether this course of development is the rule in this species.

MALE. A large specimen is $24 \mathrm{~mm}$. in length. It is somewhat more clumsy than the male of $S$. elegantula, but on the whole closely resembles this species, as e. $g$. in the shape of the median frontal plate, which, however, is a little shorter, and in the legs, the long terminal setæe of which are longer than each leg; but the anterior pair of trunk-legs seem to be smaller, compared with the basal joint of the maxillipeds, than in the aforementioned species; the caudal stylets are hardly so long. - The smallest male found is only $15 \mathrm{~mm}$. long, but it seems to be just hatched, for the frontal plate is bent downward, the rostrum backward and the antennulæ turn backward (comp. p. 60).

OVISACS. Are pretty large, but occasionally show great difference of size, being shortly oval or sub-globular.

LARVA. A single hinged specimen was found, but is lost.

POST-LARVAL DEVELOPMENT. Nine pupæ have been found, all closely covered with hairs (fig. $4 \mathrm{c}-4 \mathrm{e}$ ); the smallest $115 \mathrm{~mm}$., the largest $.25 \mathrm{~mm}$. in length. As for more particulars, I refer to the detailed account on p. 59-60.

HABITAT. The marsupium of Corophium crassicorne Bruz. from Denmark. In one specimen were found one pupa and the smallest above-mentioned female; in another the smallest female but one and one male; in a third specimen a young female and a hinged larva; in a fourth the largest female but one, one male and four ovisacs of very different size; in a fifth specimen a small female; in a sixth animal the largest female, one pupa and two males, both fixed by a frontal thread, one of them being an adult, while the other was the ahove-mentioned, recently hatched individual. In a seventh specimen four ovisacs were found, no female, but the anterior halves of two males, which had evidently been destroyed before the host was caught. Finally, in an eighth specimen, two ovisacs and seven pupæ, two of which were sitnated each on one side of the marsupial plate of the sixth (right) leg, one on the gill of the penultimate (left) leg, one on the inner side of the basal joint of the posterior left leg. 


\section{Sphæronella vestita $\mathrm{n}$. sp.}

(Pl. II, fig. 5 a -5 b.)

FEMALE. The largest specimen (fig. 5 a) is $449 \mathrm{~mm}$. long and $.335 \mathrm{~mm}$. broad; the body is ovate, and the proportionally very large head occupies about one third of the total length; another specimen of the same shape is only $44 \mathrm{~mm}$. long. Tufts or stripes of hair are found on the inner side of the basal joint of the maxillæ, on the skeleton ontside their articulation, in front of and behind the basal part of the maxillipeds, as well as above the middle of their articulation. The trunk is densely covered all over with peculiar, very broad, apparently shorter than broad, obliquely proceeding "scales", which are transformed hairs. The genital area of the large specimen (fig. 5 b) is cut off; it was shortly oval and somewhat broader than long, yet somewhat longer compared with the breadth than the preceding species; its solid chitine forms a ring which is rather broad in front, posteriorly it seems to be open; the distance between the genital apertures is moderately great; the caudal stylets are situated on the posterior margin of the area, and the distance between them is rather considerably smaller than in the preceding species; the region between and behind the genital apertures and the part surrounding the caudal stylets are closely covered with the above-described "scales", while the remainder of the skin inside the ring has much fewer "scales", and the ring itself is almost naked. The genital area of the smaller specimen seems to agree essentially with that of the larger one.

MALE. Length: $234 \mathrm{~mm}$. Resembles the male of the preceding species, but the median frontal plate seems to be a little longer and the second pair of legs a little shorter.

OVISACS. They are somewhat to not very much smaller than the females.

LARVA and POST-LARVAL DEVELOPMENT. Unknown.

HABITAT. The marsupium of Microprotopus maculatus Norm. from Denmark; found only in two specimens. In one animal were found: one female (the largest), one male and four ovisacs, which are oblong, glued together and contain larvæ which are more or less, but not fully developed. In the other specimen were found: one female, one male and five ovisacs, each of which was somewhat smaller than the female.

REMARKS. In the shape of the body, the hairs-tufts on the head and the peculiar close covering of sscales " on the trunk, the two females found agree essentially with the scarcely half-grown or very small females of $S$. danica; they are, however, somewhat larger than these; each of them had a spermatophore attached to it and a developed genital area, from which we may conclude that they are both adult and have laid the ovisacs which were found together with them. This supposition is confirmed by the circumstance that the hosts are too small to contain parasites of the size of $S$. danica. 


\section{Sphæronella Leptocheiri n. sp.}

(Pl. XIII, fig $3 \mathrm{a}-3 \mathrm{e}$ )

FEMALE. The only specimen found (fig. 3 a) was $76 \mathrm{~mm}$. long and $64 \mathrm{~mm}$. broad; its head somewhat exceeding middle size, the trunk almost globular. On the sub-median skeleton of the head (fig. $3 \mathrm{c}$ ) there are no hairs at the articulation either of the maxilla or of the maxillipeds, but a few hairs are found (though not drawn in the illustration) at the base of the inner side of the basal joint of the maxillæ. The trunk is naked, except a comparatively small area behind the median part of the head, which is provided with a number of extremely short and fine hairs. Genital area (fig. 3 d) much as in S. Atyli, but the anterior extremities of the genital apertures come much nearer to each other, and the ring is somewhat narrower. The distance between the caudal stylets is very great, and between the stylets and the posterior margins of the area it is rather considerable; the whole area and its surroundings are naked.

MALE. Length $20 \mathrm{~mm}$. (fig. 3e). The shape a little more clumsy than in S. elegantula; the median frontal plate of medium length, its lateral margin somewhat converging, but the anterior angles are acute and a little produced. The trunk-legs a little longer, or at least not shorter, than the long terminal seta.

OVISACS. I have only found an incomprehensible abnormity, viz. the outer membranes of two ovisacs, one of them containing only one single egg, the other a large and a small one; otherwise they were empty bags.

LARVA and POST-LARVAL DEVELOPMENT. Unknown.

HABITAT. In the marsupium of a Leptocheirus guttatus Grube, taken by me near Siracusa on rocky ground, twelve to twenty-five fathoms, in June 1893, were found: one female, two males and the two just mentioned, nearly empty membranes of ovisacs. (The host is determined by the Rev. Th. R. R. Stebbing).

\section{Sphæronella messinensis $\mathrm{n} . \mathrm{sp}$}

(Pl. XIII, fig. 4 a-4 c.)

FEMALE. The only specimen found (fig. $4 \mathrm{a}$ ) was $44 \mathrm{~mm}$. long and $32 \mathrm{~mm}$. broad; the borly sub-ovate, the head proportionally large and the trunk scarcely longer than broad. In fig. $4 \mathrm{~b}$ are shown some hairs at the base of the inner side of the basal joint of the maxillæ, and on the sub-median skeleton a row of hairs in front of the anterior inner angle of each maxilliped. The trunk quite naked. The genital area (fig. $4 \mathrm{c}$ ) of similar shape to that of $S$. eleguntula, conseqnently much broader than long, the larger part solidly chitinised; distance between the genital apertures moderately great, but they are turned so much that their imner and front extremity advances only very little beyond the posterior extremity, the 
result being that their muscles are nearly parallel with the median line. The caudal stylets are situated far from each other, but close behind the posterior margin of the genital area. The whole area and its surroundings are naked.

MALE. Unknown.

OVISACS. Three oblong sacs have been found, their average length being like that of the female.

\section{LARVA. Unknown.}

POST-LARVAL DEVELOPMENT. A pupa densely covered with hairs all over is $.22 \mathrm{~mm}$. in length and $16 \mathrm{~mm}$. in breadth.

HABITAT. In the marsupium of a specimen of Gammaropsis melanops G. O. Sars, taken by the author in the harbour of Messina in May 1893, were found: one female, three ovisacs and one pupa. (The Rev. Th. R. R. Stebbing has kindly determined the host; he writes: "The specimen is imperfect, but appears to be Gammaropsis melanops G. O. Sars").

REMARKS. It must be supposed that the ovisacs were laid by the small female which was found together with them, and to which a spermatophore was attached, for the host is so small that the parasite must of necessity be small too. So it appears that in this respect this species is like $S$. vestita, but there is this difference, among others, that the trunk and the genital area are perfectly naked.

\section{Sphæronella chinensis $\mathrm{n}$. sp.}

(Pl. II, fig. $6 \mathrm{a}-6 \mathrm{f}$; pl. III, fig. $1 \mathrm{a}-1 \mathrm{c}$.)

FEMALE. The only specimen found (fig. 6 a) was $1.01 \mathrm{~mm}$. long and $88 \mathrm{~mm}$. broad; the head a little above medium size, the trunk globular. The base of the maxillæ and the part in front of the maxillipeds covered with hairs, as in the preceding species. The trunk rather scantily furnished with most peculiar membranous hairs, the base of which forms a very broad and flattened oval, and from this broad base the flattened hair increases somewhat in breadth, whereupon it is rounded off rather abruptly, which gives the whole hair almost the outline of an egg, the tapering end of which is cut off. The genital area has about the same shape as in S. vestita, so it is longer compared with the breadth than in the other species, and forms a short oval, but the larger part of it is solidly chitinised; the distance between the genital apertures is a little shorter than in $S$. vestita, but their form and direction are as in this species; the distance between the caudal stylets is of medium length and about equal to their distance from the area. The area is provided with membranous hairs, which in several places form a covering as close as the "scales in S. vestita; finally, the surface extending from the area to somewhat beyond the caudal stylets is furnished with similar hairs; the greater part of these hairs are much narrower than those of the trunk and also different in shape, the hair in its proximal part being of equal width and then gradually tapering ends in a point. 
MALE. The only specimen found (pl. III, fig. $1 \mathrm{a}-1 \mathrm{~b}$ ) is $174 \mathrm{~mm}$. long. The body comparatively somewhat shorter and broader than in $S$. elegantula; the median frontal plate of medium length, a little broader at the end than behind the middle, with rounded anterior angles. Trunk-legs, the first pair particularly, a little shorter and somewhat more slender than in $S$. elegantula and a little shorter than the long terminal seta.

OVISACS and LARVA. Unknown.

POST-LARVAL DEVELOPMENT. Two pupæ have been found, one of them $146 \mathrm{~mm}$. long (fig. $6 \mathrm{c}$ ), in which no animal had as yet developed itself (fig. 6e) (the strongly coagulated contents are marked in the drawing by darker shading); the other, .24 $\mathrm{mm}$. in length (fig. 6d, hair-covering omitted) contains an almost fully developed female (fig. $6 \mathrm{f}$ ). Both pupæ, a more detailed mention of which is given on p. 58-60, are elosely covered with hairs all over, except on the area in front of the mouth.

HABITAT. The marsupium of Corophium Bonellii M.-Edw. from Hong-Kong. In one specimen were found: one female, one male and one pupa, in another one pupa. The hosts were taken by H. Koch (1872) and kindly determined for me by the Rev. Th. R. R. Stebbing.

\section{Sphæronella antillensis $\mathrm{n}$. sp.}

(Pl. III, fig. $2 \mathrm{a}-2 \mathrm{f}$. )

FEMALE. There have only been found very small, recently hatched specimens and a single large one, which was quite torn. We begin by describing the latter. Rather few hairs are seen on the proximal part of the inner side of the basal joint of the maxillæ, and a small tuft in front of the foremost inner angle of each maxilliped. The trunk is quite naked. The genital area (fig. $2 \mathrm{~d}$ ) chitinised and shaped almost as in S. Atyli, but the anterior and posterior margins are somewhat less concave; the distance and position of the genital apertures as in the last-mentioned species, but the candal stylets are somewhat closer together and only at a short distance from the posterior margin of the area; the area and its surroundings naked. - In the three young ones, two of which are recently hatched and the third on the point of moulting (fig. $2 \mathrm{c}$ ), the hair-tufts on the head are exactly like those of the adult specimen. In the two specimens the trunk is naked, in the third it is furnished with a number of exceedingly short and fine hairs, which occupy a short part behind the head. The genital area is not developed, thus agreeing with the above-described area in a young one of $S$. danica; between and behind the genital apertures are found a number of very fine hairs.

\section{MALE. Unknown.}

OVISACS. Of medium size, somewhat elongate (fig. 2 b); an ovisac which was measured appeared to be $35 \mathrm{~mm}$. in length and $27 \mathrm{~mm}$. in breadth. 
LARVA. Fig. $2 \mathrm{e}$ shows the drawing of a larva (of the natatory legs only the base is represented); it measures $15 \mathrm{~mm}$. in length, and it is used as type in the description on p. 105 of the larva in this group of species.

POST-LARVAL DEVELOPMENT. One pupa, -185 mm. in length (fig. $2 \mathrm{f}$ ) is naked on about the front half of its body, while the posterior part is furnished with numerous very fine and short hairs. Another specimen, $172 \mathrm{~mm}$. in length, is well provided with hairs all over, like the pupæ of S. danica and S. chinensis. A third specimen (fig. 2 a and fig. 2 c) had lost the foremost third part of its skin, where a young female, $245 \mathrm{~mm}$. long, was just emerging; the part of the skill of the pupa which encloses the trunk of the female has the usual hair-covering.

HABITAT. The marsupium of Corophium Bonellii M.-Edw. from Cuba. In one specimen were found a very young female and one larva (or perhaps three larvæ) ${ }^{1}$ ); in another the female shown in fig. 2 a, which has burst the skin of the pupa; in a third the pupa drawn in fig. $2 \mathrm{f}$; in a fourth a recently hatehed female; in a fifth the anterior part of a female, four ovisacs glued together and a pupa covered with hairs, hinged on a gill; finally, in a sixth specimen were found one large, but torn female and two ovisacs. The hosts were taken by Mr. Iversen (1871) and determined by the Rev. Th. R. R. Stebbing.

REMARKS. It is most remarkable that both this and the former species, S. chinensis, occurred in hosts of the same species, from two localities as far removed from each other as Cuba (West-Indies) and Hong-Kong. These localities are no doubt correctly stated, as it is scarcely possible that there can be any mistake in the old labels on the two glasses which contained the hosts. And indeed, there is a great difference, not only in the haircovering of the trunk, but also in the shape of the genital area in the females of the parasites from the two localities, so that one is perfectly justified in establishing them as two separate species. - Whether the afore-mentioned difference in the hair-covering of the pupæ is of any importance, cannot be decided from this find.

\section{Sphæronella Calliopii n. sp.}

(Pl. III, fig. $3 \mathrm{a}-3$ l.)

FEMALE. A large specimen is $2.38 \mathrm{~mm}$. in length and $2.05 \mathrm{~mm}$. in breadth, and the head, which is rather small, is well defined from the sub-globular trunk. In somewhat smaller specimens the trunk is more oblong. The median part of the frontal margin is provided with short hairs (fig. $3 \mathrm{~d}$ ). Antennulæ of medium length, 3-jointed, with rather short terminal setæ. Antennæ small, but distinct, the number of joints - probably two -

1) With regard to two of these larvæ notes are wanting; they were possibly found together with the third one. 
could not be ascertained; the terminal seta is rather long. The mouth is rather large; the mouth-border of medium breadth; the maxillæ provided with a well developed additional branch. The maxillæ moderately large, the distal margin of the basal joint is furnished with hairs along the larger part of the articular membrane (fig. $3 \mathrm{c}$ ). The maxillipeds (fig. $3 \mathrm{f}$ ) scarcely of medium length, all joints separated, the basal joint somewhat clumsy, provided at its distal margin with a few short rows of hairs, a similar row a little outside the middle of the inner margin, and a tuft at the same distance from the base on the opposite margin; the terminal joint ending in three points. The sub-median skeleton between the rostrum and the maxillipeds consists of a pair of moderately narrow lists on each side; the skeleton between the maxillæ and the maxillipeds has a long transverse belt of hairs, some of which are long (in fig. $3 \mathrm{~d}$ the hairs are only drawn on one half of the head.) The lateral margin of the head, as far forward as somewhat behind the base of the antennulæ, is furnished with numerons moderately long hairs, a little outside of which another row of similar hairs, advancing forward outside the base of the antennulæ to somewhat in front of it. The trunk is closely covered all over with short, most peculiar hairs, each of which is divided from its base into three branches, the central one of which is double the length of each of the other two. Trunk-legs are found. The genital area is much narrower than the head, it is as long as broad (fig. $3 \mathrm{~g}$ ) and solidly chitinised all over; the oblique genital apertures are rather far apart, the caudal stylets situated close together between the distal parts of the genital apertures. The whole genital area is almost naked, except some rows of normal, fine hairs between the genital apertures, furthermore, a crescent-shaped area in front of and outside the anterior half of the genital area is likewise naked, whereas the peculiar haircovering of the posterior part of the trunk extends up to the caudal stylets and to the posterior extremities of the genital apertures.

MALE. A large male is $30 \mathrm{~mm}$. in length, whereas an abnormally small, probably far from adult specimen is only $182 \mathrm{~mm}$. long; the proportion between length and breadth is approximately as 4 to 3 . So the male is very small in proportion to the adult female (fig. $3 \mathrm{~b}: \mathrm{fig} 3 \mathrm{a}$ ). The head is about the size of the trunk (fig. $3 \mathrm{~h}$ and $3 \mathrm{i}$ ). The frontal border is very considerably produced, and its margin furnished with a row of fine, very short hairs; it is crenate, being divided into three pairs of rounded lobes, the outermost pair of which is much lower and broader than the others. The antennulæ much like those of the female. The antennæ short, having at least two joints; terminal seta long. The rostrum, maxillulæ and maxillæ nearly similar to those of the female. The maxillipeds differ from those of the other sex in having the basal joint longer, more slender and almost naked. The sub-median skeleton without processes and naked. The lateral margin of the head fringed with hairs of medium length, and a little in front of the posterior end of the margin originates a very narrow stripe of long hairs, which runs upward across the side, and further in a somewhat oblique line a little backward across the back of the animal, the hairs being exceedingly long in the dorsal part of the stripe. Behind this stripe, the back, 
the sides and the posterior part of the animal are very closely covered with tiny dots which resemble the base of fine hairs, yet no such hairs could be seen. From the outer angle of the first pair of legs this curious area is crossed by a narrow naked stripe which runs upward in an oblique direction and somewhat backward across the side and the back (fig. 3i); the ventral surface of the trunk between the legs and the caudal stylets is covered with moderately long hairs. The first pair of legs are good-sized, with a broad basal part and both branches well developed; the inner branch, which is a little shorter than the outer one, is pointed, the outer branch is blunt, terminating in two setæ, one of which is plumose and double the length of the branch. The second pair of legs about as long as, or a little shorter than, the outer branch of the first pair, having near its base a short conical outer branch with a short terminal seta, whereas the terminal seta of the inner branch is still longer than that of the outer branch of the first pair of legs. The caudal stylets of moderate length, terminating in some setæ, the longest of which is only a little longer than the stylet.

OVISACS. Globular or oval (fig. $3 \mathrm{c}$ ) and rather small in proportion to the adult female (fig. 3 a); the eggs in each ovisac comparatively small and pretty numerous.

LARVA. The length of a free specimen (fig. $3 \mathrm{k}) \cdot 24 \mathrm{~mm}$. The cephalothorax ovate. The front (fig. 3l) has an oblique list inside the anterior angle of each antennula; this appendage is 2-jointed, its olfactory seta reaching somewhat beyond the middle of the cephalothorax, and being somewhat more than double the length of the antennula. The antennæ a little shorter than the antennulæ, 3-jointed, first and second joints of equal length, the third joint short, provided with a terminal seta which is of equal length to, or longer than, the two last joints combined. The maxillulæ each with four branches, the foremost and inner one of which is rather short, the three others long and powerful, the hindmost bending backward and distinctly plumose. The maxillæ normal, with smooth joints. The second joint of the maxillipeds slightly longer than the third one, the fourth joint with a few setæ inside the apex. The thick seta at the posterior angle of the first abdominal segment reaches somewhat beyond the extremity of the caudal stylets; the third segment is very short, and the caudal stylets more or less distinctly set off, their terminal seta being about as long as the cephalothorax.

\section{POST-LARVAL DEVELOPMENT. Unknown.}

HABITAT. The marsupium of Calliopius laviusculus (Kr.) from the East coast of Asia between lat. $40^{\circ} \mathrm{N}$. and lat. $51^{\circ} \mathrm{N}$. In a large material were found altogether seven specimens infested with parasites. One specimen is from slat. $40^{\circ} \mathrm{N}$., long. $134^{\circ} \mathrm{E}$., Capt. Andréa, 1869 «; in its marsupium were found two moderately small females, the smallest male found, no ovisacs, but numerous - about thirty-three - free larvæ. Three specimens are from »lat. $45^{\circ} 40^{\circ} \mathrm{N}$., long. $139^{\circ} \mathrm{E}$., Andréa, 1869 ; in the largest of them were found six females, two males and twenty-five ovisacs, in the second specimen four females and six ovisacs, in the third three females, twenty-four ovisacs and at least two males (the host has 
not been closely examined). Two specimens are from 》lat. $49^{\circ} 30^{\circ} \mathrm{N}$., long. $142^{\circ} 8^{\circ} \mathrm{E}$., Sartung in Sachalin, Andréa, 1869"; they have not been closely examined. One specimen is from »lat. $51^{\circ} \mathrm{N}$, long. $141^{\circ} 20^{\circ} \mathrm{E}$., sin sea-weed ", Andréa, 1869 ", and in its marsupium were found: one female, five males and eight ovisacs (none of them containing developed larvæ). - In several specimens the marsupium was very much extended by the parasites; the hosts were always sterile.

REMARKS. The female is easily recognised by its hair-covering and its peculiar genital area; the male differs from all other species by its crenate frontal margin and by the peculiarly dotted surface of the back and the sides of the trunk.

With regard to the determination of the host, I will add that I myself was incapable of distinguishing the numerous specimens from East Asia from Greenlandish specimens; therefore I sent some of the non-infested Asiatic specimens to Prof. G. O. Sars, who in his new important work about the Norwegian Amphipoda, writes on p. 450, that he was mable to distinguish them from the Norweyian Call. lceviusculus. So it is interesting that I have found no parasite in specimens from Greenland, nor in any of the very numerous Danish specimens which have been referred to this species, but it must be observed that in Sars' opinion these animals belong to Call. Rathkiei (Zadd.), about which, however, Sars himself does not seem to be absolutely certain, whether it can be maintained as a species.

\section{Sphæronella irregularis n. sp.}

(PI. XIII, fig. 5 a-5 d.)

FEMALE. The only specimen found (fig. 5 a) was $\cdot 73 \mathrm{~mm}$. long and $59 \mathrm{~mm}$. broad; the body is ovate, the head tolerably defined. The sub-median part of the frontal margin furnished with a number of moderately long hairs. (The antennulæ broke off under the preparation). The antennæ 3-jointed, with a terminal seta (which broke off). The maxillæ normal. The maxillipeds with all four joints distinctly separated; the basal joint naked, the terminal joint with trifid apex. The sub-median skeleton consists of narrow lists, and a distinct, centrally uninterrupted, list runs between the lıead and the trunk; between the base of the maxillæ and the maxillipeds rms a pretty long transverse stripe of long hains. The lateral margins of the head with a thin row of moderately long hairs. The whole surface of the trunk is rather sparingly trimmed with peculiar hairs, which consist of a very suall but comparatively thick basal part, from which proceed two, sometimes three hairs, of which the one proceeding from the centre of the basal part is always nuch longer than the other or the two others. The trunk-legs are distinct. The genital area (fig. 5 d) in my only specimen is so irregular in shape that it must be misshaped; it is a little narrower than the base of the head, most of its median part is thin-skinned, the more solidly chitinised part forming a kind of heart-shaped ring with an opening to the front. The genital aper- 
tures are rather far apart and turned forward in an oblique direction: the skin between them is closely covered with normal hairs of medium length, and this hair-coat extends forward as far as to the orifices of the receptacula seminis and backward as far as behind the genital apertures, whereas the peculiar hairs of the trunk are found on nearly all the remainder of the area. The well-developed caudal stylets are situated within the chitinised part, close together a little behind the genital apertures; each of them is provided with two setæ, one of which is exceptionally long.

MALE. Unknown.

OVISACS. They differ somewhat in size and are more or less oblong; an ovisac of medium size (fig. $5 \mathrm{~b}$ ) is $44 \mathrm{~mm}$. long, $36 \mathrm{~mm}$. broad; the eggs are large and not numerous.

LARVA and POST-LARVAL DEVELOPMENT. Unknown.

HABITAT. In the marsupium of a female of Metopa rubrovittata G. O. Sars were found one female (with three spermatophores) and four ovisacs.

\section{Sphæronella paradoxa n. sp.}

(Pl. III, fig. $4 \mathrm{a}-4$ l; pl. IV, fig. $1 \mathrm{a}-1$ h.)

FEMALE. A very large specimen is $1.26 \mathrm{~mm}$. in length, the animal represented in fig. $4 \mathrm{a}$ is $.92 \mathrm{~mm}$. and that in fig. $4 \mathrm{~b}$ only $.71 \mathrm{~mm}$. in length. In the older specimens the body is not regularly globular, for its ventral surface shapes itself more or less conspicuously into a very broad, low cone, near or from the top of which proceeds a short thread by which the animal is fastened in the marsupium of the host; in consequence of this shape the animal does not show its longest dimension in the distance from its small, but well defined, head to or behind the genital area. In order to explain these peculiarities it will be to the purpose to mention the young specimens. A young animal which is breaking out of the skin of the pupa (fig. $1 \mathrm{~g}$ ) is $207 \mathrm{~mm}$. in length, with an oblong, normal trumk. A somewhat larger specimen, $36 \mathrm{~mm}$. long, is represented in fig. $1 \mathrm{~h}$; at some distance behind the middle of the ventral surface of the trunk we see a proximally broad, short, conical projection ( $\mathrm{t}$ ), which terminates in a short, pretty thick thread, the end of which is expanded into a small disk (n) and this disk is fastened, e. $\mathrm{g}$. to one of the gills of the host. In the specimen represented the conical part has been flattened and pushed to one side. This attachment continues throughout the life of the animal, and as a lule the thread gets very much twisted (fig. $4 \mathrm{a}$ and fig. $4 \mathrm{~b}$ ). becanse the animal turns itself, and at the same time it gradually gets its longest diameter from the base of the thread, or a little behind it, up to the dorsal surface somewhat behind the head, whereas the genital area, the place of which is shown in fig. $4 \mathrm{~b}$ by a spermatophore, becomes situated more or less high up on the dorsal surface; in other words: nearly the whole ventral surface forms a much stronger, somewhat conical curve and a much more extensive area than the back, which no 
doubt has something to do with the strain causer by the attachment. As fig. 4 a shows, the animal is almost symmetrical.

The frontal margin is fringed with short, fine hairs (fig. 1a). The antennulæ are rather long, with very long terminal setæ. The maxillulæ with well developed additional branch. The inixillæ and the inaxillipeds normal, naked, the latter pair having all four joints distinctly separated, and the terminal joint ending in three or four points. The submedian skeleton with a tolerably broad list near the maxillæ; a list between the head and the trunk which is not interrupted in its centre; 120 hairs whatever surrounding the base of the various appendages. The lateral margin of the head provided with a narrow stripe of rather short hair's. The trunk perfectly naked; trunk-legs very small, easily found in small specimens, but scarcely to be detected in large ones. The genital area (fig. 1 b) is narrower than the hear and somewhat broader than long; its chitinised part forms a posteriorly somewhat concave, rather nalrow ring, the anterior half of which is more feebly chitinised than the posterior part, or, as in fig. $1 \mathrm{~b}$, it is sometimes altogether wanting; the genital ipertures are sitnated near each ocher and turn forward in an oblique direction. The caudal stylets are found close together on the chitinous ring quite near the genital apertures; at least in two adult specimens they were withont setx - which may have been broken off by the preparation, for they are found in small specimens (fig. $1 \mathrm{~g}$ and $1 \mathrm{~h}$ ). (Besides in fig. $1 \mathrm{~b}$ are seen the orifices of the receptacula seminis, which are marked by a dotted line). Genital area and surroundings naked.

MALE. A large specimen is $.27 \mathrm{~mm}$. in length. The body is somewhat elongate (1)al, the breadth being about one third shorter than the length, consequently it is of pretty good size in proportion to the female (fig. $4 \mathrm{c}$ : fig. $4 \mathrm{a}$ ). The head is somewhat larger than the trunk (fig. $4 \mathrm{~h}$ and $4 \mathrm{i}$ ). The frontal border is rather produced, its margin evenly curved and naked. Antenuule, antennæ, mouth, maxillulæ and maxillæ essentially as in the female (fig. 41 will give an idea of a strongly protruding rostrum and show the maxillula, with its additional branch proceeding from a kind of foot, and the antenna). The maxillipers very long and slender, all joints well separated, the basal joint provided with a few hairy spots. The sub-median skeleton with all three pairs of processes; the first pair (at the base of the maxillæ) are blunt; the second pair which originate nearly at the anterior angle of the base of the maxillipeds, are long, turn backward and are distally somewhat curved, and between their posterior parts are found the third pair of processes, which are pointed, but not half the length of the second pair. The lateral margin of the head is lrovided with a stripe of moderately long hairs, and from its posterior end, which curves upward, the hair-covering is continued obliquely upward and somewhat backward across the side and back of the animal: behind this line, the back, the sides and the ventral surface of the trumk are covered with hairs of medium length, yet on the back, somewhat behind the anterior limit of the hair-covering, we see a transverse area which is naked and rather short (at the median line); the anterior part of the ventral surface is also naked. The head 
of the male in its posterior and lateral parts shows the peculiar feature (mentioned above on p. 42) of large, hollow spaces beneath the skin (fig. $4 \mathrm{k}$ ).

The first pair of trunk-legs are long and consist of one branch, and it is no donbt the onter branch which is preserved (sometimes even it appears to be set off by an articulation); the peduncle is long, proximally rather large, partly hairy; the branch ends in a seta which is nearly as long as the whole leg. The second pair of legs consist of a shorter, cylindrical basal part and a somewhat longer, a little more slender, cylindrical branch, which terminates in a seta which is even considerably longer than that of the first pair of legs. The caudal stylets are thick, their terminal seta being even longer than that of the second pair of legs, and about half to more than half the length of the whole animal. - The male is frequently found hinged by a frontal thread (fig. $4 \mathrm{~h}, \mathrm{~s}$ ) which measures about three eighths of the length of the body, and the distal part of which dilates gradnally towards the end.

OVISACS. 'They are oblong, varying from a moderate to a very large size; the specimen represented in fig. $4 \mathrm{~d}$ is $69 \mathrm{~mm}$. in length and 50 in breadth; it contains rather numerous eggs which are comparatively large.

LARVA (fig. 1c). Length $22 \mathrm{~mm}$. The body slender; the cephalothorax about $2 / 3$ longer than broad; the front with an oblique list inside the anterior angle of the antennulæ. Antennulæ 2-jointed; olfactory seta comparatively short, less than double the length of the antennula and about a third of the length of the cephalothorax. Antennæ considerably shorter than the antennulæ, the first joint (comp. fig. 1e, for in fig. 1c there is a fault in the engraving) pretty thick, of the same length as the second one, third joint short, and the terminal seta equalling in length the two last joints combined. Of the maxillulæ we find the posterior branch and one of the anterior branches in the shape of long setx, the hindmost of which is naked, and close in front of its base is seen a rather small conical process (fig. 1e), which is a rudimentary branch. Maxillæ and maxillipeds normal, with smooth joints. Abdomen chiefly as in S. Calliopii; however, the last segment and the caudal stylets which are distinctly set off, are a little larger, but the terminal seta is scarcely so long, a little more than half the length of the animal.

POST-LARVAL DEVELOPMENT. The attachment of the larva and subsequent great change of form (fig. $1 \mathrm{~d}$ ), as well as the highly interesting development, is described in detail above, p. 57-58, to which we refer.

HABITAT. The marsupium of Bathyporeia norvegica G. O. Sars, B. pelagica Sp. Bate and $B$. Robertsonii Sp. Bate from Denmark. In a considerable material $I$ found altogether eleven infested specimens, two of which are $B$. norvegica, four $B$. pelagica and five $B$. Robertsonii ${ }^{1}$ ).

1) G. O. Sars, in his excellent work: "An Account of the Crust. of Norway, Vol. I", admits altogether five species of Bathyporeia from Norway and the Baltic. Of these species B. norvegica G. O Sars and B. gracilis G. O. S. are decidedly good, and well distinguished from the three others, but whether these three species can be maintained, or have to be reduced at least to two (in regarding B. pilosa Lindstr. as a freshwaterform of $B$. pelagica), perhaps even to one, is difficult to decide, and must be submilted to a new, thorough 
I can indicate the special localities of only three specimens of $B$. pelagica: they were all

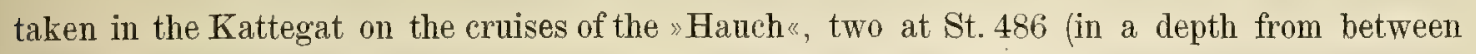
eight to eighteen feet, on sandy bottom, and the third at St. 113 (depth: four fathoms, on coarse, white sand). - In order to give an idea of the unique degree in which this species infests its host, it will be sufficient to copy my notes on the contents of the marsupium in five of the most infested specimens. In one animal were found: three large females, all attached, one to a gill, the other to one of the plates of the marsupium, further: two very small attached females, seventeen males, three good-sized ovisacs and two larvæ, one of which was hinged to a gill. In another specimen were found: one large female, ten males (at least three of which were hinged, one on each side of the same gill, the third to another gill, and they were so solidly attached that I conld examine the phenomenon more closely); further: one ovisac, one rather broad larva and four thick larvæ (»male pupæ»). In a third specimen were found: four females of very different size (in one specimen, the longest diameter of which measured $41 \mathrm{~mm}$, the ventral thread was $13 \mathrm{~mm}$. in length), eight males, four ovisacs, one narrower and one broader larva, as well as one "male pupa«. In a fourth specimen occurred: one large and two small females, eight males, no ovisacs, four broad larvæ, sixteen »male pupæ (six of which were hinged on the gill of the third right leg" together with a broad larva) and one female pupa.

In the marsupium of three specimens of Perioculodes longimanus (Sp. Bate) $(=$ Monoculodes Grubei Boeck) from Denmark I have found females which I cannot possibly distinguish from this species. In one specimen occurred: one female, the longest diameter of which is $.47 \mathrm{~mm}$, and four ovisacs of sub-equal size, one of them was $\cdot 39 \mathrm{~mm}$. in length and $30 \mathrm{~mm}$. in breadth; on each of the other two specimens was found only one female, the larger one of which measured $71 \mathrm{~mm}$. On account of similarity in their mode of attachment, in the structure of the antennulæ with their long terminal setæ, in the hairs on the frontal margin, in the shape of the maxillæ and of the maxillipeds and in the essential features of the structure of the genital area, I must for the present admit these animals as belonging to S. paradoxa, but as long as the male is not known, it is safer not to pronounce any definite judgment about such small and rather difficult forms.

REMARKS. The name of the species is chosen on account of the very peculiar, hitherto unique, ventral attachment of the female.

\section{Sphæronella abyssi $\mathrm{n}$. sp.}

(PI. IV, fig. 2a-2e).

FEMALE. The only specimen found was $96 \mathrm{~mm}$. in length, $1.13 \mathrm{~mm}$. in breadth, somewhat irregularly crooked and rather flattened (fig. 2a). The head was squeezed against

investigation. In this work I have accepted the established species in separating B. pelagica and $B$. Robertsonii from each other according to the existence or non-existence of spines on the dorsal part of the fourth abdominal segment. 
the lower surface of the body, but was lost before I could get it drawn. The trunk is naked; I have found no trunk-legs, but they probably exist nevertheless. The genital area (fig. 2c) is much narrower than the head and consists of a plate well chitinised all over, which is about one half broader than long, with flatly convex anterior margin and deeply concave posterior margin; the genital apertures oblique, the distance between them moderately large (in the drawing they are both open) and two long-stalked spermatophores are shown, as well as half the stalk of a third one. The caudal stylets (one of them is torn off') are situated close together on the smooth membrane adjoining the posterior margin of the plate; the latter and its surroundings are naked.

MALE. A good specimen is $25 \mathrm{~mm}$. in length, and the body seen from below (fig. 2 d), is regularly ovate. Compared with the female it is about middle-sized (fig. 2 b : fig. $2 \mathrm{a}$ ). The head is considerably larger than the trunk. The front is not strongly produced, its anterior margin is evenly rounded and naked. The antennulæ are tolerably strong, the terminal setæ short. The antennæ are long, 3-jointed, the conical terminal seta the length of the last joint. The month is small. The maxillulæ with an additional branch of medium length. The basal joint of the maxillæ has a conical process where the posterior and the inner side meet. The basal joint of the maxillipeds is long and naked, the three other joints distinctly separated. The sub median skeleton with the first pair of processes not developed, the second pair are long, somewhat diverging and feebly curved. The lateral margin of the head has only very few hairs; somewhat before reaching its posterior angle the hair-covering expands a little, then continues as a thin fringe upward and backward in a very slanting line across the back, leaving only a small dorsal part of the trunk to be seen behind it. On the back, close behind this fringed line, is a considerable naked area, so that only the hindmost extremity of the trunk, the larger part of its lateral surface and the ventral surface between the legs have a rather thin covering of moderately short hairs. At the back and the sides we see empty spaces beneath the skin similar to those in $S$. paradoxa. The first pair of trunk-legs are rather long; the clumsy peduncle is continued in a pretty long and clumsy outer branch, while the inner branch is a short cone; the former terminates in two setæ, one of which is considerably longer than the whole leg, nay even longer than the basal joint of the maxilliped, whereas the other seta is abont three times shorter; the inner branch ends in a long seta which is a little shorter than the basal joint of the maxilliped. The second pair of legs are moderately long, unbranched, ending: in two setæ, one of which equals in length the short seta on the onter branch of the first pair of legs, whereas the second somewhat exceeds in length the long seta of the lastmentioned outer branch. The caudal stylets are of medium length, their terminal seta even somewhat longer than any of the other setæ, and measuring nearly two thirds of the length of the whole animal. - The frontal thread in the specimen drawn in fig. $2 \mathrm{~d}$ is a little longer than the animal, very fine, and feebly expanded at its distal end. 
OVISACS. They are of middle size; those hitherto found are somewhat irregular trom pressure, oblong (fig. 2 a), the longest $69 \mathrm{~mm}$. long. The eggs large, not numerons.

LARVA and POST-LARVAL DEVELOPMENT. Unknown.

HABITAT. The marsupium of Astyra abyssi Boeck from Finmarken (Norway). In one specimen were found: the female mentioned, with the two ovisacs glued together and adhering to its foremost part, and a third one glued to its ventral surface, besides two males, one of which was fastened by the frontal thread shown in the drawing. In another specimen were found only four ovisacs, and these were discovered in examining some specimens of the above-mentioned Amphipod kindly offered to our Museum by Prof. G. O. Sars, upon which on my applying to him, he lent me his whole material for investigation, and I discovered the specimen which supplied me with both sexes of the parasite.

REMARKS. The description of the female is, unfortunately, very defective on account of the loss of the head. The male is exceedingly characteristic owing to the unique development of the terminal setæ of its trunk-legs and caudal stylets.

\section{Sphæronella Argissæ n. sp.}

(Pl. IV, fig. $3 a-3 n$ ).

FEMALE. The only adult specimen (fig. 3a) was somewhat shrunk and rendered crooked by pressure; its length was $.85 \mathrm{~mm}$; a small, recently hatched specimen represented in fig. $3 \mathrm{c}$ (enlarged on the same scale as fig. 3a) and strongly magnified in fig. $3 \mathrm{~d}$, is crooked and empty; its length is $15 \mathrm{~mm}$.. The head is small and well defined. The frontal margin is naked. The antennulæ have moderately long terminal setæ. The antennæ are 3-jointed, their terminal seta quite as long as the last joint. The mouth-border of medium breadth. The maxillulæ with additional branch. The maxillæ smooth. The maxillipeds slender, their basal joint naked, the following three joints distinctly separated, the terminal joint pointed. The sub-median skeleton has narrow longitudinal lists inside the maxillæ and no real transverse list at the median line behind the base of the maxillipeds; it is naked all over. The lateral margin of the head provided with rather short and fine hairs. The trunk quite naked; the trunk-legs well developed in the young ones, and probably also present in the adults. The genital area (fig. 3f) broader than the head (fig. 3a), somewhat broader than long; the solid chitine forms a semi-circle which opens towards the front; it is very broad posteriorly and decreases gradually in breadth; its two extremities form irregular lobes with inward curving points; the posterior margin is semicircular. The genital apertures oblique, the distance between them of medium length (in fig. $3 \mathrm{f}$ they are wide open and a spermatophore is attached to the entrance of one of the receptacula seminis). The caudal stylets are small but well developed and situated close together on the firm chitine inımediately behind the genital apertures. The whole genital area is naked (the young one represented in fig. $3 \mathrm{~d}$ has no genital area yet). 
MALE. In the largest specimen the length of the body is $19 \mathrm{~mm}$; seen from below (fig. $3 \mathrm{~g}$ ), it is short and broad, only a little longer than broad, its circumference is nearly rhombic, with broadly rounded angles. The second specimen is of the same length, but is considerably more slender, though scarcely as slender as the male of the following species (S. Metope). So the male is rather small compared with the female (fig. $3 \mathrm{a}$, where a male is marked $m$ ). The head is not a little larger than the trunk (fig. $3 \mathrm{~h}$ ). The front is somewhat produced, its anterior margin naked, slightly convex in the middle, slightly concave towards the sides somewhat in front of the antennulæ. Antennulæ, antennæ, mouth and maxillulæ essentially as in the female. The basal joint of the maxillæ has a short conical process on its posterior side. The maxillipeds of medium length; their basal joint has several stripes and spots covered with hairs, and their inner margin an incision and two considerable, shortly conical processes, which can only be seen distinctly when looking at the maxilliped from in front (fig. $3 \mathrm{k}$ ) or from behind, so that all its joints present themselves on the same plane; the terminal joint has a small spine inside its point. The sub-median skeleton has its first pair of processes developed into short conical taps which turn outward, one behind the base of each of the maxillæ; posteriorly, between the bases of the maxillipeds, the skeleton takes the shape of a pretty considerable, somewhat raised area, the median part of which extends into a broader plate, cut off posteriorly; laterally are found the second pair of processes which are shaped like long narrow cones, a little curved near their base and turned straight backward. The lateral margin of the head provided with a row of moderately long hairs, and from its posterior angle the hair-covering is continued as a belt upward and rather obliquely backward across the side and the back. The dorsal part and the upper lateral parts of the head show hollow spaces beneath the skin. The dorsal surface of the trunk with a broad and pretty long, naked area, in front of which is found the above-mentioned, moderately narrow belt of hairs of medium length; the lateral surfaces of the trunk, its posterior extremity and the greater part of its ventral surface are closely covered with hairs of medium length. The first pair of trunk-legs of about medium length; the basal part broad; the inner branch is a short knot, the outer branch of medium length and ending in two setæ, one of which is almost half the length of the body, the second about a third or scarcely a third the length of the first one, besides, the branch has on its outer side a conical process which ends in a short seta; the terminal seta of the inner branch is scarcely the length of the shorter terminal seta of the outer branch. The second pair of legs are short, the inner branch with one short and one extremely long terminal seta, which almost exceeds in length the one on the outer branch of the first pair of legs; the outer branch is a conical tap terminating in a thin seta which is a little shorter than the leg. The terminal seta of the caudal stylets not more than about thrice the leugth of the stylet, and the same length as, or shorter than the secondary seta of the outer branch of the first pair of legs. 
OVISACS. They are very large and somewhat oblong (fig. $3 \mathrm{~b}$ ); those I found were a little flattened, the one drawn is $74 \mathrm{~mm}$. in length. Each of the ovisacs containing numerous middle-sized eggs.

LARVA. The only specimen found (fig. $3 \mathrm{n}$ ) is $22 \mathrm{~mm}$. in length. Inside the base of the antennula an oblique, somewhat geniculated, pretty considerable list. The antennulæe 2-jointed, their terminal seta exceptionally long; the olfactory seta scarcely half the length of the cephalothorax. The antennæ somewhat shorter than the antennulæ; the second joint of the same length or a little longer than the first one; third joint short, its terminal seta about as long as the whole antenna. Of the maxillulæ I have only been able to find a single rather short branch on one side. The second joint of the maxillæ proportionally long and rather slender, the third joint comparatively short; the joints snooth. The abdomen much as in S. paradoxa, however, the long setæ of the first segment extend a little further behind the caudal stylets, and the terminal setæ of these stylets are scarcely half the length of the body.

POST-LARVAL DEVELOPMENT. A single pupa (fig. 31 and fig. $3 \mathrm{~m}$ ) has been found and is mentioned above on p. 56.

HABITAT. Argissa typica Boeck from the west-coast of Greenland. In the marsupium of a female was found the large female represented and a male attached to it, besides an unattached male, a larva and four ovisacs, two and two glued together, all without larvæ and not varying much in size. In an immature specimen without marsupium was found the pupa represented; in another young specimen the recently hatched female represented in fig. $3 \mathrm{c}$ and $3 \mathrm{~d}$; it was hinged to a gill by a rather broad, triangular (in fig. 3d visible) adhesive plate, which on the gill expanded into a circular disk.

REMARKS. The female presents very few peculiar characters, whereas the very beantiful male is distinguished from kindred species by several characters. A lateral view of the male, when placed under the microscope, so as to leave out the dorsal outline, presenting only the part immediately above it, shows the peculiar aspect of the spaces beneath the skin represented in fig. $3 \mathrm{i}$.

\section{Sphæronella Metopæ n. sp.}

(Pl. IV, fig. 4a; pl. V, fig. $1 \mathrm{a}-1 \mathrm{~g}$ ).

FEMALE. The specimen represented in fig. $1 \mathrm{a}$, which is the largest and best, is $.40 \mathrm{~mm}$. in length and $33 \mathrm{~mm}$. in breadth; the head is tolerably large and well defined from the sub-globular trunk; probably the female can become somewhat larger. The frontal margin is naked (fig. $1 \mathrm{~d}$ ). The antennulæ of about medium length, with rather short setæ. The antemnæ good-sized, 3-jointed; the basal joint short, the terminal seta about the length of the last joint. The mouth-border of about medium breadth. The maxillulæ with well 
developed additional branch. The basal joint of the maxillæ with a conical process on the boundary between the inner side and the posterior side. The maxillipeds tolerably robust; the basal joint smooth and naked; (whether the second and the third joints are separated could not be made out with certainty); the last joint has a few short setre inside its point. The sub-median skeleton has narrow lists inside the maxillæ and a well-developed list between the head and the trunk behind the base of the maxillipeds; no hairs on the skeleton between the appendages. The lateral margins of the head naked. The trunk naked; the trunk-legs distinct. The genital area (fig. 4a) much narrower than the head, much broader than long; the solid chitinised part forms a somewhat sinuous semi-circle, which posteriorly has a narrow interruption at the median line, and anteriorly a very broad opening; the hindmost submedian part is nearly straight, the anterior corners bent inward; the ring itself is rather narrow except outside the posterior extremity of each genital aperture, where it expands on the inward side. The genital apertures are large, strongly curved and situated close together; the well-developed caudal stylets are found in very close proximity on the soft skin which divides the ring on its posterior side. The genital area is naked, except a number of very fine hairs on the ring near the caudal stylets and on a smaller spot behind them.

MALE. The only specimen (fig. $1 \mathrm{f}-1 \mathrm{~g}$ ) is $20 \mathrm{~mm}$. in length; its breadth is a little more than two thirds of the length. This shows that it is tolerably small compared with the chief bulk of males, but extremely large compared with the female (fig. $1 \mathrm{~b}$ : fig. 1a). The animal is flatly rounded anteriorly and with very obtuse angles in the middle of its lateral margins; its head is only a trifle larger than its trunk. The front is feebly produced, its margin is naked. Antennulæ, antennæ, mouth, maxillulæ and maxillæ much as in the female. Maxillipeds of medium length, the basal joint with smooth inner margin, and a moderately large part of the outer surface provided with hairs, these, as usual, arranged in stripes and spots; the terminal joint as in the female. The sub-median skeleton with all three pairs of processes developed; the first pair, behind the maxillæ, are broadly rounded, depressed, plate-like; the second pair long, slender, almost cylindrical and strongly diverging; the third pair are situated at some distance from each other between the second pair and are not half the length of these. The lateral margin of the head is furnished with hairs (and as in much the greater number of species, this hair-covering begins in front of the base of the antennulæ), continues in an oblique direction upward and backward across the side and the back, forming laterally a rather narrow band of moderately long hairs, being reduced on the back almost to a line of very long hairs. Behind this line the back has a long, naked transverse area, whereas the remainder of the back, the sides, the posterior extremity and the ventral surface - except on its foremost part - are closely covered with hairs of medium length. The dorsal and upper lateral parts of the head have hollow spaces beneath the skin. The first pair of trunk-legs are short, with a broad basal part and two short, subcylindrical branches situated far apart from each other; the outer branch ending in two setæ, one of which is about the length of the second joint of the maxillipeds, whereas the 
second is not much shorter than half the length of the body; the inner branch ending in a long seta which, however, is somewhat shorter than that of the outer branch, and which in the only specimen examined is rather unlike in the two sides. The second pair of legs are much as in S. Argisse, yet somewhat more slender; the outer branch ends in a short seta, the inner one in two setæ, which are both a trifle longer than the two setæ on the outer branch of the first pair of legs. The caudal stylets are of medium size, each ending in two setæ, one of which is of the same length as, or a little longer than the stylet, the other about five times the length of it.

OVISACS. They are sub-globular and disproportionately large; the longest diameter of one of the smallest is $37 \mathrm{~mm}$., and of one of the largest, represented in fig. $1 \mathrm{c}$, even $41 \mathrm{~mm}$., consequently larger than the female (fig. $1 \mathrm{c}$ : fig. $1 \mathrm{a}$ ), but as all ovisacs contain about half-developed young ones and, as a matter of course, are larger than those whose eggs have preserved their original form, these measures cannot be compared immediately and without reduction with those of the other species. The eggs are rather few in number and proportionally very large.

LARVA and POST-LARVAL DEVELOPMEN'T. Unknown.

HABITAT. The marsupium of Metopa Bruzelii (Goës) from West-Greenland off Godthaab, »deep water" [probably 40-60 fathoms], in Sertularia, C. Holböll. In one specimen were found: one female and three ovisacs; in another: one female and two ovisacs; in a third: one female, one male, and three ovisacs glued together in a lump. These three specimens were found in a material, of which five other specimens were infested with Stenothocheres egregius (comp. this species).

\title{
15. Sphæronella Holbölli n. sp.
}

\author{
(Pl. V, fig. $2 \mathrm{a}-2 \mathrm{~g}$.)
}

FEMALE. The largest specimen fig. $2 \mathrm{a}$ is $1.44 \mathrm{~mm}$. in length and $1.57 \mathrm{~mm}$. in breadth. The head is rather small, well defined. Frontal margin naked. Antennulæ, antennæ, mouth, maxillulæ, maxillæ and sub-median skeleton much as in S. Metopæ; there are, however, two lists between the head and the trunk behind the maxillipeds. The maxillipeds are of medium size; their basal joint having some small, scattered groups of short hairs, the three following joints distinctly separated, and the last joint ending in several very fine spiniform processes (fig. $2 \mathrm{~d}$ ). The lateral margin of the head hairy; the haircovering begins outside the antennulæ, continues in a stripe of moderately long hairs and expands posteriorly into a comparatively broad area with shorter hairs. The trunk is naked; the trunk-legs distinct. The genital area (fig. 2e) a little narrower than the base of the head, much broader than long; the solid chitine forms an almost rectangular, transverse plate, which is somewhat narrower anteriorly than posteriorly; the posterior angles are very 
broadly rounded, the median part of the posterior margin has a broad and very deep incision; the median part of the plate, outside and especially in front of the genital apertures, consists of soft membrane. The genital apertures are rather large, strongly curved and situated pretty close together. The caudal stylets are very small and sitnated near each other on the soft membranous part on a line with the posterior margin of the chitinous plate. On each side of this plate, at a considerable distance from the margin, runs a very long, curved line of very long, outward turning hairs, and from the part between the genital apertures towards the caudal stylets run four stripes, anteriorly very narrow, posteriorly broader, of extremely short, fine hairs.

MALE. The best preserved specimen has become crooked through pressure (fig. 2f); it is $.21 \mathrm{~mm}$. in length, consequently of small size compared with the female (fig. $2 \mathrm{~b}:$ fig. $2 \mathrm{a}$ ) and has a broad shape similar to that of the male of S. Argissce (represented in pl. IV, fig. $3 \mathrm{~g}-3 \mathrm{~h}$ ), whereas in hair-covering and in the structure of the trunk-legs etc. it bears great resemblance to $S$. Metope ( $\mathrm{pl} . \mathrm{V}$, fig. $\mathbf{1 f}-\mathbf{1} \mathrm{g}$ ). The head seems to be somewhat larger than the trunk. The front is somewhat produced as in S. Argissa, but the margin scarcely concave in front of the antennulæ. Antennulæ, antennæ, mouth, maxillulæ and maxillæ essentially as in S. Metopa. The basal joint of the maxillipeds has a short, broad, conical process on its inner surface, besides several groups or stripes of moderately long hairs; the last joint is digitated, at the apex ending in about four points. The three pairs of processes of the sub-median skeleton are somewhat like those of $S$. Metope, but the first pair are longer and more pointed, the second pair a little shorter and more or less diverging. The lateral margin of the head is fringed with somewhat longer hairs than in $S$. Metopre, and from its posterior angle a somewhat broader stripe of longer, and dorsally very long hairs runs almost vertically upward across the side and the back; behind this stripe is a moderately long, naked, dorsal transverse area, whereas the remainder of the trunk is covered with hairs as in S. Metope, however, the hairs are proportionally longer and coarser. The dorsal and lateral parts of the head have hollow spaces beneath the skin. The first pair of trunk-legs nearly as in S. Metopa; the most important difference is that the terminal seta of the inner branch is considerably shorter, and shorter than the distance between the base of the leg and the end of the outer branch. The second pair of legs are somewhat larger than in $S$. Metope, but the shape and setæ are much the same as in this species. The candal stylets end in a single seta which is scarcely as long as in the preceding species.

OVISACS. They are comparatively rather small (fig. 2 c), sub-globular or oval, differing rather slightly in size; one of the largest which is $63 \mathrm{~mm}$. in length and $52 \mathrm{~mm}$. in breadth, is represented. The eggs are proportionally rather small and pretty numerous.

LARVA and POST-LARVAL DEVELOPMENT. Unknown.

HABITAT. The marsupium of Paramphithoë Boeckii H. J. H. from West-Greenland, off Godthaab, „deep water" [probably 40-60 fathoms], on Sertularia, C. Holböll. In 
one specimen were found: one female and one male, and in front of the female were lying seven ovisacs, behind it one; another specimen contained one female and one male.

REMARKS. The genital area of the female in several respects (shape, chitinisation and arrangement of hairs) deviates much from all the other species. By the nanie given to this species I have commemorated Lieutenant-Captain Inspector C. Holböll, to whom the study of Greenlandish Malacostraca owes so much, and who more than half a century ago sent home rich collections of these animals. A considerable part of this material was worked out by $\mathrm{H}$. Kröyer. In the writings of this author we also find interesting biological observations by Holböll concerning Greenlandish species of Lysianassidæ etc.

\section{Sphæronella intermedia n. sp.}

(Pl. V, fig. $3 \mathrm{a}-3 \mathrm{~h}$. )

FEMALE. The largest specimen is $.89 \mathrm{~mm}$. in length, $.81 \mathrm{~mm}$. in breadth and somewhat flattened; the specimen represented in fig. $3 \mathrm{a}$ is $57 \mathrm{~mm}$. long and $47 \mathrm{~mm}$. broad. The head in the adult specimen is well defined and rather small. The frontal margin provided with fine and close hairs (fig. 3d). The antennulæ moderately long, with long setæ. The antennæ much as in the three preceding species, but the basal joint equals in length one of the two following joints. The good-sized mouth with a rather broad border. The maxillulæ with well-developed additional branch. The basal joint of the maxillæ without any process. The maxillipeds with a slender, naked basal joint, the three other joints all separated, the terminal joint has two short spines inside its point, and a single one on the outside. The sub-median skeleton has a single, rather narrow list inside each maxilla; a transverse area in front of the basis of each maxilliped is covered with numerous tolerably long hairs; between the head and the trunk two chitinised transverse lists. The lateral margin of the head with a fringe of hairs, which off the maxille and the maxillipeds spreads over a pretty considerable triangular area. The trunk very sparingly set with simple, rather short hairs, which are closest together behind the sides of the head; the trunk-legs distinct. The genital area (fig. 3 e) large, quite as broad as the base of the head (fig. 3 a), somewhat broader than long; the whole area forms a solid plate which is nearly heart-shaped, deeply incised in front and with a semicircular posterior margin. The genital apertures are somewhat curved, but their direction is nearly parallel with the median line of the animal, and they are situated pretty near each other close behind the deep incision of the anterior margin of the plate. The plate is furnished with a number of irregularly scattered hairs, and the caudal stylets are situated close together at a good distance inside the posterior margin of the plate, a little behind the genital apertures. (In the illustration we also see the orifices of the receptacula seminis, which are marked by dotted lines.) 
MALE. The only specimen is $19 \mathrm{~mm}$. in length and a trifle narrower; compared with the female represented, it is tolerably large (fig. $3 \mathrm{~b}:$ fig. $3 \mathrm{a}$ ), but only of medium size compared with the largest female. Seen from below (fig. $3 \mathrm{f}$ ), the body is nearly pentagonal; the anterior outline, which only in its middle part is formed by the slightly curving frontal margin, but towards the sides of parts belonging to a lower level, is but feebly curved and comparatively broad, the lateral angles are obtuse, but the posterior margin of the body forms a rather broad curve. The head is somewhat larger than the trunk. The aforementioned, scarcely produced frontal border has a fringe of hairs. The antennulæ are slender, of medium length and provided with long setæ. The antennæ and the maxillulæ much as in the female; the mouth smaller than in the latter. The maxillæ have a distinct conical process on the posterior side of the basal joint. The basal joint of the maxillipeds has a sinnate inner margin, its outer surface is supplied with hairs, and its anterior side has two transverse rows of tolerably long hairs; the last joint ends in three points of unequal length. In the sub-median skeleton are only found the two first pairs of processes; the first pair which are situated behind the maxillæ, are broad, somewhat produced and rounded, the second pair which are situated between the maxillipeds, are scarcely of medium length and feebly diverging. The lateral margin of the head fringed with long hairs, and the earshaped arch round the base of the antennulæ distinguishes itself particularly by its very long hairs. The stripe of hairs which proceeds from near the posterior angle of the lateral margin, running upward across the side and the back, is somewhat more oblique than in S. Holbölli, and its hairs are somewhat shorter, otherwise the hair-covering of the trunk and its dorsal, naked transverse area are much as in this species, and the same resemblance appears in the empty spaces beneath the skin of the head. The first pair of legs consist of a very broad and rather long, hairy basal part, from which proceeds a single moderately long branch, which terminates in a single seta of the length of the whole leg or of the first joint of the maxillipeds. 'The second pair of legs entirely like those of the former species, the only terminal seta of the inner branch about the length of that of the first pair of legs. The very thick caudal stylets have a terminal seta which is scarcely as long as that of the second pair of legs.

OVISACS. They differ very much in size, even if not containing larvæ. Of ten ovisacs belonging to the same female the smallest one is globular and has a diameter of $.30 \mathrm{~mm}$., the largest (represented in fig. $3 \mathrm{c}$ ), is $53 \mathrm{~mm}$. long and $43 \mathrm{~mm}$. broad. In another female was found a still larger ovisac which is $64 \mathrm{~mm}$. in length and $49 \mathrm{~mm}$. in breadth. So these ovisacs are large compared with the females, and the eggs themselves are large and not numerous.

LARVA. I have found two ovisacs containing larvæ which were serviceable, yet not quite capable of swimming away, and these specimens have served as models for fig. $3 \mathrm{~h}$. A list curving somewhat like an $\mathrm{S}$ is seen inside the anterior angle of the antennula. The olfactory seta of the 2-jointed antennulæ is long; a little shorter than the cephalothorax. 
The antennæ somewhat shorter than the antennulæ, the first joint a little shorter and thicker than the second, the third joint short, and its'seta scarcely as long as the two last joints combined. Of the maxillulæ I have only found two setæ. The second and third joints of the maxillæ proportionally pretty long; all joints smooth. The second joint of the maxillipeds shorter than the third one. The seta on the posterior angles of the first abdominal segment reach far beyond the caudal stylets, which are small and distinctly separated from the small third segment. The body not having quite reached its final shape, the relative length of the terminal setæ of the candal stylets cannot be indicated with full certainty, but they are probably half the length of the body.

\section{POST-LARVAL DEVELOPMENT. Unknown.}

HABITAT. The marsupium of Bruzelia typica Boeck from Norway. The species was discovered by Prof. G. O. Sars, who sent me one female and eight ovisacs mutually glued together, two of them with the larvæ described. Later on he presented our Museum with some specimens of the host taken at Mosterhavn in a depth of 150 fathoms, and in one of these specimens I found two ovisacs, beneath them the female represented, and behind this female eight ovisacs glued together in a lump (none of them containing larvæ), but I am uncertain whether all these ovisacs were lajd by the female found, or whether eight of them were not rather laid by a female which may have fallen ont. At last I bought Prof. Sars' whole material and found in one specimen a female (the largest), a male and four good-sized ovisacs mutually glued together.

REMARKS. The species is nearly related to $S$. Holbölli, yet both sexes distinguish themselves from it by several good characters, the female e. g. by the fringe of hairs on the frontal margin and by the hairs in front of the maxillipeds, the male by the structure of the first pair of legs.

\section{Sphæronella capensis $\mathrm{n}$. sp.}

(Pl. V, fig. $4 \mathrm{a}-4 \mathrm{c} ; \mathrm{pl}$. VI, fig. $1 \mathrm{a}-1 \mathrm{~d}$.)

FEMALE. The only specimen (fig. 4 a) was $.52 \mathrm{~mm}$. in length and $45 \mathrm{~mm}$. in breadth, shortly ovate, broadest in front of the middle and scarcely as thick as broad. The head, which is well defined, and the genital area are both found on the ventral surface of the body, at some distance from the anterior and the posterior end respectively. The frontal margin naked. The antennulæ of medium length, with long setæ, the terminal seta much longer than the whole antennula (fig. $1 \mathrm{a}$ ). The antennæ, the mouth, the maxillulæ and the maxillæ much as in $S$. intermedia; the maxillipeds with a somewhat shorter, naked basal joint and with a pointed terminal joint, without distinct secondary spines. The sub-median skeleton with a moderately narrow list inside the maxillæ, naked all over; behind the maxillipeds two transverse lists between the head and the trunk. The lateral margin of the head naked. The trunk naked; only one trunk-leg is supposed to be found. The genital 
area (fig. 1 b) broader than the head (fig. 4a), a little broader than long, and consisting of a somewhat angular chitinous plate, which has a membranous part outside and behind the genital apertures. These apertures are somewhat curved, their direction is approximately parallel with the median line of the animal; their distance from each other is less than moderately great, and they are situated somewhat in front of the posterior margin of the area, but behind the middle of it. The whole area is naked, and I have been unable to find caudal stylets. In the middle of the area we see the orifices (o) of the receptacula seminis, one of which ( $\mathrm{r}$ ) is represented by a dotted line.

MALE. The only specimen is $166 \mathrm{~mm}$. long and almost as broad (fig. $1 \mathrm{c}$ and $1 \mathrm{~d}$ ); though actually small, compared with the female, it is more than middle-sized (fig. $4 \mathrm{~b}$ : fig. 4a). Seen from below, in general shape and in most details it resembles the male of the previous species. The head a trifle larger than the trunk. The frontal margin is naked. The antennulæ proportionally long, slender, with long setæ. The antennæ and the maxillulæ much as in the previous species; the mouth small. The maxillæ differ from all other species in the structure of the basal joint, which in its distal part close to the boundary between the inner side and the posterior side is provided with a protruding plate, the margin of which runs out into a number of spiniform, partly somewhat curved processes; the claw can be folded up along the inner side of this plate, which is very conspicuous in a lateral view of the animal (fig. $1 \mathrm{~d}$ ); the basal joint, besides, has a knot-like protuberance on its outer side. The maxillipeds are long; their basal joint has a sinnate inner margin and several shortel and longer transverse rows of moderately long hairs on the anterior surface; the terminal joint seems to be bifid at its apex. The sub-median skeleton has only the same two pairs of processes as the preceding species, the first pair somewhat produced and rounded, the second pair comparatively close to each other, rather short, triangular, pointed, slightly diverging. The ear-shaped arch surrounding the base of the antennula is furnished with hairs of medium length, and from that point the hair-covering continues in a broad stripe of similar hairs along the whole length of the outside of the protruding lateral border of the head; from the posterior angle of this border a fringe of particularly long hairs runs upward and backward across the side and the back in a very slanting line. On the back behind this line we find the usual naked area, which indeed is rather long, but much narrower than in the preceding species; the remainder of the back, the sides, the posterior end and the ventral surface are rather densely covered with hairs of medium length. The hollow spaces beneath the skin of the head as in the preceding species. The first pair of legs much as in $S$. intermedia, except that there is a shorter process on the exterior side of the branch near its base, and the terminal seta is a little shorter than the basal joint of the maxillipeds. The second pair of legs also much as in the preceding species, but the outer branch is reduced to a smaller excrescence; the terminal seta of similar length to the first pair of legs. The caural stylets rather thick; the terminal seta quite the length of those of the legs. 
OVISACS. They are moderately large, without considerable difference of size; one of the largest is represented in fig. $4 \mathrm{c}$, it is shortly ovate, and its longest diameter is $37 \mathrm{~mm}$. The eggs are moderately large, somewhat numerous.

LARVA and POST-LARVAL DEVELOPMENT. Unknown.

HABITAT. In the marsupium of a female of Lemboides afer Stebb. from South Africa, at or near the Cape of Good Hope, were found: one female, one male and eleven ovisacs, the latter united in two lumps, one of them with eight, the other with three ovisacs. Our material of the host is examined and described by the Rev. Th. R. R. Stebbing.

\section{Sphæronella Gitanopsidis n. sp.}

(Pl. VI, fig. 2a-2g.)

FEMALE. The only specimen found (fig. $2 \mathrm{a}$ ) is $.97 \mathrm{~mm}$. in length and $85 \mathrm{~mm}$. in breadth; the head well defined and the trunk sub-globular. The frontal margin naked (fig. 2 d). Antennulæ comparatively long, with moderately long setæ. Antennæ 3-jointed; their basal joint of the length of the second joint (is incorrectly reproduced in the drawing); the terminal seta about the length of the last joint. The mouth of medium size. The maxillulæ with a good-sized additional branch. The basal joint of the maxillæ with a small tap on the posterior side. The maxillipeds slender, the basal joint naked, the following three joints mutually separated, the last joint with a couple of spines inside the point. The sub-median skeleton with rather narrow longitudinal lists and with a pretty small process inside the inner angle of each maxilliped; a considerable, centrally much expanded transverse list behind the maxillipeds, between the head and the trunk. The trunk naked; the trunklegs distinct. The genital area (fig. $2 \mathrm{e}$ ) somewhat narrower than the head (fig. 2 a), much broader than long; the more solid chitine forms a broad, anteriorly open, semi-circle, of which a rather small or large lateral part is slightly, the remainder solidly chitinised. The genital apertures are rather oblique, they are moderately far apart from each other, and they are situated close up to the anterior margin of the solid chitinous list, while the caudal stylets are placed close together immediately behind its posterior margin; the whole area is naked.

MALE. The only specimen found (fig. $2 \mathrm{f}-2 \mathrm{~g}$ ) is but $\cdot 153 \mathrm{~mm}$. long and $\cdot 120 \mathrm{~mm}$. broad, consequently smaller than any other male of this genus, but I am unable to say whether it is quite full-grown; it is also small compared with the female (fig. 2b: fig. 2a). Seen from below, it is oblong with obtuse lateral angles and broadly rounded anteriorly and posteriorly. The head as large as the trunk. The frontal border considerably produced, evenly rounded, its margin naked. The antennulæ of medium length, the terminal seta the length of the antennula. Antennæ, mouth, maxillnlæ and maxillæ essentially as in the female. The maxillipeds of medinm length, their basal joint on its anterior side provided with some groups of very fine hairs. The first pair of processes of the sub-median skeleton 
short and rounded, the second pair short, somewhat produced and strongly converging. The lateral margin of the head in its whole length supplied with hairs of medium length; somewhat in front of the posterior extremity of this margin begins the line which runs upward and backward in a somewhat oblique direction across the side and the back; in the latter place the hairs become long, but in this species this line only forms the anterior boundary of a broad belt of hairs of medium length, behind which we find the usual naked transverse area, which is rather long and also broad; the remainder of the trunk: its sides, posterior extremity and ventral surface, are closely covered with hairs, part of which are proportionally rather long. The head has empty spaces beneath its skin. The first pair of trunk-legs are rather small, with a single, pretty short branch, and a tolerably short and thick process on the outer side at its base; the branch ends in two setæ, one of which is short, the other long, but scarcely the length of the basal joint of the maxillipeds. The second pair of legs are of less than medium size, with a shorter outer branch and a somewhat longer inner branch; the terminal seta of the outer branch scarcely half the length of the whole leg, whereas the inner branch has a short seta on its outer side, and the terminal seta is nearly the length of that of the first pair of legs. The candal stylets rather short, each with a pair of terminal setæ, which are somewhat thicker and longer than the hairs of the trunk.

OVISACS. Only two are found; they are tolerably large and of about equal size; the one represented (fig. 2c) somewhat flattened and rather triangular in outline, its longest diameter being $59 \mathrm{~mm}$. The eggs pretty numerous, about middle-sized.

LARVA and POST-LARVAL DEVELOPMENT. Unknown.

HABITAT. The marsupium of Gitanopsis arctica G. O. Sars from Varangerfjord (the most northern part of Norway) at Vadsö. Prof. Sars discovered the parasite in a single specimen, which he subsequently lent me, and in which were found: one female, one male and two ovisacs.

\section{Sphæronella Giardii n. sp.}

(PI. VI, fig. 3a-31.)

FEMALE. One specimen (fig. $3 \mathrm{c}$ ) which has laid six ovisacs and no doubt has finished laying eggs, and which is oblong and somewhat shrunk, measures $63 \mathrm{~mm}$. in length and $45 \mathrm{~mm}$. in breadth, whereas another female (fig. $3 \mathrm{a}$ ), which had not yet begun laying eggs, is $1.24 \mathrm{~mm}$. long and $1.31 \mathrm{~mm}$. broad - consequently broader than long - and about double the length and nearly three times the breadth of the first mentioned specimen. The head is proportionally small and well defined from the trunk. The frontal margin is naked (fig. $3 \mathrm{e}$ ). Antennulæ of medium length, pretty robust, with short apical setæ. Antennæ 3 jointed, the second joint longer than the first or the third; the terminal seta of medium length. The mouth-border of medium breadth. The maxillulæ with a good-sized additional 
branch. The maxillæ normal, with smooth basal joint. The maxillipeds scarcely of medium length; the basal joint pretty robust, naked; second and third joints coalescent; the last joint with a spine inside the point. The sub-median skeleton much as in $S$. Holbölli. On each of the lateral borders of the head we find an area - more narrow towards the front and broad posteriorly -, which is closely covered with exceedingly short and fine hairs. The trunk is naked; trunk-legs are found. The genital area (fig. $3 \mathrm{f}$ ) is much narrower than the head (fig. 3a), much broader than long; the solidly chitinised part forms a sometimes narrow, sometimes tolerably broad semi-circle (in the latter case as in the following species, fig. 4d), which opens broadly towards the front, with the foremost end of each side curved somewhat inward; the posterior margin is tolerably concave, and from the median part of the ring proceeds a considerable plate, which occupies the rather broad space between the oblique, somewhat curved genital apertures, advancing somewhat beyond their anterior ends, and being cut off anteriorly by a straight line. The caudal stylets a little apart, situated on or closely behind the posterior margin of the solid chitine. The whole genital area is naked.

MALE. It attains a length of about $21 \mathrm{~mm}$; seen from below (fig. $3 \mathrm{~g}$ ), it is only about one sixth narrower than long, and seen laterally (fig. $3 \mathrm{~h}$ ), it is very thick; compared with the female, it is about middle-sized (comp. fig. $3 \mathrm{c}$, fig. 3 a and fig. $3 \mathrm{~b}$ ). The head scarcely as large as the trunk. The frontal border but feebly produced and naked. The antennulæ a little more slender than in the female, their setæ a trifle longer. The antennæ and the maxillulæ as in the female; the mouth-border proportionally broader than in the latter. The basal joint of the maxillæ provided on its posterior side with a comparatively pretty long, oblique tap. The basal joint of the maxillipeds longer than in the female, with about three conical processes on the inner margin; on the distal part of the anterior side about three transverse stripes of ordinary hairs, on its proximal part two to four tiny, naked, transverse keels and a group of hairs at the base; the terminal joint with a couple of spines close inside the point. The sub-median skeleton with the two first pairs of processes distinct; the first pair small, the second pair long and parallel. From in front of the base of the antennula the lateral margin of the head is furnished with a line of hairs of medium length, which from the posterior end of the margin proceeds upward and forward in a slightly oblique direction across the side and the back. Behind this boundary, the back, the sides and the ventral surface of the trunk are closely covered with setaceous hairs of medium length; however, a careful examination shows that the trunk is covered with numerous small, somewhat oblong, transverse knots, from each of which proceed two or (more commonly) three hairs, the central one of which is the longest. (This arrangement, which is difficult to observe, is not reproduced in fig. $3 \mathrm{~g}$ and fig. $3 \mathrm{~h}$, as it was not discovered till after the plate was printed). However, on the back, far from the anterior boundary of the hair-covering, we find a short and not very broar, naked transverse area. The first pair of trunk-legs have a peduncle of medium breadth, a rather short inner branch and a little longer outer branch; each branch, 
as a rule, ends in one or two short and one longer setæ, the latter of which, however, is only half or scarcely half the length of the basal joint of the maxillipeds (sometimes there are two about equally long setæ at the end of the outer branch), and finally a rather short seta on an angular process of the peduncle outside the outer branch. The second pair of legs comparatively pretty long, with a short outer branch at their base, ending in a shorter seta, while the inner branch ends in several setæ, the longest of which is distinctly longer than the setæ of the first pair of legs. The caudal stylets are rather small, with short setæ. - The frontal thread is between two thirds of or the entire length of the whole body, simple, ending in a thick disk.

OVISACS. They are of medium size (fig. $3 \mathrm{~d}$ ), without great mutual difference (at least if not containing young ones), for the most part shortly oval; the ovisac represented is $.47 \mathrm{~mm}$. long and $39 \mathrm{~mm}$. broad. The eggs of medium size, not very numerous.

LARVA. I have found no free specimen, and the larva which I pulled out of the ovisacs were not sufficiently developed to allow of giving a description of them.

POST-LARVAL DEVELOPMENT. Some pupæ of both sexes have been found (fig. 3i-31), and their interesting development is described on p. 54-5̌5.

HABITAT. The marsupium of Protomedeia fasciata $\mathrm{Kr}$. from Denmark. In a large material without specialised locality are found eleven infested specimens; a twelfth one - was taken by Dr. Joh. Petersen in the Kattegat at Stat. 403 (twelve fathoms). Only seven of these twelve specimens have been very closely examined, but a statistic account of four of them will be sufficient. In one specimen were found: the female represented in fig. $3 \mathrm{c}$, with a male adhering to its ventral surface, and six ovisacs partly glued together. In another specimen were found: a good-sized female, a male and seven ovisacs, thus distributed: three ovisacs were lying beside and in front of the female, the remaining four and the male lying behind it; finally, a pupa was hinged to the base of the gill of the hindmost leg but one. In a third specimen occurred: one good-sized female, five males, three ovisacs and five pupæ; four of the males and all the pupæ were hinged to gills, to marsupial plates or to the epimera of the second - sixth pair of legs. In a fourth specimen appeared the extremely large female represented in fig. $3 \mathrm{a}$, one male and one pupa; the female occupied the front half of the marsupium, whereas its hindmost half was occupied by six of the host's eggs, containing young ones about half developed; in which the limbs were very distinct.

\section{Sphæronella Bonnieri n. sp.}

(PI. VI, fig. $4 \mathrm{a}-4 \mathrm{~d}$; pl. VII, fig. $1 \mathrm{a}-1 \mathrm{~b}$.)

FEMALE. The specimen represented in fig. $4 \mathrm{a}$ - the largest one found - measures $.97 \mathrm{~mm}$. in length and $.94 \mathrm{~mm}$. in breadth. In the head and its organs of this species compared with the preceding, I have not been able to find any deviation which would seem 
qualified to form a character of species. Trunk naked; trunk-legs present. Genital area (fig. 4d) essentially as in the preceding species, for in S. Giardii the chitinised semi-circle can be almost as broad as in S. Bonnieri; the only deviation found is the situation of the caudal stylets which in the latter are placed a little more towards the front on the ring itself, but whether this is a valid character, I am not prepared to decide.

MALE. Considerably larger than in $S$. Giardii, two specimens being respectively $28 \mathrm{~mm}$. and $29 \mathrm{~mm}$. in length, but they differ chiefly from that species in the swollen appearance of the trunk, - its volume several times exceeding that of the head -- and in a very different hair-covering (fig. $1 \mathrm{a}$ and fig. $1 \mathrm{~b}$ ). Its frontal margin, antennulx, antennæ, mouth, maxillulæ, maxillæ and maxillipeds do not exhibit really good characters. The first pair of processes of the sub-median skeleton seem to be longer, whereas the second pair are a little shorter than and differ in shape from S. Giardii. The hair-covering of the lateral border of the head as in this species, but the border itself is shorter and vanishes outside or a little belind the base of the maxillæ, and from this point the boundary line between the naked head and the hair-covered trunk runs upward and backward in a slightly oblique direction across the side and the back. The whole dorsal surface, the sides and the ventral surface, except its foremost pretty considerable part, are closely covered all over with simple, moderately long hairs which grow separately (not as in S. Giardii two or three from the same little eminence); the back without naked transverse area. On account of the swelling of the trunk, the legs and the caudal stylets are much further removed from the lateral and the posterior outline than in nearly all other species, and the caudal stylets are situated almost in the middle of the ventral surface. Both pairs of trunk-legs are proportionally smaller, and their long terminal setæ a little shorter than in S. Giardii; from the peduncle of the first pair of legs outside the onter branch proceeds a distinct process ending in a seta, but the other differences in the length of the setæ etc. between this and the preceding species are of slight or no value.

(Three, but not the fourth, of the males found are more or less closely wrapped up in long, fine threads, or rather, it looks as if a thread were wound round the body in numerous curves and with projecting nooses, but $I$ have tried in vain to find out the origin and nature of these remarkable threads. Fig. $4 \mathrm{~b}$ exhibits one of the closely wrapped specimens.)

OVISACS. These are oval or shortly oval (fig. 4c), a little larger than and with somewhat larger eggs than in S. Giardii, otherwise as in this species. The ovisac represented (fig. $4 \mathrm{c}$ ) is $53 \mathrm{~mm}$. long and $43 \mathrm{~mm}$. broad.

\section{LARVA and POST-LARVAL DEVELOPMENT. Unknown.}

HABITAT. Protomedeia fasciata $\mathrm{Kr}$. from West-Greenland. I have found it in old specimens which were determined by Kröyer, but unfortunately I neglecterl at the time to put down statistics ahout the number of hosts etc. of the prrasites fornd, viz.: one adult female, one half-grown female, one very small female, one male without surroming threads 
and three ovisacs. I found further in the marsupium of a female from the harbour of Godthaab (2-3 fathoms, sand with sea-weeds, collected by Th. Holm ${ }^{3 / v I I} 1886$ ): one adult female, one male in a close wrapping of threads, and two ovisacs glued together; in the marsupium of another female from the same locality were found: one adult female, one closely wrapped male, and six of the host's own eggs; in a young female without marsupium, taken in a depth of ten to fifteen fathoms in that harbour were found: one small female, only $\cdot 34 \mathrm{~mm}$. in length and nearly as broad, on which, nevertheless, occurred two spermatophores, and a male, round which a few threads were spun, was also attached to it.

REMARKS. It is an interesting fact, that the same Amphipod, Protomedeia fasciata $\mathrm{Kr}$., has one parasite in Denmark and another very closely allied species in West-Greenland. The two parasitic species seem to be distinguishable from each other with certainty only by the differences between their males.

\section{Sphæronella longipes n. sp.}

(Pl. VIl, fig. 2a-2g).

FEMALE. One single tolerably large, but flattened and ill-treated specimen has been found, which measures $73 \mathrm{~mm}$. in length and $92 \mathrm{~mm}$. in breadth, and besides, several well preserved specimens, all of which, however, are but scarcely half-grown or recently hatched, so that the largest one (fig. 2 a) is not more than $46 \mathrm{~mm}$. long and somewhat longer than broad, while a very small specimen, represented in fig. $2 \mathrm{~d}$ and fig. $2 \mathrm{e}$, is only $26 \mathrm{~mm}$. long, and the proportion between the length and breadth of this animal is as 7 to 4 . The head is well defined. The frontal margin naked. Antennulæ rather long and slender, with long terminal setæ. Antennæ 3-jointed, third joint shorter than the second (fig. 2c, c); terminal seta about the length of the two last joints combined. Mouth-border of medium breadth. Maxillulæ with well developed additional branch. Maxillæ with smooth basal joint. Maxillipeds rather long and slender; basal joint naked, second and third joints coalescent, last joint digitated at the end with three exceedingly short points. The sub-median skeleton with a somewhat narrow list inside the maxillæ, naked all over; no transverse list between the head and the trunk. Lateral margin of the head naked. Trunk naked. Trunk-legs compared with those of the other species of this genus exceptionally good-sized, consisting of a proportionally rather long cylindrical joint, from the end of which proceeds a proximately thickened very long seta, three to four times the length of the joint, and besides another seta equal to, or somewhat exceeding the length of the joint. About the genital area no information can be given; in the small specimens it is not developed. The caudal stylets considerably shortel than the legs, each ending in three setæ of unequal length, the longest of them almost equalling in length the short seta of the trunk-legs.

MALE. Unknown. 
OVISACS. Of about equal size, elongated oval (fig. $2 \mathrm{~b}$ ); the specimen represented measures $71 \mathrm{~mm}$. in length and $46 \mathrm{~mm}$. in breadth. Eggs numerous, about middle-sized. Judging from the size of the ovisacs, the adult females of this species must be supposed to be $1 \mathrm{~mm}$., or somewhat more, in length.

LARVA. A specimen found free (fig. $2 \mathrm{f}$ ) is $16 \mathrm{~mm}$. long. Cephalothorax more than $1 / 2$ time longer than broad. The front with a long, almost straight list inside the base of the antennula. Antennulæ 3-jointed; olfactory seta about three times longer than the antennula and scarcely half the length of the cephalothorax. Antennæ much as in the larva of $S$. intermedia. Of the maxillulæ only a single seta has been discovered. First joint of the maxillæ of a little more than medium length, smooth; the two others normal. Second joint of the maxillipeds shorter than the third. Abdomen small, its first segment somewhat longer and a trifle broader than the second, and its long seta reaching a little beyond the ends of the caudal stylets; second segment scarcely longer and not broader than the third, from which the relatively good-sized caudal stylets are well set off, but their long setæ are defective in my two larvæ.

POST-LARVAL DEVELOPMENT. A single pupa (fig. $2 \mathrm{~g}$ ) found on the glass during the preparation is $17 \mathrm{~mm}$. long and $11 \mathrm{~mm}$. broad; it is described above on p. 60 .

HABITAT. Ampelisca tenuicornis Lilljbg. from Denmark. I have found the parasite on nine specimens, six of which were rather young, without marsupium. On each of five of these occurred a not half-grown or very small female (in one case it was evidently just hatched); on the sixth specimen I found two free larvæ. In a specimen with halfdeveloped marsupium occurred one not half-grown female. The two other hosts were females with fully developed marsupium; in one of them occurred five ovisacs, in the other the abovementioned flattened female and four of the host's own eggs.

REMARKS. By the very long setæ of the trunk-legs this species is easily distinguished from all other hitherto known species of this genus.

\section{Sphæronella Amphilochi n. sp.}

(Pl. VII, fig. 3a-3b).

FEMALE. The only specimen found was adult and measured $54 \mathrm{~mm}$. in length and $40 \mathrm{~mm}$. in breadth. The head (fig. $3 \mathrm{a}$ ) is well defined from the trunk. The frontal margin with short and very fine hairs. Antennulæ tolerably long, with pretty long setæe. Antennæ 3-jointed, the basal joint appears shorter than the following joints; the terminal seta about the length of the last joint. Mouth-border of about medium breadth. Maxillulæ with rather short additional branch. Basal joint of the maxillæ smooth. Basal joint of the maxillipeds long, slender and naked, second and third joints coalescent, last joint ending in a point. Sub-median skeleton naked, but a peculiar characteristic in this species is that the 
hindmost, broadest and thinnest of the two transverse lists which are found on the ventral side between the head and the trunk, is provided with short hairs throughout its whole length. The lateral margin of the head supplied with hairs of medium leugth, which anteriorly are arranged only in a single line, but somewhat in front of the base of the maxillæ begins a broader area, which runs obliquely backward and outward. The trunk naked; trunklegs not found, but no doubt present. The genital area (fig. $3 \mathrm{~b}$ ) not quite as broad as the head, somewhat broader than long; the more solid chitine forms about two thirds of a ring, which opens broadly in front; laterally the ring is narrow, but posteriorly it is broad, its median part forming an area which consists of an expansion of the hindmost part of the ring and of a triangular process advancing anteriorly between the genital apertures and dilating into a small plate in front of the anterior extremity of the apertures; the whole median part of this area again is occupied by an oblong, anteriorly pointed area of thin skin. The genital apertures come pretty close together in front and are situated quite near the advancing process just described; they are rather oblique and a little curved. The candal stylets are situated on the hindmost part of the just mentioned membranous little central area; each of them ends in two or three setæ; one of which is quite exceptionally long. The margin and the foremost part of the chitinots plate situated between the genital apertures, are provided with fine hairs, some of which are rather long; some hairs are also scattered outside the genital apertures on the thin membrane covering their muscles.

MALE. Unknown.

OVISACS. The two ovisacs found are irregularly shaped, probably owing to pressure; they are somewhat oblong and flattened; the largest is $42 \mathrm{~mm}$. in length. The eggs middle-sized, not numerous.

LARVA and POST-LARVAL DEVELOPMENT. Unknown.

HABITAT. In the marsupium of a specimen of Amphilochoides pusillus G. O. Sars from Denmark were found: one female and two ovisacs adhering to each other.

REMARKS. The female of this small species is no doubt well characterised by the hairs on its head, the structure of the genital area and the particularly long seta of the caudal stylets. The name of $S$. Amphilochi is perhaps not quite suitable, but is was given, and the plate engraved, before a renewed examination of the host by means of the new work by G. O. Sars, revealed that it belonged to a species of the recently established genus Amphilochoides G. O.S. not hitherto observed in Denmark.

\section{Sphæronella Dulichiæ n. sp.}

(PI. VII, fig. $4 \mathrm{a}-4 \mathrm{~d}$ ).

FEMALE. The only specimen found (fig. $4 \mathrm{a}$ ) is $.72 \mathrm{~mm}$. in length, $59 \mathrm{~mm}$. in breadth and a little thinner than broad. The head of very good size in proportion to the 
trunk, well defined and musually broad in proportion to its length. The frontal margin naked (fig. 4c). Antennulæ short, with tolerably short setæ. Antennæ well developed, but partly broken off. Mouth good-sized, mouth-border of medium breadth. Anterior branch of the maxillulæ very long, additional branch rather short. Basal joint of the maxillæ hardly middle-sized, smooth. Maxillipeds proportionally small, much shorter than in any of the preceding species; the basal joint, in proportion to its length, rather thick, naked; second and third joints coalescent, last joint pointed. The sub-median skeleton deviating much in appearance from those in the preceding species (comp. fig. 4c), naked. Lateral margin of the head with a series of moderately short hairs. Trunk naked; trunk-legs small, with short setæ. Genital area (fig. 4d) much narrower than the head, considerably broader than long, forming a transverse, pretty solidly chitinised plate, which is sub-oval, yet a tolerably large part of the posterior margin forming a straight line; the genital apertures are large, the distance between them of about medium length; they are furthermore considerably curved, and the anterior half of their inner lip nearly parallel; their posterior extremities are found a little in front of the posterior margin of the plate. The caudal stylets are situated close together on the posterior margin of the plate; they are small, with shorter setæ. The part of the plate which is situated behind the genital apertures, and a narrow area surrounding the membranous part, which, as usual, is found outside each genital aperture, are furnished with numerous fine and rather short hairs; the remainder of the genital area is naked.

MALE. Unknown.

OVISACS. Compared with the female found, they are very large (fig. $4 \mathrm{~b}:$ fig. $4 \mathrm{a}$ ) and without much difference in size: the largest, which is represented, is $56 \mathrm{~mm}$. in length. The eggs are large, not numerous.

LARVA and POST-LARVAL DEVELOPMENT. Unknown.

HABITAT. In the marsupium of a female of Dulichia monacantha Metzger from Denmark were found: one female and four ovisacs.

REMARKS. The female is easily distinguishable from all other species by its very short, but otherwise quite normally constructed maxillipeds.

\section{Sphæronella Acanthozonis n. sp.}

(PI. VII, fig. $5 \mathrm{a}-5 \mathrm{~d})$.

FEMALE. The only specimen found is very large, namely $4.2 \mathrm{~mm}$. in length, $3.4 \mathrm{~mm}$. in breadth, and nearly as thick as broad. The body seen from below (fig. $5 \mathrm{~b}$ ), is regular and rather shortly ovate, narrowest towards the front, the head and the genital area situated at a not very short distance from the anterior and the posterior outline respectively, and the trunk-legs very far from the lateral outline; seen laterally (fig. 5a), the 
head protrudes somewhat like a small triangle, besides, we see a knot-like protuberance. somewhat in front of the middle, at a short distance from the outline of the back. The head is exceedingly small in proportion to the trunk, and it is distinguished by the particular solidity of the chitinised parts to the front and on the sides, which, moreover, laterally and anteriorly extends considerably on the lower surface, so as to render the area with the appendages somewhat smaller than in the other species. The frontal margin naked (fig. 5c). Antennulæ slender, of medimm length, second joint proportionally longel than in the preceding species, the setæ of about medium length. Antennæ 3-jointed, basal joint short, second joint longer than the third, and the latter longer than the seta. Mouth large, with border of medium breadth. Additional branch of the maxillnla well developed. Maxillæ rather small, their basal joint smooth. Maxillipeds comparatively short and slender. yet somewhat longer than in S. Dulichice; the basal joint has one or two stripes of excessively short hairs (not shown in the drawing) on the inner side, and similar hairs on the inner part of the terminal margin; second and third joints separated, the last joint pointed. Sub-median skeleton provided with thick lists, naked; a double list between the head and the trunk, somewhat behind the base of the maxillipeds. Lateral margin of the head naked. Trunk naked; the trunk-legs are small but conspicuous, rounded knots without setæ - thus deviating much from all other species. Genital area (fig. 5d) somewhat narrower than the head, much broader than long, firmly chitinised all over; it has a long, somewhat concave, anterior margin, convex, oblique lateral margins and a shorter, deeply incised, posterior margin. The genital apertures situated somewhat behind the middle of the plate; they are of medium size, close together anteriorly, and somewhat diverging posteriorly. The caudal stylets in close proximity on the plate close to its posterior margin; they are small, each ending in a rather long seta. The whole genital area naked. (In the illustration the orifices of the receptacula seminis are seen at a short distance in front of the genital apertures).

MALE, OVISACS, LARVA and POST-LARVAL DEVELOPMENT. Unknown.

HABITAT. In the marsupium of a female of Acanthozone cuspidata (Lepech.) from the Kara Sea was found a single female.

\section{Sphæronella frontalis $\mathrm{n}$. sp.}

(Pl. VII, fig. 6a-6i; pl. VIII, fig. $1 \mathrm{a}-1 \mathrm{e}$ ).

FEMALE. The largest specimen (fig. 1a) is $1.84 \mathrm{~mm}$. long and $1.71 \mathrm{~mm}$. broad, and the thickness about three fifths of the breadth. The body is narrower towards the front, and its long posterior outline is sligthly concave in the middle. The head nearly middle-sized and distinctly defined from the trunk. An excellent character of this species is that the naked frontal margin expands in the middle into an oval, transverse, flat cup (fig. 1d), the breadth of which somewhat exceeds the diameter of the basal joint of the 
maxillipeds. Antennulæ scarcely of medium length, with setæ of medium length. Antennæ 3-jointed, first joint short, the third Ionger than the second, but shorter than the seta. Mouth rather large, with mouth-border of medium breadth. Basal joint of the maxillæ smooth. Maxillipeds middle-sized, proximal part of the basal joint with some transverse lines of short, fine hairs on their anterior side; second and third joints separated, the last joint ending digitated in four or five points. Sub-median skeleton very powerful, naked, with a double list between head and trunk somewhat behind the base of the maxillipeds. Lateral margin of the head has a tolerably broad longitudinal belt of short and fine hairs. Trunk naked; trunk-legs normal. Genital area (fig. 6i) much narrower than the head: the solid chitine really consists of two halves, each of them forming an oblique, irregular arch, which begins within the genital aperture a little behind the anterior angle of its lips, whence it continues very close to the lips, following their direction to the posterior angle, then advancing forward and outward in an oblique line; its anterior extremity curving a little inward; the two arches connected between the genital apertures are strongly curved and placed at a pretty considerable distance from each other. The caudal stylets are somewhat apart and comparatively far from the genital area; their setæ have no roubt fallen off. The skin between the genital apertures is closely covered with very short and fine hairs, which also extend somewhat further backward, though not nearly as far as to the caudal stylets; besides, a tolerably large part of the clitinous arches - not their anterior part, however, - is furnished with fine hairs.

MALE. It is large in proportion to the female (fig. $1 \mathrm{~b}:$ fig. 1a), indeed quite exceptionally so, namely $69 \mathrm{~mm}$. long and $53 \mathrm{~mm}$. broad. The head occupies only between a third and a fourth of the whole body, consequently it is very short and also narrow, compared with the large trunk (fig. $6 \mathrm{a}-6 \mathrm{~b}$ ). The frontal border somewhat produced; the margin evenly curved, without cup, naked. Setæ of the antennulæ tolerably long. Antennæ (fig. 6c) seem to be 4-jointed; the basal joint short and coalescent with the skeleton of the head; the connective membrane between the third and fourth joints is long, the terminal seta very long, yet somewhat shorter than the antenna, with a transverse division not very far from the base. Mouth as in the female. Maxillulæ (fig. $6 \mathrm{~d}$ ) with two long principal branches, the anterior one the longest, and at the base of it an extra branch of about half of its length; the additional branch $\left(e^{\prime}\right)$ is long; and its basal part forms a pretty thick, articulated foot. Maxillæ as in the female. Maxillipeds tolerably long; basal joint powerful, its inner margin armed with a pair of rather short, pointed processes (fig. 6e); its anterior surface is decorated in a peculiar way by scattered areas covered with long hairs alteruating with partly large groups of very small, transverse eminences supplied with very short hairs; its other sides are decorated in a more or less similar way; second and third joints separated; the terminal joint ending in at least a couple of points. The first pair of processes of the sub-median skeleton short and blunt, the second pair long and projecting straight backward; 
the base of each of these merges gradually into a strong list, and these two lists run forward, nearly parallel, towards the posterior margin of the rostrum. Lateral margin of the head with a stripe of moderately long hairs, which from the posterior angle of the margin continues upward in a vertical line across the side and the back, but the hairs of this part are long. The whole trunk, except the foremost part of the ventral surface, is closely supplied with peculiar, small, transverse eminences, each of which (fig. $6 \mathrm{~h}$ ) bears about ten hairs, which radiate backward and obliquely sideways; on the greater part of the trunk these hairs are short, but on its hindmost third part, following a line from the caudal stylets obliquely backward and outward towards the second pair of trunk-legs, and thence further, obliquely backward, they are pretty long. Trunk-legs comparatively small. The first pair (fig. $6 \mathrm{a}$ and fig. $6 \mathrm{f}$ ) consist of a clumsy peduncle with two branches, the outer one a little shorter than the peduncle and ending in two about equally long, hairy setæ, the longest of which is not twice the length of the branch, and rather thick; the inner branch is difficult to understand. it is of the same length as, but much thinner than the outer one, with an articulation in its middle and, especially outside this articulation, provided with a number of hairs. The second pair of legs (fig. $6 \mathrm{~g}$ ) about the length and breadth of the outer branch of the first pair; on the outer side, at a short distance from the basis, a short, blunt process (presumably an outer branch) ending in a seta, and the leg ends in two hairy setæ, the longest of which is double the length of the leg and very thick. The caudal stylets are situated far to the front on the ventral surface, a little behind the middle of the trunk; they are rather slender, each ending in a hairy seta, which is equal in length to the longest seta of the second leg.

OVISACS. They are middle-sized (fig: 1c), oblong, somewhat flattened; the specimen represented has young ones in the Nauplius stage, and is $1.03 \mathrm{~mm}$. in length and $69 \mathrm{~mm}$. in breadth. Eggs numerous and small.

LARVA. Fig. 1e is drawn from specimens pulled out of the egg-membranes. The front on each side inside the base of the antennula has a long, oblique list, the ends of which are curved inward. Antennulæ 3-jointed; the olfactory seta about half the length of the cephalothorax. Antennæ almost the length of the antennulæ; second joint somewhat longer and considerably more slender than the first one, the third joint very short, the terminal seta the same length as or longer than the second joint. Maxillulæ as in S. Calliopii, with four branches which, however, are shorter and more slender than in this species, and the hindmost branch only is hairy (not, as in the drawing, the penultimate one as well). The joints of the maxillæ each of medium length, smooth. Secoud joint of the maxillipeds considerably shorter than the third. Segments and setæ of the abdomen as in S. Calliopii, with the exception that the long setæ of the caudal stylets are only half the length of the body (and perhaps even relatively shorter in the free swimming larva).

POST-LARVAL DEVELOPMENT. Unknown. 
HABITAT. The marsupium of Ampetisen macrocephall Lilljeborg from Denmark. Only a single infested specimen has been found, and in the anterior part of its marsupium occurred: a deformed female, which had probably finished laying eggs, one male and seven mutually adhering ovisacs, one of which contained full-grown larre; in the hindmost part appeared the large female represented, one male and six mutually adhering ovisacs; one ovisac had fallen out before its place was ascertained.

REMARKS. The name of the species points to the remarkable cup on the frontal margin of the female. The male deviates much from all other hitherto known forms.

\section{Sphæronella microcephala Giard and Bonnier.}

(Pl. VIII, fig. 2a-2k).

Sphceronella microcephala Giard and Bonnier, Compt.rend. de l'Acad. des Sc., 25 sept. 1893.

Bull. scientifique de la France et de la Belgique, T. XXV, fasc. 2, 1895, p. 464, pl. XII, fig. 40-47.

FEMALE. The largest specimen, which had only just begun laying eggs, was $1.44 \mathrm{~mm}$. in length and of the same breadth and thickness (fig. $2 \mathrm{a}$ ), sub-globular, yet a little produced and almost pointed towards the front, which is due to the fact that the trunk merges evenly into the hear without any separation. The frontal border is present as a small crescent-shaped transverse plate (fig. $2 \mathrm{e}$ ), which is scarcely double the length of the diameter of the mouth; lateral borders are wanting (fig. $2 \mathrm{~d}$ ); so we only find the various appendages and a tolerably developed sub-median skeleton, but, as the lateral parts of the skeleton, viz. the lateral borders, are wanting, this parasite differs from all the preceding, but agrees with several of the following species of this genus, in having no lateral limitation to the surroundings of the month-limbs. Antemulæ very short, without distinct vestiges of articulation, with a seta on the anterior margin at a short distance from the base (no doubt corresponding to the usual pretty long seta at the anterior angle of the first joint), and four terminal setæ of unequal length, the longest of which are a little longer than the antennula. Antennæ seem to be altogether wanting. The mouth of medium size, with a rather narrow mouth-border. Maxillulæ well developed, with good-sized additional branch. Maxilla far removed from the rostrum and much closer together than in any other species of the genus; the basal joint large and smooth. Maxillipeds small and feeble; their basal joint pretty short, very slender and liaked, the second and third joints fused into a very short and slender joint; the last joint scarcely half the length of the preceding, rounded at the end; the reduced state of the two (or three) last joints, in particular, proves this pair of appendages to be almost valueless as prehensile organs. The sub-median skeleton is provided with a somewhat prominent list on each side of and at a short distance from the 
median line; a narrow list is found between the maxillæ; the whole skeleton is naked. The trunk entirely naked; trunk-legs wanting. The genital area (fig. $2 f$ ) deviates strongly from all other species; it is considerably larger than the head (fig. 2 a) and much longer than broad. The solid chitine forms posteriorly a narrow semi-circle which opens towards the front, each branch dilating anteriorly on the internal side to a considerable breadth, after which both branches run on parallel a long way, at the same time gradually declining in breadth; the whole structure may also be described by saying, that there are two anteriorly pointed, posteriorly broader, mutually parallel lists, which again decrease in breadth in their hindmost part, converge, and at last join in a semi-circle. The somewhat curved genital apertures are situated at some distance from each other, so that their outer ends come close to the inner side of the semi-circle; their muscles run forward and a little outward towards the broadest part of the lists, close in front of the foremost part of the semi-circle. (About the orifices of the receptacula seminis which are omitted in the drawing, see above on p. 14.) The whole area is naked, and caudal stylets are altogether wanting.

MALE. The body, apart from the rostrum, is $18 \mathrm{~mm}$. in length; seen from below, it is ovate, only about one sixth longer than broad; the thickness in proportion to the breadth is almost like two to three; so it is exceedingly small compared with the female (fig. $2 \mathrm{~b}$ : fig. 2 a). It deviates strongly from all other species, and in spite of much study and long deliberation, I have been unable to understand all its details. Head and trunk of about equal size. The frontal border is not produced, its margin flatly curved, naked. Antennulæ long, without articulation, with setæ of medium length. Antennæ wanting. Rostrum unusually long, very broad at its base, and in the specimens found, strongly protruding, which gives it, when seen from below, the shape of a large, distally blunt cone, projecting considerably beyond the frontal margin. Maxillulæ as in the female. Basal joint of the maxillæ somewhat compressed, broad between the foremost and hindmost angles; the basal margin is long, and its acute posterior angle is further removed from the head than the articulation of the second joint; its outer side is armed with a pair of conical taps. Maxillipeds of medium length, the basal joint somewhat fusiform, on the inner and anterior sides some areas covered with numerous extremely short hairs; second and third joints coalescent, last joint pointed. The sub-median skeleton possesses only the first pair of processes, each of which being long, very slender and nearly setiform (fig. $2 \mathrm{~h}, \mathrm{i}$ ), and being a prolongation of a list rumning inside the maxillæ. The lateral margin of the head is prolonged backward to the middle of the trunk, and it is provided with a stripe of rather short hairs which are situated more or less close together. The ventral surface of the trunk is for the most part covered with tolerably short hairs, many of which are arranged in transverse rows, whereas the back, the lateral surface and the hindmost extremity are naked. I have been unable to understand the basal parts of the trunk-legs, I cannot even make out with absolute certainty which pair are the foremost. I consider the narrow pair of appendages which are situated near the median line to be the caudal stylets, and the limbs which are seen a little outside 
these appendages, to be the first pair of trunk-legs, the lateral legs would then make the second pair. The proximal part of the first pair of trunk-legs being incomprehensible to me, I must content myself with referring to fig. $2 \mathrm{~g}$, which is drawn as accurately as possible; the distal part is a rather short and broad joint divided at the posterior outer angle by a rather deep incision into two unequal processes, the outer one of which is conical and ends in a shorter seta, while the inner one is broader and is cut off posteriorly in a straight line, bearing on its end a small joint which terminates in a pretty long seta, of more than half the length of the basal joint of the maxilliped. The second pair of legs resemble the distal part of the first pair, but their onter process (outer branch?) is shorter, with the terminal seta somewhat longer, the inner process lacks the small joint, whereas its seta is a little shorter than in the first pair of legs. Each of the caudal stylets is a tap ending in a pair of conspicuous, though not long, setæ, besides having a short seta proceeding from an angular expansion on the outside at the base; each stylet is a direct prolongation of a long, anteriorly somewhat expanded, prominent list, which runs forward towards the base of the trunk. The caudal stylets, the distal part of the first pair of legs and the second pair of legs are sitnated almost on the same transverse line.

OVISACS. They are pretty small, mostly somewhat flattened, their circumference varying between a circular and a very oval shape; the specimen represented in fig. $2 \mathrm{c}$ is $.72 \mathrm{~mm}$. long and scarcely more than half as broad. As many as fifteen ovisacs may be found in one female. The eggs of medium size, not numerous.

LARVA. The body of a specimen (fig. $2 \mathbf{i}$ ) which had just attached itself, is $25 \mathrm{~mm}$. in length. It deviates very much from all the other known larvæ of the genus, and partly of the family, in its extremely short antennæ, its long and very slender maxillæ and maxillipeds, its slender natatory legs and very slender abdomen. The front without lists, in the specimen figured it is covered throughout its whole breadth by the viscous substance which attaches it to the host. Antennulæ 2-jointed, olfactory seta rather long, about three fourths the length of the cephalothorax. Antennæ extremely short, almost rudimentary, 3-jointed, with a proportionally thick, but very short, seta on the penultimate joint, and an exceedingly short terminal seta. Mouth very large. Of the maxillulæ I have discovered three very fine branches, the anterior one moderately long, the two others a little shorter. Maxillæ long and very slender, the basal joint, in particular, is comparatively very long and extremely slender; all joints smooth. Basal joint of the maxillipeds long and very slender, second joint unusually long, and considerably longer than the third one. The posteriorly free pouch on the ventral side of the cephalothorax small and very short. The second section, the free segment, of the cephalothorax proportionally much smaller than in other species. Peduncle of the natatory legs unusually slender. Abdomen considerably more slender than in other species; the long seta projecting from the posterior angle of the first segment, is more than double the length of that part of the abdomen which is posterior to the point where this seta projects, the second somewhat shorter seta is also unusually long. Second segment a 
little shorter than the first one, and somewhat longer than the third one combined with the not rlefined candal stylets; the terminal setæ of these stylets almost two thirds the length of the whole body.

POST-LARVAL DEVELOPMENT. After the preparation I found on the objectglass an individual (fig. $2 \mathrm{k}$ ) which I consider to be a pupa of this species; it is mentioned above on p. 61.

HABITAT. The marsupium of Ampelisca typica Sp. Bate from Denmark. In one specimen occurred: one female, two males, twelve ovisacs, three of which were free, and nine adhering to each other in a lump (two of them with scarcely quite developed larvæ), and finally, two larvæ which had evidently been attached. In another specimen were found: one female and some ovisacs; in a third: one female and fifteen ovisacs, thirteen of which adhered to each other in a lump (and one of them contained developed larvæ); in a fourth specimen were found: one male (the largest represented), two free ovisacs and two of the host's own eggs.

REMARKS. This parasite in all its stages is far removed from all other species of this genus, still the differences are not of such a quality that I have felt justified in establishing the species as a type of a new genus, as which, in my eyes, it would not be fully equivalent to the other genera. Grard and Bonnier have described the female and ovisacs of a species taken in Ampelisca tenuicornis Lilljeborg from le Croisic (Brittany), but in spite of the great differences between their description and my own of the head and its appendages, I nevertheless consider my species identical with theirs, and I refer to my detailed critique of their account given above on page 13-14.

\section{b. Parasites on Cumacea.}

In six species of Cumacea I have found parasites in the marsupium, and I have referred them to five species. Hitherto they have occurred only in fully developed marsupia. These five species show mutually very great difference in both sexes, nevertheless, they are distinguished in several features from the species found on Amphipoda; the larvæ of all these parasites, especially, are characterised by some peculiarities which are not noticed in any of the previously described larvæ, whereas a few of them appear in the larva of S. Munnopsidis which lives in Munnopsis typica M. Sars belonging to the order Isopoda. For several reasons, among others in order to avoid unnecessary repetitions in the description of the two sexes and the larvæ of each species, it may be to the purpose to give a view of their peculiarities.

THE FEMALES. Antennæ only 2-jointed or, mostly, wanting. The mouth-border moderately broad or narrow. The basal joint of the maxillipeds decorated on the anterior side with small groups or rows of very short or rudimentary hairs, which, in many cases, only look like small, distinct dots; the spine proceeding from the distal inner angle of the penultimate 
joint is large, and one of its margins is provided with a row of very short setiform processes. Trunk-legs seem to be altogether wanting.

THE MALES. They are always distinguished by a very peculiar - though mutually extremely varying - development of the frontal border, the margin of which is in a great measure decorated with numerous fine, or exceedingly small, spiniform processes, which are mostly arranged in a single line. Trunk-legs and caudal stylets either tolerably small, or - frequently - altogether wanting.

OVISACS. They are middle-sized or pretty small, but exceptionally numerous, for in three of the species occurred about twenty, in a fourth even twenty-eight sacs, which decidedly had been laid by the same female.

THE LARV E. The front is decorated, either with some good-sized lists, mutually connected on each side, or (mostly) with numerous fine processes, arranged in one or more rows. Each maxillula has four branches. The basal joint of the maxillæ has a donble comb of fine, almost cylindrical, apically rounded processes along the margin, against which the second joint is folded (pl. VIII, fig. 30 ); the third joint has two or more pointed processes along its inner margin. The second joint of the maxillipeds much shorter than the third. Abdomen of medium length. or (mostly) tolerably long and powerful; first segment goodsized, and the setæ proceeding from its posterior angle extending to, or somewhat beyond, the caudal stylets; second segment about as long as or a little longer than the first one and a little more voluminous; third segment very short, and the caudal stylets set off by a distinct articulation:

\section{Conspectus of the Females.}

1. Maxillæ well developed. . . . . . . . . . . . . . . . . . . 2 1'. Maxillæ quite rudimentary. . . . . . . . . . . . . . 31. S. marginata n. sp.

2. An odd, good-sized, vanlted eminence, provided with a prominent median plate, a little behind and inside the base of the maxillipeds. . . . . . . . 27. S. decorata n.sp.

2'. No eminence behind the maxillipeds . . . . . . . . . . . . . . . . . 3

3. The head well defined from the trunk, with frontal border and lateral borders well developed. Caudal stylets well developed............. 28. S. modesta n. sp.

3'. The head not defined from the trunk, frontal border and lateral borders wanting. No

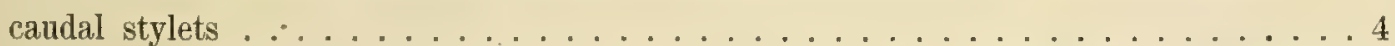

4. The solid chitine of the genital area surrounds the genital apertures posteriorly and laterally, not anteriorly...................... S9. dispar n. sp.

4'. The solid chitine of the genital area surrounds the genital apertures on all sides.

30. S. insignis n.sp.

\section{Conspectus of the Males.}

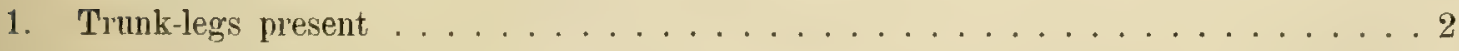

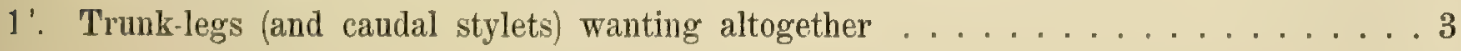


2. Frontal border produced into a good-sized, anteriorly blunt, plate. Candal stylets manting. 27. S. decorata

2'. Frontal border slightly produced. Caudal stylets good-sized....... 28. S. modesta

3. Front strongly produced; seen from below, it tapers considerably towards the distal end, then expands into a tolerably broad disk, the margin of which - except posteriorly is provided with a single row of fine processes. . . . . . . . . . . . . . 4

3'. Front broad and somewhat emarginate in the middle, the margin with some rows of fine processes. ................................ S1. marginata

4. Frontal disk nearly circular .................... . . . . dispar

4'. Frontal disk broader than long, with rectangular lateral angles..... 30. S. insignis.

\section{Sphæronella decorata n. sp.}

(PI. VIII, fig. 3a-30; pl. IX, fig. 1a-1b.)

FEMALE. The largest specimen, represented in fig. $3 \mathrm{a}$, is $2.15 \mathrm{~mm}$. in length and $2.47 \mathrm{~mm}$. in breadth, and it has laid six ovisacs; another specimen, only $1.33 \mathrm{~mm}$. long and $1.52 \mathrm{~mm}$. broad, has laid eight ovisacs. Thus the body is broader than long. The small head is distinctly defined from the trunk; it is comparatively well chitinised all over, except in the part which surrounds the mouth-appendages and is limited by the low lateral borders, and this part, forming a triangle, is prolonged anteriorly beyond the anteunulæ, continuing a rather good distance along the dorsal side of the head, where this peculiar extension terminates in an acute angle (fig. $3 \mathrm{~d}$ ). So there is no leal frontal border. Antennulæ (fig. $3 \mathrm{e}$ ) short, 2-jointed, the two first joints being coalescent; setæ short. Antennæ tolerably short, 2-jointed, the basal joint short, second joint longer and thicker, terminal seta short. Maxillulæ well developed, additional branch good-sized, with a distinct foot. Maxillæ middle-sized, basal joint smooth, but numerous chitinous taps appear on the inner side of the large membrane between the first and the second joints. Maxillipeds powerful and comparatively pretty long; the basal joint on its anterior side and on a small part of its inner side, bears four or five groups of very small prickles (rudimentary hairs), arranged in transverse belts; further, at a short distance from the distal margin, a transverse row of very fine hairs, besides similar hairs on the distal margin itself; second and third joints coalescent, the distal spine long and rather slender, with fine processes on its inner margin; last joint a little expanded towards its rounded, flattened end, which terminates in numerous fine processes arranged in a line. The sub-median skeleton slightly developed; a ventral transverse list between head and trunk, and adjoining the anterior margin of this list, an odd, good-sized, considerably vaulted eminence, which is rounded, a little broader than long, and provided at its median anterior part with a rounded protruding plate. Lateral margin of the head naked. Trunk naked. Genital area (fig. 1a) considerably smaller than the head (fig. 3a), nearly as long as 
broad; the solid chitine forms a somewhat irregularly shaped plate (fig. 1 a), in which a tolerably large area of the anterior third part is thin-skinned and partly merging in the skin surrounding the plate (though in two dissected specimens the shape of the plate and of the membranous part were somewhat different, the present description will do for both). The genital apertures are seen far to the front on the posterior half of the plate; they are strongly curved and situated at a moderately long or rather short distance from each other, in such a position that their muscles turn very much sideways and a trifle forward. The space between the genital apertures has some longitudinal stripes of very short hairs; the remainder of the area is naked. At a short distance behind the apertures appear a couple of small cones, which doubtless are the rudimentary caudal stylets.

MALE. A good-sized specimen is $55 \mathrm{~mm}$. long and $42 \mathrm{~mm}$. broad, which is large indeed, thongh, considering the proportion between the sexes in other species, it is but middle-sized (fig. $3 b$ : fig. 3a) comparatively to the females, which are large. Seen from below, its shape is very characteristic, almost hexagonal, the posterior margin of the trunk forming a somewhat convex line, its lateral outline being moderately long and somewhat concave, whereas the head has a long, slightly curved, lateral outline and a very short anterior margin. The head nearly the size of the trunk. The frontal border strongly produced, with converging lateral margins; terminal margin short, cut off in a straight line, with a uretty deep incision in its median part, while distally each lateral margin has two deep and mather broad incisions and, somewhat in front of the antennula, a slight depression; these incisions form three pairs of lobes, the hindmost of which are low, the others good-sized with almost right angles; the terminal margin of all the lobes is furnished with a row of numerous minute processes. Antennulæ short, 2-jointed, with short setæ. Antennæ of scarcely medium size, 3-jointed, second joint the longest; terminal seta the length of the last joint. Moutl-border a little broader than in the female; maxillulæ as in the female. Maxillæ (fig. 1 b) nearly as in the female, and the two last joints coalescent as in the other sex. Maxillipeds of medium length, basal joint rather slender, otherwise this joint as well as the other's constructed and equipped (fig. $3 \mathrm{f}$ and fig. $3 \mathrm{~h}$ ) as in the female. The sub-median skeleton has the two first pairs of processes, first pair about middle-sized, second pair powerful, long and diverging slightly backward. The lateral border of the head has a peculiar shape, curving strongly towards the base of the maxillæ, then turning backward and obliquely sideways almost at right angles; the margin fringed in the middle with moderately long hairs, anteriorly and posteriorly with long hairs, and from its hindmost end a narrow stripe of extremely long hairs runs upward across the side of the animal, where it curves slightly forward (fig. $3 \mathrm{~g}$ ), then continues across the back in an oblique line. Behind this stripe the back and sides, as well as the ventral surface of the trunk, are densely covered with moderately long, and in front of the second pair of legs, with long hairs. About the middle of the back of the trunk is seen a short and very narrow transverse area. First pair of trunklegs pretty small, their basal part indistinctly defined, and from this part proceed two 
tolerably small branches of equal length, each of which consists of a somewhat thicker; very short joint, from the end of which proceeds a thick, but rather short, partly hairy seta. The second pair of legs are situated at the posterior angles of the trunk and greatly resemble the first pair, but the basal part is even more indistinct, the joint of the inner branch much shorter than that of the outer branch, and the terminal setæ - particularly that of the outer branch - longer than in the first pair. Caudal stylets altogether wanting.

OVISACS. They are pretty small or of medium size, circular or oval and mostly somewhat flattened; the ovisac represented in fig. $3 \mathrm{c}$ is one of the larger ones and is $94 \mathrm{~mm}$. in length. Eggs numerous and comparatively small.

LARVA. Fig. 3i-3o are drawn from specimens which had just broken out of the egg-membrane. The larva is $30 \mathrm{~mm}$. long and so slender that its cephalothorax is a little more than twice as long as broad. The front is richly decorated (fig. 31): its margin with a series of rather short and very short processes which begin at some distance from the base of the antennula and stop a short distance from the median line; the eight or ten processes nearest to this line are really situated somewhat within the margin and are much longer than the more lateral processes which proceed from the edge; somewhat inside the more lateral part of the frontal margin appears on each side a long, oblique row of tolerably long, narrow processes, turning forward and outward in an oblique line; somewhat behind them we see a curved transverse list, and at the inner angle of this list - consequently in front of the mouth at a short distance from the median line - four or five rather long, and especially comparatively thick, anteriorly somewhat diverging processes with rounded apex. Antennulæ 2-jointed, their olfactory seta somewhat more than half the length of the cephalothorax. Antennæ equal in length to the antennulæ; first joint broad, sometimes with a strong: indication of being formed of two coalescent joints (fig. $3 \mathrm{~m}$ ), the first of which is short (comp. the following species); second joint of the same length as or a little longer than the first; third joint short, with two terminal setæ, one of them short, the other nearly the length of the two last joints combined. The maxilluliæ have all four branches well developed, the outermost being the longest, curved outward and backward, hairy. The basal joint of the maxillæ has two rows of processes (fig. 30), but one of them is often covered by the second joint (fig. 3n), which has no setæ; the third joint has two good-sized processes on its inner margin, but the distal one, which is the largest, is smaller than the long, curved, terminal part of the joint. Abdomen pretty long; a description of it is found above on p. 14y. Setæ of the caudal stylets more than three fifths the length of the borly.

POST-LARVAL DEVELOPMENT. Unknown.

HABITAT. Found in the marsupium of six specimens of Diastylis Rathkei (Kr.) from West-Greenland and in one specimen from the Kara Sea, but not in Denmark. It may be pointed out that I have found parasites in nearly half of the adult females from the two localities mentioned, which I have seen, whereas an investigation of several scores of females from various Danish waters gave a negative result. In one specimen occurred: one 
female (the one figured), no male, but six free ovisacs; in another specimen were detected: one female, one male and eight free ovisacs (all with eggs); in at third: one female, one male and nine ovisacs (four of these glued together); in a fourth: one female, one male, and nine ovisacs (some of them with Nauplii). In a fifth specimen I discovered: one female, two males and twenty ovisacs, ten of which adhered to each other in one lump, four in another; several of them contained larvæ, some of which had evell thrown off the eggmembrane. In a sixth specimen, at least seventeen ovisacs adhered to each other in a big lump which surrounded the female, so that only part of one of its sides helped to form the outer wall of the lump, while a male was sitting in a hole between the ovisacs on the opposite side; the whole lump had shaped itself after the cavity of the marsupium, it was nicely smoothed and had a slight longitudinal groove on the surface, which was turned towards the ventral side of the animal; all the ovisacs were more or less flattened and fitted together like mosaic; some of them contained eggs, some of them half-developed, others quite developed larvæ.

\section{Sphæronella modesta n. sp.}

(Pl. IX, fig. 2a-2i).

FEMALE. It always seems to be longer than broad, ovate, and a specimen which had laid numerous ovisacs, was $1.23 \mathrm{~mm}$. long and $87 \mathrm{~mm}$. broad (fig. $2 \mathrm{a}$ ). The head is small, well defined from the trunk. The frontal border rather considerably produced; its margin naked and centrally a little emarginate; close behind this margin on the lower side is an odd, tolerably good-sized square area (fig. $2 \mathrm{~d}, \mathrm{x}$ ) with ronnded corners; the area seems to be pierced with rather numerous holes. Antennulæ pretty long and powerfiul, 3-jointed, with some setæ of medium length. Antennæ wanting. Principal branches of the maxillulæ rather short, additional branch long. Basal joint of the maxillæ large and smooth; a number of taps are seen on the distal part of the connecting membrane between the first and the second joint; second and third joints separated. Maxillipeds good-sized, their basal joint his several rather short transverse rows of very fine, short hairs, second and third joints separated; the last joint terminates in a point inside which it has some spines; the spine at the end of the third joint shorter than in $S$. decorata, but of a similar shape and equipment. Submedian skeleton well developed, with three pairs of longitudinal lists, parts of which are rather broad, inside the maxillæ; no eminence behind the base of the maxillipeds. The lateral nargin of the head has a row of short hairs. In one specimen the trunk is quite naked, in another it has a number of simple, moderately lomg lairs which are partly arTanged in rows on a minor area behind the liead. Genital area smaller than the head (fig. 2 a), much broader than, or abont twice as broad as. $\operatorname{lng}$ (fig. $2 \mathrm{e}$ ); it is a chitiniserl, somewhat irregular and, according to the individnals, somewhat differently shaped plate with a centrally inflexed posterior margin; the genital apertures oblique and considerably cmed, 
not very far apart, and their hindmost extremity pretty close to the posterior margin of the plate; the plate is naked but for very few hairs between the anterior part of the genital apertures. The candal stylets, situated close together and near the posterior margin of the plate, are very peculiar: each stylet consisting of a rather short, but thick joint, on the inner posterior angle of which is articulated a joint twice as long, but scarcely half as thick, which must be explained as a transformed seta, outside which are seen one or two simple setæ.

MALE. It is of medium size compared with the female (fig. $2 \mathrm{~b}:$ fig. $2 \mathrm{a}$ ); a goodsized specimen is $28 \mathrm{~mm}$. Iong and $.22 \mathrm{~mm}$. broad. Seen from below, its broadest dimension appears far towards the front, off the maxillæ, and seen laterally, it is unusually thick. The head - considered as extending to the limit of the hair-covered part - is considerably smaller than the trunk (fig. $2 \mathrm{~h}$ ). The frontal border but slightly produced; it has five incisions, and six small lobes (fig. $2 \mathrm{~g}$ ), each of which is twice as broad as one of the lateral incisions, and their slightly curved terminal margin is furnished with a row of fine, spine-shaped processes. Antennulæ 3-jointed, scarcely of medium length, with tolerably short setæ. Antennæ wanting (fig. 2f). The mouth-border provided with long hairs, considerably longer than in the female. Maxillæ of medium size, their basal joint bearing some normal hairs at the margin of the distal connecting membrane, second and third joints scarcely separated from each other. Basal joint of the maxillipeds rather long, at its base a small area with minute prickles, and at its distal end a few hairs; the other joints as in the female. The sub-median skeleton possesses the two first pairs of processes; the first pair are removed further backward than usual, and a little overlapping the base of the maxillipeds, they appear as pretty good-sized, somewhat protuberant, thick cones; the second pair are all but rudimentary. The ear-shaped stripe surrounding the base of the antennula is provided with long hairs, the short lateral margin of the head with moderately long hairs, and from its posterior extremity to off, or a litte behind, the base of the maxillæ the anterior limit of the hair-covered part runs obliquely forward and upward along the side of the animal (fig. $2 \mathrm{~h}$ ), then curves very slightly and continues in a straighter line across the back; the result is that the naked part of the body becomes unusually small, compared with the remainder. The median part of the ventral side of the trunk, in front of the caudal stylets, has an extremely close covering of fine hairs of medium length; the remainder of the ventral surface, as well as the sides and the back up to the boundary of the hair-coat are closely covered all over with pretty coarse, tolerably long, or long hairs, and each of these proceeds from a distinct little knot; rather frequently, though by no means always, the long hair seems to proceed from the centre, and a much shorter one from each end of such a knot, but the denseness of the covering renders a close examination exceedingly difficult and uncertain. The first pair of trunk-legs consist of a relatively small basal part, from which proceeds a single, short, almost cylindrical branch without terminal seta. The second pair are so small and so much hidden in the dense hair-coat, that I have been unable to discern with certainty more than a single tap, which is shorter than the surrounding hairs. The 
candal stylets are found at a considerable distance from the posterior margin of the trunk; they are comparatively large and nearly of a similar structure to those of the female, only I have not been able to find any ordinary seta beside the one which is shaped like a joint.

OVISACS. They are small (fig. $2 \mathrm{c}$ ), nearly round, frequently somewhat flattened, with but few eggs, but then again as many as twenty-eight ovisacs may be found with one female. The longest diameter of one of the ovisacs represented (containing eggs) is $42 \mathrm{~mm}$. The eggs of about medium size.

LARVA. The specimens examined, of which the one partly represented in fig. $2 \mathrm{i}$ had a total length of $23 \mathrm{~mm}$., were pulled out of the egg-membranes, so the shape of their body in a free state cannot be determined with absolute certainty, however, their cephalothorax seems to be comparatively somewhat shorter and broader than that of the preceding species, and to agree more with $S$. dispar. The larva is easily distinguished from all the other species by having no processes whatever on its front, instead of which, however, we find half its surface occupied by three pairs of transverse, partly curved, outwardly connected lists. In many specimens, e. g. the one figured, the olfactory seta of the antennulæ is remarkably short, not half the length of the cephalothorax, whereas in other specimens I have found it reaching to the natatory legs (this difference is inexplicable to me). Antennæ much as in the preceding species, except, indeed, that the broad basal part consists of two pretty distinctly separated joints, the first of which is short; so the antenna is 4-jointed. Maxillulæ much as in $S$. decorata. First joint of the maxillæ as in the preceding species, second joint with some fine hairs on the ventral side of the distal end; third joint sometimes as in $S$. decorata, but most frequently with three processes on the inner side, and then the curved end of the joint itself is generally shorter than the most distal of the processes. Abdomen as in $S$. decorata.

POST-LARVAL DEVELOPMENT. Unknown.

HABITAT. The marsupium of Eudorella emarginata (Kr.) from Denmark. In a large material I have found altogether seven infested specimens. The following statistics can be given. In one specimen were found: one shrunk female, three males and thirteen mutually adhering ovisacs, most of them with eggs, some of them with Nauplii; in another specimen occurred: one good-sized female, one male and twenty-two mutually adhering ovisacs, a few of which contained developed larvæ. In a third specimen the female and the ovisacs together formed an oblong lump; the female, which was good-sized, was so closely surrounded by the considerably flattened, mutually pretty firmly adhering ovisacs, that only a very small part of it was visible on the side turning towards the ventral surface of the host; of ovisacs I found twenty-eight, some of which contained eggs, most of them brood in different stages, but in hardly any of them were the larvæ ready to burst the egg-membrane; a single male was attached to the outside of the lump.

REMARKS. In the structure of the caudal stylets in both sexes, and in the frontal area of the female, this parasite differs from all other species. 


\section{Sphæronella dispar n. sp.}

(Pl. IX, fig. $3 \mathrm{a}-3 \mathrm{k}$.)

FEMALE. A large specimen (fig. $3 \mathrm{~d})^{\mathrm{1}}$ ) which had only laid three ovisacs was $.69 \mathrm{~mm}$. long and $79 \mathrm{~mm}$. broad, thus being broader than long; two other specimens without ovisacs were of the same shape and size, whereas a fourth specimen (fig. 3a), which had laid about a score of ovisacs, was much smaller, $49 \mathrm{~mm}$. in length and $38 \mathrm{~mm}$. in breadth, thus being longer than broad. The head is not defined from the trunk at all, and the area bearing the month-appendages is survounded by a soft membrane; the usual chitinised parts, such as frontal border and lateral border's, are altogether wanting (fig. 3f). Antemulæ short, 2-jointed, with about three pretty short setæ. Antennæ wanting. The setæ of the month-border I have not been able to discern with certainty. Maxillulæ small, with tolerably short principal branches, and additional branch wanting. Basal joint of the maxillæ smooth; the connecting membrane between the first and the second joint without chitinous taps; second joint distiuctly separated from the third, which is comparatively long and slender, and terminates in a few fine setaceous branches. Maxillipeds of medium size, but appear to be weak; the basal joint being provided on its anterior side with several irregular rows of very short and fine hairs; second and third joints fused into one rather clumsy joint with a somewhat sinnous outline, the distal spine being a little broader than in the preceding species; the last joint terminates bluntly and its end is surrounded by a row of numerous, very short and fine setæ. The sub-median skeleton is much reduced. The trunk is naked. The genital area is rather small (fig. $3 \mathrm{~d}$ ), much broader than long (fig. $3 \mathrm{~g}$ ); the solid chitine forms a kind of seni-circle which opens towards the front, its sides are narrow, and its posterior part broad. Genital apertures comparatively large, much curved, anteriorly parallel, and not far apart, the space between them solidly chitinised. The whole area naked; caudal stylets wanting.

MALE. It is middle-sized or pretty large in proportion to the female (fig. $3 \mathrm{~b}$ : fig. $3 \mathrm{~d}$ and fig. $3 \mathrm{a}$ ); its length is $21 \mathrm{~mm}$. to $22 \mathrm{~mm}$. Seen from below (fig. $3 \mathrm{~h}$ ), its ontline comes close to that of $S$. decorata, but its front is very different. Head and trunk of about equal size. The front much produced, its lateral margins converging strongly a long way, till the distance between them is a little shorter than the diameter of the month, after which their anterior extremity expands into a disk, which is a little larger than the month, and thus is situated on a short peduncle. The larger part of the free margin of the disk is furnished with a row of slender, almost setaceous processes, and on the ventral surface of the disk, towards its base, we see a small chitinous ring; on its inner side this ring is provided with four expansions, which turn towards its centre and constitute the surrounding of a

1) The mouth-appendages (as is partly shown in the drawing) were placed in an abnormal position by pressure. 
cross-shaped very small area. Close behind the pednncle of the disk, the lateral margin of the elongated front is provided with a low. Iongitudinal keel (fig. $3 \mathrm{~h}, \mathrm{y}$ ), which bears a row of rather short setaceous processes. The antennul are short, without distinct articulation, very sinuous in outline, and most sparingly provided with setx; one of these is a peculiar olfactory seta, placed at some distance from the apex, on the posterior side. Antennæ wanting. Mouth-border rather narrow. Maxillula somewhat larger than in the female, without additional branch. Maxillæ small and constructed like those of the female, except the third joint, which is pointed. Basal joint of the maxillipeds long and somewhat slender, on their anterior side proximally decorated with areas and rows, patly of minute prickles, partly of very short hairs, distally provided with several transverse rows of somewhat longer hairs; second and third joints coalescent, last joint essentially as in the female. The suhmedian skeleton with the two first paits of processes conspicuous; the first pair (i) of medium size, triangular and sitnated a little behind the base of the maxillæ; the second pair $(j)$, which are placed inside the base of the maxillipeds, are modelately long, shaped like narrow cones and strongly diverging. The lateral margin of the head essentially like that of the species which live typically on Amphipoda; in its whole length, from a point somewhat in front of the base of the antennula, furnished with long hairs; off the base of the maxilla, and before reaching the posterior end of the lateral margin, the outline of the haircoat runs upward and slightly forward on the side of the animal till, on the middle of the side, it turns backward, then again continuing straight upward across the back, in a line with the posterior end of the lateral margin (fig. $3 \mathrm{i}$ ). Sides and back of the trunk closely covered with proportionally long hairs; the central and posterior part of the ventral surface covered with hairs of medium length, while basally, and for a part, sub-laterally, it is quite or almost naked. Trunk-legs and caudal stylets altogether wanting.

OVISACS. They are middle-sized in proportion to the females, but here I have met with the peculiar fact that the smaller ovisacs with few eggs, represented in fig. $3 e$, have been laid by the small female drawn in fig. $3 \mathrm{a}$, whereas the larger ovisacs, each containing several more eggs, enlarged on the same scale and represented in fig. $3 \mathrm{e}$, have been laid by the large female drawn in fig. $3 \mathrm{~d}$. The eggs are comparatively large.

LARVA. A free specimen (fig. $3 \mathrm{k}$ ) is $21 \mathrm{~mm}$. in length. The cephalothorax is an oblong oval (the length in proportion to the breadth is as $13: 8$ ). It can be distinguished from the other species by the decoration of its front: there are no laked lists, but from one antennula to the other, with only a very short central interuption, runs a transverse curve of fine processes; on the sub-median part of the front the anterior ends of the processes are decidedly a little removed from the frontal margin. whereas in the more lateral part, they almost reach the margin, and this is due to a break in the transverse curve just in the middle between the median line and each antennula, so that the sub-median processes recede a little. The olfactory seta of the antennulæ is extremely long, nearly as long as the cephalothorax and, when turned backward, reaching the middle of the abdomen. Antennæ 
much like those of the preceding species, only the penultimate joint and the long terminal seta are comparatively a little shorter. Maxillulæ as in the preceding species. Basal joint of the maxillæ as in $S$. decorata, second joint distally provided with a number of tolerably long, stiff setæ, thind joint has at its inner margin four processes, the ontermost of which is much longer than the others and conspicuously longer than the curved end of the joint. Abdomen as in the two preceding species; the setæo the caudal stylets somewhat exceeding half the length of the body.

POST-LARVAL DEVELOPMENT. Unknown.

HABITAT. The marsupium of Eudorella truncratula (Sp. Bate) from Denmark. Iı a large material I found only four infested specimens; one of them has no special locality, whereas the three others were taken in the Kattegat on the cruises of the "Hauch ", two of them at Stat. 383 (fourteen fathoms), the third at Stat. 387 (seventeen fathoms). In one specimen (from Stat. 387) occurred: only one female and one male; in another (from Stat. 383): one female, two larvæ (intruders) and about twenty-four of the host's own eggs; in a third specimen (from Stat. 383) were detected: one female, one male, three mutually adhering ovisacs and one of the host's own eggs. In the fourth specimen were discovered: an oblong lump consisting of about a score of firmly adhering ovisacs, partly covering a female which was lying towards the front, further: a male and a disturbed ovisac, the larvæ of which were breaking out.

\section{Sphæronella insignis $n$. sp.}

(Pl. IX, fig. 4a-4g; pl.X. fig. $1 \mathrm{a}-1 \mathrm{~h}$.)

To begin with, I will observe that I have assigned to this species specimens from two species of the genus Diastylis, viz. D. Tavis Norm. and D. cornuta Boeck. However, from each of these species I possess only one female, one male and some full-grown larvæ. To the differences between the two females I can attribute no value, and the differences between the two males from the two species of hosts are not greater than those which I have found in other forms of the family between specimens taken on the same species of hosts; between the larvæ there is no difference. However, in order to present the deviations found, I give three double sets of figures, and point out the differences in the corresponding text; but, in spite of the scantiness of my material, I really do not doubt that it is the same parasite which lives in both species of hosts.

FEMALE. A specimen (from $D$. laris) was $1.16 \mathrm{~mm}$. long, $88 \mathrm{~mm}$. broad (fig. 4a), and somewhat flattened. The head is not defined from the trunk, and it agrees very closely (fig. $4 \mathrm{c}$ ) in all details with the preceding species. The antennulæ (fig. $4 \mathrm{c}$ from $D$. laris, fig. $4 \mathrm{f}$ from $D$. cormuta) scarcely offer any characteristic, and the same remark applies to the mouth. The branches of the maxillulæ, at least in the specimen from $D$. lavis, is somewhat longer than in $S$. dispar; additional branch wanting. The maxillæ a little smaller 
than in the former species. - The last joint of the maxillipeds and the terminal spine on the penultimate joint in the specimen from $D$. lavis are not very different from $S$, dispar, and distally much less expanded than in the specimen from $D$. cornuta (fig. $4 \mathrm{~g}$ ), but this difference is scarcely of any value. The trunk is naked. The genital area, in both specimens, is a rather small, transverse plate of irregular shape, and for the most part very thin, which, in the specimen from $D$. cornuta (fig. 4 e) is about twice as broad as long, on the whole reminding of a rectangle; in the specimen from D. lavis (fig. $4 \mathrm{~d}$ ) it is comparatively a good deal longer, somewhat heart-shaped, having a concave front margin, and an irregular, lobed posterior margin; in both specimens the genital apertures are middle-sized, somewhat oblique and curved, anteriorly not far apart; the area is naked, caudal stylets wanting. ('The differences in the shape of the genital areas are indeed very considerable, but in both specimens the plate is so irregularly shaped, so unsymmetrical and so feebly chitinised, that I do not think its shape is of any importance; on the contrary, I expect that other specimens of this species will exhibit other shapes of the plate.

MALE. In proportion to the female, it almost exceeds medium size (fig. $4 \mathrm{~b}:$ fig. $4 \mathrm{a}$ ); the specimen from $D$. lavis (fig. $4 \mathrm{~b}$ and fig. $1 \mathrm{a}-1 \mathrm{~b}$ ) is $29 \mathrm{~mm}$. long, the one from D.cornuta (fig. 1 c-1d) $31 \mathrm{~mm}$. long. The specimen from $D$. lavis is - seen from the side (fig. 1a) - considerably thicker than the other specimen (fig. $1 \mathrm{~d}$ ), however, this thickness seems to he due to a swelling of the body which is scarcely normal. Otherwise there are no other differences between the two specimens than those which may be detected in comparing fig. $1 \mathrm{~b}$ and fig. $1 \mathrm{c}$, viz. some slight deviations in the anterior part of the front and in the hair-covering in front of the antennulæ. -- Seen from below, it bears great resemblance to $S$. dispar, but the greatest breadth of the body lies more backward, and it deviates especially in the somewhat different shape of the front, and in the equipment of the maxillæ and of the sub-median skeleton. The distance from the antennulæ to the narrowest part of the frontal plate is shorter than in $S$. dispar; the expanded distal part is not circular, but considerably broader than long, limited to the front by a regular arc, the third of a circle, and decorated with processes as in $S$. dispar; the lateral angles are almost rectangular, and posteriorly the dilated part is limited by oblique lines. From the base of this expansion, backward along the lateral margin itself, runs a pretty good-sized keel (fig. $1 \mathrm{~b}, \mathrm{y}$ ), which is also limited by an arc of a circle, and which is armed with setaceous processes similar to those of the median expansion. In the middle of the ventral side of the expansion we find the small chitinous ring mentioned in the description of $S$. dispar, but in $S$. insignis the four processes are prolonged and meet in the centre so as to form a cross within the ring. Antennulæ, mouth and maxillulæ nearly as in S. dispar. Maxillæ small; their basal joint has on its posterior side proximally a row of tolerably small, rather clumsy, processes directed backward, distally some much smaller processes; the third joint is well set off and acute. Basal joint of the maxillipeds scarcely as long as in S. dispar, its anterior side furnished with several rows of hairs; the other joints nearly as in the preceding species. 
The sub-median skeleton without processes, but the part obliquely inside and behind the base of the maxillæ is covered with pretty numerous setæ. Shape and hair-covering of the lateral margin of the head nearly as in S. dispar; from its posterior extremity the boundary of the hairy part proceeds at first vertically upward across the side of the animal, then somewhat obliquely backward across the back. The back and sides of the trunk and the posterior part of the ventral surface are closely covered with rather long hairs, nearly all the remainder of the ventral side has hairs of medium length. Trunk-legs and caudal stylets wanting.

OVISACS. In $D$. lavis they were small, almost globular, with few eggs; in $D$. cornuta they differed considerably in size, from rather small to middle-sized, and were irregular on account of mutual pressure. Eggs of medium size.

LARVA. There is no appreciable difference between the larvæ found in $D$. lavis and in D. cornuta. A well-developed free larva from D. cornuta is $20 \mathrm{~mm}$. long and has served as type for fig. $1 \mathrm{e}-1 \mathrm{~g}$. It bears great resemblance to $S$. dispar, but is sharply distinguished by several characters. The cephalothorax like that of the last-mentioned species. The decoration of the front is very characteristic (fig. 1f): a transverse list is found inside the base of the antennulæ; further, a sinuate transverse series of processes, with a broad central interruption, runs from one antennula to the other; the inner half of this series begins far behind the frontal margin, below the anterior side of the rostrum, thence it continues in an oblique direction running forward and outward towards the margin, consisting only of five or six longer processes; then comes a little break in the row, the next process being somewhat further removed from the frontal margin, after which the row is continned to the anterior angle of the antennula, but in its latter part the processes are shorter than the sub-median ones. The olfactory seta of the antennulæ is even longer than in S. dispar, as, when bent backward, it may reach as far as the posterior end of the second abdominal segment. Antennæe and maxillulæ as in the preceding species. Second joint of the maxillæ without setæ (fig. $1 \mathrm{~g}$ ), third joint with three or four processes on its inner margin, the outermost of which is longer than the curved extremity of the joint, but scarcely longer, at least not considerably so, than the penultimate process. The abdomen and its setæ as in the preceding species.

POST-LARVAL DEVELOPMENT. In D. cornuta a single pupa was found (fig. $1 \mathrm{~h}$ ), which is $14 \mathrm{~mm}$. in length and sub-globular. It is described in detail above on p. 56 .

HABITAT. The marsupium of Diastylis cornuta Boeck and D. lavis Norm. from Denmark. In a specimen of $D$. cornuta were found: an empty skin of one female, one male and seven small ovisacs with young ones in different stages, as well as twelve free larvæ and one pupa. In one specimen of $D$. lavis occurred an oblong lump of adhering ovisacs surrounding a female; they were irregularly shaped on account of pressure; on one side of the lump the larger part of one side of the female was uncovered, and on the side turning towards the abdomen of the host, there was a longitudinal impression in the lump, in which a 
small part of the body of the female was visible, and a male was situated somewhat behind it; there were at least twenty ovisacs, some of them containing eggs, most of them young ones in very different stages of development, and one of them contained perfectly developed larvæ.

\section{Sphæronella marginata $\mathrm{n}$. sp.}

(Pl. XIII, fig. $6 \mathrm{a}-6 \mathrm{~h}$ ).

FEMALE. The only specimen found (fig. 6a) was $58 \mathrm{~mm}$. long and $39 \mathrm{~mm}$. broad, oblong ovate. The head (fig. 6d) is not defined from the trunk. A frontal border is rather feebly developed and runs in a slightly curved line from a point a little in front of one to a little in front of the other antennula, and behind this line the skin is sunk and a little softer than in front of it; but lateral borders and lateral skeleton are entirely wanting, and the sub-median skeleton is reduced to a posteriorly geniculate, anteriorly ramified list between the rostrum and the base of each maxilliped. The antennulæ (a) are short, with two well separated joints, with a tolerably long seta at one angle of the first joint, a much shorter one at the middle of this joint, and two very short setæ at the end of the last joint. Antennæ wanting. Hairs of the mouth-border rather long. The maxillulæ have very short principal branches; additional branch wanting. The maxillæ (f) are quite rudimentary, each consisting only of a very small pointed conical joint, which looks rather like a process. Basal joint of the maxillipeds extremely swollen, especially its proximal part, which on its inner side and on half of its anterior side is furnished with four long, straight, transverse rows of fine, short hairs, while the distal part of its exterior side and the onter part of its anterior side have two transverse rows of similar hairs; second and third joints are coalescent and form together a long and very thick joint, the apical spine of which is very broad and flattened and provided with a number of extremely fine points at its oblique terminal margin; the last joint is short, very broad, dilated towards the flattened end, the oblique terminal margin of which is furnished with numerous very fine points. On the head, a little in front of the base of each maxilliped, are seen rows and stripes of more or less short or long hairs. The trunk is naked. The genital area (fig. 6e) is somewhat broader than long and consists of a thin plate surrounded by a thick border, which is wanting on the greater part of the anterior margin, and its fiee anterior angles are curved somewhat inward and backward; the plate with curved lateral margins and posteriorly emarginate. The genital apertures are very large, very close together, and their posterior extremity nearly reaches the hind margin of the plate; moreover, they are considerably curved, and their anterior ends are somewhat diverging, their posterior ends very much so, while their muscles are turned obliquely outward and strongly forward. Close behind one of the genital apertures appears a very small caudal stylet, which is furnished with a pair of very short 
setr; the other stylet is wanting; the whole area is naked. (In fig. 6e to the front the two receptacula seminis are indicated by dotted lines).

MALE. The only specimen found is tolerably large in proportion to the female (fig: $6 \mathrm{~b}: \mathrm{fig} .6 \mathrm{a}$ ); it is $21 \mathrm{~mm}$. in length, but on account of pressure it is somewhat crooked, so that the normal shape of its body cannot be precisely determined. The frontal border is rather considerably produced, its margin very long, somewhat emarginate in the middle and forming on each side of this inward curve a gently convex margin, which on its upper, as well as its lower side, is' provided with a narrow border of numerous short (in the drawing a little too short) setaceous processes; further, across the lower side of the front a little in advance of the rostrum, runs a long; straight, very narrow list, which almost reaches the lateral margin, and which is armed with a series of very small conical processes. Antennulæ small, terminating in a setaceous point and with only a single, moderately long seta, which no doubt is olfactory. Antennæ wanting. Mouth-border with long hairs. Anterior principal branch of the maxillulæ developed only as a somewhat protruding rounded corner; the hindmost principal branch extremely short, tap-shaped; additional branch wanting. Maxillæ small, all three joints entirely fused together, with no vestige of articulation, but the general outline of the maxilla nearly as in S. dispar, however, its distal part is very slender and terminates in a point. Basal joint of the maxillipeds a little more than medium length, not swollen, smooth; on its anterior side near the apex it has a large process, the basis of which is constricted, while the remaining part forms an oval knot parallel with the outline of the joint; second and third joints are fused into a single short joint with a short and broad terminal seta, whereas the last joint is very short, broad and flattened, with denticulated terminal margin. Nearly on a line with the anterior angle of the base of the maxilipeds are seen, close to each other, two small, short, conical processes, whereas other processes are wanting; but inside of and behind the posterior angle of the maxillipeds are found peculiarly shaped lists. The lateral margin of the head developed as in the two preceding: species; from the base of the antennula it is furnished with rather long hairs, and from the posterior angle of the margin, as far as I have been able to see, the boundary of the hairy part runs upward and somewhat obliquely backward across the side and the back. The trunk, on its back, its sides and the posterior half of its ventral surface, is covered with long hairs; the anterior half of its ventral surface is naked. Trunk-legs and caudal stylets wanting.

OVISACS. Those that have been found are rather small (fig. 6c), yet, as each of them contains six or seven nearly or fully developed larvæ, they must be considerably larger than when they were laid. The ovisac represented is $34 \mathrm{~mm}$. in length and $\cdot 27 \mathrm{~mm}$. in breadth.

LARVA. Though very similar to those of the nearest preceding species, it presents various good characters (fig. $6 \mathrm{~g}$ ). Length of the body ab. $21 \mathrm{~mm}$. The cephalothorax is an oblong oval, a little narrower than in the two last-mentioned species. The front has a 
curved list in advance of the base of the antennula; from the margin, in front of this list, runs a transverse series of shorter processes; finally, from the part before the rostrum, extending outward and forward up to the anterior margin, we see an area covered with some rows of similar processes placed close together. The olfactory seta of the antennulæ extends at least far back on the second abdominal segment. The antennæ differ widely from those of the four preceding species; they are short, 2-jointed, the first joint is moderately long and rather thick, the second joint is only half its length and ends in two setæ, one of which is short, the second a little longer than the first joint. The innermost and foremost branch of the maxillulæ, which e.g. in $S$. dispar is situated far in front of the three other branches, in S. marginata is placed further backward, so as to be nearly at the same height as the two branches closest to it, besides being reduced to a short process; the outermost branch here is shorter than the two intermediate ones, and seems, moreover, to be naked. First joint of the maxillæ as in the four preceding species, second joint without terminal setæ, the third one (fig. $6 \mathrm{~h}$ ) serrated, having some very fine acute processes at its inner margin. Second joint of the maxillipeds short, third joint exceptionally long, several times the length of the second. Abdomen comparatively somewhat smaller than in the nearest preceding species, but the mutual dimensions between the segments are the same; the long setre of the first segment extend pretty considerably beyond the end of the caudal stylets, and the terminal setæ of these stylets are more than half the length of the body.

\section{POST-LARVAL DEVELOPMENT. Unknown.}

HABITAT. The marsupium of Iphinoë trispinosa (Goods.) from Messina. In a specimen which had Homoeoscelis mediterranea (s. p. 97) in its branchial cavity occurred: one female, one male and four ovisacs containing larvæ. This was the only specimen infested with this parasite in the material mentioned more specially above on p. 97.

REMARKS. The most noteworthy feature in this interesting species is no donbt that its maxillæ as well as its maxillipeds differ so much in the two sexes, and at the same time, in both sexes, especially in the female, deviate widely from these appendages in all other hitherto known species, not only of this genus, but of the whole family.

\section{a. Parasites on Isopoda.}

In three species of Isopoda, all belonging to the group Asellota, I have discovered three species of the genus Spharonella. The females of two of the species show great similarity to the normal species of the genus which live on Amphipoda, but the third species deviates very considerably from these parasites. The only character's common to the females of all three species are: antennæ seem to be wanting; the mouth is large with a broad or very broad mouth-border, the hairs of which are remarkably thick; the maxillulæ are well developed, with long principal branches and at least very distinct additional branch; the 
maxillie are normal, with a large, thick basal joint; the maxilliperls are 4-jointed; the genital area is plate-shaped. The male is known only in one of the two first mentioned species, but it differs widely from all the other males known of the family. Of the species (S. Munnopsidis), the female of which deviates most from the species found in Amphipoda, I have found scarcely quite developed larvæ, which in the structure of antennæ and maxillæ come close to the species of the genus which live in Cumacea, but they differ from these parasites in having the second joint of the maxillipeds much longer than the third, whereas the fourth joint is armed with three spiniform processes on the distal part of the inner margin The larva of the two other species, unfortunately, is unknown. So the knowledge of this little group is rather defective.

\section{Conspectus of the Females.}

1. The head distinctly defined from the trunk, frontal and lateral borders well developed.

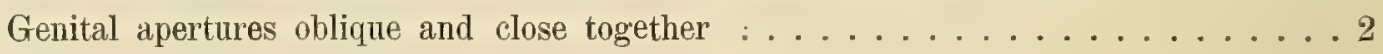

1'. The head not defined from the trunk, no frontal or lateral borders. Genital apertures transverse, comparatively far from each other ...... 34. S. Munnopsidis n. sp.

2. The genital area is a very large plate, only a little broader than long, and the longest dimension of the muscles of the genital apertures is shorter than the distance from their outermost extremity to the margin of the plate ......32. S. curtipes n. sp.

2'. The genital area is a large plate, considerably broader than long, and the muscles of the genital apertures are a good deal longer than the distance of their outermost extremity from the margin of the plate.............. S3. affinis n. sp.

\section{Sphæronella curtipes n. sp.}

(Pl. X, fig. 2a-2g).

FEMALE. The only specimen found (fig. $2 \mathrm{a}$ ) is $2.4 \mathrm{~mm}$. long, $2.2 \mathrm{~mm}$. broad and considerably flattened; anteriorly the body tapers a little. The head is well defined, but very small, and especially very short, nearly twice as broad as long (fig. $2 \mathrm{~d}$ ). The slightly curved frontal margin is furnished in its whole length with excessively short hairs. Antennulæ of about medium length, 3-jointed, the terminal setæ somewhat shorter than the antennula. Antennæ not found. Mouth very large, with extremely broad mouth-border. The maxillulæ have tolerably long and powerful principal branches and a good-sized additional branch. Maxillæ very large, the basal joint long and very thick, smooth. Basal joint of the maxillipeds long and slender, bearing a few short hairs at the distal end, otherwise naked; the three other joints slender, and the last joint provided with a single spine a little inside its pointed end. The sub-median skeleton bas a broad list inside the maxillæ, 
and a transverse row of long hairs is seen in front of the base of each maxilliped; two lists are found between head and trunk behind the maxillipeds. The lateral margin of the head has a tolerably broad stripe of rather short hairs; this hair-covering extends upward on the proximal part of the lateral surface of the head, besides forming a narrow transverse belt immediately behind the head across the anterior part of the trunk. Except this hairy belt the trunk is naked, and trunk-legs I have not been able to find. The genital area is much larger than the head (fig. 2a) and consists of a very large round plate which is a little broader than long (fig. 2e); the central part of the plate is more thinly chitinised (marked in the drawing by a light greyish tint), whereas the larger part of it is thick and light brown. The genital apertures which are situated a little in front of the centre of the plate, are exceedingly small in proportion to its size and are found close together; their anterior extremities rum nearly parallel, further backward they diverge considerably; their muscles are turned a little forward and strongly outward, but do not reach half the distance to the margin of the plate. The thin part of the plate in front of and partly outside the genital apertures is furnished with a number of short hairs, and a considerable part of the thinner area of the plate behind the muscles has some very short hairs; close behind the genital apertures we see the candal stylets which are exceedingly small, and in front of these a diminutive transverse area very closely covered with extremely short hairs; the remainder of the plate is naked (in the drawing one of the receptacula seminis is indicated by a dotted line and marked $r$ ).

MALE. It is large compared with the female (fig. $2 \mathrm{~b}:$ fig. $2 \mathrm{a}$ ), and in reality comparatively very large, exceeding in size all other males of the whole family: the smaller one of my two specimens measuring $84 \mathrm{~mm}$., the larger one $92 \mathrm{~mm}$. in length. In shape it stands far apart from all species known. Seen from below (fig. $2 \mathrm{f}$ ), its length is to the breadth as 5 to 3 ; the animal is broadest at or a little in front of the middle, somewhat narrower towards both flatly rounded ends; moreover, the head is much shorter than the trunk. Off the posterior margin of the month the lateral border of the head is very sloping, bending strongly outward, and more backward it forms a deep inward curve stretching posteriorly to a point a little outside the base of the maxillæ; these arched borders and the frontal border combined form the sides of a deep cup, the posterior part of which — if it were not wanting - would pass across the base of the maxillæ; in the middle of this cup the rostrum is situated. Seen laterally (fig. $2 \mathrm{~g}$ ), the body is strongly curved, its ventral side being pretty deeply concave, the dorsal outline very convex. This line, moreover, is divided by three bends which are rather far apart and at equal distance from each other; the foremost of these bends is on a line with the month, and coinciding with it at the back the boundary of the hair-covering runs in a slightly oblique line towards the posterior angle of the outstanding lateral border of the head, whereas from the two other dorsal bends trausverse depressions continue a good way on the lateral surface of the trunk. Finally, we see on the hindmost half of the ventral side of the trunk a large, but not very thick, flatly 
vaulted, almost square protuherance, which in a lateral view of the trunk makes it appear very different from other species. The frontal border is considerably produced, the larger median part of the margin is slightly curved, naked, separated by a rather deep incision from a lower, evenly rounded lobe which extends to the angle close in front of the base of the antennula; this lobe is much thinner than the remainder of the frontal border and supplied with very short marginal hairs. The antennulæ are moderately short, 3-jointed, with short setæ. The antennæ are very short, probably only 1-jointed, with a short seta. The mouth rather large, the mouth-border of medium breadth. Maxillulæ normal, with a long additional branch. The basal joint of the maxillæ is small and smooth, the two following joints (as in most other species) are coalescent. Maxillipeds fairly small, with the normal proportion between the joints; the basal joint is slender, provided on the anterior side with some hairs at both ends; the last joint is sligthly digitated at its end. The sub-median skeleton has two pairs of processes, the first pair robust, the second pair rather short and strongly diverging; the part between the maxillæ and the maxillipeds is furnished with numerous moderately short hairs. The above-mentioned boundary of the hair-covering between the head and the trunk has a pretty narrow belt of rather short hairs and dorsally of hairs of medium length; the back, the sides and the posterior end of the trunk are furnished with extremely short hairs, and this covering reaches ventrally to the second pair of legs and to the protuberance on the posterior half of the trunk; the anterior ventral half is naked, except a pretty good-sized transverse area stretching from the first pair of legs to the lateral margin which is furnished with rather short hairs, and finally, the protuberance is covered nearly all over with pretty similar hairs. The trunk-legs very small, each consisting of two generally somewhat oblong joints of about equal size and ending in one or two setæ which are of the same length or a little shorter than the leg. Each of the posterior angles of the afore-mentioned protruding ventral part is produced into several rather short, usually rounded eminences and processes, some of which are very thick, others fairly slender; the stoutest of them bears a single pretty long, thick seta, and on the posterior part of the protuberance, closely inside of the innermost eminence of the posterior angles, we find a short, oblong candal stylet jointed on; the two stylets accordingly being very far apart. (Spermatothecæ appear underneath the foremost third of the protuberance).

OVISACS. They are middle-sized, shortly ovate (fig. 2c) or sub-globular, but slightly differing in size; the largest specimen is $1.6 \mathrm{~mm}$., the smallest $1.3 \mathrm{~mm}$. in length. The eggs comparatively small and numerous.

LARVA and POST-LARVAL DEVELOPMENT. Unknown.

HABITAT. The marsupium of Janira spinosa Harg. from the Davis Straits at lat. $66^{\circ} 32^{\prime} \mathrm{N}$, , long. $55^{\circ} 34^{\prime} \mathrm{W}$., 100 fathoms; Th. Holm $\% /$ vil 1884 . In a specimen occurred: one female, two males and twelve ovisacs, two of them with eggs and two with Nauplii. 


\section{Sphæronella affinis $n$. sp.}

(P1. X, fig. 3a-3d.)

FEMALE. The only specimen in hand is $.87 \mathrm{~mm}$. long, $90 \mathrm{~mm}$. broad, and its thickness is about $3 / 4$ of its breadth; seen from below (fig. $3 \mathrm{a}$ ), it is posteriorly broad and flatly rounded, anteriorly somewhat produced, and its lateral ontline a little concave at some distance from the head. The head is small, well defined, somewhat broader than long (fig. 3c) and thus considerably narrower than in $S$. curtipes. The frontal margin curves strongly forward and is naked. Antennulæ, maxillulæ and maxillipeds exactly like those of the preceding species, whereas the mouth-border is a little narrower. Basal joint of the maxilla a little less clumsy, with two tolerably small processes situated at some distance from each other where the inner and lower sides meet. The sub-median skeleton has a narrow list inside the maxillie, and behind their base a transverse stripe of long hairs (drawn only on one side in the figure). The lateral margin of the head has a rather narrow stripe of tolerably short hairs, and this covering does not continue upward on the lateral surface of the head. Somewhat more than the anterior half of the trunk is furnished with short hairs; trunk-legs are wanting. Genital area much larger than the head (fig. 3 a), consisting of a fairly solid, yellowish, centrally somewhat thinner and lighter plate (fig. $3 \mathrm{~d}$ ), which is considerably bxoader than long, rounded; its anterior margin is almost straight, its posterior margin convex; a little behind the middle the proportionally very small genital apertures wre situated close together, their muscles turning outward and a little forward and reaching beyond half the distance towards the margin of the plate. The area is naked, except the part between the genital apertures, which is provided with a number of short hairs; candal stylets I have not been able to find. (Fig. 3d. shows a fragment of the stalk of a spermatophore and the outlines of both receptacula seminis.)

MALE. Unknown.

OVISACS. With a female occurred six ovisacs mutually glued together, all of them short and broad, somewhat angular, the largest a little flattened; none of them contained advanced larvæ. They differed very much in size, the largest being $\cdot 77 \mathrm{~mm}$. in length, the specimen drawn (fig. $3 \mathrm{~b}$ ) $63 \mathrm{~mm}$. long and broad, the smallest $47 \mathrm{~mm}$. long. The eggs numerous and tolerably small.

LARVA and POST-LARVAL DEVELOPMENT. Unknown.

HABITAT. The marsupium of Janira maculosa Leach from Herö, Norway. Prof. G. O. Sars discovered a single infested specimen and lent it me; I found one female, the posterior half of which was surrounded by six ovisacs mutually glued together. The parasite was lying with its head turned obliquely forward and somewhat sideways. - An examination of our pretty considerable material of this Isopod from Greenland and Denmark gave a negative result. 


\section{Sphæronella Munnopsidis n. sp.}

(Pl. X, fig. $4 \mathrm{a}-4 \mathrm{~d}$.)

FEMALE. The only specimen found was torn and half empty; it was ab. $5 \mathrm{~mm}$. in length and a little shorter than broad. The head is very small and not separated from the trunk at all; frontal and lateral borders are altogether wanting, whereas the sub-median skeleton is developed into a single, good-sized, solid plate, to which the maxillæ and maxillipeds are articulated (fig. 4b). Antennulæ rather short, not distinctly jointed, but the length of the first joint is easily seen, as its distal anterior angle protrudes in the usual way and is furnished with setæ which, however, are short; the setæ on the distal part of the anteunulæ are scarcely of medium length. Antennæ are wanting. The mouth is good-sized and the mouth-border broad. The principal branches of the maxillulæ are pretty long, the additional branch a little shorter. The maxillæ are good-sized; their basal joint smooth, supplied with two rows of short, thick, blunt setæ or small processes along the inner margin of the skin that connects it with the second joint. Basal joint of the maxillipeds of medium length; on the inner side of its distal half are two areas of extremely short hairs; second joint of normal length, somewhat dilated towards its distal end, on the inner side of which are seen some minute hairs; third joint short and clumsy; in the left maxilliped it has at its distal inner angle a short and very broad, rounded spine which is funished with exceedingly short hairs; in the right maxilliped this spine is wanting, but the joint is still shorter and broader, and its inner margin is hairy; in the left maxilliped the fourth joint is tolerably short and hairy along the rounded end, in the right maxilliped excessively short and hairy along both margins. Sub-median skeleton quite naked. Trunk naked; trunk-iegs wanting. Genital area somewhat larger than the part occupied by the mouth-appendages; it consists of a transverse plate which is a little more than twice as broad as long, fairly rectangular, but the outline is irregularly sinuate; properly speaking, this plate consists of a moderately broad ring of thick yellow chitine surrounding a thinner light area, which, however, is somewhat more solidly chitinised than the skin which surrounds the ring. The genital apertures are situated comparatively far apart, each at one end of the thinner area and on its posterior margin; their distance from each other somewhat exceeds the length of each; their direction is almost rectangular to the longitudinal axis of the animal, so that their muscles are turned nearly straight in advance parallel with the axis, and their hindmost lip is strongly curved. Somewhat in front of each genital aperture we see at the posterior margin of the foremost transverse list of the frame a circular hole $(\mathrm{k})$, which is no doubt the orifice of a gland which otherwise I have been able to detect only in Mysidion abyssorum and in Aspidoecia. Only one of the receptacula seminis ( $\mathbf{r}$ ) is shown in the drawing, but to the orifice of each receptaculum is fixed a spermatophore, one of which (s) is well preserved, whereas of the other $\left(s^{\prime}\right)$ only the stalk is left. These orifices are situated 
obliquely in front of and at some listance from the genital apertures and somewhat closer to the median line than the apertures. The whole genital area is naked. Candal stylets are wanting.

\section{MALE. Unknown.}

OVISACS. They differ widely in size, as fig. $4 \mathrm{a}$ shows; in the marsupium represented occurred twenty ovisacs, which are irregularly shaped and angular on account of mutual pressure, and the largest of them which contains half reveloped young ones, is $2.73 \mathrm{~mm}$. in length and $1.74 \mathrm{~mm}$. in breadth, the smallest ab. $92 \mathrm{~mm}$. long and $75 \mathrm{~mm}$. broad. In another specimen the ovisacs are oval or sub-globular.

LARVA. None of the ovisacs contained fully developed larvæ. I took some larvæ out of the ovisac which contained the most advanced specimens and prepared them ont of their membranes, so that I succeeded in giving a representation (fig. $4 \mathrm{~d}$ ) of several of the most important appendages, but about the final shape of the larva etc. no detailed account can be given. The front has no decoration, at most a small list inside the anterior angle of the antennulæ. The olfactory seta of the antennula is tolerably short, may be about half the length of the cephalothorax. The antennæ of medium length, t-jointed, the two first joints broad, the third one slender, longer than the second, the fourth joint short, and its longest terminal seta shorter than the third joint. The mouth-border exceptionally broad with distinct, thick hairs. The basal joint of the maxillæ has two dense combs of fine processes (one of which is not visible in the drawing), second joint is slender, third joint has some spines on its immer margin. Second joint of the maxillipeds much lomger than the third; the fourth joint has three conspicuous, slender and spiniform processes at the distal part of its inuer margin. The abdomen of less than medium size; its first segment almost louger and somewhat broader than the second one, and its long spines reach far beyond the caudal stylets, which are distinctly set off from the small third segment. The setæo of these stylets seem to be proportionally pretty short.

\section{POST-LARVAL DEVELOPMENT. Unknown.}

HABITAT. The marsupium of Munnopsis typica M. Sars from the Kara Sea. Fig. 4 a represents the greater part of a large specimen of the host, in which the ovisacs of the parisite are visible through the diaphanous plates of the marsupinm. The marsupium was pretty strongly extended, it contained twenty ovisacs, partly with eggs, partly witl Nanplii or with more developed larræ, but - as stated above - none of these was ready to swim out; the above described female was lying against the ventral side of the host towards its anterion end. In a smaller specimen were discovered nine ovisacs; the female and some sacs had evidently been washed out. 


\section{Choniostoma Н. J. Н. (1886).}

FEMALE. The body is somewhat flattened; seen from below, it is broader than long, nearly pentagonal, with rounded angles, one of which forms the centre of the posterior margin, and two on each side, whereas the anterior margin forms but a sight curve and is longer than the distance between the lateral angles on each side, and between the hindmost lateral angle and the posterior central angle. The head is situated on the ventral side a little behind its anterior margin, and the skeleton is transformed into a transverse ring-shaped frame which is considerably broader than long, and the anterior part of the frame, which forms the frontal border, may sometimes rise a little above the skin in front of it, whereas the remainder, or sometimes the whole frame, is on a level with the ventral plane. The frame surrounds a good-sized, thin-skinned area, in or a little behind the middle of which the rostrum and the mouth-appendages are found. The antennulæ are normal, 3-jointed and inserted on the ring. The antennæ are certainly 3-jointed and furnished with a terminal seta. The mouth is good-sized, the mouth-border of about average breadth. Maxillulæ well developed, with a long additional branch. Maxillæ powerful, constructed as in the typical species of Sphreronella. Maxillipeds rudimentary, each consisting of two very small or quite diminutive joints. Trunk-legs and caudal stylets - where such are found as in Sphceronella. The genital area is more than twice as broad as it is long; the thickest chitine is found in the middle and along the lateral margins; the genital apertures are situated close together in the middle of the area, and close in front of them appear the orifices of the long sausage-shaped receptacula seminis, which are turned obliquely forward and outward. - No spermatophores have been observed.

MALE. Unknown.

OVISACS. They are always deposed freely, their shape is sub-globular, and as many as eleven or twelve may be found in one female. Each ovisac contains an exceedingly great number, on an average at least one thousand, minute eggs (comp. my figures p. 47).

LARVA. Is known of both species and is quite similar in structure to the larvæ of some of the species of Spharonella living in Amphipoda; the only differences are, that the cephalothorax is shorter and broader, and the spiniform setæ at the posterior angles of the first abdominal segment longer, and especially thicker, than in any Spharonella known to me.

POST-LARVAL DEVELOPMENT. The pupæ found are described in detail above on p. $56-57$.

HABITAT. The branchial cavity of two species of the genus Hippolyte Leach belonging to the order Decapoda, and the presence of the parasite causes the part of the carapace which is situated above the intruder and its ovisacs to vault strongly, so as to form a large swelling, which as a rule is exactly similar to that caused by Gyge Hippolytes 
(Kr.). Hitherto found only in the Kara Sea, the Murman Sea, near Tromsö (Norway) and off the West-coast of Greenland, and the genus has been found only on Hipp. Gaimardii M.-Edw. and Hipp. polaris (Sab.).

REMARKS. The genus contains only two species. As, in spite of the most careful investigation, the male has not been found, our knowledge is defective in an important point. Judging from the structure of the female, the ovisacs, the larva and the pupa, the genus comes very near to Sphcronella, and the only really good character appears to me to be the rudimentary maxillipeds of the female. A biologically important character is that - as stated above - it lives in the branchial cavity of Decapoda Caridea, as the genus Homoeoscelis lives in the branchial cavity of Cumacea.

\section{Conspectus of the Females.}

The frame of the head is an almost regularly transverse oval and provided exteriorly on each side with a very long list which proceeds from the centre of the lateral outline and rums ontward, and especially backward, in an oblique direction...... 1. Ch. mirabile H. J. H.

In the frame of the head the foremost lateral angle is strongly produced, forming a good-sized, fairly broad and not quite short projection, a large part of which is covered by the skin, whereas the very long lateral, essentially backward running list mentioned in the preceding species is wanting ... 2. Ch. Hansenii Giard and Bonnier (without description).

\section{Choniostoma mirabile H. J. H.}

(Pl. X, fig. 5 a -5 c; pl. XI, fig. $1 \mathrm{a}-1 \mathrm{k}$.)

Choniostoma mirabile H. J. Hansen, Dïmphna-Togtets zool.-bot. Udbytte, 1887 ), p. 271 - 78, Tab. XXIV, fig. $7-7 \mathrm{~h}$.

- $\quad$ - Giard and Bonnier, Bull. scient. de la France et de la Belgique, T.XX, 1889, p. 346, etc.

- $\quad$ - Giard and Bonnier, Bull. scient. de la Fr. et d. l. Belg. T. XXV, 1895, p. 479.

FEMALE. The specimen represented in fig. 5 a is $3.5 \mathrm{~mm}$. in length, $4 \mathrm{~mm}$. in breadth; its shape is described in the diagnosis of the genus. The smallest specimen found is a young one, $1.35 \mathrm{~mm}$. Iong and $1.28 \mathrm{~mm}$. broad, thus a little longer than broad, almost circular in appearance, and somewhat flattened like the adult. The area surrounded by the frame of the head (fig. 1a) is regularly rounded, somewhat shorter than broad; the anterior part of the frame is fairly narrow between the antennulæ, scarcely rising above the surromnding soft membrane and exhibiting outwardly only a very narrow list, while its broader part (indicated by a dotted line) is covered by the skin. The lateral and posterior parts of

1) Separate copies of my contribution were distributed in the beginning of July 1886, whereas the whole volume with the résumé appeared in 18 : 7. 
the almost regularly oval transverse frame are fairly broad, and from the centre of the lateral ontline proceeds a very long solidly chitinised list (k') ontward, and especially hackward, in an oblique direction; its proximal part is pretty broad, and its hindmost extremity extends even a little beyond the posterior margin of the frame. Inside the acute angles formed at the origin of the lists, and at the points where the curved lateral margins of the frame meet the almost straight posterior margin, we perceive thick solid parts (k') which, as lying beneath the skin, in this as in the following species are indicated by dotted lines, and outside the frame by a light shade. In the soft membrane between the anterior part of the frame and the rostrum appear two small, oval, tolerably solid chitinous rings ( $\mathrm{t}$ ) situated rather far from each other, and each surrounding a very suall area; obliquely in front of them, and somewhat closer together, are two smaller and feebler, almost circular rings $(u)$. The antenmulæ (a) are short, with setæ of nearly medium length, among which is a single sensory seta (b). Antennæ (c) of almost average length; they seem to be 3-jointed, having an exceedingly short basal joiut, whereas the two next joints are well developed, the terminal seta being of the same length as, or longer than the last joint. Mouth-border of medium breadth. Maxillæ middle-sized; basal joint smooth. Maxillipeds (g) quite rudimentary and difficult to detect, each consisting of two diminntive joints, the last of which is pointed. The sub-median skeleton (h) forms on each side, obliquely inside and partly behind the maxillæ, a plate which is pierced with a hole and divided by incisions into irregular lobes. The head is naked all over. The trunk is naked in the adults as well as in the abovementioned very young specimen; the latter has small trunk-legs, whereas I have not been able to discover these appendages in the large specimens. The genital area (fig. $1 \mathrm{~b}$ ) has very oblique and anteriorly strongly converging lateral margins; one of the receptacula seminis (r) is represented in the drawing.

\section{MALE. Unknown.}

OVISACS. They are scarcely middle-sized (fig. $5 \mathrm{~b}$ and $5 \mathrm{c}: \mathrm{fig} .5 \mathrm{a}$ ), sub-globular, with slight difference in size where the contents are equally developed (while fig. $5 \mathrm{~b}$ compared with fig. $5 \mathrm{c}$ shows the nsual difference of size between au ovisac containing eggs and another with full-grown larvæ). The longest diameter in the ovisac shown in the drawing fig. $5 \mathrm{~b}$, is $1.8 \mathrm{~mm}$. As many as twelve ovisacs may be found in one female. The eggs are relatively extremely small and excessively numerous.

LARVA. The specimen represented in fig. $1 \mathrm{e}$ is $24 \mathrm{~mm}$. long, but, as it was hinged to a gill (by the adhesive plate s) in order to undergo its metamorphosis, the cephalothorax is somewhat shorter and broader than in a specimen, which has not yet hinged itself (and the third joint of the maxillæ is bent forward); fig. $1 \mathrm{f}$ shows the front part of a larva prepared ont of an ovisac. As T have met with no larva about to swim out, or with one which had just entered the branchial cavity of a new host, I am unable to determine the shape of the cephalothorax in the free larva with absolute certainty, however, it seems to be somewhat broader than in any other of the larvæ I have observed, and not much longer than 
broad. The front has a curved list inside the anterior angle of each antennula (some transverse stripes showl in fig. If, I am mable to explain). Antennulæ 3-jointed, olfactory seta comparatively short, not half the length of the cephalothorax. Antennæ a little longer than the antennula, in all respects like those of Sphcer. dispar, except that the broad basal part sometimes seems clearly to consist of two joints (fig. $1 \mathrm{f}$ ), while sometimes only one joint is discernible (fig. 1 e) The maxillulæ consist of three moderately long naked branches, which spring from a low eminence. The joints of the maxillæ are smooth, the last one seems to end in two extremely short points. Second joint of the maxillipeds a little shorter than the third. The peduncle of the natatory legs fairly broad. First abdominal segment somewhat longer and considerably broader than the second, and the setæ of its posterior angles twice the length of the following segments and the caudal stylets, exceptionally thick and hairy on their distal half; third segment much smaller than the second; the caudal stylets pretty well defined, and their setæ about $3 / 4$ the length of the cephalothorax.

POST-LARVAL DEVELOPMENT. On the gills of a Hippolyte appeared specimens of all the transitional stages between larva and pupa, besides numerous pupæ (fig. $1 \mathrm{~g}-1 \mathrm{k}$ ) of somewhat different shape and considerable difference of size. With regard to these pupæ I refer to p. 56-57 where a detailed account of them is given.

HABITAT. The branchial cavity of Hippolyte Gaimardii M.-Edw. from the Kara Sea. In a female without eggs I discovered under a swelling of the carapace on the left side: one female and twelve ovisacs, the contents of which presented the most different degrees of development; in one ovisac, for instance, appeared full-grown larvæ; the five gills of the host, belonging to the trunk-legs, were all a little curled, the two foremost, especially, were distinctly deteriorated. Beneath a large swelling of the carapace of another female Hippolyte without eggs occurred one female and nine ovisacs, which, however, have not been all taken out, nor the gills examined. In a third female without eggs one female and six ovisacs appeared under a swelling on the right side of the carapace; the two foremost of the gills of the trunk-legs were atrophied, the three others were normal. A female of the host with numerous eggs containing half-developed young ones, had on its right side a swelling on the carapace about $2 / 3$ of the normal size, but parasites and ovisacs had disappeared, and so had the two foremost of the gills of the trunk-legs; the three hindmost were normal, without brood of parasites. There was no swelling on the left side of the carapace, but far to the front appeared the small above-mentioned female which was $1.35 \mathrm{~mm}$. in length, moreover, in the two foremost of the gills of the trunk-legs, occurred numerous pupæ and hinged larvæ in all stages transitional to that of the pupa, altogether twenty-one pure and fourteen larvæ; the hindmost gills also revealed some larvæ and pupæ, but each of them only a few, except the penultimate, which contained many at one end. The larvæ and pupæ were attached to the surface of the foliaceons gill-fibres at their base; sometimes, though seldom, two were situated cluse to each other, sometimes they were found far in between the origin of two gill-fibres. 
REMARKS. What I describer and figured in "Dijmphna-Togtet" as Ch. mimbite, were specimens of this species; besides, I was of the opinion that all my specimens on Hipp. Gaimardii, and an exceedingly large specimen on Hipp. polaris, belonged to the same species. Giard and Bomnier, in their paper of 1889, supposed that the large specimen detected on Hipn. polaris, was of another species, especially because it occured on another species of host, and they named it Ch. Hanseni, but without material of course they could give no description. Their supposition proved right to a certain extent, as the parasite on Hipp. polaris did really belong to a species which differs from $C h$. miratrite, but it became evident at the same time that Ch. Hansenii is found in Hipp. Gaimardii as well. After this discovery I examined in our Museum all the specimens kept of both species of Hippolyte, and in a very large material of Hipp. Gaimardii from the Kara Sea I succeeded in finding: two more specimens infested with small parasites, one of which is the above-mentioned specimen with larvæ and pupæ on its gills, whereas the parasites on the other specimen belong: to Ch. Hansenii. I suppose the larvæ and pupæ found to pertain to this species, because they occurred together with the small female $(1.35 \mathrm{~mm}$. in length), but $I$ must point out that this proof is not quite decisive, as allowance must be made for the possibility that these larvæ and pupæ may belong to the following species, or some of them to Ch. mirabile, others to $C h$. Hansenii. It is worth noticing that I have not been able to detect any difference between larvæ taken out of the ovisacs of either species.

Max Weber describes ovisacs taken in the branchial cavity of Hipp. Gaimardii from the part of the Murman Sea which is South of Nova Zemblia, and these ovisacs decidedly belong to this genus, but the species cannot be determined. - J. Sparre Schneider in: "Tromsø Museums Aarshefter 14, 1891", p. 112, says that be has found "Choniostoma mirabilis " on a specimen of Hipp. Gaimardii from Hillesö in the Malangen-Fjord (on p. 98 he furthermore states that the same specimen was also infested with a Phryxus [Hemiarthrus abdominatis $(\mathrm{Kr}$.)]), and that he had moreover observed it near Tromsö; but it cannot be ascertained here either, whether it is Ch. mirabile, Ch. Hansenii, or both species, which have been seen.

In a large specimen of Hipp. Gaimardii from the Davis Straits, lat. $66^{\circ} 30^{\prime} \mathrm{N}$, long $54^{0} 50^{\circ} \mathrm{W}$., forty fathoms, under a swelling of the carapace eight ovisacs occurred, and the foremost gills were reduced and contained two pupæ, but as the female was wanting, in this case also it is impossible to determine the species. However, we may state at once that not this species, but $C h$. Hansenii was discovered later on at the coast of West-Greenland.

\section{Choniostoma Hansenii Giard and Bonnier (without description).} (P1. X, fig. $6 \mathrm{a}-6 \mathrm{~b} ; \mathrm{pl}$. XI, fig. 2a-2f.)

Choniostoma Hansenii Giard and Bonnier, Bull. scient. de la France et de la Belgique T. XX, 1889, p. 366 [without description].

- $\quad$ - Giard and Bonnier, Bull. scient. de la Fr. et d. 1. Belg. T. XXV, 1895, p. 479. 
FEMALE. The largest specimen is $5.3 \mathrm{~mm}$. long, $5.5 \mathrm{~mm}$. broad and ab. $3.9 \mathrm{~mm}$. thick; the specimen represented in fig. $2 \mathrm{a}$, which had laid eleven ovisacs, was $3.15 \mathrm{~mm}$. long, $3.65 \mathrm{~mm}$. broad and $2.7 \mathrm{~mm}$. thick; the young specimen drawn in fig. $2 \mathrm{~b}$, was $1.7 \mathrm{~mm}$. long and broad. The anterior part of the frame of the head (fig. $2 \mathrm{~d}$ ) rises somewhat above the skin in fiont of it; it is tolerably narrow in the middle, broader towards the base of the antennulæ; the foremost lateral angle of the frame is strongly produced and forms a considerable, tolerably broad and not quite short, outstanding, rounded projection, a large part of which, however, is covered by the soft skin. A good deal of the lateral borders and of the short hindmost part of the frame is likewise covered by soft skin similar to that of the surroumdings, and on each side, where the lateral and the anterior parts meet, we see, moreover, two good-sized chitinous parts beneath the skin. On the other hand, the long list which in Ch. mirubile runs ontward and backward from the centre of the exterior side of the frame, is altogether wanting. The two pairs of small rings in the skin in front of the rostrum are advanced to close behind the anterior part of the frame; the sub-median pair are larger, the more lateral pair much narrower than in the preceding species. The antennulæe are a little longer than in $C h$. mirabile, and have longer setæ. The antennx are also longer than in the last-mentioned species, distinctly 3-jointed, the basal joint short, the two next joints about sub-equal in length, the terminal seta longer than the third joint. Month-border fairly broad. Maxillæ good-sized, larger than in Ch. mivabile. Maxillipeds rudimentary, yet somewhat larger than in the preceding species and otherwise of the same structure. The hindmost part of the sub-median skeleton consists on each side of a tolerably narrow, posteriorly somewhat expanded list; as in the preceding species a long and robust branch proceeds anteriorly from the exterior side outward just behind the base of the maxilla. In front of the antennulæ, before and outside the foremost free lateral angle of the frame, and thence more or less backward outside its lateral margins, we see in the adult specimens a number of fairly short or short setæ (fig. $2 \mathrm{~d}$ ), obliquely outside the lateral angle some very long setæ; fig. 2 a, moreover, shows a fairly broad stripe furnished with scattered setæ ruming from each lateral angle somewhat forward and strongly outward along the ventral sufface of the animal towards its anterior outline. Younger specimens (fig. 2 b) not only have setæ - some of them very long - on these last-mentioned parts (fig. $2 \mathrm{e}$ ), but also a number of similar setæ on the sides and on a small part of the ventral surface, as well as a few scattered setæ on the back, whereas the greater part of the ventral side is naked. The trunk-legs are very distinct in the smaller specimen represented in fig. $2 \mathrm{~b}$, but in the larger animal (fig. 2 a) I have not been able to find any. The lateral margins of the genital area (fig. $2 \mathbf{f}$ ) differ somewhat in shape from $C h$. mirabile, being geniculate in the centre, so that only their foremost half turns inward. As in the preceding species, the genital area sends forth from its posterior central part two strongly diverging, tolerably short lists, between which, in the half-grown as well as in the adult specimens, we find the 
caudal stylets situated close together; they are very small, and each of them is providert with a pair of fairly long setæe.

MALE. Unknown.

OVISACS. They resemble those of the former species. The ovisac represented in fig. $2 \mathrm{c}$ is $1.7 \mathrm{~mm}$. long and $1.4 \mathrm{~mm}$. broad. In one female were found eleven ovisacs.

LARVA. Specimens which are fill-grown though they have been pulled out of an ovisac, resemble those of the former species to such a degree that $I$ have not been able to find a single distinguishing mark which appeared to me valid.

POST-LARVAL DEVELOPMENT. Unknown.

HABITAT. The branchial cavity of Hippolyte polaris (Sab.) and Hipp. Gaimardii M.-Edw. from the Kara Sea. My material from this locality is as follows: in a female without eggs of Hipp. polaris appeared beneath a large swelling on the left side of the carapace, the above-mentioned gigantic specimen. In an adult male of Hipp. Gaimardii occurred under a swelling on the right side of the carapace: a female (represented in fig. 2 a) and eleven ovisacs (containing eggs, Nauplii and fully developed larvæ respectively); besides an adult male and a much smaller, exceedingly young female of Gyge Hippolytes (Kr:); the two foremost gills of the host, pertaining to the trunk-legs, had disappeared, the three hindmost ones were well preserved; under the apparently sound left-hand side of the carapace of the host, one male Gyge was discovered. In another somewhat smaller male of Himp. Gaimardii occurred in the front part of the left branchial cavity three rather small females, placed obliquely in a longitudinal row, in the right branchial cavity five similar females, three of them far to the front. All the parasites were of sub-equal size and about 1.6 to $\mathbf{1 . 7} \mathrm{mm}$. in length; the gills were somewhat crumpled, and the carapace showed small cavities on its inner side in the parts which covered most of the parasites, though its outside did not as yet show any real swellings. No Epicaridea were discovered.

This species has been found besides at the West-coast of Greenland: in the KarajakFjord, district Umanak (on ab. lat. $70^{2} / 3^{\circ}$ N.), by Dr. E. Vanhöffen. This naturalist having: informed me in a letter that he had found Choniostoma, I asked him to lend me his material, and he kindly placed it at my disposal, as well as his own particulars about it. He possessed in all four females; two of these belonged to $C h$. Hansenii, he had foum them free in a bow-net, and he writes about them: $» . .$. die ich lose fand, und die aus Krebsen stammen müssen, welche in meiner Reuse sich häuteten oder verzehrt wurden «; about the others he writes: "Ein drittes Exemplar wurde in $H$. Gaimardii...., ein viertes in $H$. polaris... gefunden"; one of these was $C h$. Hansenii, but the other was »zur Hälfte aufgeschnitten", so that I could not determine it, and I do not know in what species of host the specimen had been found. So at least three of the four parasites pertained to this species, moreover, it seems very probable that it lives in both species of Hippolyte. 
Besides, it is not at all unlikely that at least some of the specimens from the Davis Straits, from the most northern part of Norway (Malangen and Tromsö) and from the Murman Sea mentioned under the preceding species, belong to this one.

REMARKS. This species is sharply distinguished from $C h$. mirabile, especially by the shape of the frame of the head. It offers an exellent example of the fact that the same species of parasite may be found in two different species of hosts; besides, the specimen with the eight young females shows very clearly indeed that it is the parasite itself which causes the swelling in the carapace of the host, and that it does not - as snggested by Giard and Bonnier - lodge itself on $01^{\circ}$ together with a Gyge, or in a swelling formed and afterwards left by this parasite.

\section{Mysidion n. gen.}

FEMALE. The body shortly ovate. The head pretty well defined from the trunk, but in elderly specimens it is usually found in front on the ventral side of it, as an anteriorly and laterally rather well defined eminence; frontal border is wanting, and the skin in front aud on the sides of the wanting or at most very indistinctly marked lateral border is rather thin. The antennulæ are either fairly short and 2 -jointed or almost rudimentary, 1-jointed. Antennæ seem to be wanting. The mouth moderately large, the mouth-border narrow, but frequently partly covered with a viscous substance. Maxillulæ well developed, with a good-sized additional branch (pl. XII, fig. $2 \mathrm{~d}, \mathrm{e}^{\prime}$ ). Maxillæ powerful; the basal joint has at its terminal margin one or two processes, against which the last joint can be folded up. The maxillipeds rather short and weak; their basal joint has an irregularly simmate outline; second and third joints fused into one short joint, terminal joint of nearly average length, pointed. The trunk is now naked, now in a few places most sparingly provided with single hairs of about medium length; trunk-legs and caudal stylets altogether wanting. No genital area is found; the genital apertures are placed very far apart at the place where the posterior and the lateral outlines meet (pl. XI, fig. 3 b); each aperture has - besides its usual two lips - its own skeleton consisting of a list which forms a semicircular curve (pl. XII, fig. 2 b), or the greater part of an oval (pl. XI, fig. $3 \mathrm{f}$ ), the longitudinal direction of which is parallel with the median line of the animal, and whose open side turns towards this line (pl. XI, fig. $3 \mathrm{e}$ ); the hindmost lip of the genital aperture is quite close to the posterior part of this list, and the muscles radiate forward to its anterior part. The entrance (or perhaps rather: entrances) to the odd receptaculum seminis (pl. XI, fig. $3 \mathrm{e}, \mathrm{r}$ ) is or are situated at the median line far in front of the genital apertures; the membrane which covers the receptaculum is often closely covered with a great number - as many as twenty six - of spermatophores, amowg which are seen, moreover, stalks of other spematophores, the vesicles of which have disappeared. - The spermatophores (at least in Mys. commune) ar'e somewhat elongated ovals. - Various parts of the head, as lateral margins, month etc., are fiequently 
partly covered with the gluey substance, by which the female is attached to the inside of the marsupium, and it seems as if in these cases the animal had got its head irregularly covered with glue just after this substance had been secreted and before its becoming stiff (dry).

MALE. This sex is known in both species. The body is short and clumsy. On the dorsal side of the head, somewhat in front of the hair-coat and at some distance from the median line, we see a knot or short cone (pl. XI, fig. $3 \mathrm{~h}, \mathrm{x}$ ). The head is provided with well developed frontal and lateral borders. Antenulæ short, 2-jointed. Antennæ wanting. Hairs of the mouth-border short, but distinct. Maxillulæ and maxillæ as in the female. Maxillipeds rather anomalous: their basal joint curved, at least with one good-sized, thick process on the outer side of its distal end; second and third joints coalescent, the terminal joint conical. The sub-median skeleton without processes at the base of either maxillæ or maxillipeds. The trunk hairy; trunk-legs and caudal stylets wanting. The frontal thread furnished with peculiar expansions.

OVISACS. Typically they are shortly pyriform and attached to the lips of the genital aperture by a fairly short stalk. Fig. $2 \mathrm{~b}$ in pl. XII shows the genital aperture (g), the lips of which are covered with a stiffened secretion, which, besides, forms a pretty large plate (h) covering the hindmost end of the semicircular list and the skin nearest to it; from this plate proceed numerous, distally thickening threads, which are cut off in the drawing (i); they are the stalks of the ovisacs, so the plate must be understood as being the coalescent basal parts of these stalks. The ovisacs are numerous, twelve, fourteen, seventeen, or even more (see Mys.abyssorum), sometimes varying exceedingly in size (pl. XI, fig. 3c), and mutual pressure not unfrequently having caused their shape to become irregular and their attachment difficult to discern (pl. XI, fig. 3a); frequently again, they are af about equal size, of regular shape, and their attachment easy to observe (fig. $3 \mathrm{~b}$ ).

LARVA. It is known in both species, and on the whole only differs from the species of Spharonella living in Amphipoda by the shortness of the setæ of the caudal stylets, these setæ being not nearly half as long as the cephalothorax.

POST-LARVAL DEVELOPMENT. Is partly known in one of the species, and the stages known, which are very remarkable, are described in detail above on p. $61-63$.

HABITAT. In the marsupium of species belonging to the genera Erythrops G. O. Sars and Parerythrops G. O. S. (family Mysidæ, order Mysidacea) from Norway.

REMARKS. This genus is admirably distinguished from the three preceding genera by the following characters: the genital apertures in the female are placed far apart from each other and from the odd receptaculum seminis, each has a skeleton of its own, finally, the ovisacs are attached to the lips of the genital apertures. In the three last characters it agrees with the following genus, but in the latter the female lacks maxillipeds, the genital apertures are much closer to each other etc. The males differ from all the preceding genera and agree with the following in possessing the two dorsal knots on its head. The metamorphosis deviates very strongly from anything else I have observed of this kind. 
For my whole abundant material of this and of the following genus I am indebted to Professor G. O. Sars. It consisted partly of infested Mysidæ with indication of their localities, partly of similar animals without such indication, further, of parasites taken out of their hosts, the latter not being mentioned; these last animals have scarcely been used at all. I have determined the hosts in accordance with the above-mentioned naturalist's wellknown excellent work about the Mysidæ of Norway, but 1 have felt bound to follow Stebbing in adopting the older names of two of the species. - Besides, in his "Report on the Challenger Schizopoda * G. O. Sars himself mentions having observed in the genus Erythrops »a peculiar Lernæid, apparently the Sphcronella leuckartii of Salensky«, otherwise he does not give any more details about his finds.

\section{Conspectus of the Species.}

\section{The Females.}

Antenmæ almost rudimentary, 1-jointed. Head naked. ..... 1. M. commune n. sp. Antennæ larger, 2-jointed. A lateral longitudinal belt on the head and a considerable area behind the maxillipeds covered with hairs. . . . . . . 2. M. abyssorum n. sp.

\section{The Males.}

The head tapering considerably towards the front, provided with a narrow frontal border. The basal joint of the maxillipeds has on its outer side a shorter process in the centre and a long one at its distal end. The trunk is covered with innumerable minute transverse eminences, from each of which project several short hairs..... 1. $M$. commune

The head anteriorly broad, almost truncate, with a moderately broad frontal border. The basal joint of the maxillipeds has on its outer side only a single tolerably large process placed at its distal end. The trunk is without transverse eminences, the hairs normal, of

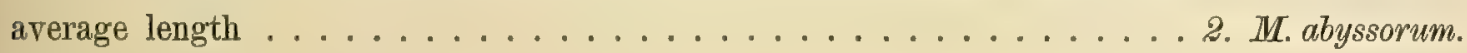

\section{Mysidion commune n. sp.}

(Pl. XI, fig. 3a-3i; pl. XII, fig. $1 \mathrm{a}-1 \mathrm{~d}$ ).

FEMALE. In fig. 3 a are represented the essential contents of a marsupium, consisting of a shrivelled female and seventeen ovisacs; the whole bulk was $2.9 \mathrm{~mm}$. long and $2.3 \mathrm{~mm}$. broad. The female represented in fig. $3 \mathrm{~b}$ is mole normal, large, and had probably not finished laying eggs; it is $1.14 \mathrm{~mm}$. in length and $94 \mathrm{~mm}$. in breadth, shortly ovate, and 
part of its posterior margin is nearly straight; it is seen from the dorsal side, the frontal part of the head is turned backward, and the maxillipeds (g) forward; however, this position is an anomaly, no doubt produced by pressure acting on its very soft skin in the marsupium during its growth. - The head (fig. 1 a) without real lateral borders, and in the adults, the part surrounding the mouth-appendages is irregularly folded up against these appendages, or even overlapping the outer side of the maxillipeds. The antennulæ (a) almost rudimentary, as broad as long, 1-jointed, ending in several very short setæ. Somewhat in front of the antennulæ are seen two taps $(u)$, the nature of which is quite incomprehensible to me (possibly cones of viscous substance secreted through the orifices of glands?). The terminal margin of the basal joint of the maxillæ is concave, rising at its posterior angle into a broad, rather short process. The maxillipeds have no spine at the distal inner angle of their penultimate joint. The lower side of the head naked all over. The list of the genital apertures forms about two thirds of an oval ring.

MALE. It is small in proportion to the female (fig. $3 d$ : fig. $3 \mathrm{~b}$ ). The specimen represented in fig. $3 \mathrm{~h}$ is $164 \mathrm{~mm}$. long, the one drawn in fig. $3 \mathrm{~g}$, measures $174 \mathrm{~mm}$. The body is not flattened. Seen from below, the head nearly equals the trunk in length, but the latter is somewhat thicker; seen sideways, the outline of the hair-coat runs from the base of the maxillipeds somewhat obliquely backward up across the side and the back, so that the dorsal line of the head becomes much longer than that of the trunk, and the short conical processes $(x)$ are placed a little in front of the hair-covering. Seen from below, the lateral borders of the head converge from behind their centre up to a point in front of the base of the antennulæ, so that the frontal border becomes very narrow; in proportion to its breadth it is considerably produced, and has a strongly curved, naked anterior margin. Antennula short, 2-jointed; second joint somewhat shorter as well as narrower than the first one, furnished with a few short setæ. Maxillæ large; the terminal margin of the basal joint essentially as in the female. The basal joint of the maxillipeds has on its outside in the centre a fairly short, thick, rounded process, and distally a thick and very long, slightly curved process; the next joint (second and third fused together) has a larger or smaller outstanding process somewhat on the boundary between the anterior and the outer side. The lateral margin of the head is furnished with a row of fine, rather short hairs, and a similar row is seen somewhat outside the margin. The trunk is closely covered all over with very small transverse eminences, from each of which spring several short, fine hairs. - The frontal thread, if found, is long and of peculiar shape; in fig. $3 \mathrm{~h}$ such a thread, lettered with an $s$, is shown as fixed to a marsupial plate (t); it is somewhat longer than the male, thin in the greater part of its length, then dilates pretty quickly and evenly towards its distal end, forms a collar-like ring, continues dilating, and forms a second ring at the thickest part of its expansion; beyond this ring it is still thick, though slowly decreasing in circumference, and at last increases a little up to the distal end, by which it attaches itself. 
OVISACS. They are mentioned in the description of the genus. In pl. XI, fig. $3 \mathrm{~b}$ and fig. $3 \mathrm{c}$ are drawn on the same scale of enlargement, thereby illustrating the relative size etc. of the ovisacs. The largest of the ovisacs, represented in fig. $3 \mathrm{~d}$, is $.90 \mathrm{~mm}$. in length and contains larvæ, of which only six are drawn.

LARVA. Full-grown larvæ prepared out of an ovisac agree closely with those of the following species; the only difference $I$ have been able to find is, that the inner side of the terminal joint of the maxillipeds is smooth in this species and spinous in the following one. As for the rest, the reader is referred to the description of the next species.

POST-LARVAL DEVELOPMENT. The stages found are described in detail above on p. $61-63$.

HABITAT. The marsupium of Erythrops serratus G. O. Sars and Parerythrops obesus G. O. S., and a female together with the following species in the marsupium of Erythrops abyssorum G. O.S.; all from Norway. The following special data can be given. In a specimen of Parer. obesus withont special locality, one large female was found attached to the inner side of the hindmost right marsupial plate near its base; it carried fifteen ovisacs, one of which was empty; and two males appeared together with it. In an $\mathrm{Er}$. serratus (with two specimens of Aspidoecia) without special locality, occurred: an almost empty female (with twenty-one spermatophores), carrying fourteen ovisacs of widely differing sizes, one of them half emptied of young ones, another quite empty, and to the latter were attached six males, one of which had four spermatophores fixed to the ventral side of its trunk; further: an empty, partly destroyed skin of a seventh male, another male (the eighth) fixed by a frontal thread, and a larva abont to become a pupa. In another Er. serratus, the locality of which was not specified, was discovered one large female (type specimen of fig. $3 \mathrm{~b}$ ) attached by its head to the basal part of a marsupial plate and carrying thirteen ovisacs (six and seven), and together with it a half-grown female and a female in the stage represented in fig. $1 \mathrm{~d}$, each fixed to a separate marsupial plate by a dorsal thread. In one specimen of Er. serratus (with at least one Aspidoecia), from Kvalö, a part of the contents of the marsupium was washed away, but still three adult females, all with ovisacs, and one male were found; in a specimen of the same species from Sunde, the marsupium contained only one female with two ovisacs. Another specimen of the same species from Sunde was highly interesting. Its marsupium contained, to begin with, the bulk represented in fig. $3 \mathrm{a}$, the greater part of which consisted of a rather shrivelled female with seventeen ovisacs, some of which contained eggs, others Nauplii or pretty old larvæ, two were nearly emptiet of larvæ, and one of the ovisacs was three-lobed, the majority of the others more or less distimetly pyriform. The bulk was placed as follows: the part of it which is uppermost in the drawing, was foremost in the marsupiun, the part of it which turned towards the ahdomen of the host, was flat, but the opposite, ventral side strungly arched, as shown in the illustration. This bulk contained, moreover, two males, the pupra fastened by a dorsal thread and drawn in fig. $1 \mathrm{c}$, and a very small pupa, like the one represented in fig. $3 \mathrm{i}$. 
Between the marsupial plates of the host were further found: three males, two of them attached by frontal threads to a marsupial plate, on its edge and a little inside it on the surface; and finally: the minute pupa drawn in fig. $3 \mathrm{i}$, and the very young female represented in fig. $1 \mathrm{~d}$, which was attached to one of the plates by a dorsal thread.

And lastly, in the marsupium of an Er. abyssorum, infested with the following species (to which we refer), occurred a very young female which adhered to the female of the other species.

\section{Mysidion abyssorum n. sp.}

(Pl. XII, fig. 2a-2i).

FEMALE. A specimen containing fourteen ovisacs was $1.39 \mathrm{~mm}$. long and $965 \mathrm{~mm}$. broad; its shape much like that of the specimen of Mys. commune represented on pl. XI, fig. $3 \mathrm{~b}$, but its head was not turned upward on the dorsal side, it was placed as usual anteriorly and, if anything, on the ventral side. The general ontline of the head as in the preceding species. Antennulæ (a) rather short, 2-jointed, basal joint thick, second joint short, terminating in some short setæ and a much longer olfactory seta. No taps on the anterior side of the head. The basal joint of the maxillæ has on its terminal margin two good-sized processes, one of them near the centre, the other at its posterior end. The maxillipeds are armed with a conspicuous spine at the distal inner angle of the penultimate joint. The part of the head which corresponds to the lateral border is furnished in its whole length with a fairly broad belt of rather short hairs, and somewhat behind the base of the maxillipeds we see a very good-sized, odd, triangular area, covered with moderately short hairs; the longest line of this triangle is turned towards the front, the opposite hindmost angle is on the median line; and finally, on each side, between the maxilla and the maxilliped, is a rather small, transverse, hair-covered area. On the trunk behind the head we see some scattered hairs. The list of the genital apertures is almost semicircular (fig. 2 b), with a hole (h) at its anterior end. (This hole, no doubt, is the orifice of a gland, and - strangely enough - I have not been able to find it in the preceding species, but I have found it in Aspidoecia and in Sphoronella Munnopsidis; however, I cannot make out with certainty whether it is one tolerably large hole, or perhaps rather a small area with a very thin membrane pierced with a number of small holes).

MALE. A specimen of normal size is $\cdot 164 \mathrm{~mm}$. long, nearly of the same breadth and somewhat flattened (fig. $2 \mathrm{e}$ and fig. $2 \mathrm{f}$ ), thus of small size compared with the female. A couple of specimens were abnormally small, one of them only $099 \mathrm{~mm}$. in length (their size in proportion to the normal male is shown by comparing fig. $2 \mathrm{~d}$ and fig. $2 \mathrm{c}$ ), similar in shape to the larger specimens, so these nales are considerably smaller than any other male of this family, but it remains an open question, whether they are adults, or - perhaps more 
likely - recently hatched animals (comp: my observations about other species, stated above on p. 58 and p. 60). - The head is much narrower and somewhat shorter than the trunk; seen laterally (fig. $2 \mathrm{f}$ ), the limit of the hair-coat runs from the base of the maxillipeds upward and in a slightly oblique direction forward across the side and the back, and the two flatly conical eminences $(x)$ are placed somewhat in front of the limit. Seen from below, the distance between the outstanding lateral borders of the head is much shorter than its broadest diameter; in fig. 2e - partly on account of the position of the animal - the outstanding frontal border does not reach the front ontline of the head. The frontal border scarcely attains to medium breadth, yet it is much broader than in the preceding species, slightly produced, with pretty well curved margin. Antennulæ rather short, 2-jointed; second joint somewhat shorter and a little narrower than the first one, with comparatively short setre and a sensory seta which nearly equals the others in length. Maxillæ of medium size; the terminal margin of the basal joint as in the female. The basal joint of the maxillipeds has on its outer side only one process which is placed at its distal end and which, though good-sized, is much smaller than in Mys. commune; the next joint has no process, but bears a pretty large spine inside the base of its short terminal joint. Everywhere, except on the front part of its ventral surface, the trunk is covered with simple hairs of nearly average length. We see furthermore on the ventral side two long lines (fig. $2 \mathrm{e}, \mathrm{u}$ ), rumning right and left of the median line at some distance from it; posteriorly they are further removed from this line, and near the posterior margin they recurve, continue forward and outward, and soon vanish altogether; what these two lines are meant for is quite incomprehensible to me. - The afore-mentioned dwarfish specimens were attached by a peculiar frontal thread (fig. $2 \mathrm{~d}$ and fig. $2 \mathrm{~g}$ ), which is a little longer than the body; the thread (in both specimens) was fusiform near its centre, and thickened by a high collar at its broadest point, and somewhat in front of its distal end appeared a similar, but still wider expansion with a similar collar; the distal end by which it is attached (not drawn in the figure), seems to have been discoid.

OVISACS. They are exactly like those of the preceding species, varying in the same way as to size and shape.

LARVA. A full-grown specimen pulled out of an ovisac is represented in fig. $2 \mathrm{~h}$, (the natatory legs are omitted); it is $196 \mathrm{~mm}$. long. The cephalothorax very elongated, scarcely twice as long as broad. The front has a sinuate oblique list inside the base of each antenuula. The purpose of the two transverse stripes rendered in the illustration, is not clear to me. Antennulæ 3-jointed; olfactory seta scarcely half the length of the cephalothorax. Antennæ very short, consisting of three very short, comparatively thick joints, the last one terminating in an exceedingly short seta. Of the maxillulæ only two branches are seen, one of them long, powerful and originating comparatively far towards the front, the other very short, spiniform and situated further backward. 'l'he basal joint of the maxillæ bears some very short hairs at the distal end of its inner 
margin, the second joint tolerably short, the third one of about medium length, smooth, and in the specimen drawn, as well as in other larva taken out of the same ovisac, this joint is curved forward in the same way as in the hinged specimens of other species. The basal joint of the maxillipeds is long, the second joint a little shorter than the third; the fourth joint has five or six setiform processes along the central part of the inner margin. The peduncle of the natatory legs is rather slender. The abdomen of medium length; the first segment somewhat longer and broader than the second, and the setæo of its posterior angles reaching only a little beyond the caudal stylets; the third segment somewhat narrower and shorter than the second; the caudal stylets well set off, their setæ unusually short, not nearly half the length of the cephalothorax. - Fig. $2 \mathrm{i}$ shows a larva in the act of changing into a pupa (or a male?); it is represented in a dorsal view; the cephalothorax is short and broad; the outline of the contents is shown by an inner line.

POST-LARVAL DEVELOPMENT. Unknown.

HABITAT. The marsupium of Erythrops abyssorum G. O.S. from Norway. In a specimen without indication of locality (bearing a specimen of Aspidoccia), occurred a large female with fifteen ovisacs of widely differing sizes, as well as a considerable lump of enıty ovisacs, which could not be counted; no male. In another specimen without locality (with two small specimens of Aspidoecia), appeared one female with fomrteen ovisacs, extremely varying in size, and a great deal of them adhering to each other, one of them being empty; moreover, a female glued to an ovisac; no male, but the above-mentioned small female of Mys. commune. In a specimen from Kvalö (bearing one large aud four small specimens of Aspidoecia on its carapace), occurred one completely torn female with twelve fine, almost equally large, mostly short and broad, somewhat flattened ovisacs, which on account of mutual pressure were somewhat polyhedrous in shape; among them were found a male, also the head and the skin of the anterior fourth part of the trunk of another female, and to this skin were attached five males and the broad larva represented in fig. $2 \mathrm{i}$; furthermore, I found two good normal males and the two above-mentioned dwarfish males, which were fastened to the marsupial plates by their frontal threads, - which makes altogether ten males -; finally four broad larvæ which had no doubt been hinged, and the contents of which were undergoing the transformation.

\section{Aspidoecia Giard and Bonnier (1889).}

FEMALE. The body is considerably broader than long. The head, which is pretty well defined, occupies a somewhat different position relatively to the genital apertures, from that of the earlier forms: in fig. $3 \mathrm{c}$ the genital apertures in relation to the head are placed 
some distance up on the dorsal side of the animal; fig. $3 \mathrm{f}$ is drawn in such a position as to show the head a little behind the middle of the trunk, and fig. $3 \mathrm{~g}$ presents the same animal turned half round, with its genital apertures ( $r$ ) behind the central point, and the entrances of receptaculum seminis $\left(r^{\prime}\right)$ far to the front; so we arrive at the result that the distance from the anterior limit between the trunk and the head along the dorsal surface of the animal to the genital apertures is considerably shorter than the distance from the base of the maxillæ past the receptaculum seminis to the genital apertures. (The same proportions also appear in fig. $3 \mathrm{~b}$ ). - The head is pretty well chitinised; the anterior and lateral parts evenly rounded (fig. $3 \mathrm{~h}$ ); no outstanding frontal and lateral borders. Antennulæ (a) rather short, 1-jointed; antennæ wanting. The month exceeding average size; mandibles robust; hairs of the mouth-border not to be detected (though they probably exist). Maxillulæ very small, principal branches short, additional branch wanting. Maxillæ middle-sized, normal, with smooth joints. Maxillipeds altogether wanting. The sub-median skeleton forms a plate which fills up the whole surface between the maxillæ, but ends a little behind their base. The head quite naked. The trunk naked; trunk-legs and caudal stylets wanting. As in Mysidion, no genital area is found, but each genital aperture possesses (besides the lips), its own skeleton, which consists of a tolerably good-sized, somewhat wry ring (fig. 3e, e; fig. $3 \mathrm{i}, \mathrm{e}$ ) formed of a pretty broad list, but the part of it (fig. $3 \mathrm{i}, \mathrm{f}^{\prime}$ ) which is turned obliquely inward and forward is more thinly chitinised than the remaining larger part. The genital aperture $(\mathrm{g})$ is placed against that part of the ring which turns towards the median line of the animal, and the muscles (m) by which the aperture opens go in the opposite direction; to the front, in the list of the ring itself, is a good-sized hole $(\mathrm{k})$, which is the orifice of a gland. The distance between the two rings varies from being a little larger (fig. $3 \mathrm{~g}$ ) to much smaller than the diameter of each ring. Far in front of the genital apertures are seen two knots at a short distance from each other (fig. $3 \mathrm{~b}, \mathrm{r}^{\prime}$; fig. $3 \mathrm{~g}, \mathrm{r}^{\prime}$, and especially fig. $3 \mathrm{e}, 0)$, which show, as it were, irregular cracks in the thick chitine; most likely we stand here at the entrances of the receptaculum seminis, though $I$ have not been able to trace regular holes, nor have I found spermatophores on the females. The receptaculum seminis (fig. $3 \mathrm{e}, \mathrm{r}$ ) is large, odd and much broader than long; at each end it curves evenly backward, and continues as a wide, centrally somewhat narrower, and distally again expanding duct, which is about parallel with the other duct and runs up to the genital aperture itself.

MALE. The body is not a third longer than broad, of a tolerably normal shape, but altogether hairless (fig. $3 \mathrm{k}$ and fig. $3 \mathrm{l}$ ). The head somewhat longer than the trunk, but the latter somewhat broader; the frontal border strongly produced, and the lateral borders well developed; on a line with the front extremity of the maxillæ, and on the border between the sides and the back, we see the two low conical eminences. Antennulæ extremely short, 1-jointed, with a single seta (b) which is olfactory and several times the length of the antennula. 
Antennæ wanting. Mouth middle-sized; mouth-border provided with very distinct hairs. Maxillulæ small, probably constructed like those of the female, and without additional branch. Maxillæ extremely large, the basal joint much compressed and very broad; the two last joints, which are entirely fused, form a long and powerful, proximally somewhat curved, distally almost straight joint. The basal joint of the maxillipeds somewhat smaller than in most species of Sphreronella, second and third joints fused into one exceedingly short joint, which has no spine at its distal inner angle; last joint slender, pointed, perceptibly longer than the penultimate one. The sub-median skeleton without processes on its posterior part. The trunk without legs and caudal stylets. (Fig. $3 \mathrm{k}$ only shows one single, but exceptionally large spermatotheca $(q)$, but this no doubt is an anomaly in the specimen illustrated, as in two other individuals I found, as usual, two much smaller and normally situated spermatothecæ.

OVISACS. They are hinged to the lists of the genital apertures, sub-globular or shortly pyriform, from scarcely middle-sized to small; their number can amount to thirteen or fourteen. Eggs of average size, not numerous.

LARVA. Resembles in nearly all its features (fig. $3 \mathrm{~m}$ ) the larvæ of certain species of Sphcronella parasitic on Amphipoda. The essential differences found are as follows: the second joint of the maxillæ is short and comparatively thick (fig. $3 n$ ), the third joint is finely serrated at its inner margin; the seta of the caudal stylets is short, not half the length of the cephalothorax.

POST-LARVAL DEVELOPMENT. The male comes out of the larva (fig. 3m) directly, without any intermediate stage. Whether the female passes throngh the pupa stage is not known, but it appears more probable to me that its development resembles that of the male.

HABITAT. The females live attached to the eye-stalks, the carapace, the back and sides of the free thoracic segment and the six first abdominal segments of all species of the genus Erythrops G. O. Sars (order Mysidacea), in Norway.

REMARKS. The genus comes very near to Mysidion, and the characters by which both genera are distinguished from those previously described are stated in the remarks about the last-mentioned genus. From the latter the female differs in the lack of maxillipeds, in the tolerably short distance between the genital apertures, in the ring by which each of these apertures is surrounded, and by the two conspicuous chitinous knots above the receptaculum seminis. The male deviates both from Mysidion and from all other genera in the minute size of the antennulæ and in the smallness of the distal part of the maxillipeds. And this genus deviates from all other forms by living attached to the outside of the free surface of its hosts. - The whole of my large material collected by Prof. G. O. Sars I have referred to one species; the subsequent remarks about this parasite will form a supplement to the above account of the type. 


\section{Aspidoecia Normani Giard and Bonnier.}

(PI. XII, fig. $3 a-3 n)^{1}$ ).

Aspidoecia Normani Giard and Bonnier, Compt.-rend. de l'Acad. d. Sciences, 29 avril 1889.

- - Giard and Bonnier, Bull, scient. de la France et de la Belgique, T. XX, 1889, p. 342 etc., pl. X-XI.

- $\quad$ - Giard and Bonnier, Bull. scient. d. 1. Fr. et d. l. Belg. T. XXV, 1895, p. 479.

FEMALE. The specimen represented in fig. $3 \mathrm{~b}$ is an adult female (with two rudimentary ovisacs and three attached larvæ), which is $65 \mathrm{~mm}$. long and $75 \mathrm{~mm}$. broad and is attached to Er. serratus G. O. S.; the specimen represented in fig. $3 \mathrm{c}$ and taken on the same species (with two males, $\mathrm{x}$, hinged by frontal threads) is $.536 \mathrm{~mm}$. long and $685 \mathrm{~mm}$. broad; the individual drawn in fig. $3 \mathrm{f}$ and fig. $3 \mathrm{~g}$ and found on $E$. abyssorum G. O. S. is $.82 \mathrm{~mm}$. long, $1.03 \mathrm{~mm}$. broad and one of the largest in hand. Fig. $3 \mathrm{~h}$ shows the head, seen from below, cleaned with caustic potash, so as to show the antennulæ, whereas fig. $3 \mathrm{~d}$ shows the head partly in front, as it is attached to the female by a large adhesive plate (s) which covers the antennulæ. Far to the front on the head, beneath the skin, and far apart from each other appear a pair of peculiar rather large hollow spaces (t) with a strange refraction of light, somewhat like that of a viscous substance, but what they are meant for I cannot make out. In the specimen cleaned with potash the antennulæ (fig. $3 \mathrm{~h}$, a) are seen to consist of one single, comparatively broad joint with convex inner margin, whereas the outer margin is furnished with several short setæ. In most individuals the genital rings are closer together than the length of the diameter of each (fig. 3e); in the larger, but not in the smaller, younger specimens living on Er. abyssorum, they are further apart than this line (comp. the remarks below).

MALE. The smallest specimen from Er. serratus is $138 \mathrm{~mm}$. long (fig. 3I), another specimen from the same species is $147 \mathrm{~mm}$. long and $120 \mathrm{~mm}$. broad (fig. $3 \mathrm{k}$ ); a specimen from $\mathrm{Er}$. abyssorum is $158 \mathrm{~mm}$. in length. The frontal border is strongly produced in all specimens and slightly emarginate in the middle. The frontal thread is even, though a little expanded at its distal end; in the specimen drawn in fig. $3 \mathrm{k}$, it is scarcely half the length of the body, in another specimen (fig. $3 \mathrm{a}, \mathrm{m}$ ) between twice and three times the length of the animal.

OVISACS. Mentioned in the diagnosis of the genus.

LARVA. Of larvæ I have found only a few specimens, one of them attached at the front to the carapace of a host (fig. $3 \mathrm{a}, \mathrm{l}$ ), the others fastened to females, and about to develop into males. So the shape of a free specimen cannot be described. Proportionally the cephalothorax of the attached specimens is not broad; in one of them its breadth is $\cdot 12 \mathrm{~mm}$., the length of the body $20 \mathrm{~mm}$. Antennulæ 3-jointed, the olfactory seta about half the length of the cephalothorax, minus its free segment (fig. $3 \mathrm{~m}$ ). Antennæ fairly short,

1) On pl. XII the name of the species is written Normanni instead of Normani. 
3-jointed, basal joint thick and pretty long, the two next joints thin and short, terminal seta short. Maxillulæ? - Maxillæ (fig. 3n) with smooth basal joint, second joint short and comparatively thick, third joint of average length with finely serrated inner margin. Maxillipeds (fig. 3n) proportionally rather below medium size, second joint longer than the third, terminal joint smooth. Peduncle of the natatory legs moderately broad. Abdomen much as in Mysidion, but the third segment is as long as the second.

POST-LARVAL DEVELOPMENT. My observations and conclusions are stated in detail in the general part p. 54.

HABITAT. In the diagnosis of the genus I have entmerated the different parts of the body to which the females may be seen attached. They have been found in all the northern species of the genus Erythrops, viz. Er. erythrophthalmus (Goës) (= Er. Goësii G. O. S.), Er. elegans G. O.S. (= Er. pygmreus G. O. S.), Er. microphthalmus G. O. S., Er. serratus G. O. S. and Er.abyssorum G. O.S. About the depth in which these species live, and about the remainder of their biology, I refer the reader to the monograph by Sars. Most of my twenty-one infested specimens were without special locality, some specimens of Er. serratus and Er, abyssorm were taken off Kvalö, one Er. erythrophthatmus off Tjötö. The parasites appear on adult males, on immature females and on females with marsupium, but in the latter the marsupium was either empty or filled with a parasite of the genus Mysidion. To show the occurrence of the parasites, I will give the following extract of my notes arranged according to the hosts.

1. Er. erythrophthalmus (Goës). On a female from Tjötö in which the development of the marsupinm had commenced, appeared a large parasite with fourteen ovisacs on the back of its second abdominal segment.

2. Er. elegans G. O. S. In a female whose marsupium was disturbed, occurred three parasites, two on the back of the second abdominal segment; one of these animals was nearly full-grown, the second somewhat smaller; the third, almost adult, female, was found on the back of the sixth abdominal segment near its posterior margin. On a female without marsupium were found altogether five females: one half-grown specimen on the upper side of the right eye, at the boundary between the cornea and the stalk; another somewhat smaller specimen on the inner side of the same eye-stalk; on the dorsal side of the carapace were two good-sized individuals, and a large one with three ovisacs, each containing only one egg, was attached to the second abdominal segment, at the centre of its dorsal side.

3. Er. microphthalmus G. O. S. On a specimen with empty marsupium appeared a large female without eggs on the dorsal side of the last thoracic segment. In a female without marsnpium was found a large parasite with six ovisacs on the dorsal side of the second abdominal segment. On a male I met with a large parasite with six ovisacs on the back of the first abdominal segment.

4. Er. serratus G. O. S. In an adult male was seen a good-sized female on the upper side of the right eye close behind the cornea. In a female with marsupium containing. 
Mysidion, occurred two parasites, one of which - a female with twelve ovisacs - was placed to the front on the carapace, a little to the left of the median process, the other a female with three ovisacs - was placed on the dorsal side of the last thoracic segment. On a young individual without marsupium appeared two parasites, one of them - a female without eggs - nearly in the centre of the back of the second abdominal segment, the other, a female with two males hinged by their frontal threads (fig. 3c), somewhat to the right side on the back of the first abdominal segment. In a hardly adult female (from Kvalö), on the dorsal part of the second abdominal segment (fig. $3 \mathrm{~b}$ ), I found an adult female with two minute ovisacs without eggs, and four larvæ (v), one of which fell off on being touched, so that it was not drawn in fig. $3 \mathrm{~b}$, but it is the specimen represented in fig. $3 \mathrm{~m}$ with an adult male beneath the larval skin.

5. Er. abyssorum G. O.S. On a female with empty marsupium: five parasites, viz. two very small females on the right side of the thorax close behind the carapace; and at a short distance in front of these animals, on the carapace itself, one small and one good-sized female, to the latter of which was attached near its mouth a strongly impaired male with a large spermatophore, and the anterior half of another male was fixed by a thread to the side of the trunk; finally: at the centre of the dorsal surface of the sixth abdominal segment, a good-sized female (fig. $3 \mathrm{f}$ and fig. $3 \mathrm{~g}$ ) - all parasites without ovisacs. In a female (from Kvalö) with Mysidion abyssorum in its marsupium, occurred five parasitic females, all on the carapace; one of them, which was very small, was situated somewhat behind the middle of and a little above the left lateral margin, the four others were placed close together at some distance behind the centre on the back and a little down on the right side; one of these was very small, the two others a little larger, the fourth large, without ovisacs, but with two larvæ attached to it. On an adult male (fig. 3a) appeared altogether nine parasitic females and one larva: one female (a) with six ovisacs is placed on the left hand side of the carapace; somewhat behind it and further up towards the back, the larva (l) is situated; in an irregular transverse row on the dorsal side of the first abdominal segment are found altogether five females, one of them pretty small, the four others large(a), two of them each with one, the two others together with many ovisacs, which can scarcely be counted accurately without a dissection; on the back of the second abdominal segment is placed a female with seven ovisacs, as well as a male $(\mathrm{m})$ hinged to the female by a long thread, which had the larval skin on its anterior end; to the right of the latter large female is found a very small female, and on the boundary between the second and the third abdominal segment, a tolerably small female (in the illustration the last two specimens are marked b.)

REMARKS. I must consider the parasites on all five species as belonging to the same species. In the females of the four smaller species of hosts, the distance between the genital apertures is from much to a little smaller than the diameter of each ring, in not full-grown individuals of the largest specimen, $E r$. abyssorum, this distance varies from being a little shorter than to about the same length as the diameter, but in the adult spe- 
cimens it is appreciably longer. The females which are parasites on the smallest species of Erythrops, in their adult stage attain to a much smaller size and, as a rule, produce a smaller number of ovisacs than the females which live on larger and the largest species; thus: the females are small in Er. elegans (= pygmous), larger in Er. serratus, largest in Er. abyssorum. That the distance between the genital apertures is larger in Er. serratus than in Er. elegans or Er. microphthalmus, and largest in Er. abyssorum, seems to me to be accounted for by the fact, that the entire skin of the trunk, and, as a matter of course, also the part between the genital apertures, grows more in the large than in the small species, whereas the rings themselves and the head of the animals do not grow; this will also be seen by comparing fig. $3 \mathrm{c}$ with fig. $3 \mathrm{f}$ plus fig. $3 \mathrm{~g}$, for in the first mentioned figure is represented on a larger scale a specimen which is about one third narrower than the one drawn in fig. $3 \mathrm{f}$ and fig. $3 \mathrm{~g}$ : in the two last figures the head and the genital rings are much smaller, compared with the trunk, than in fig. $3 \mathrm{c}$, but the distance between the genital rings is much greater in fig. $3 \mathrm{~g}$ than in fig. $3 \mathrm{c}$. I have come to this conclusion by examining the material, and the fact that I have not been able to find any difference between the males of the parasites from Er. serratus and Er. abyssorum - the male from Er. microphthalmus will be mentioned presently - speaks strongly in favour of my opinion, that all these parasites belong to the same species.

Giard and Bonnier have established the genus and the species on a female with five ovisacs and two males taken on Er. microphthalmus from Solemsfjord near Florö, Norway. Finding the female with her males sitting under one end of an obliquely placed specimen of Aspidophryxus Sarsi G. and B., they were led to suppose that the Copepod was parasitic on the last-mentioned form, but this is not the case, and the occurrence of the two parasites close to each other is quite accidental. (In my large material I have found no more than one Aspidophryxus, which was placed on the back of an Er. erythrophthalmus, which had no Aspidoecia on it). Based on the examination of the female, and especially of one of the males, which has been studied by the authors, I have given a detailed critique of their account above, on p. $6--8$, to which the reader is referred. Here I will only observe that in examining their male, I did not find any difference between this specimen and those which I had in hand myself, so I am perfectly sure of the correctness of my determination. 


\section{EXPLANATION OF THE PLATES.}

\section{PLATE I.}

1. Stenothocheres egregius n. gen., n. sp.

1 a. Female seen from below, $\times 58$; $\alpha$. antennula, $c$. antenna, $f$. maxilla, $g$. maxilliped, $m$. first trunk-leg, $n$. second trunk-leg, $p$. caudal stylet, $r$. genital aperture.

$1 \mathrm{~b}$. The same female seen from left side.

1 c. Male seen from below, $\times 58 ; s$. frontal thread.

$1 \mathrm{~d}$. Three eggs, $\times 58$.

1 e. Head of female, $\times 192 ; b$. olfactory seta of the antennula, $c$. antenna, $e$. maxillula, $h$. submedian skeleton.

$1 \mathrm{f}$. First trunk-leg of female seen from the inner side, $\times 240 ; i$. inner branch.

$1 \mathrm{~g}$. Abdomen and posterior part of the trunk of female seen from below, $\times 240 ; \mathrm{g}$. genital aperture, $t$. caudal stylets, $u$. trunk-leg of second pair.

$1 \mathrm{~h}$. The same parts as in fig. $1 \mathrm{~g}$ seen from left side, $X 240 ; g$. genital aperture, $m$. its muscles, $r$. receptaculum seminis, $u$. trunk-leg.

1 i. Male seen from below, $\times 255 ; a$. antennula, $b$. its olfactory seta, $c$. antenna, $d$. mouth, e. maxillula, $f$. maxilla, $g$. maxilliped, $m$. first trunk-leg, $n$. second trunk-leg, $o$. abdomen.

$1 \mathrm{k}$. The same male seen from left side; $e$. maxillula.

11. Larva seen from below, $\times 230$; on the right side of the figure the second trunk-leg, on the left side the branches of the first trunk-leg are omitted. $b$. olfactory seta of the antennula, $e$. maxillula, $l$. pouch, $m$. first pair of trunk-legs, $m$ '. transverse outstanding list between the legs of the first pair, $n$. second pair of trunk-legs, $n$ '. transverse list between the legs of the second pair, $o$. abdomen, $p^{\text {}}$. long seta of the caudal stylet.

\section{Stenothocheres Sarsii n. sp.}

2 a. Large female seen from below, $\times 26 ; s$. frontal threads.

2 b. Male seen from below, $\times 26$.

2 c. Lump of eggs, $\times 26$.

$2 \mathrm{~d}$. Smaller female seen from below, $\times 48$.

2 e. The same female seen from left side.

2 f. Head of female, $\times 165$; antennulæ omitted; $c$. antenna.

$2 \mathrm{~g}$. Antennula of female, $\times 170$; the olfactory seta partly broken off.

$2 \mathrm{~h}$. Trunk-leg of first pair of female seen from below, $\times 170$; e. exterior branch.

$2 \mathrm{i}$. Abdomen and posterior part of the trunk of female, $X 170 ; g$. genital aperture. 
$2 \mathrm{k}$. Male seen from below, $\times 170 ; s$. frontal thread, $x$. spines, perhaps rudiments of a third pair of trunk-legs.

2 l. The same male seen from left side, $\times 170 ; x$. spines, perhaps rudiments of a third pair of trunk-legs.

\section{Homoeoscelis minuta n. gen., n. sp.}

3 a. Genital area and surroundings of female, $\times 190$; $e$. solid chitinous list, $r$ receptaculum seminis, s. spermatophore, $t$. caudal stylets.

$3 \mathrm{~b}$. Pupa hinged by a frontal thread to the epipod of the host, $\times 170$; $a$. antennula, $c$. antenna, $f$. maxilla, $g$. maxilliped, $m$. first trunk-leg, $n$. second trunk-leg, $p$. caudal stylet, $s$. frontal thread, $x$. rudiment of a third trunk-leg?

\section{PLATE II.}

1. Homoeoscelis minuta n. gen., n. sp. (continued).

1 a. Not full-grown female, with four spermatophores, $\times 62$.

$1 \mathrm{~b}$. Large female which had not begun laying eggs, $\times 62$.

$1 \mathrm{c}$. Female which had nearly finished laying eggs, $\times 62$.

1 d. Male, $\times 62$.

1 e. Rather small ovisac, $\times 62$.

$1 \mathrm{f}$. Fairly large ovisac, $\times 62$.

$1 \mathrm{~g}$. Free larva, $\times 62$.

$1 \mathrm{~h}$. Head of female, $\times 226$.

1 i. Male seen from below, $\times 182$. (The hairs on the frontal margin are too long).

$1 \mathrm{k}$. The same male seen from left side.

1 1. Larva, prepared out of the egg-membrane, $\times 266$.

2. Sphæronella elegantula n. sp.

2 a. Adult female with two spermatophores, $\times 27$.

2 b. Male, $\times 27$.

2 c. Ovisac, $\times 27$.

2 d. Pupa, $\times 27$.

2 e. Genital area and its surroundings of female, $\times 162$. Of most of the membranous hairs only the base is drawn.

$2 \mathrm{f}$. Male seen from below, $\times 147$. The maxilliped and the distal part of the first trunk-leg on the left side were wanting.

$2 \mathrm{~g}$. Another and very large male seen from left side, $\times 143$.

3. Sphæronella Atyli n. sp.

3 a. Head of female, $\times 132$.

$3 \mathrm{~b}$. Genita] area and its surroundings of female, $\times 232$.

\section{Sphæronella danica $n$. sp.}

4. Genital area and its surroundings of an adult female, $\times 213$.

4 b. Frontal thread of male, $\times 236$. 
Figute

4 c. Pretty large pupa seen from below, $\times 70$.

4d. Small pupa seen from right side, $\times 70$.

4 e. Anterior part with the thread of the pupa shown in fig. $4 \mathrm{~d}, \times 285$.

\section{Sphæronella vestita n. sp.}

5 a. Female, with a spermatophore, $\times 100$. The hair-covering of the trunk is only indicated on its anterior part, but with the exception of the outline on the left side of the figure, only the bases of the hairs, the "scales", are drawn.

$5 \mathrm{~b}$. Genital area and its surroundings of female, $\times 251 ; r$. receptacula seminis, indicated by dotted lines.

6 a. Female, $\times 38$.

\section{Sphæronella chinensis n. sp.}

6 b. Male, $\times 38$.

6 c. Pretty young pupa, $\times 38$.

6 d. Old pupa, $\times 38$. The hair-covering omitted.

$6 \mathrm{e}$. The pupa shown in fig. $6 \mathrm{c}$ seen from below, $\times 148$.

$6 \mathrm{f}$. The pupa shown in fig. $6 \mathrm{~d}$ seen from below, $\times 114$. Appendages, mouth and genital apertures of the young female are seen through the skin of the pupa.

\section{PLATE III.}

1. Sphæronella chinensis $n$. sp. (continued).

1 a. Male seen from below, $\times 198$.

$1 \mathrm{~b}$. The same male seen from left side.

1 c. Antennula of female seen from below, $\times 284$.

\section{Sphæronella antillensis $n$. sp.}

$2 \mathrm{a}$. Young female, having thrown off the anterior third part of the skin of the pupa, $\times 48$.

2 b. Ovisac, $\times 48$.

2 c. The young female shown in fig. $2 \mathrm{a}, \times 188 ; c$. antenna.

$2 \mathrm{~d}$. Genital area and its surroundings of female, $\times 294$. On the right side of the figure the receptaculum seminis is indicated by a dotted line, and a spermatophore attached to its orifice.

$2 \mathrm{e}$. Larva seen from below, $\times 316$. Of the natatory legs only the base of the peduncles is drawn.

2 f. Pupa seen from below, $\times 119$.

3 a. Female, $\times 12$.

\section{Sphæronella Calliopii n. sp.}

3 b. Male, $\times 12$.

3 c. Ovisac, $\times 12$.

$3 \mathrm{~d}$. Head of female, $\times 83$. The hairs on the lateral borders and on the sub-median skeleton drawn only on the left side of the figure.

$3 \mathrm{c}$. Distal part of the left maxilla of female seen from below, $\times 166$.

3 f. Left maxilliped of female seen from below, $\times 166$. 
Higure

$3 \mathrm{~g}$. Genital area and its surroundings of female, $\times 150$.

$3 \mathrm{~h}$. Male seen from below, $\times 121$.

3 i. Another male seen from left side, $\times 151$.

$3 \mathbf{k}$. Larva seen from above, $\times 117$.

3 l. Larva seen from below, $\times 185$. Most part of the long setæ of the caudal stylets and the hairs on the branches of the left natatory leg of the first pair (thus on the right side of the figure) and of the right natatory leg of the second pair are omitted.

\section{Sphæronella paradoxa n. sp.}

4 a. Female seen from below, $\times 30$.

4 b. Another female with a spermatophore seen from right side and attached by its ventral thread to a marsupial plate, $\times 30$.

4 c. Male, $\times 30$.

$4 \mathrm{~d}$. Ovisac, $\times 30$.

4 e. Hinged larva, developing itself into a male, $\times 30$.

$4 \mathrm{f}$. "Female pupa" seen from below, $\times 30$.

$4 \mathrm{~g}$. Young female that has just burst the "skin of the pupa" (the shrivelled skin of the larva), $\times 30$.

4 h. Male seen from below, $\times 134 ; q$. spermatothecæ, $s$. frontal thread.

4 i. Another male seen from left side, $\times 134$.

$4 \mathrm{k}$. The dorsal side of the herd of the male shown in fig. $4 \mathrm{i}$, exhibiting the hollow spaces beneath the skin, $\times 134$.

4 1. Much protruding rostrum of a male, exhibiting the mouth-border, the antenna and the maxillula with its two principal branches and the additional branch, $\times 270$.

\section{PLATE IV.}

1. Sphæronella paradoxa n. sp. (continued).

1 a. Head of female, $\times 263$.

$1 \mathrm{~b}$. Genital area of female, $\times 220$. The receptacula seminis indicated by dotted lines; the caudal stylets without setæ.

1 c. Free larva, $\times 167$. Parts of the natatory legs omitted.

$1 \mathrm{~d}$. Hinged larva, developing itself into a male, $\times 103$. Comp. pl. III, fig. $4 \mathrm{e}$.

1 e. Anterior half of the cephalothorax of a larva which had been hinged a rather short time, $\times 236 ; s$. adhesive plate.

1 f. "Female pupa" seen from below, $\times 170$. The female develops itself beneath the larval skin which has shrunk extremely, and most of the appendages of which are seen: $a$. antennula, $c$. antenna, g. maxilliped, $m$. first natatory leg, $n$. second natatory leg, $o$. abdomen, s. adhesive plate.

$1 \mathrm{~g}$. Young female that has just burst the "skin of the pupa" (the same animal as shown in pl. III, fig. $4 \mathrm{~g}$ ), seen from right side, $\times 150 ; s$. adhesive plate.

$1 \mathrm{~h}$. Rather young female, seen from below, $X 88$; $t$. ventral projection terminating in a thread; $u$. the disk-like expanded end of the thread. 
Figure 2. Sphæronella abyssi n. $\mathrm{sp}$.

2 a. Female with two ovisacs adhering to its anterior outline, $\times 26$.

2 b. Male, $\times 26$.

2 c. Genital area of female, $X 174$. The genital apertures are open; one caudal stylet is absent; two spermatophores and the proximal part of the stalk af a third one are seen.

2 d. Male seen from below, $\times 152$.

2 e. The same male seen from left side.

\section{Sphæronella Argissæ n. sp.}

3 a. Adult, but shrunk and crooked female with a male attached to it near the genital area, $\times 30 ; m$. male.

$3 \mathrm{~b}$. Ovisac, $\times 30$.

3 c. Recently hatched female attached to a gill, $\times 30$.

3 d. The same female, $\times 240$.

3 e. Part of the sub-median skeleton, right maxilla and the proximal part of right maxilliped of the adult female, seen from below, $\times 276$; e. maxilla, $f$. base of the maxilliped.

$3 \mathrm{f}$. Genital area, with one spermatophore, of female, $X 150$.

$3 \mathrm{~g}$. Male seen from below, $\times 205$.

$3 \mathrm{~h}$. The same male seen from left side.

$3 \mathrm{i}$. Outlines of hollow spaces beneath the dorsal skin of the head of the male, $\times 205$.

$3 \mathrm{k}$. Right maxilliped of male seen from the anterior side, $\times 316$. At the proximal end is shown a process of the second pair of the sub-median skeleton.

3 l. Female pupa seen from below, $\times 162$; $a$. antennula, $c$. antenna, e. maxillula, $f$. maxilla, $g$. maxilliped, $p$. caudal stylets, $s$. funnel-shaped adhesive plate.

$3 \mathrm{~m}$. The same female pupa seen from left side.

$3 \mathrm{n}$. Anterior half of cephalothorax of larva, $\times 260$.

4. Sphæronella Metopæ n. sp.

4 a. Genital area of female, $\times 254$; 0 . orifice of one of the receptacula seminis.

\section{PLATE V.}

1 a. Female, $\times 68$.

1. Sphæronella Metopæ n. sp. (continued).

1 b. Male, $\times 68$.

1 c. Ovisac with about half-developed young ones, $\times 68$.

1 d. Head of female seen from below, $\times 224$.

1 e. Greater part of the head of female seen from left side and showing the antennula (the setæ omitted), rostrum with antenna and maxillula, the maxilla, and the base of the maxilliped.

$1 \mathrm{f}$. Male seen from below, $\times 185$.

$1 \mathrm{~g}$. The same male seen from left side.

2 a. Female, $\times 20$.

\section{Sphæronella Holbölli $\mathrm{n}$. sp.}

2 b. Male, $\times 20$. 
2 c. Ovisac, $\times 20$.

2 d. Head of female, $\times 152$. The distal part of one maxilliped broken off.

2 e. Genital area of female, $\times 125$.

2 f. Male, somewhat crooked, seen from below, $\times 173$. The distal part of one maxilliped broken off.

$2 \mathrm{~g}$. The same male seen from left side.

\section{Sphæronella intermedia n. sp.}

3 a. Smaller female, with two spermatophores, $\times 48$.

3 b. Male, $\times 48$.

3 c. Ovisac, $\times 48$.

$3 \mathrm{~d}$. Head of female, $\times 270$.

3 e. Genital area of female, $\times 181$.

3 f. Male seen from below, $\times 203$.

$3 \mathrm{~g}$. The same male seen from left side.

$3 \mathrm{~h}$. Cephalothorax of larva, $\times 223$. Natatory legs totally and appendages on right side of the figure almost totally omitted.

\section{Sphæronella capensis n. sp.}

4 a. Female, $\times 53$.

4 b. Male, $\times 53$.

4 c. Ovisac, $\times 53$.

\section{PLATE VI.}

1. Sphæronella capensis n. sp. (continued).

1 a. Head of female, $\times 342$.

$1 \mathrm{~b}$. Genital area of female, $\times 196$; 0 . orifice of one receptaculum seminis, $r$. The other receptaculum not drawn, but its orifice is seen.

1 c. Male seen from below, $\times 243$.

$1 \mathrm{~d}$. The same male seen from left side.

\section{Sphæronella Gitanopsidis $n$. sp.}

2 a. Female, $\times 28$.

2 b. Male, $\times 28$.

2 c. Ovisac, $\times 28$.

$2 \mathrm{~d}$. Head of female, $\times 202$. (The antennæ not quite correct, comp. the description).

2 e. Genital area of female, $\times 205 ; t$. caudal stylets.

2 f. Male seen from below, $\times 255$.

$2 \mathrm{~g}$. The same male seen from left side.

\section{Sphæronella Giardii n. sp.}

3 a. Adult female which had not yet begun laying eggs, $\times 28$.

3 b. Male, $\times 28$.

3 c. Female which no doubt had finished laying eggs, and with a male adhering to its ventral surface, $\times 28$.

3 d. Ovisac, $\times 28$. 
Figure

3 e. Head of female, $\times 236$.

3 f. Genital area, $\times 239$.

$3 \mathrm{~g}$. Male seen from below, $\times 183$.

$3 \mathrm{~h}$. Another male seen from left side, $\times 183$. In this and in the preceding figure the hairs of the trunk are not correctly drawn, comp. the description p. 135.

3 i. Male pupa seen from below, $\times 194$; the distal part of the frontal thread broken off.

$3 \mathrm{k}$. Another male pupa seen from left side, $\times 190 ; \alpha$. antennula, $c$. antenna.

3 l. Female pupa seen from left side, $\times 190$.

\section{Sphæronella Bonnieri n. sp.}

4 a. Female, $\times 30$.

$4 \mathrm{~b}$. Male wrapped up in threads (comp. p. 13i), $\times 30$.

4 c. Ovisac, $\times 30$.

4 d. Genital area, $\times 168$.

\section{PLATE VII.}

1. Sphæronella Bonnieri n. sp. (continued).

1 a. Male seen from below, $\times 174 ; q$. spermatothecæ.

$1 \mathrm{~b}$. The same male seen from left side.

\section{Sphæronella longipes n. sp.}

2 a. About half-grown female, $\times 37$.

2 b. Ovisac, $\times 37$.

2 c. Basal part of antennula, rostrum with antenna $(c)$ and maxillula, and maxilla of a very young female seen from left side, $\times 310$.

$2 \mathrm{~d}$. Very young female, $\times 37$.

$2 \mathrm{e}$. The same female, $\times 205$.

2 f. Cephalothorax of larva, $\times 288$. The natatory legs omitted.

2 g. Pupa seen from below, $\times 164$.

3. Sphæronella Amphilochi n. sp.

3 a. Head of female, $\times 264$.

$3 \mathrm{~b}$. Genital area of female, $\times 254$.

\section{Sphæronella Dulichiø n. sp.}

4 a. Female, $\times 41$.

4 b. Ovisac, $\times 41$.

4 c. Head of female, $\times 120$.

4 d. Genital area of female, $\times 194$.

5. Sphæronella Acanthozonis n. sp.

5 a. Female seen from right side, $X^{11 / 2}$.

$5 \mathrm{~b}$. The same female seen from below, $X^{11 / 2}$.

5 c. Head of female, $\times 79$.

$5 \mathrm{~d}$. Genital area of female, $\times 77$. 


\section{Sphæronella frontalis $n$. sp.}

6 a. Male seen from below, $\times 66$; q. spermatotheca (the other spermatotheca is seen to the left). The hairs on the lateral margin of the head and on the trunk drawn only on the left side of the figure; of the maxilliped on the same side only the basal joint is drawn and its hairs are omitted.

6 b. Another male seen from left side.

6 c. Antenna of male, $\times 280$.

$6 \mathrm{~d}$. Maxillula of male seen from the exterior side, $\times 280$; e.' additional branch.

6 e. The proximal larger part of the basal joint of the left maxilliped of male seen from the anterior side, $\times 185$.

6 f. First right trunk-leg of male seen from below, $\times 265$.

$6 \mathrm{~g}$. Second right trunk leg of male seen from below, $\times 265$.

$6 \mathrm{~h}$. Small part of the skin of male from the dorsal side of the trunk a little in advance of the middle, $\times 280$.

6 i. Genital area of female, $\times 166 ; t$. caudal stylets (their setæ no doubt broken off).

\section{PLATE VIII.}

\section{Sphæronella frontalis $\mathrm{n}$. sp. (continued).}

1 a. Female, $\times 16$.

$1 \mathrm{~b}$. Male, $\times 16$.

1 c. Ovisac, $\times 16$.

$1 \mathrm{~d}$. Head of female, $\times 108$. The antennula on left side of the figure almost totally omitted.

1 e. Larger part of cephalothorax of larva (with the peduncles of first pair of natatory legs), $\times 200$.

\section{Sphæronella microcephala Giard and Bonnier.}

2 a. Large female, $\times 21$.

2 b. Male, $\times 21$.

2 c. Ovisac, $\times 21$.

$2 \mathrm{~d}$. Head of female seen from below, $\times 334$.

2 e. Plate representing the frontal border, mouth and one maxillula of another female seen from below, $\times 334$.

2 f. Genital area of female, $\times 116$. Receptacula seminis and their orifices omitted.

$2 \mathrm{~g}$. Male seen from below, $\times 206$.

$2 \mathrm{~h}$. The same male seen from left side, $\times 208 ; i$. process of the first pair from the sub-median skeleton.

2 i. Larva with an adhesive plate covering the front, $\times 196$. The branches of the natatory legs omitted.

$2 \mathrm{k}$. Animal considered to be a pupa of this species, $\times 135$.

\section{Sphæronella decorata $n$. sp.}

3 a. Large female, $\times 11$.

$3 \mathrm{~b}$. Male, $\times 11$.

3 c. Ovisac, $\times 11$. 
Figure

$3 \mathrm{~d}$. Head of female seen from in front, $\times 66$.

$3 \mathrm{e}$. Head of another female seen from below, $\times 117$.

$3 \mathrm{f}$. Male seen from below, $\times 81$.

$3 \mathrm{~g}$. Another male seen from left side, $\times 81$.

$3 \mathrm{~h}$. Distal part of a maxilliped of male, $\times 296$.

3 i. Adult larva seen from below, $\times 154$. The setæ of two of the natatory legs omitted.

$3 \mathrm{k}$. Another similar larva seen from left side. A part of the olfactory seta, the greater part of the long caudal seta and most of the setæ of the natatory legs omitted.

3 1. Frontal decoration of larva, $\times 308$.

$3 \mathrm{~m}$. Antennæ of larva seen from below, ab. $\times 250$.

$3 \mathrm{n}$. Right maxilla of larva seen from below, $\times 312$.

30 . The two proximal joints of left maxilla of larva seen in an oblique direction.

\section{PLATE IX.}

1. Sphæronella decorata n. sp. (continued).

1 a. Genital area of female, $\times 94$.

$1 \mathrm{~b}$. Left maxilla of female seen from below, $\times 323$.

\section{Sphæronella modesta n. sp.}

2 a. Female, $\times 23$.

2 b. Male, $\times 23$.

2 c. Ovisacs - some containing eggs, others young ones - $\times 23$.

$2 \mathrm{~d}$. Head of female, $\times 230 ; x$, peculiar area.

2 e. Genital area of female, $\times 180$.

2 f. Male seen from below, $\times 138$.

$2 \mathrm{~g}$. Frontal border and one antennula of the same male, $\times 264$.

$2 \mathrm{~h}$. Another male seen from left side, $\times 138$.

2 i. Anterior part of larva, $\times 294$.

\section{Sphæronella dispar n. sp.}

3 a. Small adult female, $\times 37$.

$3 \mathrm{~b}$. Male, $\times 37$.

3 c. Ovisacs laid by the female shown in fig. $3 \mathrm{a}, \times 37$.

3 d. Large adult female, $\times 37$.

3 e. Ovisacs laid by the female shown in fig. $3 d, \times 37$.

$3 \mathrm{f}$. Head of female, $\times 185$. Of the antennula on the right side of the figure only the base is indicated.

$3 \mathrm{~g}$. Genital area of female, $\times 243$.

$3 \mathrm{~h}$. Male seen from below, $\times 202 ; i$. first process of the sub-median skeleton, $j$. second process of the same, $y$. lateral keel behind the peculiar frontal plate.

3 i. Another male seen from left side, $\times 219$.

$3 \mathrm{k}$. Larva, $\times 275$. The setæ of two of the natatory legs omitted. 
4 a. Female from Diastylis laevis Norm., $\times 25$.

4 b. Male from Diast. loevis, $\times 25$.

$4 \mathrm{c}$. Head of the female shown in fig. $4 \mathrm{a}, \times 160$. Of the antennula on the right side of the figure only the base is indicated.

$4 \mathrm{~d}$. Genital area of the female shown in fig. $4 \mathrm{a}, \times 186$.

4 e. Genital area of a female from Diast. cormuta Boeck, $\times 173$.

$4 \mathrm{f}$. Right antennula of the female from Diast. cornuta seen from below, $\times 290$.

$4 \mathrm{~g}$. Distal part of right maxilliped of the female from Diust. cornuta, $\times 290$.

\section{PLATE X.}

1. Sphæronella insignis $n$. sp. (continued).

1 a. Male from Diast. lavis seen from left side, $\times 67$.

$1 \mathrm{~b}$. Anterior part of the male shown in fig $1 \mathrm{a}$ and seen from below, $\times 208 ; x$. peculiar ring, $y$. lateral keel, $v$. frontal plate.

1 c. Male from Diast. cormuta seen from below, $\times 160$.

$1 \mathrm{~d}$. The same male seen from left side.

1 e. Larva from Diast. cornuta, $\times 151$. The branches of the natatory legs omitted.

$1 \mathrm{f}$. Front part of the larva shown in fig. $1 \mathrm{e}, \times 275$.

$1 \mathrm{~g}$. Right maxilla of the same larva, $\times 350$.

$1 \mathrm{~h}$. Pupa from Diast. cornuta seen from below, $\times 207$.

2 a. Female, $\times 12$.

\section{Sphæronella curtipes n. sp.}

2 b. Male, $\times 12$.

2 c. Ovisac, $\times 12$.

$2 \mathrm{~d}$. Head of female, $\times 192$. The distal part of one maxilliped broken off.

2 e. Genital area of female, $\times 71 ; r$. one receptaculum seminis - the other omitted.

2 f. Male seen from below, $\times 51$.

$2 \mathrm{~g}$. Another male seen from left side, $\times 47$.

3 a. Female, $\times 28$.

\section{Sphæronella affinis $n$. sp.}

$3 \mathrm{~b}$. Ovisac, $\times 28$.

3 c. Head of female, $\times 292$. The hairs of the sub-median skeleton drawn only on the right side of the figure.

$3 \mathrm{~d}$. Genital area of female, $\times 146$. Both receptacula seminis are indicated by dotted lines, and on the orifice of one a stalk of a spermatophore is attached.

\section{Sphæronella Munnopsidis $\mathrm{n}$. sp.}

4 a. Anterior half (namely: the head with the basal part of the antennæ, and the larger part of the thorax with the first pair of legs and the basal portion of the three following pairs of legs) of an adult female of Munnopsis typica M. Sars, the extended marsupium of which is occupied by a female parasite with twenty ovisacs; many of the ovisacs are seen through the marsupial plates. The host is seen from below, $x^{14} / 3$. 
Figure

$4 \mathrm{~b}$. Area on the female answering to the head and showing the antennulæ and its other organs, $\times 122$.

4 c. Genital area of female, $\times 68 ; g$. genital aperture, $h$. hole (or very small thin-skinned area with minute holes), $r$. one receptaculum seminis indicated by a dotted line, with a stalk of a spermatophore, $s^{\prime}$. , attached to its orifice; $s$. spermatophore attached to the orifice of the other receptaculum which is not drawn.

$4 \mathrm{~d}$. Antennula, antenna, maxilla and maxilliped from the right side of a not quite full-grown larva seen from below, $\times 196$.

\section{Choniostoma mirabile H. J. H.}

5 a. Female seen from below, $\times 4$.

$5 \mathrm{~b}$. Ovisac with eggs, $\times 4$.

5 c. Ovisac with full-grown larvæ, $\times 4$. (These three figures, fig. $3 \mathrm{a}-3 \mathrm{c}$, are also found in my report in "Dijmphna-Togtets zool.-bot. Udbytte".)

\section{Choniostoma Hansenii Giard and Bonnier.}

6 a. Rostrum of female cut off and seen from right side, $\times 203 ; a$. membrane of the mouthborder, $b$. hairs of the mouth-border, c. maxillula, $c$. additional branch of the maxillula (its distal part is broken off, but indicated by dotted lines).

6 b. Larger part of the terminal face of the rostrum shown in fig. $5 \mathrm{a}, \times 321 ; d$. labrum, e. mandible.

\section{PLATE XI.}

1. Choniostoma mirabile H. J. H. (continued).

1 a. Head of female, $\times 104 ; a$. antennula, $b$. olfactory seta, $c$. antenna, g. rudimentary maxilliped, $h$. sub-median skeleton, $k$. frame of the head, $k$ '. lateral process of the frame, $k$ ". chitinous knots belonging to the frame and lying partly beneath the soft skin, $t$. posterior chitinous ring, $u$. anterior chitinous ring.

$1 \mathrm{~b}$. Genital area of female, $\times 104$; e. solid chitine, $r$. one receptaculum seminis indicated by dotted lines (the other receptaculum is omitted). The genital apertures are open.

1 c. Young one in the Nauplius stage seen from left side, $\times 81$.

$1 \mathrm{~d}$. Young one in the Nauplius stage seen from below, $\times 81$. (Fig. $1 \mathrm{c}$ and $1 \mathrm{~d}$ are found in "Dijmphna-Togtet".)

1 e. Hinged larva, $\times 210 ; s$. adhesive plate. The setæ of the two natatory legs on the left side of the figure are omitted.

1 f. Anterior part of a full-grown larva pulled out of its egg-membrane, $\times 261$.

$1 \mathrm{~g}$. Pupa seen from below, $110 ; a$. antennula, s. adhesive plate. Posteriorly and on the sides the outline of the contents is somewhat removed from the margin, and posteriorly are seen the hairs of the animal shining through the skin of the pupa.

$1 \mathrm{~h}$. Large pupa seen from below, $\times 40$.

1 i. Smaller pupa seen from below, $\times 40 ; s$. adhesive plate. The contents marked with a greyish tint.

$1 \mathrm{k}$. Small pupa seen from below, $\times 40$. 
2 a. Adult female, $\times 29 / 4$.

2 b. Small female, $\times{ }^{29} / 4$.

2 c. Ovisac, $\times 29 / 4$.

$2 \mathrm{~d}$. Head of an adult female, $\times 130$.

2 e. Part of the skin of the ventral side outside the head of a small female, $\times 130$.

2 f. Genital area of an adult female, $\times 128$.

\section{Mysidion commune n. gen., n. sp.}

3 a. The contents of the marsupium of an Erythrops s rratus G. O. S. seen from below and consisting of the female parasite with its seventeen ovisacs, $\times 12$.

3 b. Another female with its ovisacs from Er. serratus seen from above (the head situated on the dorsal side and its front turning backward), $\times 25 ; g$. maxillipeds. The contents indicated only in three of the thirteen ovisacs.

3 c. Four ovisacs of another female, $\times \mathbf{2 5}$. In the largest ovisac only a small part of the contents, namely six larvæ, are drawn.

3 d. Male, $\times 25$.

3 e. Posterior half of the ventral surface of female, $\times 42 ; e$ skeleton surrounding one genital aperture; $r$. transition between the receptaculum seminis and one of its ducts, $s$. spermatophores.

3 f. Left genital aperture with its lips, muscles and the surrounding skeleton seen from below, $\times 190$.

$3 \mathrm{~g}$. Male seen from below, $\times 258 ; q$. spermatothecæ. The hair-covering of the trunk drawn only on one side.

$3 \mathrm{~h}$. Another male seen from left side, $\times 258$; $s$. frontal thread, $t$. part of a marsupial plate of the host, $x$. conical eminence on the dorsal side of the head.

3 i. Very small pupa seen from below, $\times 188 ; x$. outline of a mouth (?) beneath the skin of the pupa. - This and all the other figures of this parasite are drawn from animals taken on Erythrops serratus G. O. S.

\section{PLATE XII.}

1. Mysidion commune n. gen., n. sp. (continued).

1 a. Head of female, $\times 182 ; a$. antennula, $u$. process of unknown nature (perhaps stiffened viscous substance on the opening of the gland producing it).

1 b. Pupa with dorsal thread, $X 25$. (The same enlargement as in fig. $3 \mathrm{~b}-3 \mathrm{~d}$ on pl. XI.)

1 c. Pupa seen obliquely, $\times 182 ; a$. (misscript for $c$.) antenna, $f$. maxilla, $g$. maxilliped, $r$. skeleton surrounding the future genital aperture, $t$. (misscript for $a$.) antennula, $u$. basal part of the dorsal thread shining through the animal, $v$. distal part of the thread, $x$. eminence at the mouth of the pupa stage, $y$. moulh of the pupa stage, $y$ '. chitinous lists on the side of the rostrum of the pupa. The mouth and the maxillulæ of the young female are seen at the anterior end of the animal.

$1 \mathrm{~d}$. Very young female in possession of characters which it loses afterwards, $X 182$; $a$. (misscript for $c$.) antenna, $r$. skeleton surrounding the future genital aperture, $t$. (misscript for $a$.) antennula, $u$. basal part of the dorsal thread, $v$. distal part of the dorsal thread, $x$. odd ventral process situated at the place of the mouth of the pupa stage, $z$. body of unknown nature. 


\section{Mysidion abyssorum n. sp.}

2 a. Head of female, $\times 182 ; a$. antennula, $e$. additional branch of the maxillula.

$2 \mathrm{~b}$. Genital aperture and the surrounding skeleton of female, $\times 123 ; g$. genital aperture, $h$. plate formed of a kind of viscous substance and covering the lips of the genital aperture and the skeleton behind them, $i$. stalks of ovisacs, the basal parts of which are confluent and form the plate mentioned, $k$. hole (or very small thin-skinned area with minute holes) at the anterior end of the skeleton.

2 c. Male, 43 .

$2 \mathrm{~d}$. Very small male with frontal thread, $\times 43$.

2 c. Normal male seen from below, $X 256 ; e$. maxillula, $q$. spermatotheca, $u$. line of unknown nature.

2 f. Normal male seen from left side, $\times 236 ; x$. conical eminence on the dorsal side of the head.

$2 \mathrm{~g}$. Frontal thread of one of the minute males, $\times 260$.

$2 \mathrm{~h}$. Larva seen from below, $\times 264$. The natatory legs are omitted.

2 i. Hinged larva seen from above, $\times 125$.

\section{Aspidoecia Normani Giard and Bonnier. ${ }^{1}$ )}

3 a. Male of Erythrops abyssorum G. O. Sars seen from above and infested with nine female parasites of very different size and one larva, $X^{13} / 2 ; a$. larger female, $b$. smaller females, $l$. larva, $m$. male. The posterior part of the abdomen of the host is omitted.

3 b. Female with two rudimentary ovisacs $\left(u\right.$.) and three larvæ $\left(v_{0}\right)$ attached to the dorsal surface of the second abdominal segment of Erythrops serratus G. O. Sars, $\times 24 ; r$. chitinous knots where the entrances to the receptaculum seminis must be found.

3 c. Sub-adult female attached to the back of the first abdominal segment of an Er. serratus and seen from the dorsal side, $X 39 ; x$. two males hinged by their frontal thread, $y$. part of the skin of the host.

$3 \mathrm{~d}$. Head of a female from Er. serratus, seen much from in front, $\times 350 ; d$. mouth, e. maxillula, $s$. adhesive plate, $t$. internal space possessing a peculiar refraction of light.

3 c. External genital organs and receptaculum seminis of the female whose head is shown in fig. $3 \mathrm{~d}$, $\times 70$; e. solid ring, $g$. genital aperture, $k$. hole in the ring, o. chitinous knots, $r$. receptaculum seminis with its ducts.

3 f. Adult female from Er. abyssom, $\times 24$; the head is seen in the middle.

$3 \mathrm{~g}$. The same male seen from the side opposite of that of fig. $3 \mathrm{f} ; r$. ring around a genital aperture, $r$. chitinous knots.

$3 \mathrm{~h}$. Head of the female shown in the two preceding figures, cleaned with caustic potash and seen from below; $\times 350 ; a$. antennula.

3 i. Genital aperture and its surroundings of the female shown in fig. $3 \mathrm{f}, \times 170 ; e$. ring-shaped skeleton, $f^{\prime}$. less solidly chitinised part of the ring, $g$. genital aperture with its lips, $k$. hole in the ring, $m$. muscles.

$3 \mathrm{k}$. Male from Er. serratus seen from below, $X 291 ; b$. olfactory seta of the antennula, $q$. spermatotheca. (In other specimens two spermatothecæ were found.)

3 1. Another male from $E r$. serratus seen from left side, $\times 324$.

1) On the plate is written Normanni instead of Normani. 
Figure

$3 \mathrm{~m}$. Larva which was altached to the female shown in fig. $3 \mathrm{~b}$, its skin is burst along the lateral margins, and it contains a fully developed male, $\times 184 ; a$. antennula of the larva, $b$. olfactory seta of the antennula, $s$. viscous substance procceding from the front of the male.

$3 \mathrm{n}$. Right maxilla and maxilliped with a part of the sub-median skeleton of the larva shown in fig. $3 \mathrm{a}$ as attached to the carapace of Er. abyssorum and marked $l_{\text {. }}$; the organs are scen from below, $\times 330 ; h$. sub-median skeleton.

1 a. Female, $\times 110$.

\section{PLATE XIII. \\ (Supplements to pl. II, III and X.)}

1 b. Male, $\times 110$.

1 c. Ovisac, $\times 110$.

$1 \mathrm{~d}$. Head of female, $\times 312$. The short hairs on the lateral margins omitted.

1 e. Genital area and its surroundings of female, $X 322$; the receptacula seminis are indicated by dotted lines; on the orifice of one are attached a spermatophore and the basal part of the stalk of another spermalophore, on the orifice of the other are seen parts of the stalks of two spermatophores.

1 f. Male seen from below, $\times 230$.

$1 \mathrm{~g}$. Male seen from left side, $\times 230$.

$1 \mathrm{~h}$. Full-grown larva seen from left side, $\times 297$. Most of the natatory legs omitted.

2. Sphæronella danica n. sp. (Supplement to fig. 4 on pl. II.)

2 a. Genital area and its surroundings of a scarcely half-grown female, $\times 216$.

3 a. Female, $\times 36$.

\section{Sphæronella Leptocheiri $n$. sp.}

3 b. Male, 36.

3 c. Head of female, $\times 165$.

$3 \mathrm{~d}$. Genital area and its surroundings of female, $\times 216$; e. solidly chitinised ring, $g$. genital apertures, $m$. muscles, $r$. receptacula seminis, $t$. caudal stylets.

3 e. Outline of a part of a male seen from below, showing the processes of the sub-median skeleton, one maxilliped, the legs on the right side and the caudal stylets, $\times 276$.

\section{Sphæronella messinensis $n$. sp.}

4 a. Female with two spermatophores, $\times 62$.

4 b. Head of female, $\times 214$.

4 c. Genital area of female, $\times 274$. The receptacula seminis are indicated by dotted lines, and a spermatophore is attached to the orifice of one.

\section{Sphæronella irregularis n. sp.}

5 a. Female with three spermatophores, $\times 41$.

5 b. Ovisac, $\times 41$. 
5 c. Head of female, $\times 204$. Antennulæ, one maxilliped and the distal part of the antennæ are broken off; the hairs almost totally omitted on the right half of the figurc.

$5 \mathrm{~d}$. Genital area of female, $\times 202$.

\section{Sphæronella marginatá n. sp.}

6 a. Female, $\times 41$.

6 b. Male, $\times 41$.

6 c. Ovisac, $\times 41$.

6 d. Head of female, $\times 190 ; a$. antennula, $f$. rudimentary maxilla.

6 e. Genital area of female, $\times 280$. Only one of the caudal stylets is found. The receptacula seminis indicated by dotted lines.

6 f. Male seen from below, $\times 190$. The trunk misshaped by pressure.

$6 \mathrm{~g}$. Cephalothorax of a full-grown larva, $X 273$. The natatory legs and most of the olfactory seta on the right side of the figure omitted.

$6 \mathrm{~h}$. The two distal joints of a maxilla of the larva, $\times 273$. 


\section{ERRÁTA.}

Page 4, line 6, for "J. Sparre-Schneider" read "J. Sparre Schncider".

- 7, line 5 from bottom, for "antennulæ" read "antennula".

- 9, line 5 from bottom, for "in" read "within".

- 11, line 1, for "new a" read "a new".

- 11, line 8 from bottom, for "twenty-four" read "twenty-one".

- 11, line 2 from bottom, for "Stenotocheres" read "Stenothocheres".

- 13, line 5 from bottom, for "Croisic" read "le Croisic". - The same error is found in p. 14, line 4 from bottom, and in p. 16, line 11 from bottom.

- 18, line 17, for "larvæ" read "larva".

- 33, line 1 and 2, for "of medium length" read "comparatively long".

- 37, fine 4, for "acute" read "rectangular".

- 37, line 7 from bottom, for "S. Holbolli" read "S. Holbölli".

- 47, line 12 from bottom, for "larva" read "larvæ".

- 52, line 18, for "Homoeoscelis" read "Homoeoscelis minuta".

- 52, line 16 from bottom, for "larva" read "larvæ".

- 54, line 17 from bottom, for "smaller, $125 \mathrm{~mm}$." read "between $125 \mathrm{~mm}$. and · $147 \mathrm{~mm} . . "$

- 55, line 9. for "at least the female pupa" read "the pupe of both sexes".

- 55, line 13, for "125 mm." read "147 mm.".

- 93, line 7, for "body" read "trunk".

- 115, line 2, for "maxille" read "maxillule". 

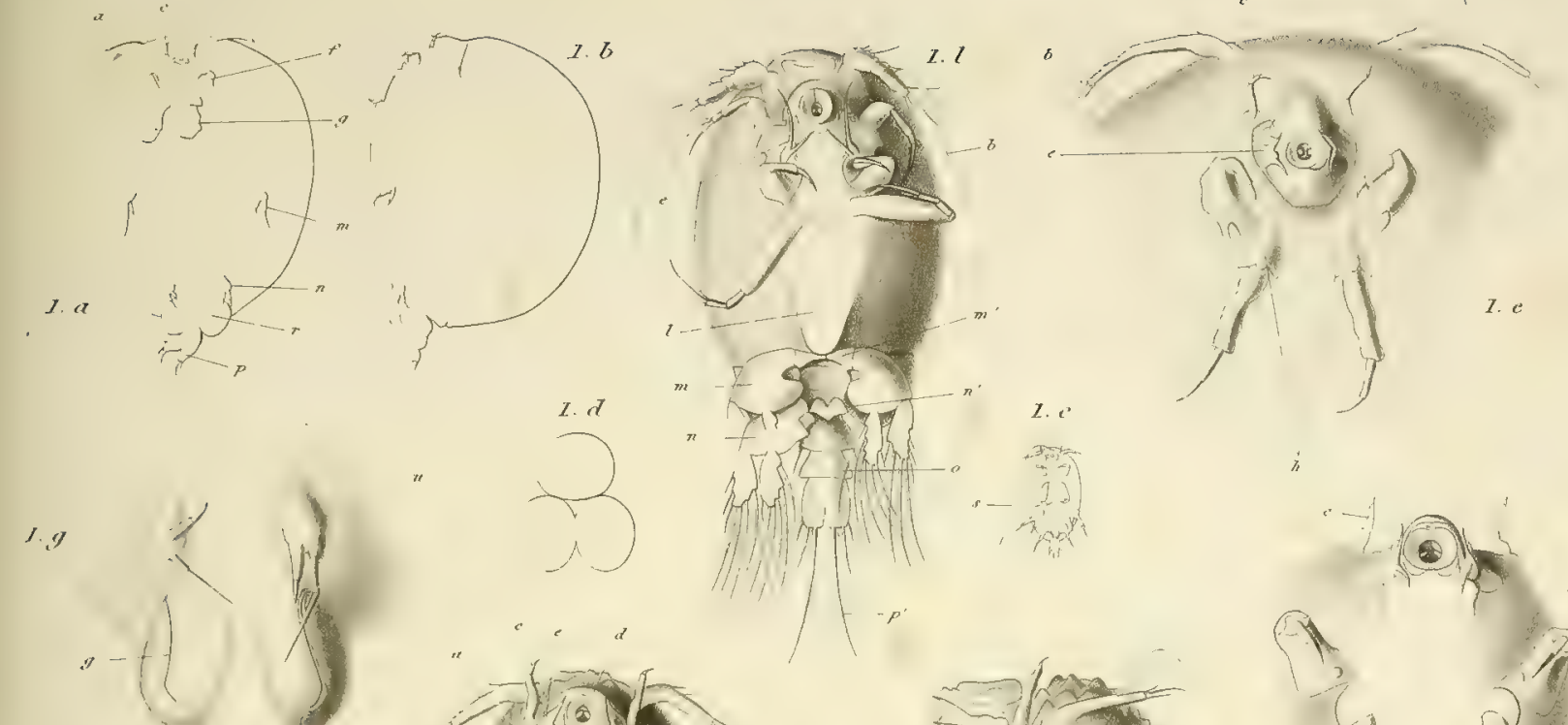


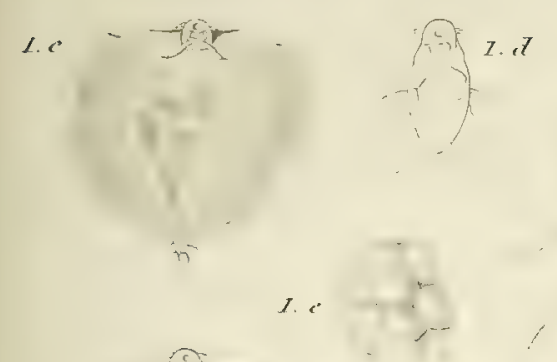

1. $b$

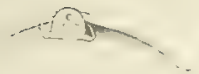

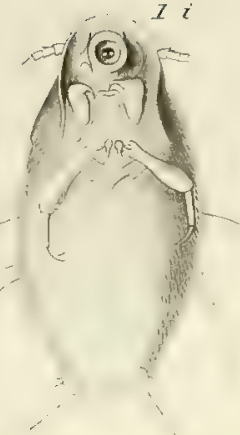
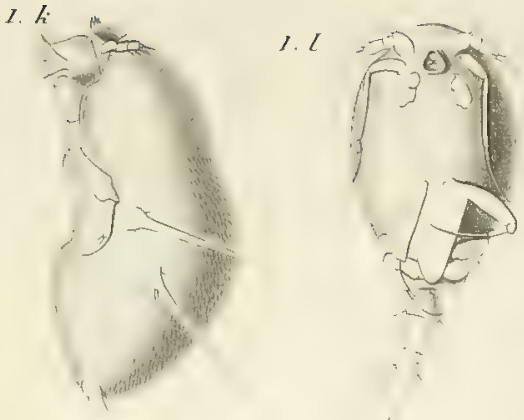

2.
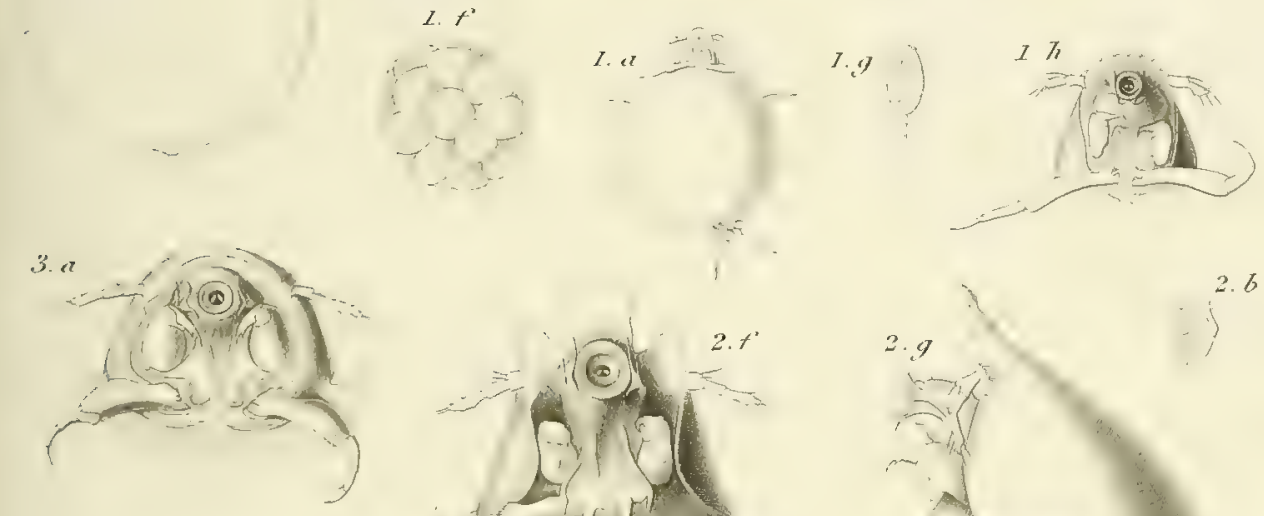

2.

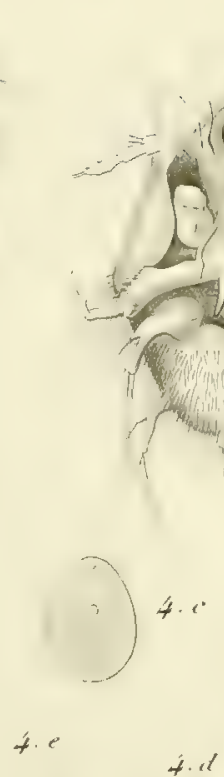

.3. 6
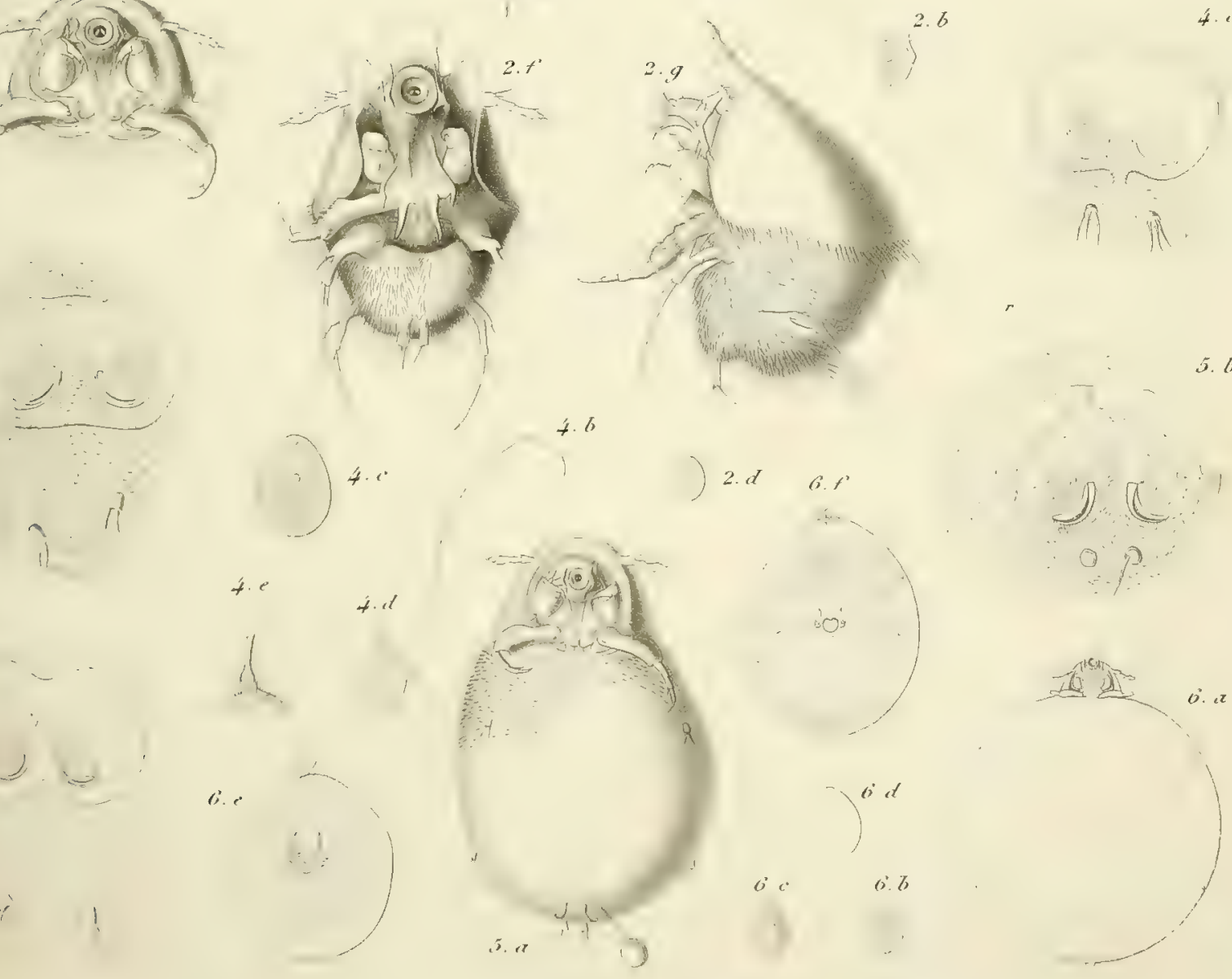

5. 6
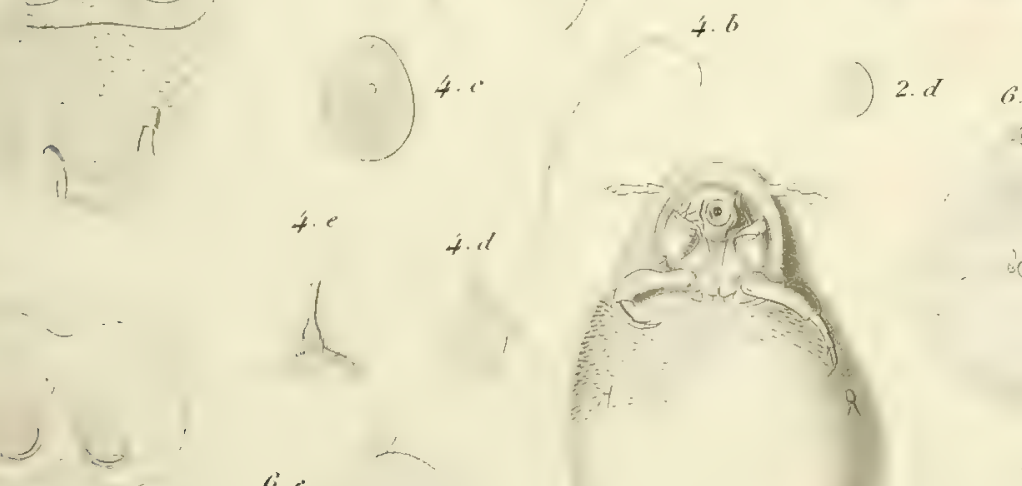



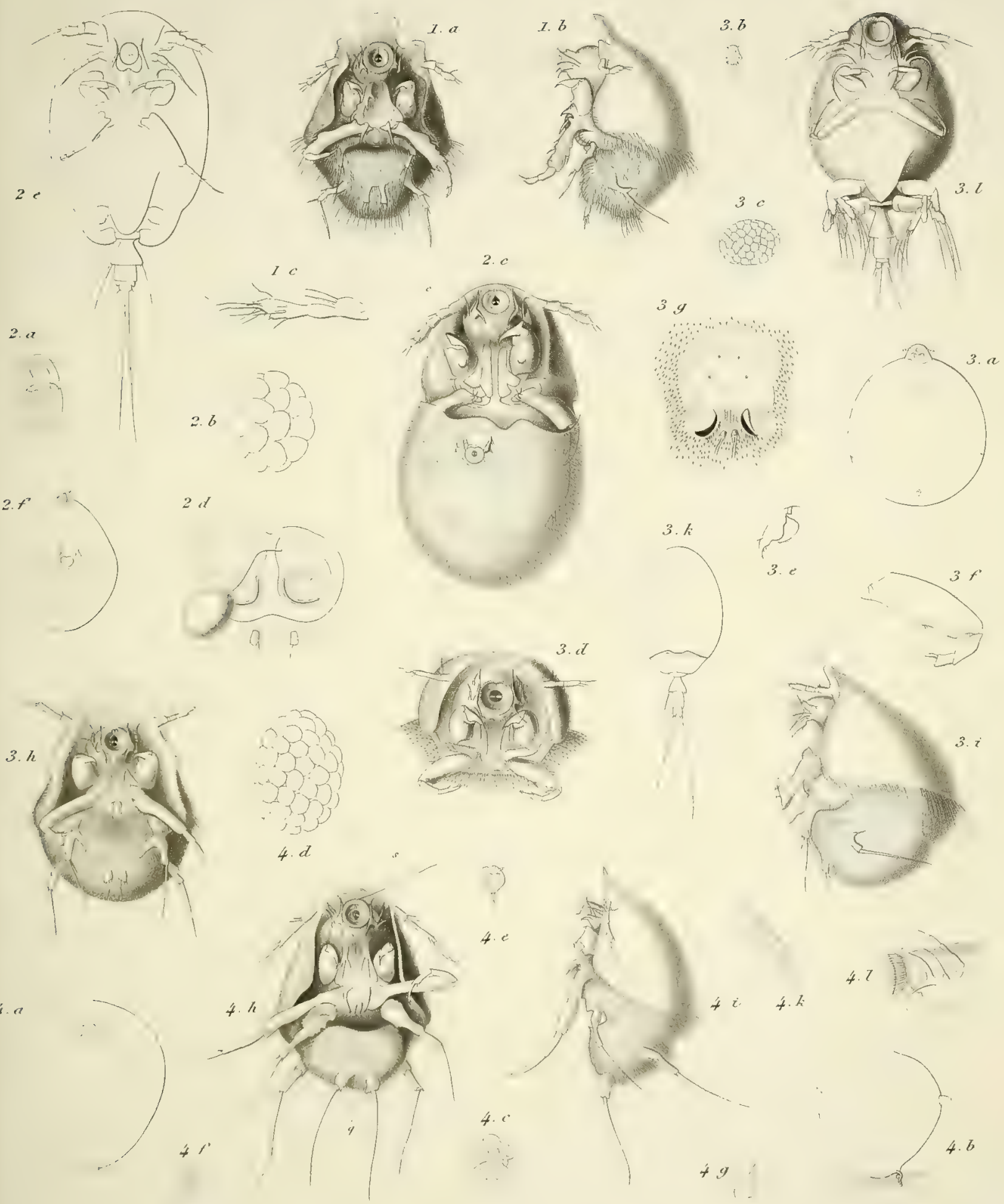

\footnotetext{
1. Splereronella x.hinensis n.sp.

2. Sptwer. antillensis nusp.

3. Spher. Calliopit n. sp. 


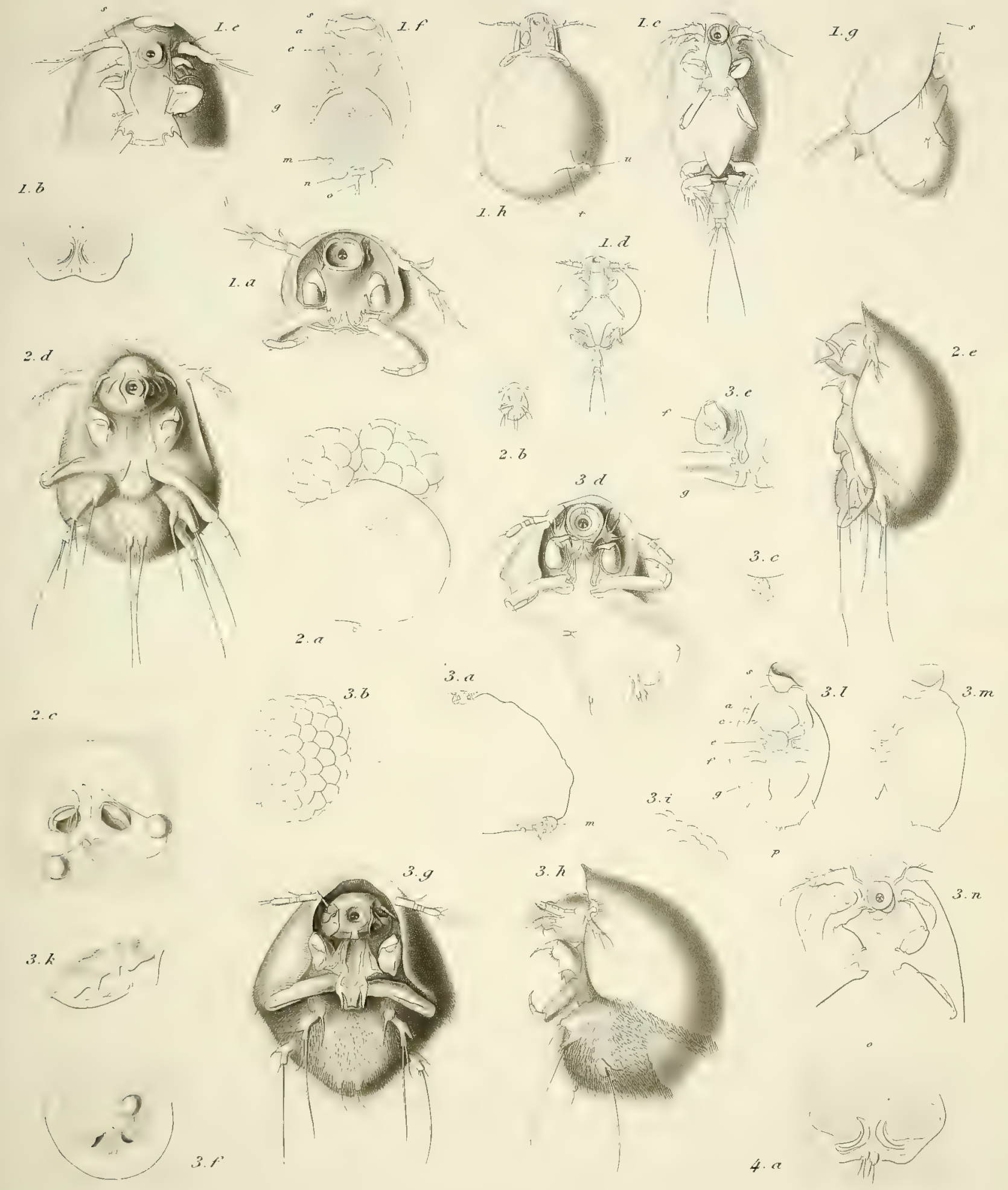

1. Spharonella paradoca nisp.

2. Sphar abyssi nusp.

3. Spher. Argisssce nusp. 
. 
II IIIAsen - CToniostomatide.
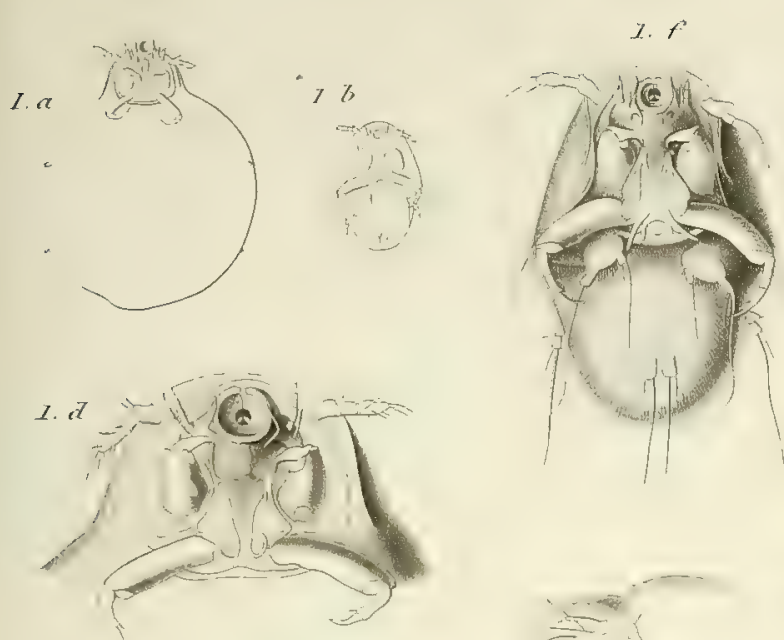

1. 9

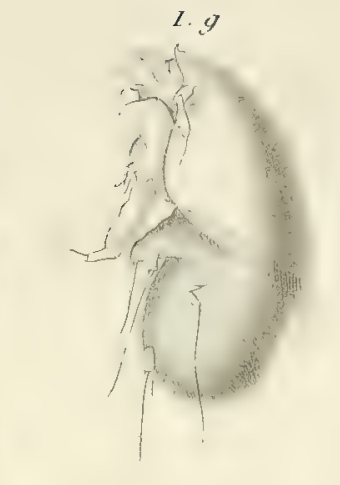

(1) $2 \cdot$

2. 8

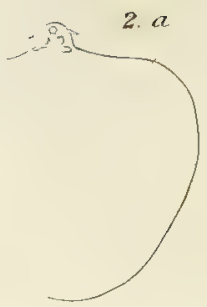

करो
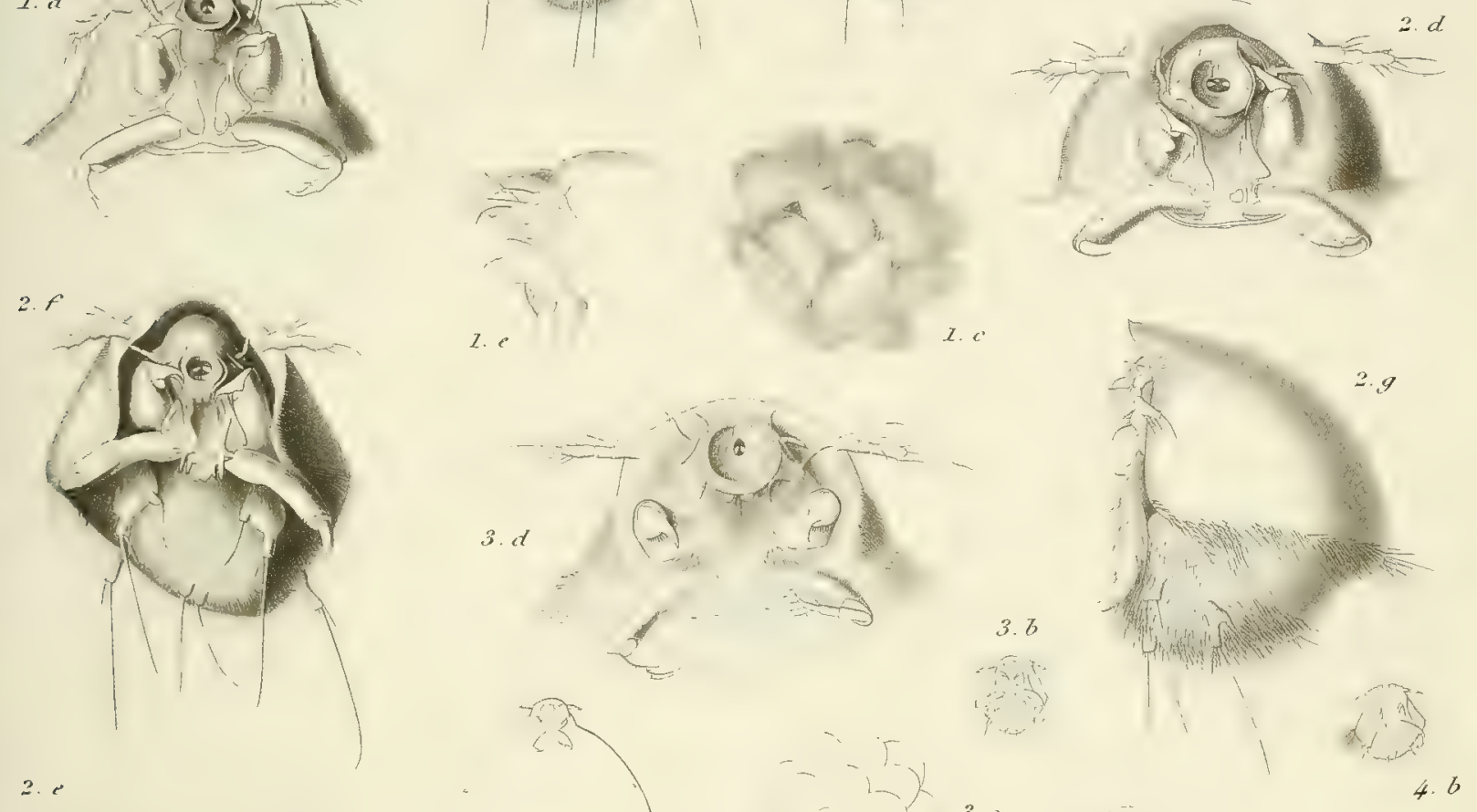

2.
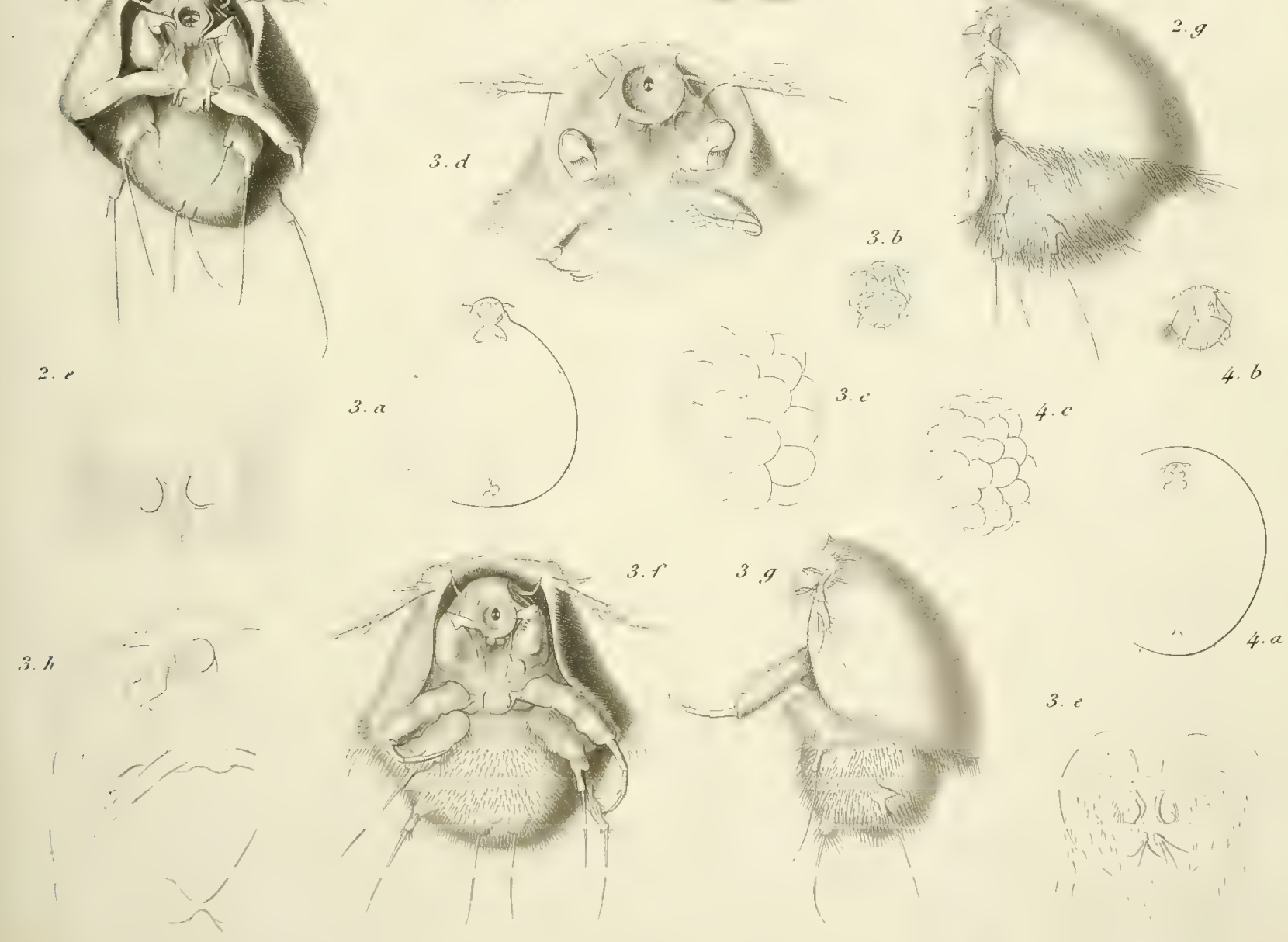

3.e

1. Spheronelle Metoper nisp.

2. Spher. Holbolli n.sp.

3. Spher. intermedia nusp. 


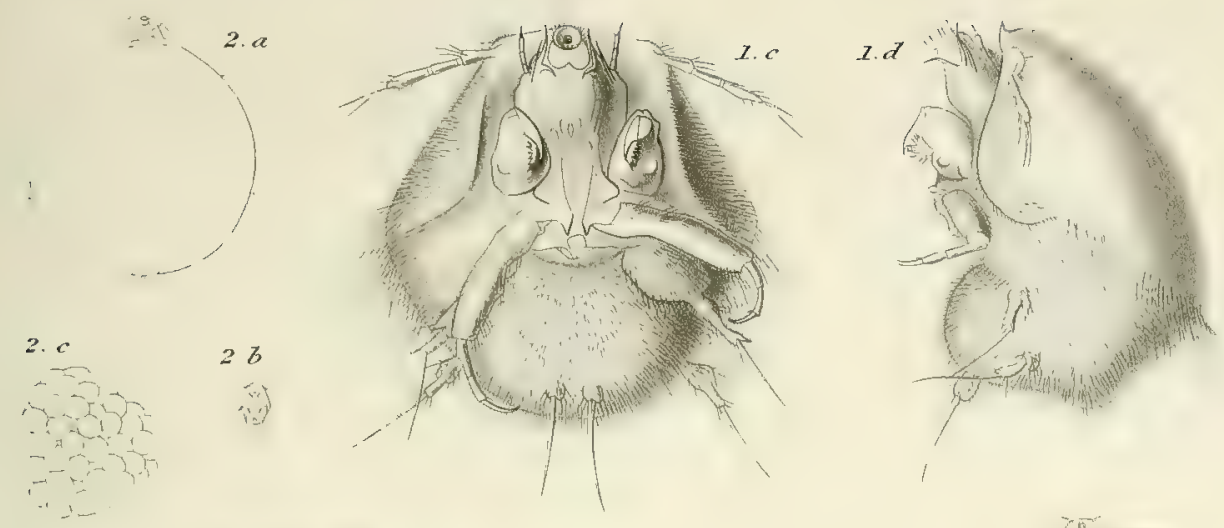

7. $b$

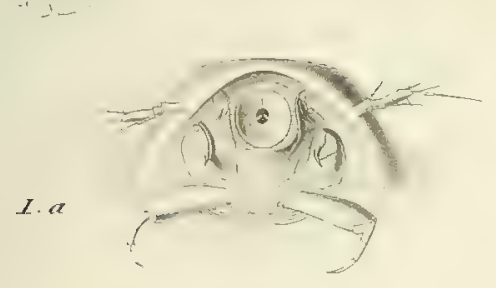

$2 e$
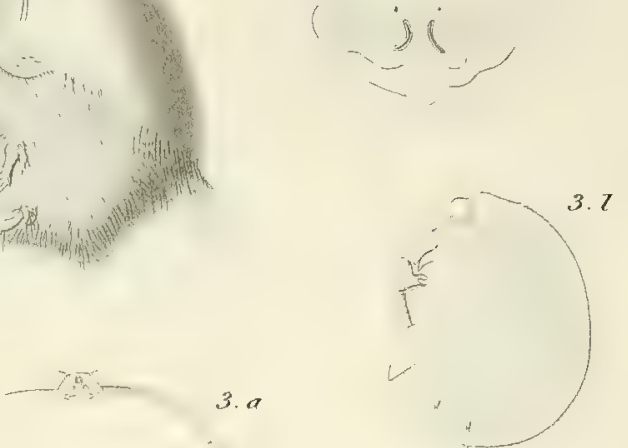

I.a $\quad j=\cdots+\cdots$
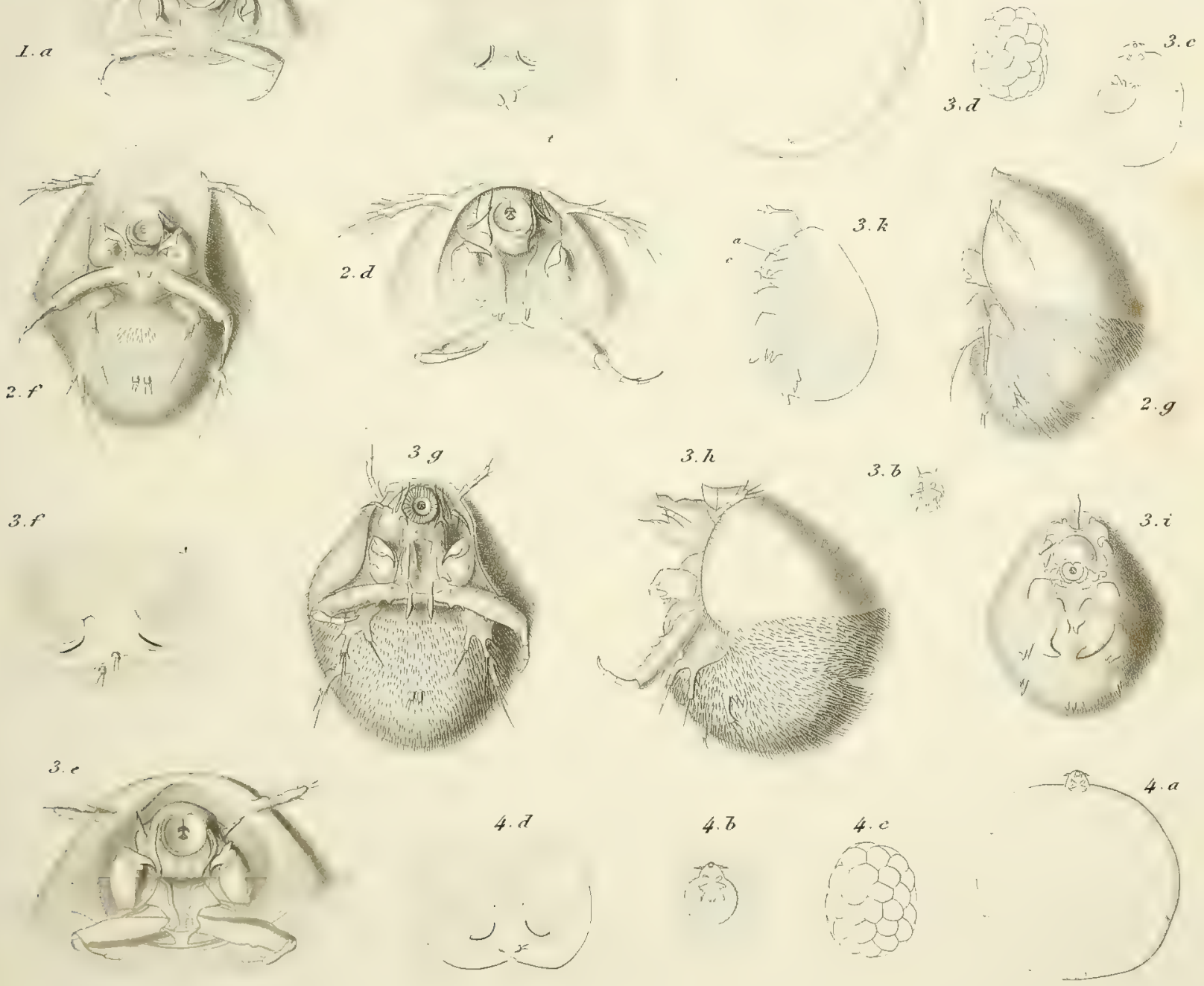

1. Spheronclla capensis $\pi$ up. 2. Spher. Gitanopsidis nu. 4. Spher. Botwieri to sp

3. Sphar. Giardii nsp. 



$$
\begin{aligned}
& 0 \\
& 19 \\
& 0
\end{aligned}
$$




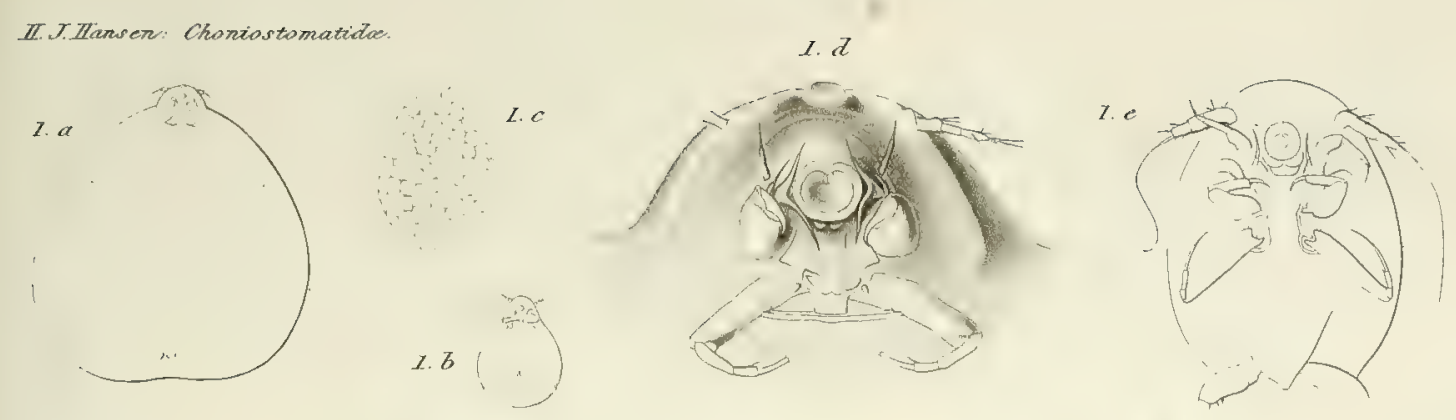

PZ. FUI

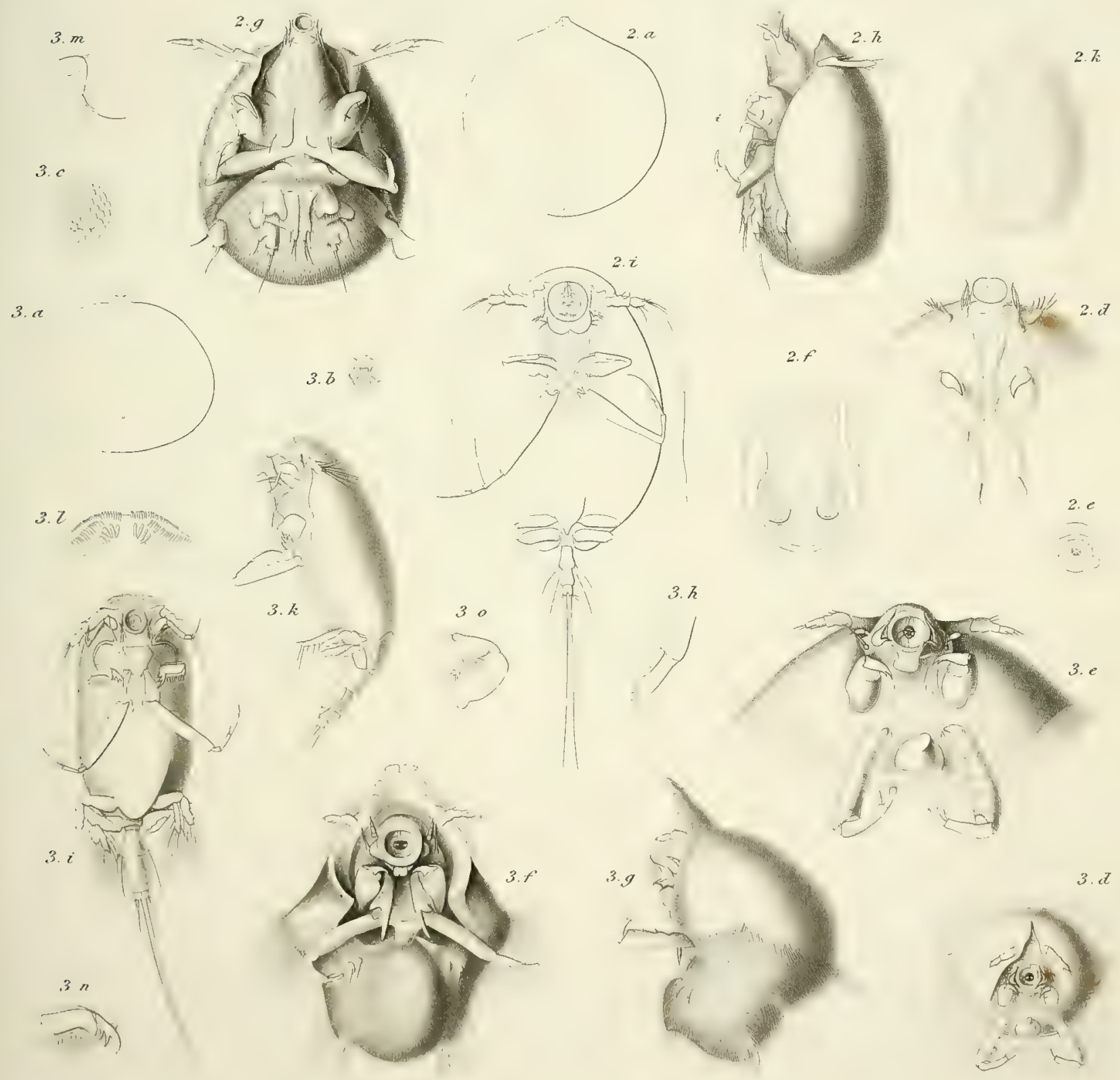

1. Spheronella frontatior nisp.

2. Sphar. microcephala Giard \& Bonew.

3. Spher. decorata nusp.

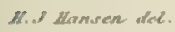




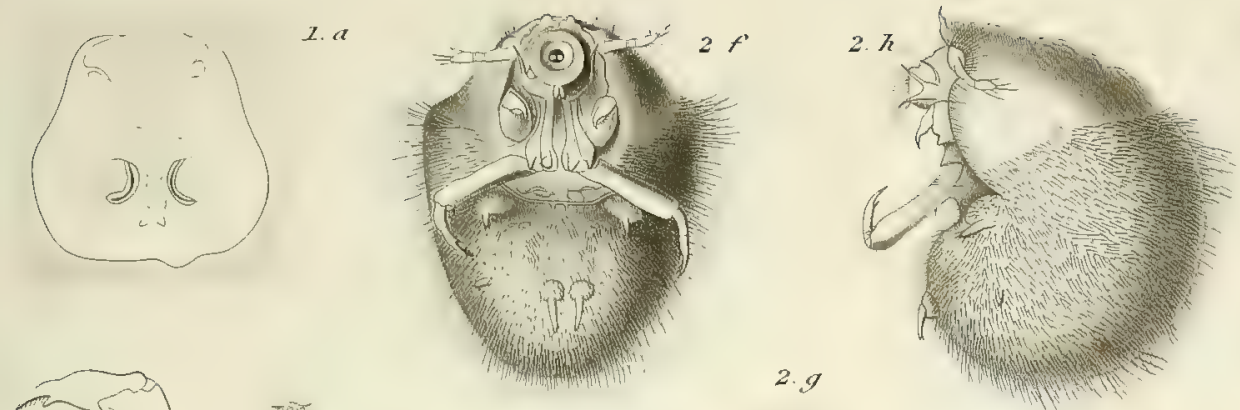

2.
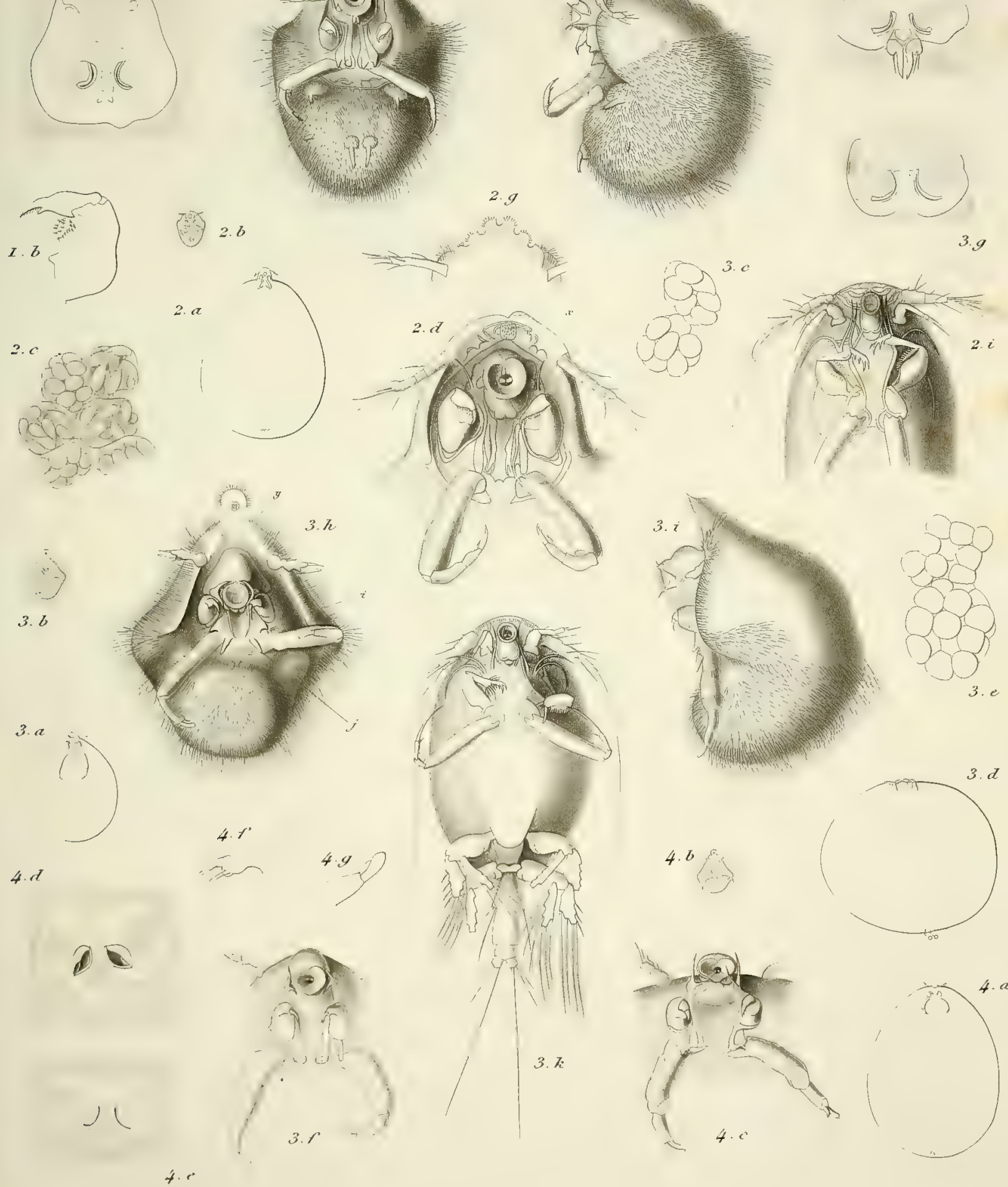
3.9
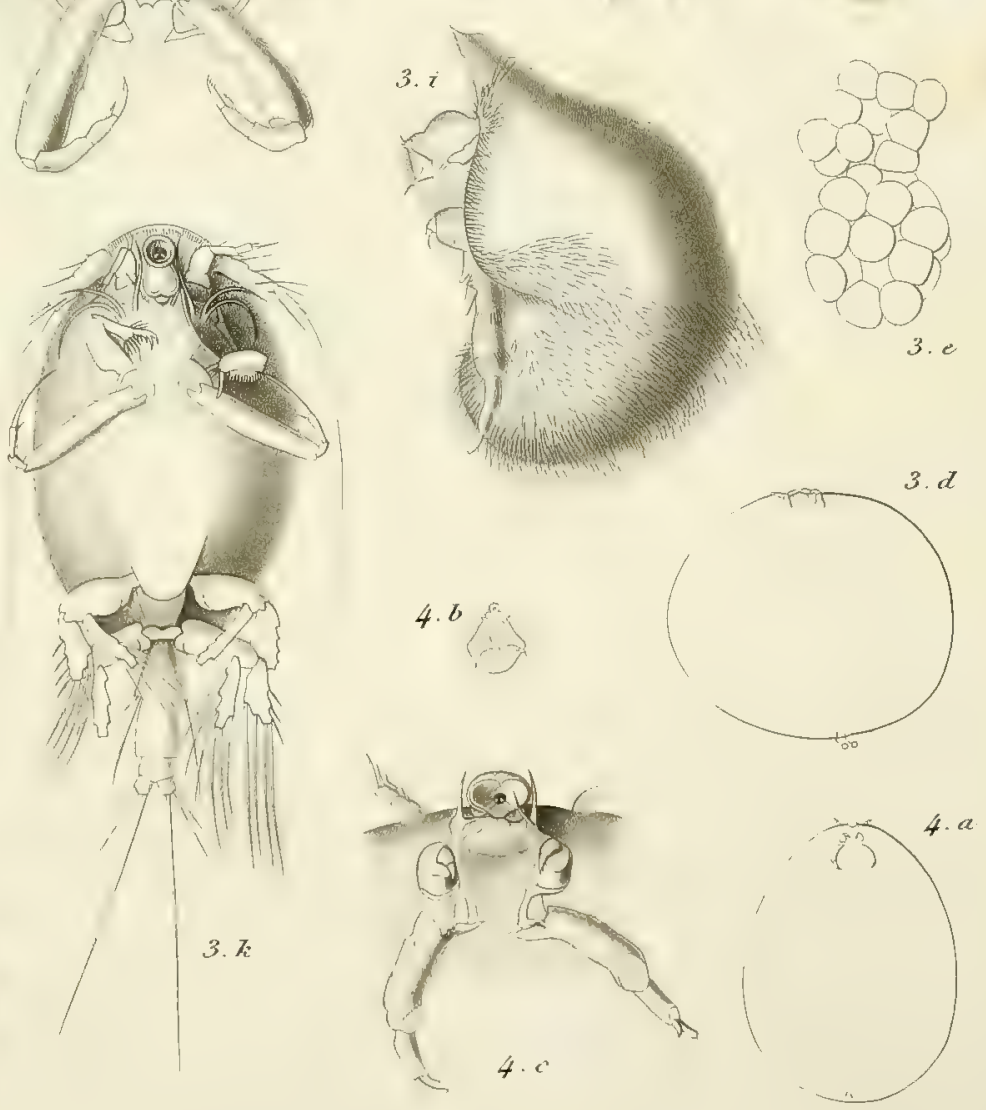

1. Sphueronella decoruta n..sp

2. Spharer. modesta n. sp.

3. Sphar: dispar n.sp. II. S Husuren del 4. Spher. insignis n.sp. 

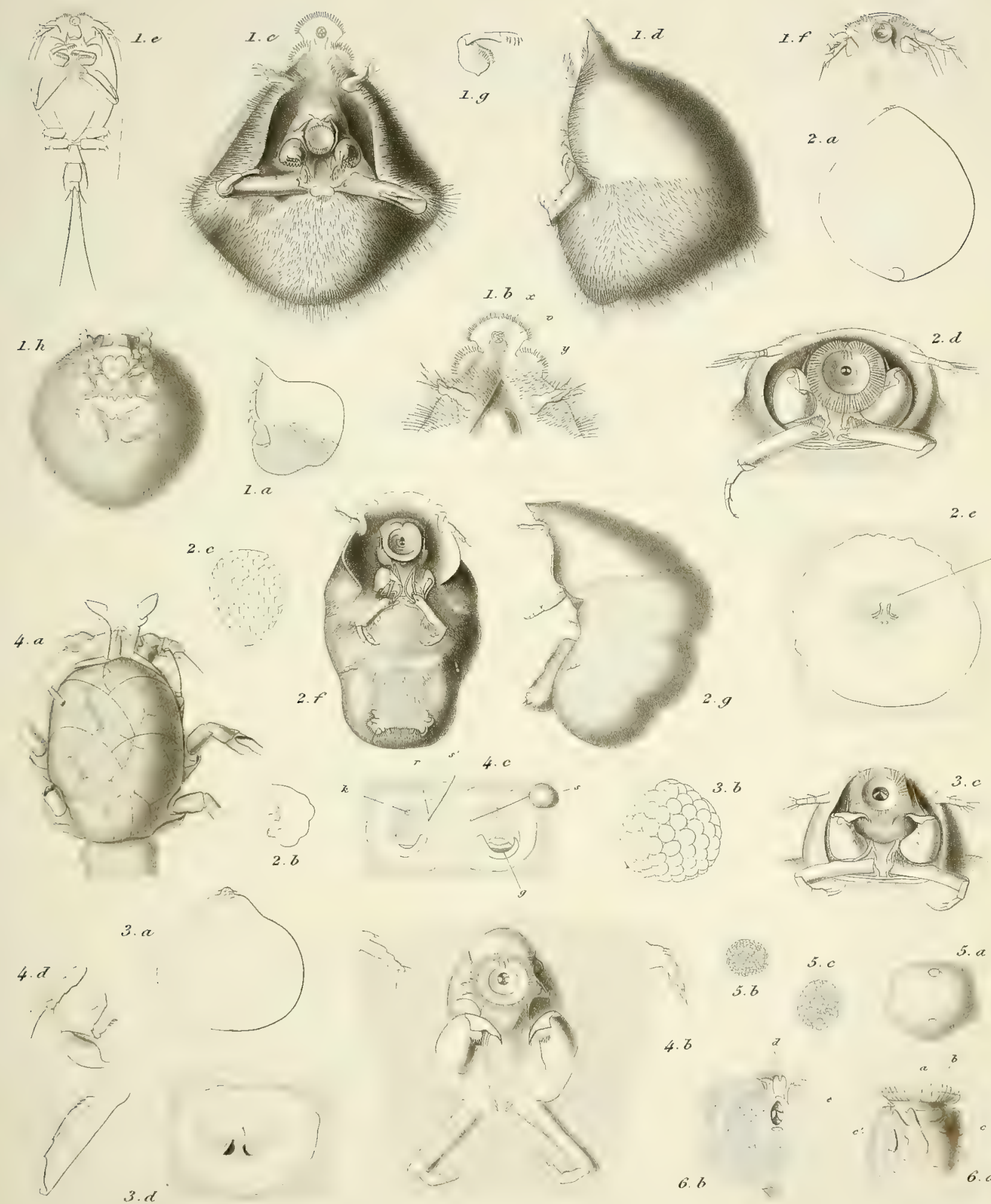

$2 \cdot 9$

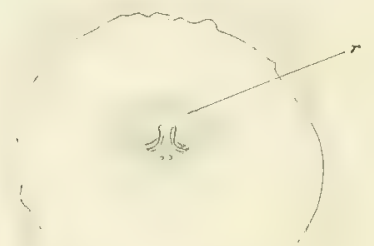

1. Spheronella insignis nusp. 2. Sphaer. curtipes nusp.

b.
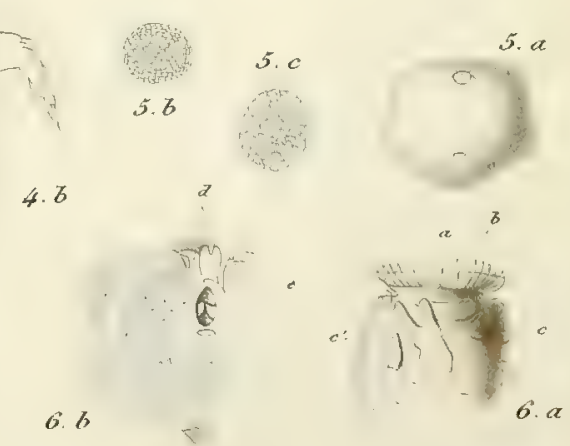
4. Spher. Munnopsidis n.sp.

5. Choniostoma mirabile II.TH.

3. Spher. affinis n. sp.

6. Chon Harssenit Giverd a Bonr. 
. 
H. T. Harwer: Choniostonutidue

PI 17 .
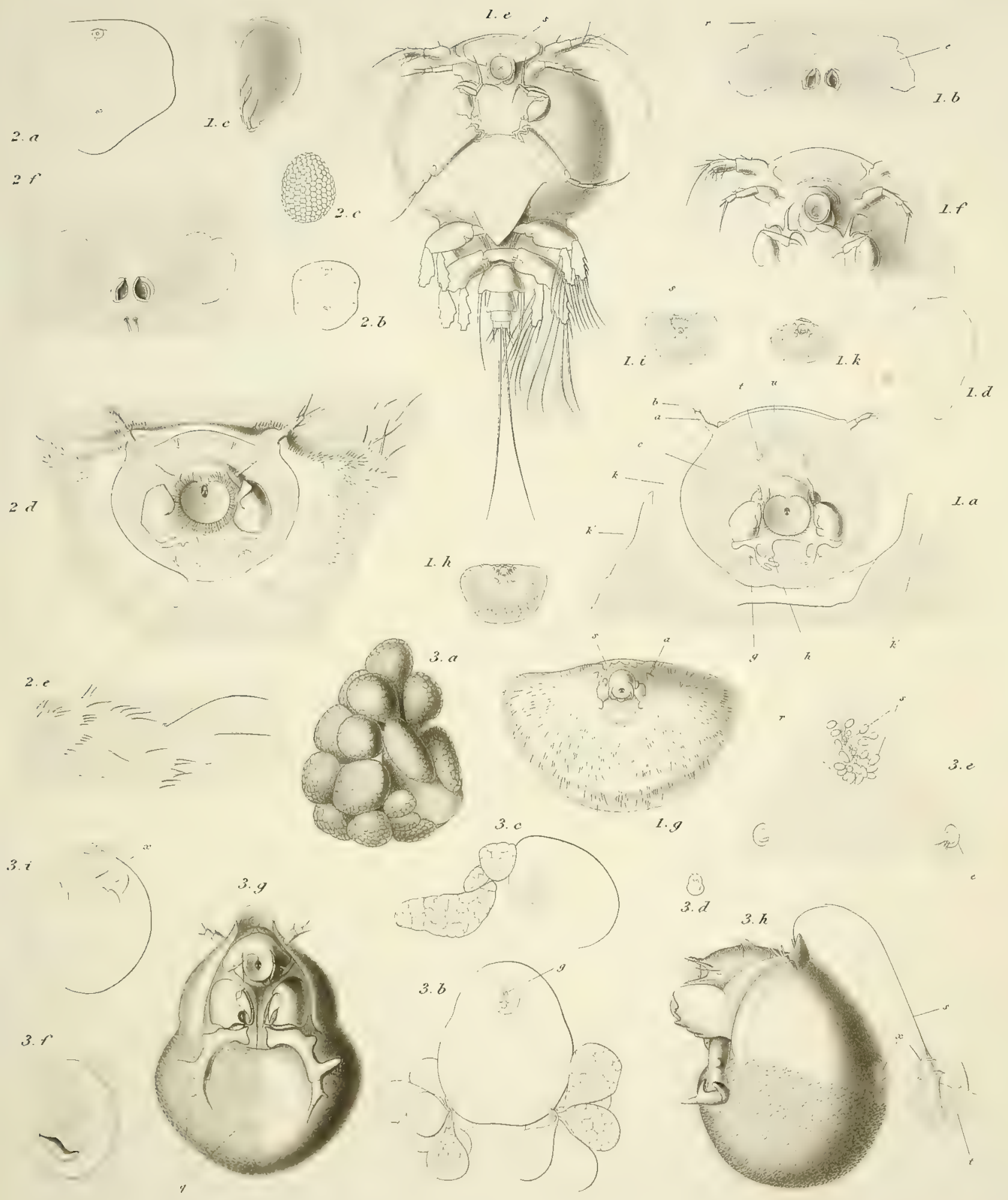

1. Choniostoma mirabile EISIT. 2. Chon. Hansenix Guard \& Bonn 


\begin{abstract}
.
\end{abstract}




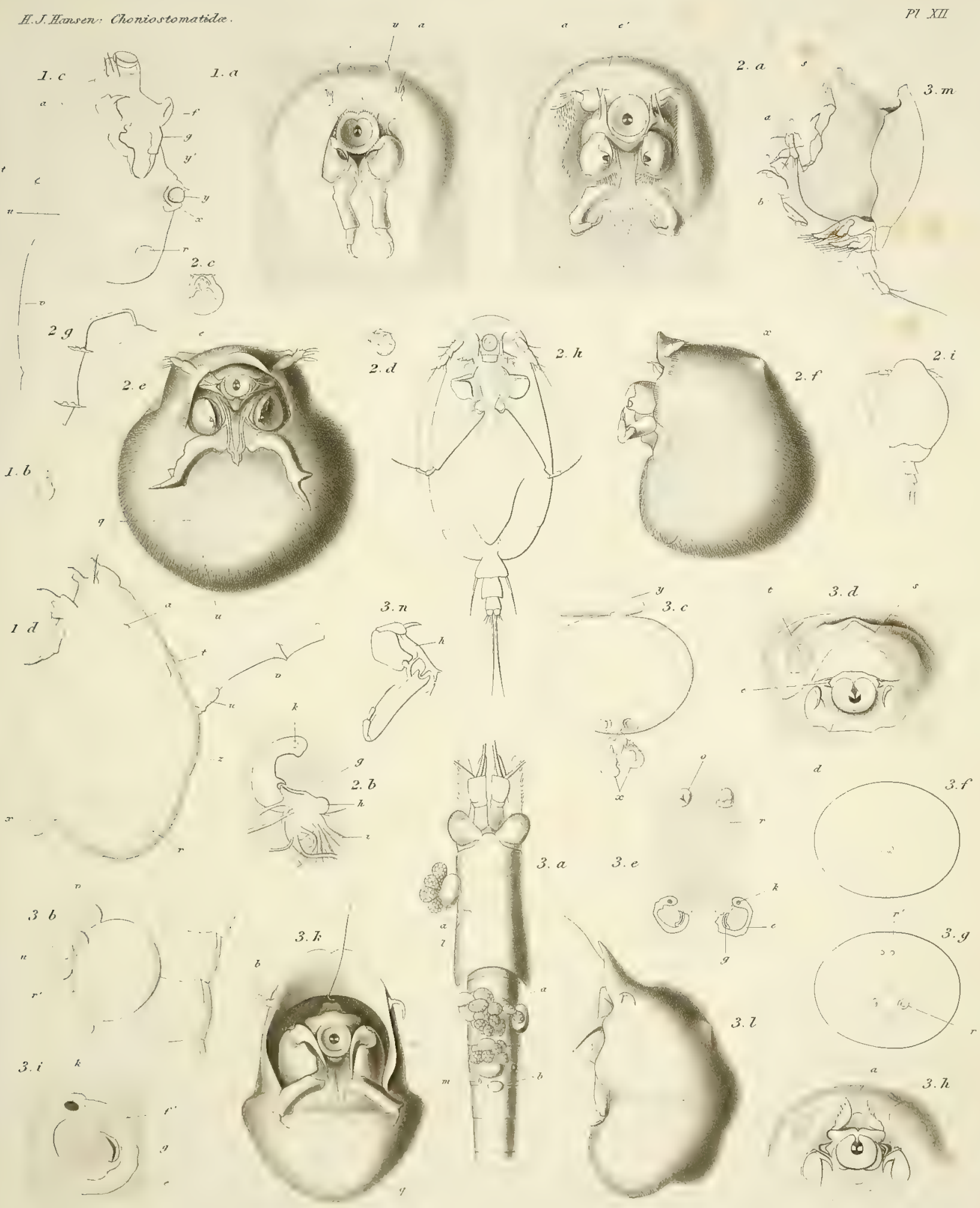

1. Mysidion commune n.sp. 2. Mysid abyssorrm nusp. 


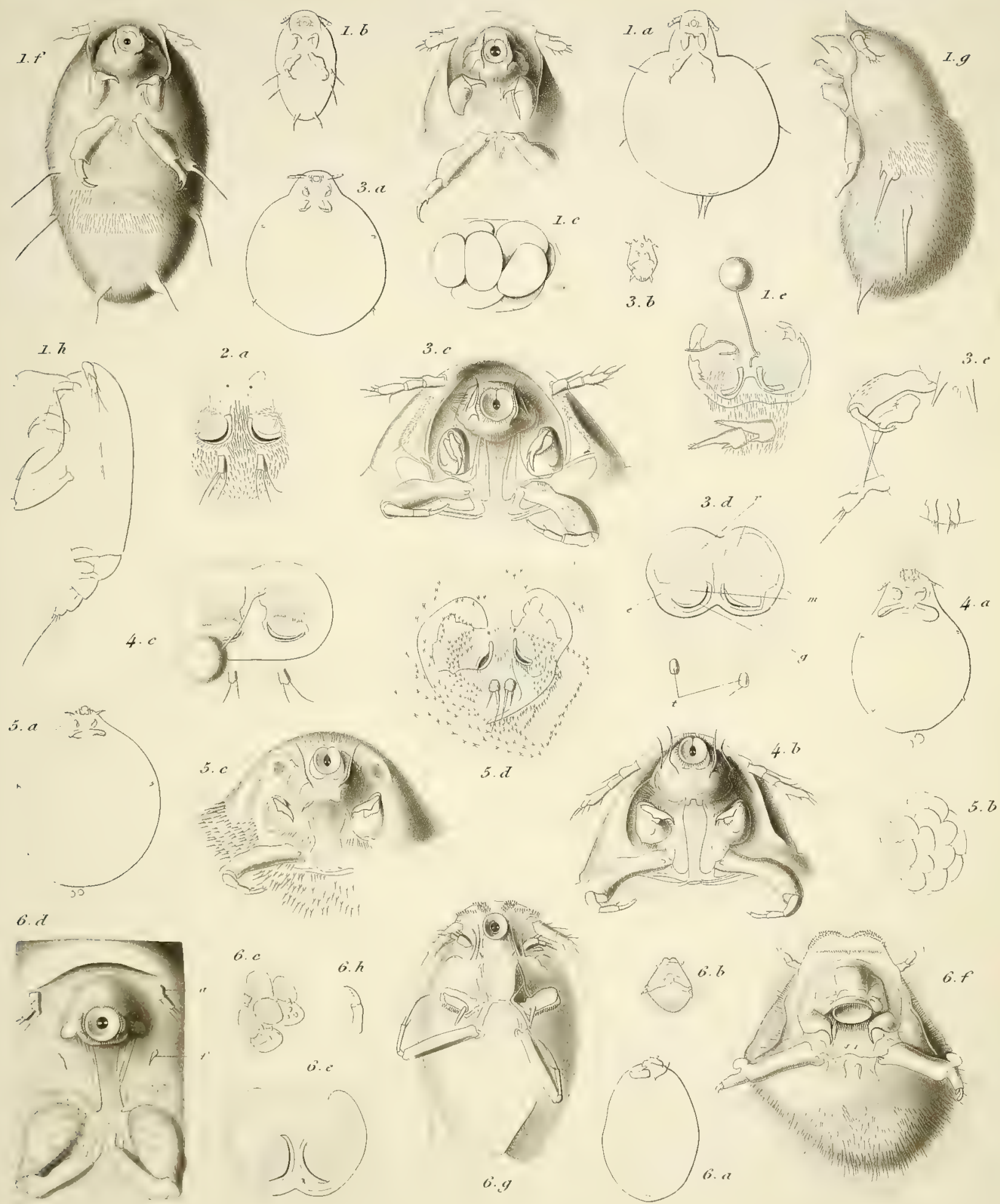

1. Hompeascitis mediterranea nigen, n.sp. 2. Spheronella danica nusp. 3. Spherer. Leptocheiri nisp. 4. Sphrer. messinethis n. sp. 5. Spher. irregularis n. sp. 6. Spher. marginata n. sp. 4. 4. 
. 
. 




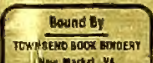


